Doctorado en Ciencias de la Educación

Facultad de Humanidades y Ciencias de la Educación

Universidad Nacional de La Plata

Tesis presentada para la obtención del grado de Doctora en Ciencias de la Educación

\title{
Leer y escribir en tres asignaturas de una escuela secundaria a la que asisten alumnos de sectores socioeconómicos desfavorecidos
}

\author{
Lic. Natalia Rosli \\ Directora: Dra. Paula Carlino
}

Fecha de presentación: Febrero 2016

Buenos Aires, Argentina 

A quienes que desafían al "no puedo" 



\section{Agradecimientos}

A mi hijo Lisandro, porque cada día me alegra y me da impulso para avanzar con mis proyectos.

A mi familia, en especial a mis padres, que siempre creyeron en mí y me apoyaron en cada proyecto que encaré. Gran parte de lo que soy se lo debo a ellos.

A Paula, directora de esta tesis, quien desde el principio confió en aquella egresada reciente de la facultad, con ganas de investigar. Porque me incentivó a presentarme a la beca CONICET cuando creí que no tenía posibilidades, porque en el camino me alentó ante cada dificultad, porque con su apertura, escucha y disposición hizo posible que esta tesis llegara a su fin.

A todos mis compañeros y compañeras del Grupo para la Inclusión y Calidad Educativas a través de Ocuparnos de la Lectura y la Escritura en todas las Materias (GICEOLEM). Además de comentar mis borradores con valiosas observaciones, se convirtieron en una red de afecto que sostuvo la aventura de una tesis doctoral. Por ello, quiero nombrarlos a todos: Manuela Cartolari, María Elena Molina, Carolina Roni, Lionel Alfie, Isabel Venazco, Jusmeidy Zambrano y Violeta Colombo. Entre los aportes que hicieron a lo largo de estos cinco años, no puedo dejar de destacar la ayuda de Manu, fundamental para analizar los datos, escribir y dar forma al capítulo de resultados didácticos. Juré no agradecerle más, pero lo hago nuevamente (y por última vez) aquí.

Al rector de la institución que me abrió sus puertas para realizar el trabajo de campo, a los tres docentes en cuyas materias observé clases y a los catorce alumnos de quinto año, por brindarme parte de su tiempo y colaborar en mi investigación.

A aquella nueva gente que se acercó a mi vida en el último tiempo y que, sin saberlo, me dio apoyo para terminar esta tesis. 



\section{Resumen}

En la presente tesis nos proponemos identificar y comprender las prácticas de enseñanza que favorecen u obstaculizan que leer y escribir se conviertan en herramientas de acceso, participación y apropiación del conocimiento en asignaturas de escuelas secundarias de sectores socioeconómicos desfavorecidos. Este objetivo se basa en que la inclusión educativa exige no solo promover la permanencia escolar sino también oportunidades de aprendizajes relevantes. Al respecto, en línea con diversas investigaciones, sostenemos que es posible promover aprendizajes disciplinares a través de involucrar a los estudiantes en prácticas de lectura y escritura en las distintas materias que cursan, como instrumentos que les permitan acceder, comunicar y reflexionar sobre el conocimiento, en especial cuando se utilizan de un modo epistémico y en forma dialógica (Dysthe, 1996, 2013; Wells, 1987, 1990a, 1990b, 2006).

A lo largo de siete meses de trabajo de campo en una institución pública de la Ciudad de Buenos Aires que recibe alumnado de estos estratos, se observaron y se audiograbaron un total de 39 clases en tres materias -Estudios Sociales Argentinos, Geografía Económica y Legislación Fiscal-, se entrevistó al director, a los docentes de esas asignaturas y a los alumnos de quinto año, y se recogieron documentos institucionales, materiales de lectura y producciones de clase. Analizamos esos datos mediante estrategias de categorización y contextualización (Maxwell y Miller, 2008).

Por una parte, identificamos acciones descritas tanto por la bibliografía reseñada como por los actores implicados como favorecedoras de la permanencia escolar. Así, describimos y categorizamos acciones institucionales y acciones interpersonales que llevan a cabo los directivos y docentes de esta escuela: asumen un compromiso con un proyecto pedagógico inclusivo, se sienten parte de un trabajo colectivo, construyen un vínculo afectivo con los alumnos, manifiestan confianza en su aprendizaje y acompañan las trayectorias escolares de los estudiantes en forma personalizada.

Por otra parte, tal como nos propusimos en el objetivo principal de esta tesis, analizamos prácticas de enseñanza que involucran leer y escribir contenidos disciplinares. Nos concentramos en las intervenciones docentes en relación con la tarea propuesta mayoritariamente en las clases de las tres materias observadas: leer para responder cuestionarios. En relación con esta tarea, identificamos que la estructura de la actividad está conformada por distintos modos de intervenir de los profesores que agrupamos en tres 
funciones: definición del medio, gestión del medio y evaluación de la tarea. Hallamos que la mayoría de las intervenciones que conforman la estructura de la actividad no propone explicitar y trabajar con las interpretaciones de los estudiantes. Por ello, conjeturamos que la noción de compresión lectora que sostiene esta estructura es aquella que concibe a la lectura como una actividad extractiva del significado dado en lo impreso.

Con nuestros resultados del análisis didáctico pretendemos aportar conocimiento respecto de otros modos para favorecer y beneficiar la permanencia escolar. Tal como sostenemos en esta tesis, si se fomentaran usos epistémicos de leer y escribir -como explicitar y confrontar las interpretaciones, volver a los materiales para corroborar o refutar argumentos, etcétera- que dieran lugar a experiencias de aprendizajes relevantes, éstas fortalecerían la permanencia escolar de los estudiantes. Aun más, creemos que si se propusiera en las clases utilizar la lectura y la escritura en forma epistémica podría favorecerse la inclusión dado que se ofrecería a los estudiantes posibilidades de acceder, comunicar y reflexionar sobre el conocimiento. Esto podría impulsar que paulatinamente éstos comprendan y cuestionen sus situaciones de vida y la realidad social y promuevan cambios al respecto.

Estos datos representan un insumo necesario para revisar las condiciones de enseñanza que se ofrecen a estos estudiantes y para plantear así nuevas secuencias didácticas que puedan ser tenidas en cuenta en la formación docente, en la elaboración y evaluación de documentos curriculares y en las políticas educativas.

Palabras clave: lectura y escritura de contenidos, enseñanza, escuela secundaria, inclusión educativa 


\section{Índice}

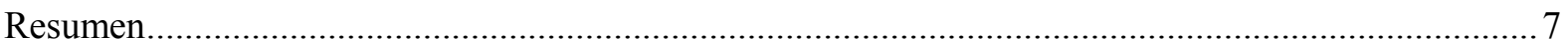

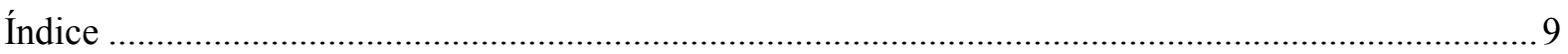

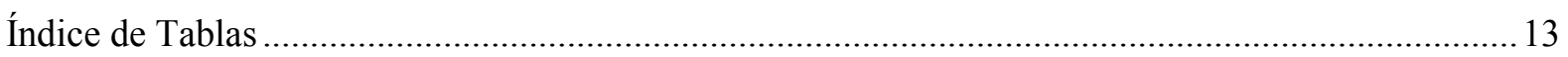

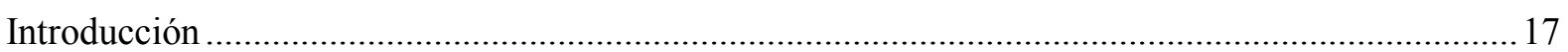

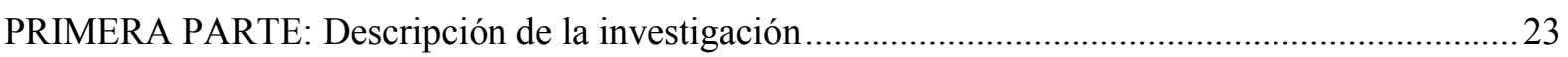

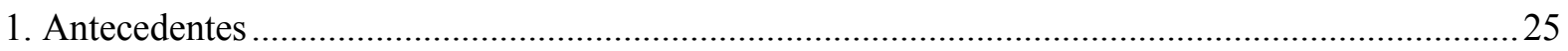

1.1. Antecedentes internacionales sobre enseñanza de contenidos mediada por lectura y escritura en instituciones que reciben alumnado de sectores socioeconómicos desfavorecidos ....................25

1.2. Antecedentes locales sobre enseñanza de contenidos mediada por lectura y escritura en instituciones que reciben alumnado de sectores socioeconómicos desfavorecidos ..........................29

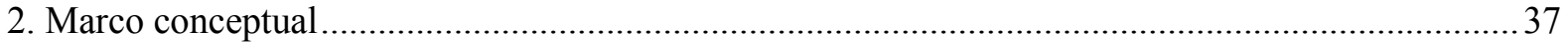

2.1. Sistema didáctico: interacciones entre docente, alumnos y saber.............................................. 37

2.1.1. Situaciones didácticas: medio, contrato didáctico, devolución e institucionalización....... 37

2.1.2. Acción conjunta: clausula proprio motu, reticencia, definición y regulación ....................40

2.1.3. Elementos de las situaciones didácticas: tareas, consignas y materiales de lectura ......... 42

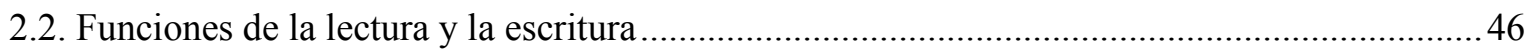

2.2.1. Leer y escribir para reproducir conocimiento: función reproductiva …….........................46

2.2.2. Leer, escribir y dialogar para construir conocimiento: función epistémica ........................ 48

2.3. Leer y escribir para aprender contenidos en materias del nivel secundario................................52

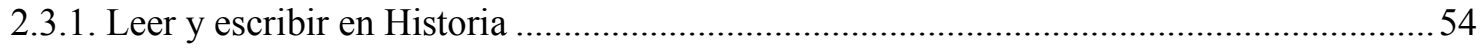

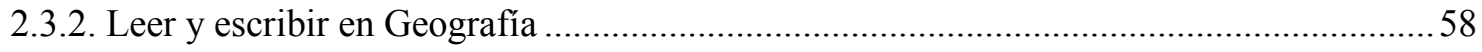

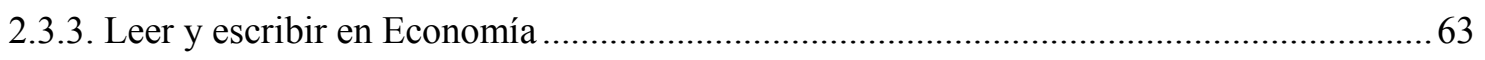

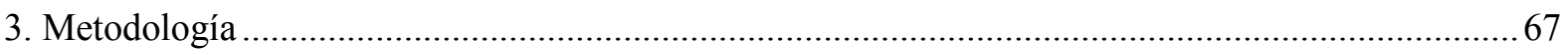

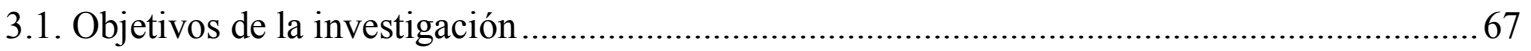

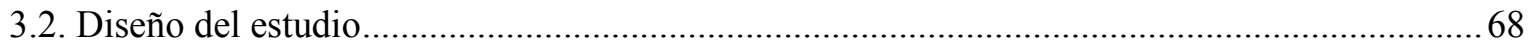

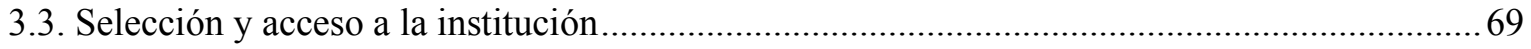

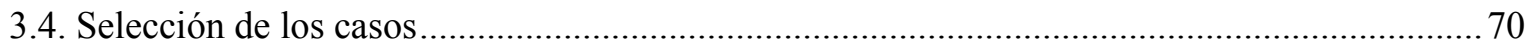

3.5. Procedimiento e instrumentos de recolección de datos .............................................................. 73

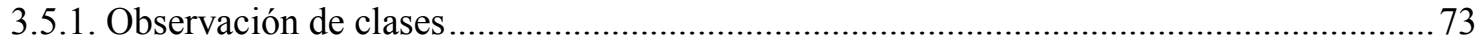

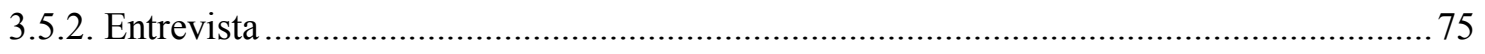

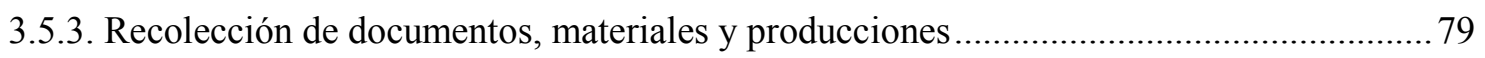

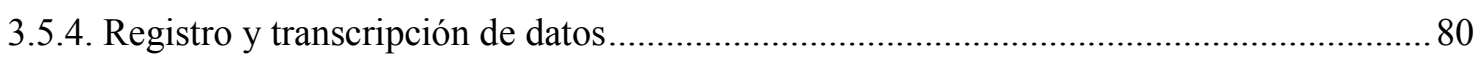

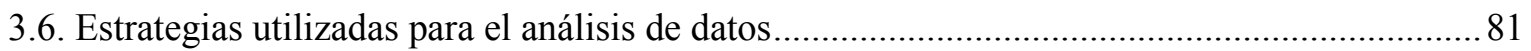

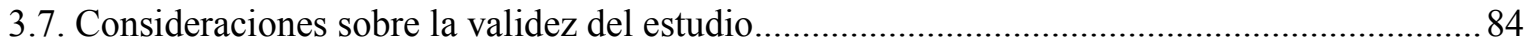


4. Definición y caracterización del contexto y la población

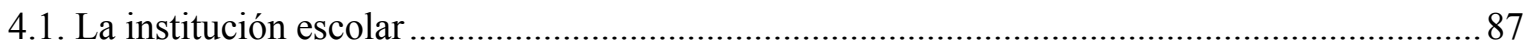

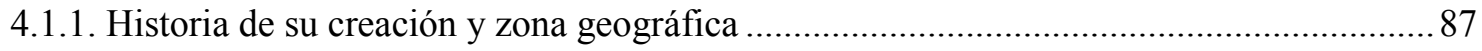

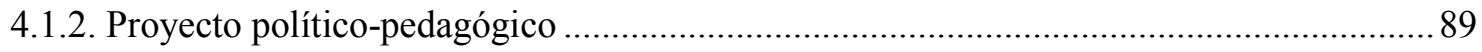

4.1.3. Tramos escolares: diferencias entre ciclo básico y ciclo superior .................................... 91

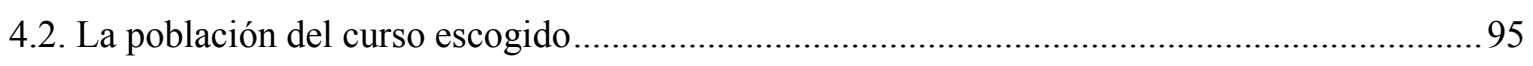

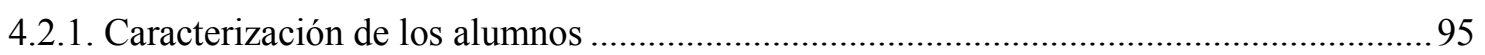

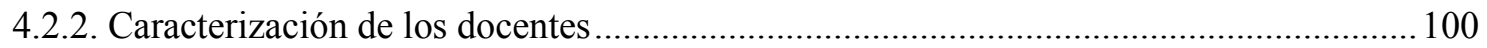

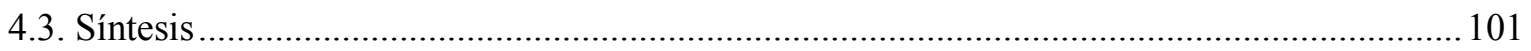

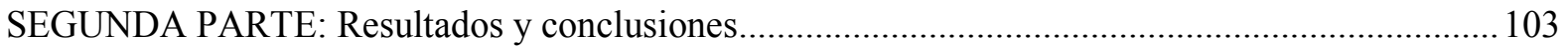

5. Acciones institucionales y acciones interpersonales que promueven la permanencia escolar........ 105

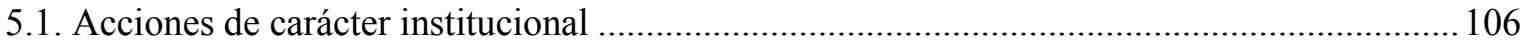

5.1.1. Asumir un compromiso con un proyecto pedagógico inclusivo...................................... 106

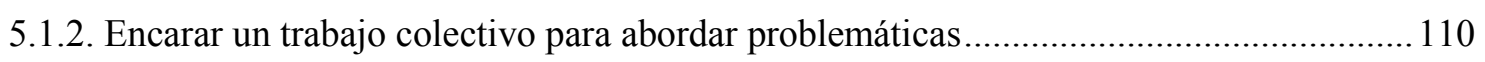

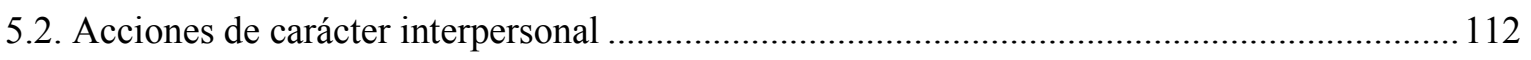

5.2.1. Construir un vínculo afectivo con los alumnos ................................................................ 112

5.2.2. Manifestar confianza en la posibilidad de aprendizaje de los alumnos ...........................117

5.2.3. Acompañar en forma personalizada la trayectoria escolar de los alumnos ..................... 121

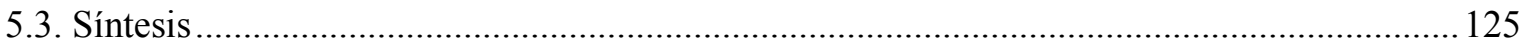

6. Prácticas de enseñanza que involucran lectura y escritura de contenidos: intervenciones docentes en

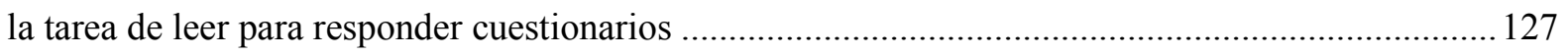

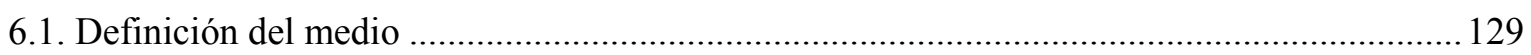

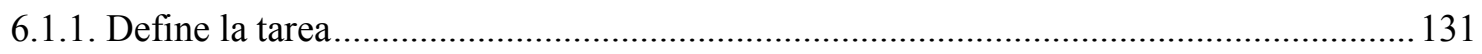

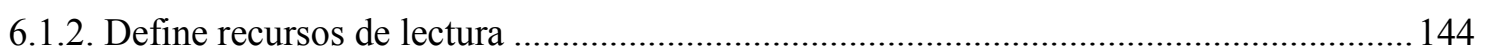

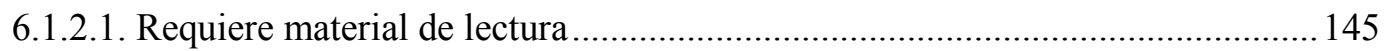

6.1.2.2. Brinda material de lectura ……………..................................................... 147

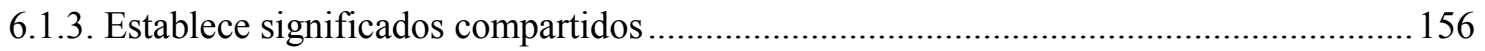

6.1.3.1. Organiza memoria didáctica.......................................................................... 158

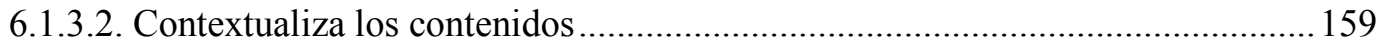

6.1.4. Propone acciones generales para facilitar la tarea .......................................................... 163

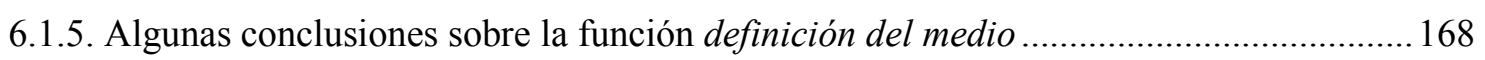

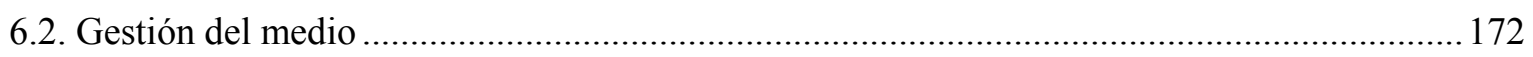

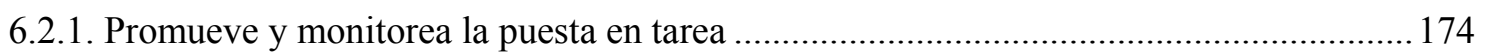

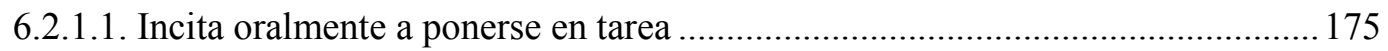

6.2.1.2. Consulta por inicio de tarea .......................................................................... 177

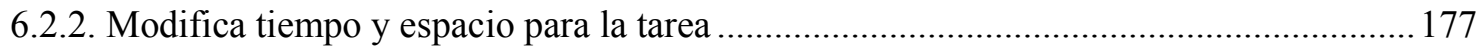

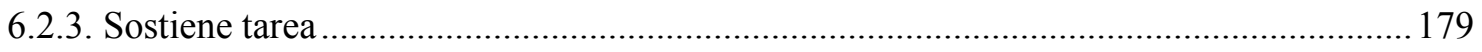


6.2.3.1. Devuelve responsabilidad por resolución de la tarea

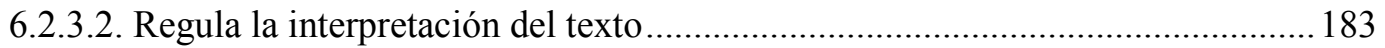

6.2.3.3. Regula la búsqueda de respuestas en el texto ................................................... 189

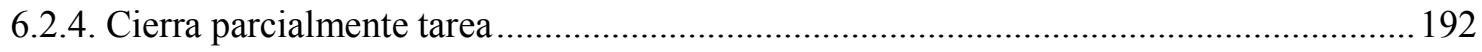

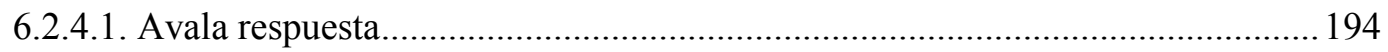

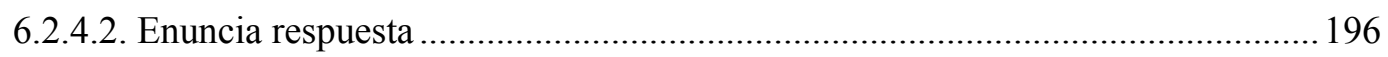

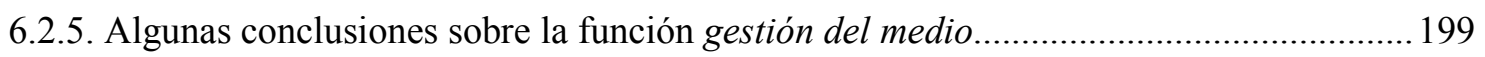

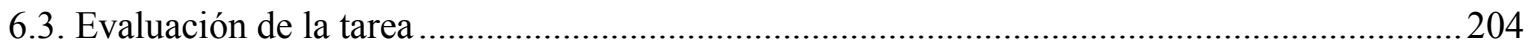

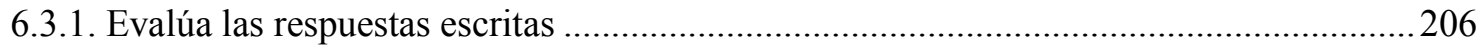

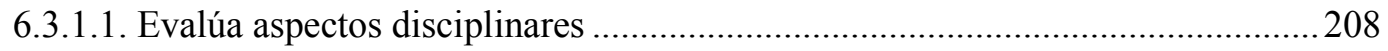

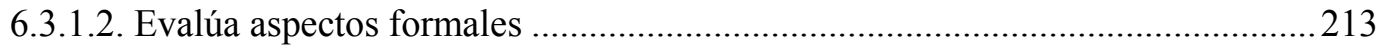

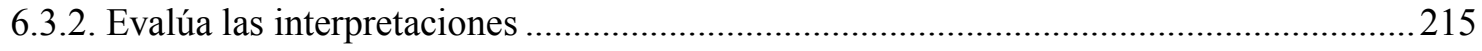

6.3.2.1. Pregunta sobre los contenidos disciplinares a los que refieren las respuestas... 216

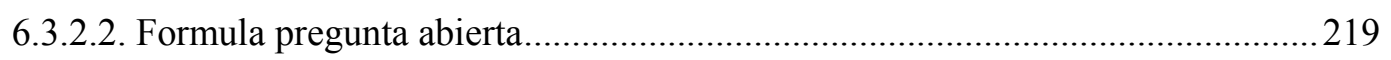

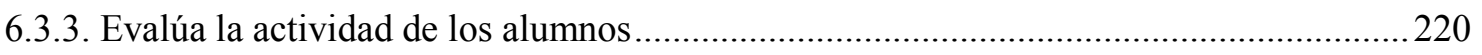

6.3.4. Propone acción general para facilitar futuras tareas .........................................................22

6.3.5. Algunas conclusiones sobre la función evaluación de la tarea .......................................225

6.4. Semejanzas y diferencias entre los casos de las asignaturas...................................................228

6.5. Conjuntos de intervenciones en un continuo entre monologicidad y dialogicidad..................231

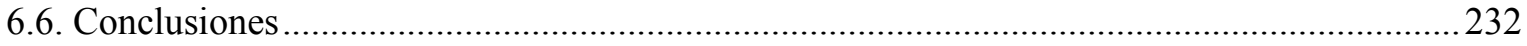

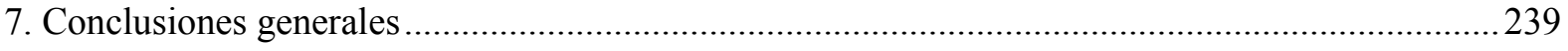

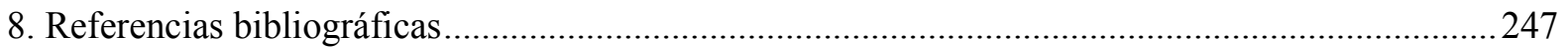

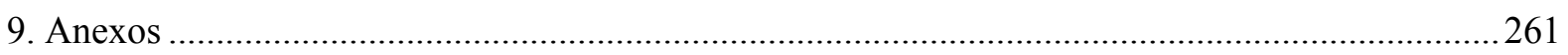

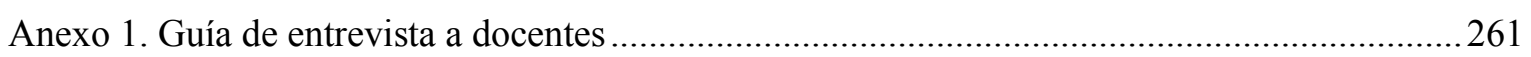

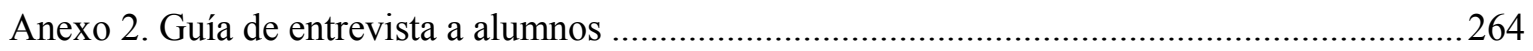

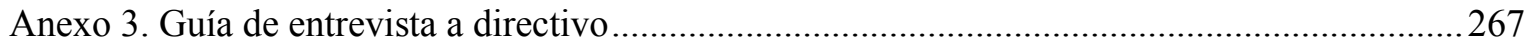

Anexo 4. Viñetas de las clases observadas en las asignaturas ......................................................269

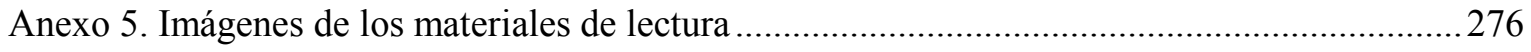

Anexo 6. Ejemplos de respuestas escritas de los alumnos a los cuestionarios ...............................284 



\section{Índice de Tablas}

Tabla 1. Duración de las clases observadas en las asignaturas.

Tabla 2. Motivos de suspensión de clases en las asignaturas observadas .75

Tabla 3. Duración de las entrevistas realizadas a los docentes .76

Tabla 4. Duración de las entrevistas realizadas a los alumnos de quinto año .......................................78

Tabla 5. Trayectorias escolares de los alumnos de quinto año ..........................................................96

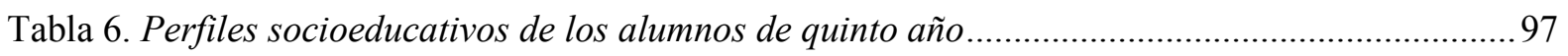

Tabla 7. Cantidad de alumnos asistentes a las clases observadas ........................................................99

Tabla 8. Datos de los docentes participantes de la investigación ........................................................ 101

Tabla 9. Categorías y subcategorías de la función docente "definición del medio" .........................130

Tabla 10. Subcategoría e intervenciones docentes de la categoría "define la tarea" ........................131

Tabla 11. Da consignas para resolver en clase. Fragmento de clase de la Asignatura B .................132

Tabla 12. Da consignas domiciliarias. Fragmento de clase de la Asignatura A .................................133

Tabla 13. Ejemplos de consignas de localización en las Asignaturas $B$ y C ......................................137

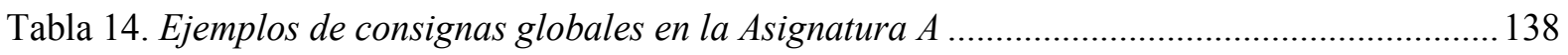

Tabla 15. Subcategorías e intervenciones docentes de la categoria “define recursos de lectura".... 144

Tabla 16. Requiere material de lectura: pregunta si han traido a clase su propio material. Fragmento de clase de la Asignatura A

Tabla 17. Requiere material de lectura: pide a quienes se ausenten fotocopiar material. Fragmento de clase de la Asignatura B

Tabla 18. Brinda material de lectura: entrega material de lectura de la biblioteca o fotocopias de textos. Fragmento de clase de la Asignatura $B$

Tabla 19. Brinda material de lectura: escribe definiciones teóricas en el pizarrón para leer y copiar.

Fragmento de clase de la Asignatura C.

Tabla 20. Brinda material de lectura: facilita su bibliografia a los alumnos que no la han traido.

Fragmento de clase de la Asignatura A

Tabla 21. Subcategorías e intervenciones docentes de la categoría "establece significados compartidos",

Tabla 22. Establece significados compartidos: organiza una memoria didáctica. Fragmento de clase de la Asignatura $B$

Tabla 23. Establece significados compartidos: contextualiza los contenidos. Fragmento de clase de la Asignatura A

Tabla 24. Subcategoría e intervenciones docentes de la categoria "propone acciones generales para facilitar la tarea", 
Tabla 25. Sugiere consultar distintas fuentes ante dudas de comprensión: recomienda consultar al docente. Fragmento de clase de la Asignatura A .....

Tabla 26. Sugiere consultar distintas fuentes ante dudas de comprensión: recomienda consultar línea de tiempo. Fragmento de clase de la Asignatura A .

Tabla 27. Sugiere consultar distintas fuentes ante dudas de comprensión: recomienda consultar al diccionario. Fragmento de clase de la Asignatura A

Tabla 28. Categorías y subcategorías en la función docente "gestión del medio"

Tabla 29. Subcategorías e intervenciones docentes de la categoría "promueve y monitorea la puesta en tarea"

Tabla 30. Promueve y monitorea la puesta en tarea: incita oralmente a ponerse en tarea. Fragmento de clase de la Asignatura $C$

Tabla 31. Promueve y monitorea la puesta en tarea: consulta por inicio de tarea. Fragmento de clase de la Asignatura A

Tabla 32. Modifica tiempo y espacio para la tarea: extiende tiempo y cambia espacio. Fragmento de clase de la Asignatura A

Tabla 33. Subcategorías e intervenciones docentes de la categoría "sostiene tarea"

Tabla 34. Devuelve responsabilidad por resolución de tarea: incita a volver al texto. Fragmento de clase de la Asignatura B

Tabla 35. Devuelve responsabilidad por resolución de tarea: devuelve la pregunta que realizan los alumnos. Fragmento de clase de la Asignatura B.

Tabla 36. Regula la interpretación del texto: explica siglas o términos disciplinares que los estudiantes consultan. Fragmento de clase de la Asignatura B

Tabla 37. Regula la interpretación del texto: explica oraciones o párrafos que los estudiantes consultan a través de ejemplos familiares y significativos. Fragmento de clase de la Asignatura C 185 Tabla 38. Regula la interpretación del texto: sitúa oralmente contenidos en determinado contexto socio-histórico ante dudas formuladas. Fragmento de clase de la Asignatura A

Tabla 39. Regula la búsqueda de respuestas en el texto: indica partes del texto donde hallar la respuesta. Fragmento de clase de la Asignatura $C$.

Tabla 40. Regula la búsqueda de respuestas en el texto: incita a leer partes del texto que contienen ideas clave leyendo su comienzo en voz alta. Fragmento de clase de la Asignatura A.

Tabla 41. Subcategorías e intervenciones docentes de la categoría "cierra parcialmente tarea".... 193

Tabla 42. Avala respuesta: avala localización de párrafos u oraciones. Fragmento de clase de la Asignatura B

Tabla 43. Avala respuesta: avala interpretación del texto enunciada por los alumnos. Fragmento de clase de la Asignatura $C$

Tabla 44. Enuncia respuesta: explicita oralmente la respuesta esperada. Fragmento de clase de la Asignatura $C$ 
Tabla 45. Enuncia respuesta: lee en voz alta la respuesta esperada. Fragmento de clase de la Asignatura A

Tabla 46. Categorías y subcategorías en la función docente "evaluación de la tarea"

Tabla 47. Subcategorías e intervenciones docentes de la categoría "evalúa las respuestas escritas"

Tabla 48. Evalúa aspectos disciplinares: avala respuesta escrita. Fragmento de clase de la Asignatura C.

Tabla 49. Evalúa aspectos disciplinares: señala errores conceptuales o incompletudes. Fragmento de clase de la Asignatura A

Tabla 50. Evalúa aspectos disciplinares: requiere lectura de respuestas de otros alumnos. Fragmento de clase de la Asignatura $C$

Tabla 51. Evalúa aspectos formales: marca error ortográfico y/o gramatical. Fragmento de clase de la Asignatura A

Tabla 52. Subcategorías e intervenciones docentes de la categoría "evalúa las interpretaciones"..215

Tabla 53. Pregunta sobre los contenidos disciplinares a los que refieren las respuestas: formula pregunta y expone acerca de los contenidos. Fragmento de clase de la Asignatura B.

Tabla 54. Pregunta sobre los contenidos disciplinares a los que refieren las respuestas: formula pregunta y la sostiene para que los alumnos argumenten. Fragmento de clase de la Asignatura A .218 Tabla 55. Evalúa las interpretaciones: formula pregunta abierta. Fragmento de clase de la Asignatura A

Tabla 56. Subcategoría e intervenciones docentes de la categoría "evalúa la actividad de los alumnos"....

Tabla 57. Evalúa la actividad de los alumnos: valora el cumplimiento de la tarea. Fragmento de clase de la Asignatura A

Tabla 58. Propone acción general para facilitar futuras tareas: sugiere revisar lo escrito antes de entregarlo. Fragmento de clase de la Asignatura A 



\section{Introducción}

\author{
"Alli donde las condiciones son más dificiles \\ es donde los objetivos pedagógicos deben ser más atrevidos. \\ Quienes tienen muy poco o casi nada \\ merecen que la escuela les abra horizontes."
}

(Ferreiro, 1992, p.5)

"Los alumnos del nivel secundario no leen ni escriben", suele escucharse en boca de docentes, políticos y educadores. Al respecto, resulta de sentido común atribuir a los estudiantes la responsabilidad exclusiva de su propio aburrimiento, cansancio, falta de interés y/o preocupación por el estudio y el aprendizaje. Mientras se sostiene esta atribución, ciertos interrogantes permanecen sin respuesta ¿qué es lo que ocurre en las aulas de las escuelas secundarias? ¿Qué propuestas de comprensión y producción de textos realizan los docentes de las asignaturas? ¿Qué oportunidades de participar en prácticas de lectura y escritura encuentran efectivamente los alumnos de este nivel?

En cierto sentido, preguntarse por las actividades que proponen los profesores en el nivel secundario es indagar sobre la inclusión educativa. Comúnmente se equipara la inclusión educativa con la permanencia de los alumnos en la escuela. En esta tesis, sostenemos que dicha inclusión, en tanto "condición para el pleno cumplimiento del derecho a la educación" (Terigi, 2009, p.10), requiere garantizar no solo la permanencia escolar sino también aprendizajes relevantes y duraderos por parte de los estudiantes. De ese modo, subrayamos la importancia de ahondar en las condiciones que se ofrecen a los jóvenes para promover aprendizajes disciplinares con esas características. Proponer a los estudiantes leer y escribir en las asignaturas, en tanto herramientas para acceder, comunicar y reflexionar sobre el conocimiento, es una de las vías para lograr estos aprendizajes. Distintos estudios han mostrado que determinadas prácticas de lectura y escritura favorecen la apropiación de contenidos (Carlino, 2005, 2008; Langer y Applebee, 1987; Miras, 2000; Olson, 1997), especialmente aquellas que plantean usos epistémicos y formas dialógicas de imbricación entre lectura, escritura y oralidad (Dysthe, 1996, 2013; Wells, 1987, 1990a, 1990b, 2006). En otras palabras, los investigadores citados estiman aquellos modos de leer y escribir en los que, por ejemplo, se buscan interpretaciones alternativas sobre lo leído, se comenta lo entendido con los compañeros y con el docente, se considera el destinatario de la producción escrita, se planifican y se producen borradores, se revisa lo escrito y se reescribe. 
Leer y escribir en tres asignaturas de una escuela secundaria a la que asisten alumnos de sectores socioeconómicos desfavorecidos - Natalia Rosli

En particular, el presente trabajo doctoral se concentra en las prácticas de enseñanza mediadas por la lectura y la escritura en asignaturas de una escuela secundaria a la que asisten alumnos provenientes de sectores socioeconómicos desfavorecidos. El foco en esta población va en línea con la amplia preocupación por su inclusión educativa: de acuerdo con la Comisión Económica para América Latina (2014), solo un 33\% de estos estudiantes logra finalizar el nivel secundario. En razón de ello, nos preguntamos ¿cómo se enseñan contenidos disciplinares con ayuda de la lectura y la escritura en asignaturas de instituciones que reciben a estos sectores? Teniendo en cuenta que, tal como mencionamos, ciertos modos de comprender y producir textos favorecen el aprendizaje de contenidos disciplinares, el objetivo central de esta tesis es identificar y comprender las prácticas de enseñanza que favorecen u obstaculizan que leer y escribir se conviertan en herramientas de acceso, participación y apropiación del conocimiento en asignaturas de escuelas secundarias que reciben alumnado de sectores socioeconómicos desfavorecidos.

Específicamente, esta tesis se pregunta ¿cómo se incluye la lectura y la escritura en la enseñanza de las materias en una escuela secundaria que atiende esa población? Para responder este interrogante se exploran cuatro variables. Por un lado, las demandas y expectativas de los docentes en relación con las tareas de lectura y escritura en sus asignaturas: qué requieren de sus alumnos y qué esperan de ellos. Por el otro, los desafíos que encuentran los estudiantes para afrontar los modos de leer y escribir exigidos, teniendo en cuenta su procedencia socioeconómica. Así, se caracterizan las prácticas de lectura y escritura desarrolladas en clase, estableciendo los retos cognoscitivos que implican para los alumnos y las intervenciones de los profesores que contribuyen a enfrentarlos. Por último, se describen las concepciones que poseen docentes y alumnos acerca de la naturaleza de la lectura y la escritura, su aprendizaje y enseñanza y los modos específicos de leer y escribir para aprender en las asignaturas.

A través del interrogante y el objetivo de investigación bosquejados, buscamos contribuir a la descripción e interpretación de usos de la lectura y la escritura que se desarrollan en escuelas a las que asisten alumnos de sectores socioeconómicos desfavorecidos. Esta descripción-interpretación representa un insumo necesario para revisar las condiciones de enseñanza y de aprendizaje que se ofrecen a estos estudiantes, con vistas a su inclusión educativa, y para plantear así nuevas secuencias didácticas que puedan ser tenidas en cuenta en la formación docente, en la elaboración y evaluación de documentos curriculares y en las políticas educativas. 
Dado que indagamos en el nivel secundario, resulta interesante destacar algunas particularidades históricas que parecen condicionar la enseñanza que hoy se ofrece en determinadas instituciones, de acuerdo con la población que reciben.

Inicialmente, la escuela secundaria fue pensada para formar a la clase dirigente urbana. Su expansión se debió al ingreso de la clase trabajadora a partir de la creación de escuelas normales, industriales y comerciales que diversificaron la oferta en respuesta a exigencias específicas del país de contar con docentes y con profesionales especializados en conocimientos administrativo-contables y técnicos. Posteriormente, durante el gobierno peronista se emprendieron diversas acciones que, al concebir la educación como un derecho social, buscaron democratizar la enseñanza e incluir a sectores sociales que se encontraban fuera del sistema educativo formal. A partir de los años 60 comenzó a acentuarse la diversificación en el nivel medio, a medida que el Estado Nacional descentralizaba su poder. Bajo este panorama educativo, en el año 1992 se sanciona la Ley $N^{\circ} 24.049$ que transfirió los establecimientos de educación secundaria y superior no universitaria a los gobiernos locales. Esta ley se basaba en un criterio de descentralización de la organización institucional que proponía aumentar el poder, la autonomía y las competencias de las comunidades locales (Almandoz, 2000). Sin embargo, diversos trabajos sostienen que esta transferencia ocultó la necesidad de aminorar el presupuesto nacional (Almandoz, 2000; Bravo, 1994; Ruiz, 2009). Como consecuencia de este traspaso y de la ausencia de una ley general que diera unidad al sistema educativo estableciendo orientaciones pedagógicas comunes, según Ruiz (2009), se profundizó la desarticulación académica. Al año siguiente de estas transferencias, la Ley Federal de Educación intentó dar respuesta a las problemáticas a través de una reforma que propuso cambios en la estructura académica y la política curricular existente. Nuevamente, bajo la política de descentralización imperante, se determinó que las jurisdicciones serían responsables de llevar a cabo estas modificaciones. Así, en contra de las intenciones de dar direccionalidad, esta legislación fomentó la pérdida de sistematicidad y uniformidad en el nivel (Ruiz, 2009, 2010). Frente a esta realidad educativa caracterizada por problemáticas de desarticulación y diversificación del nivel medio, en el año 2002, la Ley N $\mathrm{N}^{\mathrm{o}} 898$ estableció el nivel secundario obligatorio en la Ciudad de Buenos Aires; y cuatro años después, la Ley de Educación Nacional lo dispuso a nivel federal.

Tal como se desprende del breve recorrido histórico expuesto, la masificación de la escuela secundaria cambió la lógica selectiva y elitista de sus orígenes. Empero, no puede desconocerse que este fenómeno fue promovido en un escenario determinado por la diferenciación curricular y organizativa del nivel (Ruiz y otros, 2007). Estas características 
Leer y escribir en tres asignaturas de una escuela secundaria a la que asisten alumnos de sectores socioeconómicos desfavorecidos - Natalia Rosli

educativas, sumadas a la profundización de la crisis económica, política y social del país, potenciaron "mecanismos de diferenciación social" (Paviglianiti, 1988, p.46) que consolidaron la segmentación de la oferta según los grupos socioeconómicos de pertenencia del alumnado (Dussel, Brito y Núñez, 2007; Kessler, 2002). Al respecto, interesa a este trabajo doctoral dilucidar, además del objetivo descrito, si la enseñanza de contenidos disciplinares que se propone en las asignaturas indagadas da cuenta de esta segmentación, por ejemplo, fijando un horizonte de expectativas pedagógicas relacionado con la población que recibe o, si en cambio "abre horizontes", tal como Ferreiro (1992) propone en el acápite de esta introducción.

Habiendo enunciado estas particularidades históricas, explicitamos ahora el modo en que hemos organizado el trabajo. La presente tesis se divide en dos partes. La primera parte, que describe la investigación, consta de cuatro capítulos. En el primero reseñamos antecedentes anglosajones y nacionales relacionados con nuestro objeto de estudio, para mostrar el área de vacancia a la que pretendemos contribuir: la escasez de investigaciones abocadas a las prácticas de enseñanza mediadas por la lectura y la escritura en asignaturas de escuelas secundarias a las que asiste población de sectores socioeconómicos desfavorecidos (Capítulo 1). El segundo capítulo presenta el marco conceptual, es decir, las herramientas teóricas y conceptuales de las que nos valimos para realizar el análisis de los datos (Capítulo 2). El tercer capítulo describe y fundamenta las decisiones metodológicas tomadas en el presente estudio (Capítulo 3). El último capítulo de esta primera parte de la tesis describe y caracteriza el contexto en el que se inserta la institución escolar y la población que recibe (Capítulo 4).

La segunda parte de la tesis presenta los resultados y conclusiones. Primero, distinguimos acciones institucionales e interpersonales que identificamos llevan a cabo directivos y docentes de la escuela indagada para propiciar la permanencia de los estudiantes (Capítulo 5). A continuación, exhibimos un análisis didáctico centrado en la tarea de lectura y escritura propuesta con mayor frecuencia en las clases indagadas: leer para responder cuestionarios. Examinamos las intervenciones docentes relativas a dicha tarea, distinguiéndolas según tres funciones que se ejercieron en forma predominante durante su desarrollo: definición del medio, gestión del medio y evaluación de la tarea (Capítulo 6). Finalmente, el último capítulo presenta las conclusiones generales a las que arribamos y puntualiza los alcances y limitaciones de los resultados (Capítulo 7). Por último, se incluye el listado de las referencias bibliográficas utilizadas en el cuerpo de la tesis (Capítulo 8) y seis anexos: las guías de entrevista administradas a los docentes, a los alumnos y al directivo 
(Anexos 1, 2 y 3), viñetas con una síntesis de las principales tareas llevadas a cabo en cada clase observada (Anexo 4), imágenes de materiales de lectura utilizados en las materias (Anexo 5) y ejemplos de respuestas escritas de los alumnos a los cuestionarios (Anexo 6).

Por último, cabe señalar que al abordar prácticas de enseñanza este trabajo intenta comprender, siguiendo a Rickenmann (2006), porqué en un contexto dado los profesores hacen lo que hacen y con qué consecuencias. En este afán comprensivo-explicativo, buscamos interpretar la intencionalidad de los docentes, por lo que no consideramos sus prácticas en términos de desvíos de una norma, no las calificamos o descalificamos ni dictaminamos de qué otro modo se deberían haber ejercido. De ese modo, adoptamos una posición teórica similar a la que Ferreiro, Pontecorvo, Ribeiro Moreira y García Hidalgo (1996) denominan como antinormativa: buscamos comprender las acciones docentes $-\mathrm{y}$ sus efectos didácticos- evitando una visión ingenua que considere algunas de ellas como naturales, normales o correctas y otras como incorrectas. 

PRIMERA PARTE

Descripción de la investigación 



\section{Antecedentes}

En este capítulo presentamos antecedentes relativos a la temática que incumbe a esta tesis doctoral: las prácticas de enseñanza que entrelazan lectura y escritura con contenidos disciplinares en escuelas secundarias a las que asisten alumnos de sectores socioeconómicos desfavorecidos. La presente revisión se basa en la propuesta de Joseph Maxwell (2006) de seleccionar antecedentes privilegiando el criterio de relevancia por sobre el criterio de exhaustividad o amplitud. Siguiendo a este investigador, se escogieron trabajos que tuvieron implicaciones en el diseño, desarrollo e interpretación del propio estudio. Así, las publicaciones anglosajonas y nacionales que se presentan a continuación, reseñan el panorama de qué se está investigando actualmente acerca de esta temática.

\subsection{Antecedentes internacionales sobre enseñanza de contenidos mediada por lectura y escritura en instituciones que reciben alumnado de sectores socioeconómicos desfavorecidos}

En este apartado, reseñamos antecedentes relevados de publicaciones anglosajonas. Escogimos centrarnos en estudios publicados en revistas y/o libros de esa procedencia debido a nuestra posibilidad de leer en idioma inglés. Según nuestra búsqueda bibliográfica, los trabajos relevados principalmente abordan cómo leen y escriben estudiantes de sectores socioeconómicos desfavorecidos en materias del nivel universitario o cómo lo hacen alumnos inmigrantes o refugiados en asignaturas del nivel secundario.

Distinguimos dentro de los estudios relevados, trabajos correspondientes a un movimiento de reforma pedagógica denominado Writing across the curriculum (WAC), que desde 1970 promueve el uso de la escritura como herramienta para aprender en las materias. De acuerdo con la historización que Russell, Lea, Parker, Street y Donahue (2009) realizan de WAC, este movimiento surge ante la llegada a la universidad de grupos sociales anteriormente excluidos -fomentada a partir de nuevas políticas de admisión- y la constatación de ciertas dificultades de escritura de estas poblaciones. Al respecto, Bazerman y otros (2005) destacan que la originalidad de WAC fue conceptualizar estas dificultades como aspectos en los que debía centrarse la enseñanza dentro de las asignaturas, en contraposición a otros modelos, denominados deficitarios o remediales, que proponían abordarlas mediante cursos o programas extra en los primeros años de la universidad. En razón de la coyuntura socio-histórica en la que surgió, en un primer momento, este 
movimiento se centró en el nivel universitario. No obstante, sus concepciones y propuestas se extendieron a la escuela secundaria, tal como tempranamente mostraron Farrell-Childers, Gere y Young (1994) a través de la presentación de experiencias de profesores de distintas materias que las integraron en sus clases. En la actualidad, esta extensión ha dado lugar a una gran cantidad de estudios empíricos publicados en libros y revistas anglosajonas que investigan el leer y escribir para aprender contenidos en las distintas asignaturas del nivel secundario (por ejemplo, Converse, 2012; Hansen, 2009; Reichelt, 2005; Wolsey y Kelsey, 2009). Estos trabajos son diversos, presentan experiencias docentes o investigaciones en aulas en las que se incluyen la comprensión y la producción de textos al servicio del aprendizaje de contenidos disciplinares. Sin embargo, observamos que estos trabajos no refieren explícitamente a alumnado de sectores socioeconómicos desfavorecidos, población que asiste a la escuela secundaria en la cual indagamos para la presente tesis.

Además del movimiento WAC, nuestra revisión bibliográfica identifica una corriente teórica llamada New Literacy Studies (NLS), que cobra auge a partir del año 1980. Uno de sus principales representantes, Street (1984), distingue dos modelos de literacidad que interesa destacar. El primero, denominado autónomo, concibe a la literacidad en términos exclusivamente técnicos: como la habilidad o competencia neutra para codificar y decodificar los símbolos gráficos, entendida en forma descontextualizada de otros aspectos de la vida social. En cambio, el modelo ideológico enfatiza la naturaleza social y contextual de la lectura y la escritura y, con base en ello, los aspectos de poder y autoridad que se encuentran implícitos en cualquier evento letrado. Precisamente es este segundo modelo el que adopta la corriente NLS, dado que sostiene que leer y escribir son actividades concretas llevadas a cabo en contextos sociales específicos, por lo que están inevitablemente impregnadas de ideología. Basándose en esta concepción, y tal como señalan Zavala, Niño-Murcia y Ames (2004), los NLS indagan la diversidad de prácticas letradas en los diferentes ámbitos culturales así como las posibilidades de acceso o no a recursos y oportunidades de apropiación de las mismas. Debido a que esta corriente teórica considera que no existe una literacidad universal sino múltiples (las propias de cada cultura, las que corresponden a diversos dominios de la vida, las que se configuran como dominantes y aquellas vernáculas, etc.), desarrolla estudios etnográficos en relación con sus usos y concepciones en distintos contextos culturales (Street, 2004).

Aspectos de dicha perspectiva de la literacidad subyacen a los trabajos de Academic Literacies (ACLITS), corriente originada en Inglaterra en los años 90 que, tal como su nombre indica, focaliza en la escritura académica. Desde dicha tradición, Lea y Street (1998) 
caracterizan tres modelos de escritura: habilidades de estudio, socialización y alfabetización académica. El modelo de habilidades de estudio entiende que el manejo instrumental de aspectos superficiales del texto, como la gramática, la sintaxis, la ortografía y la puntuación, es central para la escritura académica. A diferencia de ello, el segundo modelo plantea que para que los estudiantes escriban académicamente se requiere socializarlos en los discursos y géneros de las disciplinas, por lo que estos deben enseñarse explícitamente. Por último, el modelo de alfabetización académica se asemeja al modelo ideológico sostenido por los NLS: destaca que en la escritura académica entran en juego prácticas institucionales, relaciones de poder, identidades y valores. Debido a que la corriente ACLITS adopta este tercer modelo, Russell y otros (2009) sostienen que los estudios que llevan a cabo priorizan una perspectiva institucional de la literacidad por sobre una perspectiva disciplinar. Ello puede verse en trabajos como los de Lea y Street (1998) y Lillis (1999, 2001), que indagan las diferentes expectativas e interpretaciones de estudiantes y profesores respecto de las tareas de escritura que se piden en la universidad. Cabe resaltar que dichos trabajos abordan especialmente experiencias de alumnos considerados "no tradicionales" por pertenecer a grupos sociales que históricamente fueron excluidos del nivel superior.

Hasta aquí reseñamos movimientos y corrientes teóricas que ponen el acento en las particularidades de leer y escribir en diferentes contextos, instituciones y disciplinas. Ahora describiremos un grupo de estudios que se concentra en cómo comprenden y producen textos alumnos del nivel secundario que provienen de sectores socioeconómicos desfavorecidos. Una parte de estos trabajos describe las dificultades que presentan alumnos inmigrantes o refugiados al tener que leer y escribir en otro idioma (Brown, Miller, y Mitchell, 2006; Roxas y Roy, 2012; Sarroub, Pernicek y Sweeney, 2007). Otra parte enfoca las prácticas de lectura y escritura que ejercen estos estudiantes por fuera de la escuela y su comparación con las que llevan a cabo dentro de la institución escolar (De la Piedra, 2010; Ek, 2009; Haneda, 2006; Sarroub, 2007; Yi, 2010).

Específicamente dentro de las publicaciones que abordan el leer y escribir de poblaciones inmigrantes en asignaturas del nivel secundario interesa destacar los trabajos de Elizabeth Birr Moje (2008, 2010) y los estudios de la línea Culturally Responsive Pedagogy. En cuanto a los primeros, resulta significativa la postura que Moje sostiene acerca del lenguaje. Esta investigadora de la Universidad de Michigan afirma que suele desconocerse al lenguaje como un aspecto integral en el aprendizaje de las disciplinas, lo que conduce a que algunos docentes planteen solo un cambio cuantitativo en sus clases: que los estudiantes lean y escriban más. En contraposición con ello, Moje propone entender las disciplinas como 
comunidades discursivas cuyos modos de producir y comunicar conocimiento los estudiantes deben aprender, al mismo tiempo que construyen las identidades disciplinares específicas. Según esta investigadora, esto requiere que los alumnos naveguen a través de las prácticas y textos disciplinares, lo que pone en juego un entrecruzamiento entre conocimiento, identidad, discurso y literacidad (Moje, 2010). Esta metáfora de navegación resulta importante como antecedente para nuestra tesis, dado que focaliza la dificultad que acarrea para algunos alumnos de sectores socioeconómicos desfavorecidos (en este caso, inmigrantes) la entrada a discursos y prácticas disciplinares que representan un "nuevo mundo" (Moje y Dillon, 2006, p.89). Al respecto, Moje sostiene que el abordaje de textos disciplinares implica un desafío muy grande para jóvenes de estos sectores, ya que al habérseles negado oportunidades de aprendizaje en sus trayectorias escolares, no poseen el conocimiento necesario para identificarse con las prácticas de las disciplinas. En este punto, señalamos al lector que en el subapartado 2.3.1 del Capítulo 2 podrá encontrar la descripción de algunos estudios de Moje en clases de alumnado predominantemente latino, que aportan evidencia empírica a sus afirmaciones.

En relación con la temática de esta tesis, también subrayamos los trabajos de la línea Culturally Responsive Pedagogy (Gay, 2010; Gere y otros, 2009; Richards, Brown y Forde, 2006; Taylor y Sobel, 2011). Asentados en principios de justicia social y multiculturalismo, los investigadores de esta corriente consideran que las identidades étnicas, las experiencias de vida y los trasfondos culturales de los alumnos inmigrantes son valiosos y deben ser incluidos en el curriculum académico. Este planteo resulta interesante para nuestra tesis por su proclama a valorar e integrar en la enseñanza la diversidad de conocimientos y experiencias culturales que los estudiantes traen consigo a la escuela.

Importa observar que si bien la procedencia socioeconómica de los estudiantes inmigrantes y refugiados, sobre los que indagan los trabajos anglosajones reseñados, es similar a la de aquellos alumnos que asisten a la escuela en la que observamos clases, los primeros conforman grupos con diferencias étnicas, lingüísticas, religiosas y de nacionalidad. Remarquemos entonces que la población que recibe la escuela indagada pertenece a un estrato socioeconómico desfavorecido pero no presenta las características nombradas. En particular, el grupo de jóvenes de quinto año -curso en el cual observamos clases- se caracteriza por poseer responsabilidades laborales o domésticas, haber realizado trayectorias escolares discontinuas y/o ser padres o madres adolescentes, tal como se detallará en el subapartado 4.2.1 del Capítulo 4. 
En síntesis, resaltamos al lector que hallamos en nuestra búsqueda bibliográfica publicaciones anglosajonas que abordan cómo se enseñan contenidos a través de leer y escribir o cómo leen y escriben en materias de la universidad estudiantes de sectores socioeconómicos desfavorecidos; empero, respecto del nivel secundario solo encontramos trabajos que indagan esta temática en alumnado inmigrante o refugiado.

\subsection{Antecedentes locales sobre enseñanza de contenidos mediada por lectura y escritura en instituciones que reciben alumnado de sectores socioeconómicos desfavorecidos}

En la introducción de esta tesis enunciamos que en nuestro país, la Ley de Educación Nacional, sancionada en el año 2006, estableció la obligatoriedad del nivel secundario, lo que promovió una ampliación en la matrícula y el desafío de garantizar tanto la permanencia escolar como aprendizajes relevantes y duraderos.

En cuanto a ese desafío, de acuerdo con nuestro relevamiento bibliográfico, la mayoría de las publicaciones nacionales sobre experiencias educativas de alumnos que provienen de sectores socioeconómicos desfavorecidos indaga solo las condiciones institucionales que favorecen la permanencia escolar. Por el contrario, son pocas las investigaciones locales que examinan cómo es la educación que se brinda a estudiantes de esos sectores en el nivel secundario. Entre los escasos trabajos nacionales que se ocupan de la enseñanza que se imparte a estos jóvenes, son menores aun aquellos que investigan la lectura y la escritura para aprender contenidos. A continuación, se describen estos grupos de estudios, ahondando algunos de sus resultados.

Como anticipamos, el grueso de los trabajos nacionales relevados aborda las relaciones y las prácticas que se producen en escuelas secundarias con el fin de asegurar la permanencia de los estudiantes y anticipar y resolver situaciones que la obstaculicen (Acosta, 2006, 2009; Belossi y Palacios de Caprio, 2004; Cantero, 1999; Dabenigno, Larripa, Austral, Tissera y Goldenstein Jalif, 2010; Feijoó y Corbetta, 2004; Krichesky y Duque, 2008, 2011b). Dentro de este grupo de publicaciones, identificamos que algunas acciones analizadas poseen carácter institucional (en tanto atañen a un conjunto de actores educativos tales como directivos, docentes, auxiliares, preceptores y asesores) y otras de carácter interpersonal (circunscriptas a los vínculos entre profesores y alumnos). Entre las primeras, se destacan la asunción de un compromiso con un proyecto pedagógico inclusivo y el trabajo en equipo para resolver problemáticas y, entre las segundas, la construcción de un vínculo afectivo con los alumnos, la manifestación de confianza en sus posibilidades de aprendizaje y el seguimiento personalizado de sus trayectorias escolares. En vista de que dichas acciones se han 
encontrado pertinentes para describir y caracterizar las estrategias que miembros de la institución que indagamos en la presente tesis llevan a cabo para favorecer la permanencia escolar (ver Capítulo 5), las detallamos subsiguientemente.

Respecto de acciones institucionales que promueven la permanencia en escuelas secundarias que reciben a poblaciones socioeconómicamente desfavorecidas, distintos estudios de caso destacan la importancia de asumir un compromiso e implicarse con un proyecto pedagógico inclusivo que tome en cuenta las particularidades del estudiantado (Acosta, 2006; Arroyo y Poliak, 2011; Dabenigno y otros, 2010; Duschatzky, 2005). Como parte fundamental de este tipo de proyectos pedagógicos, Cantero (1999) identifica una dimensión ética que evidencia las intenciones de producir cambios en vías a democratizar la educación. Según los trabajos citados, el compromiso asumido con un proyecto de tales características, al aglutinar a los docentes bajo un cuerpo de sentidos compartidos, otorga unidad y direccionalidad al trabajo pedagógico. Es por ello que quienes lo asumen suelen ser profesores que voluntariamente han decidido trabajar en escuelas públicas a las que asisten alumnos de estos sectores, tal como muestra el estudio de Foglino, Falconi y López Molina (2008) realizado en instituciones educativas cordobesas. Los docentes entrevistados en dicho estudio enuncian su deseo de trabajar en esas escuelas a pesar de las dificultades que se presentan, y sostienen valores y principios político-ideológicos afines a los del proyecto escolar.

Otra de las acciones institucionales que parece colaborar con la permanencia escolar es el trabajo en equipo entre miembros de la institución. Según la investigadora argentina Felicitas Acosta (2006), desde hace más de 20 años trabajos nacionales sobre gestión educativa subrayan el abordaje conjunto de problemáticas. Al respecto, hallamos en nuestra revisión bibliográfica distintos estudios cualitativos, en escuelas que atienden a estos estratos socioeconómicos, que sitúan la conformación de un grupo motor de integrantes como fundamental para favorecer la permanencia (Cabado y otros, 2010; Dabenigno y otros, 2010; Jacinto y Freytes Frey, 2004; Krichesky y otros, 2008). En línea con ello, una investigación en diez escuelas medias de la Ciudad de Buenos Aires resalta la importancia del director como líder que coordine y guíe el trabajo en equipo (Jacinto y Freytes Frey, 2004). En paralelo, el estudio desarrollado por Lidia Fernández (1994) sobre dinámicas institucionales en situaciones críticas identifica que cuando el trabajo colectivo involucra procesos de evaluación y reflexión crítica de la propia práctica, constituye una ayuda para plantear problemas y buscar soluciones a la vez que propulsa el sentimiento de pertenencia institucional. 
Este trabajo en equipo destacado por la bibliografía mencionada contrasta con la cultura profesoral hegemónica que Margarita Poggi (2003) advierte en la escuela media: un individualismo que promueve el aislamiento de los profesionales e imposibilita que se discutan las problemáticas que acontecen. En concordancia con ello, Mariana Belossi y María Alicia Palacios de Caprio (2004) identifican una predominancia del trabajo individual en docentes de escuelas bonaerenses que reciben a poblaciones de sectores socioeconómicos desfavorecidos.

En cuanto a las acciones interpersonales que pueden favorecer la permanencia escolar, gran cantidad de los trabajos relevados resaltan la construcción de un vínculo afectivo entre docentes y alumnos (Belossi y Palacios de Caprio, 2004; Brito, 2010; Dabenigno y otros, 2010; Dussel, Brito y Núñez, 2007; Jacinto y Freytes Frey, 2004; Krichesky, Cortelezzi, Cura y Morrone, 2010; Litichever y Núñez, 2009; Nobile, 2011; Redondo, 2006a; Ziegler, 2011). Los estudios citados coinciden en que este lazo debe configurarse a partir de la suspensión de prejuicios estigmatizadores que atribuyen etiquetas negativas a los estudiantes por pertenecer a determinado grupo socioeconómico. En relación con ello, la investigación de Valeria Dabenigno y otros (2010) muestra, a través de entrevistas a directivos, asesores pedagógicos, psicólogos, preceptores y alumnos de escuelas secundarias de la Ciudad de Buenos Aires, que cuando se establece un trato personalizado basado en el respeto mutuo y la escucha, se conoce la historia de cada estudiante y se ofrece la posibilidad de dialogar, ello motiva a los alumnos a asistir a clase y fortalece su sentido de pertenencia a la institución. En forma coincidente, otras investigaciones identifican que estudiantes de bajos recursos asignan gran importancia al involucramiento emocional con sus docentes (Belossi y Palacios de Caprio, 2004; Ziegler, 2011) y resaltan los aspectos de la subjetividad de sus profesores tales como la personalidad, el carácter y la capacidad de motivación (Kessler, 2002).

Interesa dejar sentado, además, que otras investigaciones sitúan la confianza en la posibilidad de aprender de los alumnos como núcleo central de este vínculo afectivo, ya que se ha probado que ésta influye en cómo se perciben los jóvenes como aprendices y en su autoestima en general (Acosta, 2006, 2009; Carlino, 2005; Falconi, 2011; Kaplan, 2010; Krichesky y otros, 2010; Nobile, 2011; Thisted, 2011). Al mismo tiempo, diversos estudios de caso muestran que la confianza que tienen y manifiestan profesores y directivos de escuelas secundarias que atienden a población desfavorecida socioeconómicamente se basa en una mirada no culpabilizadora de los estudiantes: en lugar de tomar las trayectorias escolares discontinuas como producto de dificultades individuales, entienden que éstas son producto de desigualdades inherentes al sistema social (Arroyo y Poliak, 2011; Nobile, 2011; 
Redondo, 2006a). Esta perspectiva de directivos y docentes disiente con la visión de algunos estudiantes, que entienden al fracaso escolar exclusivamente como su responsabilidad, tal como identificaron Dussel, Brito y Núñez (2007) en escuelas secundarias de distintas provincias del país. A diferencia de los docentes que sostienen una mirada no culpabilizadora, otros profesores sospechan sobre la "educabilidad" -entendida como capacidad de ser educados (Baquero, 2001) - de alumnos de estos sectores, y consideran que los fracasos escolares son destinos inevitables para este estudiantado, tal como hallan distintas investigaciones (Foglino, Falconi y López Molina, 2008; Frigerio, 2004; Kaplan, 2005; Redondo, 2006b).

Este vínculo afectivo entre docentes y estudiantes, forjado sobre la confianza en que los segundos aprenderán los contenidos disciplinares esperados, funciona como sostén para otra acción interpersonal que identificamos en los antecedentes nacionales relevados: el seguimiento personalizado de las trayectorias escolares de los alumnos (Coler, Con, Lacal, Lara y Susini, 2011; Dabenigno y otros, 2010; Tiramonti y otros, 2007). De acuerdo con los estudios citados, este seguimiento consta de modos de acompañamiento tutelados, "uno a uno", que aseguran proximidad con los alumnos para evaluar las dificultades con las que estos puedan toparse y ofrecer herramientas para enfrentarlas.

Habiendo reseñado estudios sobre acciones institucionales e interpersonales que favorecen la permanencia escolar, describiremos a continuación otros dos cuerpos de trabajos que indagan este asunto en poblaciones de sectores socioeconómicos desfavorecidos centrándose, por un lado, en valores, significados y sentidos construidos en torno al estar y transitar la escolaridad común $\mathrm{y}$, por el otro, en las variaciones del formato escolar tradicional.

Un grupo de trabajos que distinguimos en nuestra revisión bibliográfica caracteriza los valores, significados y sentidos que construyen alumnos y docentes sobre el estar y transitar la escuela secundaria común (Duschatzky, 2005, 2010; Duschatzky y Corea, 2008; Gabbai, 2013; Kessler, 2002; Redondo, 2006a). Estas publicaciones resaltan la importancia de relevar las voces de estos actores para identificar los vínculos que los unen a las instituciones y condicionan sus experiencias escolares. Así, determinan que, para los estudiantes entrevistados, la escuela se configura como una frontera en la que entran en tensión la cultura familiar con la institucional (Duschatzky, 2005) y como un espacio que prepara para el trabajo (Gabbai, 2013) y/o permite conseguirlo a partir de la titulación que se obtiene al finalizar la escolaridad (Jacinto, 2006; Kessler, 2002). En cuanto a los docentes que trabajan en escuelas que reciben a estos sectores, los estudios relevados advierten que 
algunos se conforman en "errantes" que se oponen a las desigualdades sociales y se disponen a aprovechar cada contingencia como posibilidad pedagógica (Duschatzky, 2010) mientras que otros oscilan entre enseñar y "dar amor" a sus estudiantes (Redondo, 2006a) o entre enfocarse en la retención escolar reduciendo las expectativas de aprendizajes de los alumnos y enseñar sin ocuparse de sus problemáticas (Kessler, 2002). Asimismo, frente al "declive institucional", esto es, la crisis actual de las instituciones modernas que conlleva la pérdida de legitimidad, Duschatzky y Corea (2008) identifican que algunos profesores adoptan posiciones de desubjetivación -sienten que no pueden hacer nada-, resistencia ante los cambios o invención de nuevas formas para educar.

Otro grupo de investigaciones que identificamos en nuestro relevamiento examina variaciones posibles del formato escolar tradicional con vistas a favorecer la retención de alumnos de sectores socioeconómicos desfavorecidos (Baquero y otros, 2009; Terigi y otros, 2013; Tiramonti y otros, 2007; Nobile, 2011; Ziegler, 2011). Estos trabajos describen iniciativas en escuelas de reingreso, caracterizan a sus integrantes y las percepciones que estos tienen acerca de su funcionamiento (Tiramonti y otros, 2007), examinan aspectos particulares tales como los vínculos entre estudiantes y profesores (Nobile, 2011) o los modos en que los docentes acompañan los aprendizajes (Ziegler, 2011), o evalúan los alcances y limitaciones de las modificaciones que introducen en el modelo organizacional, el régimen académico y el modelo pedagógico clásicos de la escuela secundaria (Baquero y otros, 2009; Terigi y otros, 2013).

En contraste con la abundancia de estudios que refieren a la permanencia escolar de alumnos de sectores socioeconómicos desfavorecidos, descrita anteriormente, encontramos en nuestra revisión bibliográfica que pocas investigaciones focalizan las oportunidades pedagógicas que se les ofrecen. Circunscribiéndonos a la lectura y la escritura, identificamos que, desde hace varias décadas, se desarrollan estudios que principalmente enfocan la alfabetización inicial y/o la enseñanza y el aprendizaje de la lengua escrita en el nivel primario. Más recientes son los trabajos que se ocupan de la comprensión y producción de textos en la enseñanza de las Ciencias Sociales en los últimos grados de la escolaridad primaria (Aisenberg, 2005, 2008, 2010; Aisenberg y Lerner, 2008; Aisenberg y otros, 2009; Torres, 2008). Estos estudios se detallan en el subapartado 2.3.1 del Capítulo 2, dado que resultan pertinentes para identificar modos posibles en que leer y escribir contribuyen a la elaboración cognoscitiva de contenidos de Historia, disciplina cuyos temas propone abordar una de las asignaturas indagadas en esta tesis. 
Respecto del aprendizaje inicial de la lectura y la escritura, cabe señalar un grupo de estudios nacionales que se centra en el acceso, la disponibilidad y la apropiación tardía de la lengua escrita en poblaciones de sectores socioeconómicos desfavorecidos (Kurlat, 2010; Kurlat y Perelman, 2013; Lorenzatti, 2006, 2008; Sardoy y Lorenzatti, 2006). Dentro de este grupo, trabajos asentados en perspectivas socioculturales resaltan la importancia de considerar los conocimientos que jóvenes y adultos de estos sectores poseen sobre la lengua escrita y que utilizan para manejarse en la vida social (Lorenzatti, 2008) y remarcan la necesidad de fortalecer la formación docente para trabajar con estas poblaciones (Lorenzatti, 2006; Sardoy y Lorenzatti, 2006). Otros trabajos de este grupo, basados en perspectivas psicogenéticas, estudian el proceso de construcción del sistema de escritura de estos alumnos, indagando a su vez las historias de exclusión por las que atravesaron (Kurlat, 2010; Kurlat y Perelman, 2013). Lo interesante de estos estudios psicogenéticos es que consideran que el aprendizaje de la lengua escrita involucra simultáneamente aspectos conceptuales, políticos, sociales, identitarios, culturales y lingüísticos, motivo por el cual proponen considerar que el modo en que estos jóvenes y adultos se apropian del leer y el escribir está influido, entre otras cosas, por sus propias vivencias de haber "fracasado" en la escuela.

También mencionamos anteriormente que nuestra búsqueda bibliográfica evidencia la escasez de trabajos nacionales que aborden cómo se enseñan en el nivel secundario contenidos disciplinares mediante la lectura y la escritura, en comparación con el grueso de trabajos que examinan la permanencia escolar. Aunque estos estudios suelen centrarse en asignaturas como Lengua y/o Literatura (Aguilar y Zanelli, 2008; Alonso Padilla, 2014; Dahl, 2014; Gerbaudo, 2006; Gómez, 2011; Tapia y Riestra, 2014), en los últimos cinco años han comenzado a desarrollarse distintas investigaciones que abordan esta enseñanza en otras materias como Biología (Borches y Roni, 2012; Roni, Alfie y Borches, 2013). Estos estudios recientes valoran la inclusión y la enseñanza de la lectura y escritura para aprender contenidos en otras materias además de Lengua y/o Literatura. En concreto, analizan intervenciones de profesores de Biología del nivel secundario que motivan la participación de los estudiantes a través de actividades de lectura y escritura con propósito claro y sentido genuino. Cabe mencionar que esos estudios se desarrollan en el marco del programa de investigación del GICEOLEM, equipo pluridisciplinar dirigido por la Dra. Paula Carlino, que desde hace más de quince años se aboca a indagar las relaciones entre enseñar, aprender, leer y escribir en disciplinas de distintos niveles educativos. Inicialmente las investigaciones de este equipo, al que pertenece la tesista, se abocaron al nivel universitario de grado para luego 
extenderse a la formación docente y la enseñanza de posgrado y, en forma reciente, a la educación secundaria.

Recapitulemos brevemente sobre las investigaciones nacionales reseñadas. Con excepción de los estudios relacionados con el aprendizaje inicial de la lengua escrita en jóvenes y adultos, las indagaciones relevadas no focalizan prácticas de enseñanza que propongan leer y escribir para aprender a alumnos de sectores socioeconómicos desfavorecidos, o bien no informan suficientemente sobre las características de la extracción sociocultural y económica de los estudiantes.

En resumidas cuentas, diremos que lo expuesto en este capítulo muestra que aun son incipientes los estudios nacionales que se ocupan de cómo se entrelaza la enseñanza de contenidos con la lectura y la escritura en materias del nivel secundario (exceptuando los trabajos respecto de Lengua y/o Literatura), y que las investigaciones locales y anglosajonas relevadas no abordan dicha cuestión específicamente en alumnado de sectores socioeconómicos desfavorecidos. Esta tesis pretende ser una contribución a dicha área de vacancia temática mediante el aporte de resultados de una investigación didáctica centrada en las prácticas de enseñanza de contenidos mediadas por la lectura y la escritura en una escuela secundaria que recibe estudiantes de estos estratos. 



\section{Marco conceptual}

Este capítulo presenta las herramientas teóricas y conceptuales que utilizamos para analizar los datos de nuestro estudio. El primer apartado, por un lado, presenta nociones fundamentales para analizar las interacciones entre docentes, alumnos y saber - provenientes de la teoría de las situaciones didácticas y la teoría de la acción conjunta- y, por el otro lado, caracteriza distintos tipos de tareas, consignas y materiales de lectura, elementos que componen las situaciones didácticas. En vista de que la presente tesis indaga prácticas de enseñanza que entrelazan leer y escribir en materias del nivel secundario, el segundo apartado aborda la lectura y la escritura como herramientas para asimilar y transformar el conocimiento, ahondando en su función reproductiva y su función epistémica. Finalmente, el último apartado detalla algunas características de la naturaleza de la construcción de conocimientos en Historia, Geografía y Economía, que nos permiten poner de relieve especificidades de las asignaturas que examinamos para este trabajo doctoral.

\subsection{Sistema didáctico: interacciones entre docente, alumnos y saber}

Para conceptualizar las interacciones entre docente, alumnos y el saber disciplinar en situaciones de clase tomamos nociones de la teoría de las situaciones didácticas y de la teoría de la acción conjunta que, según Rickenmann (2006), comparten una "concepción situada, sistémica y dinámica del funcionamiento didáctico" (p.2). Estas nociones se describen en dos subapartados que focalizan conceptos relevantes para pensar las situaciones didácticas (2.1.1) y la acción conjunta de estudiantes y profesores (2.1.2). El tercer y último subapartado describe algunos elementos que conforman las situaciones didácticas organizadas por los profesores: tareas, consignas y materiales de lectura (2.1.3).

\subsubsection{Situaciones didácticas: medio, contrato didáctico, devolución e institucionalización}

En la presente tesis, utilizamos dos conceptos principales para analizar las situaciones de enseñanza: medio y contrato didáctico. Estos conceptos fueron formulados por Guy Brousseau en los años 70, a partir de las investigaciones sobre enseñanza de la matemática que desarrolló en una escuela primaria francesa. Su teoría de las situaciones didácticas (TSD) postula a la didáctica como una ciencia cuyo objeto de estudio es la comunicación del conocimiento. Para indagar ese objeto, la TSD retoma los tres vértices centrales del sistema 
didáctico planteado por el investigador Yves Chevallard (1991) -alumnos, docentes y saberes - y analiza las interacciones en la clase, concebida como un espacio de producción. En tanto esta teoría conlleva una mirada didáctica unitaria consideramos, siguiendo a Aisenberg (1998), que resulta un punto de partida interesante para analizar fenómenos en otras disciplinas, cuidando de no incurrir en traspolaciones y aplicacionismos.

En concreto, la TSD conceptualiza las situaciones didácticas como un sistema compuesto por dos interacciones básicas: las del sujeto con el medio y las del alumno con el docente. Respecto de las interacciones sujeto-medio, Brousseau (2007) considera al medio como un "sistema autónomo, antagonista del sujeto" (p.15). Este medio que el profesor diseña tiene que presentar cierta resistencia y contradicciones propias con las cuales el sujeto se enfrente al intentar resolver el problema planteado por la situación. Por este motivo, para este investigador los alumnos aprenden cuando se adaptan a ese medio y construyen conocimientos en forma autónoma, como "producción libre" (Brousseau, 2007, p.85) que se manifiesta en forma de nuevas respuestas. Así, los estudiantes producen conocimientos asemejándose por momentos a un científico-, no a partir de la decodificación de las intenciones didácticas del docente o para cumplimentar su deseo, sino en respuesta a las exigencias impuestas por el medio (Brousseau, 1986, 1994, 2007). Puede colegirse de estas afirmaciones sobre construcción autónoma de conocimientos, una perspectiva constructivista basada en la epistemología genética de Jean Piaget.

La noción de medio que describimos a partir de Brousseau fue retomada por el investigador francés Gérard Sensevy (2007), quien la conceptualiza de dos maneras: como contexto cognitivo de la acción y como sistema antagonista. La primera definición toma al medio en tanto espacio de significados comunes entre el profesor y el alumno, que se establece como producto de enseñanzas anteriores. Este contexto cognitivo es indispensable para posibilitar la comunicación en el juego didáctico, aunque debe resultar insuficiente, de modo que presente a los estudiantes un problema para resolver. Por su parte, la segunda definición coincide con la desarrollada por Brousseau: el medio como un sistema antagonista, con recursos y restricciones que orientan la acción, organizado por el docente para que el problema -su núcleo central- comporte un desafío al poner en jaque el contexto cognitivo de los alumnos. Estas dos definiciones de medio pueden vincularse con los elementos que Rickenmann (2007) advierte que debe incluir el docente en las tareas propuestas: elementos conocidos por los estudiantes (asimilables por el contexto cognitivo) y otros que deben construirse (que representan un desafío). En relación con estos dos tipos de elementos, Sensevy (2012) sostiene que es la resistencia del medio la que hace que los estudiantes se 
enfrenten a su ignorancia y reconozcan que necesitan construir nuevos conocimientos porque los que tienen no alcanzan para resolver el problema. Finalmente, tal como señala Brousseau (1991, 2007), el modo en que funciona el medio organizado por el docente, dando lugar o no a la construcción de conocimientos, se revela a través de los comportamientos de los alumnos. En razón de ello, estos comportamientos se describen y analizan en el Capítulo 6, junto con las intervenciones observadas de los docentes en relación con la comprensión y producción de textos disciplinares.

Volvamos ahora a la otra interacción básica que según la TSD compone las situaciones didácticas: las relaciones del alumno con el docente respecto de un conocimiento, descritas bajo la noción de contrato didáctico (Brousseau, 1986, 2007). Al respecto, Sensevy (2007) sostiene que este contrato representa un sistema de conocimientos comunes moldeado por la acción conjunta cotidiana entre profesores y estudiantes, por lo cual se expresa en hábitos y expectativas que muestran "el peso de las costumbres" (p.10). De esa forma, el contrato didáctico establece responsabilidades, obligaciones y compromisos recíprocos entre los participantes de la relación didáctica que, según la investigadora argentina Patricia Sadovsky (2005), promueven la construcción de representaciones internas acerca de lo que está permitido o no en las clases y dan lugar a intenciones y expectativas implícitas y explícitas. En efecto, dado que las clausulas permanecen implícitas, este contrato "no solo se nutre de lo que explícitamente se dice, sino también de lo que se calla, de lo que se espera, de lo que se sugiere, de lo que se intenta" (Sadovsky, 2005, p.64). Por ello, cuando el docente o el alumno ejercen alguna acción inesperada en relación con el conocimiento, fuera de lo que se espera dentro del contrato didáctico, se produce una ruptura que visibiliza su existencia.

En cuanto a la negociación del contrato didáctico, Brousseau (1990, 2007) conceptualiza distintos efectos. Teniendo en cuenta el análisis didáctico que se presenta en el Capítulo 6, describimos solo dos: el efecto Topaze y el efecto Jourdain. En el primero, el docente ofrece directamente a los estudiantes las informaciones que permiten solucionar el problema, sin darles tiempo ni lugar para que lo resuelvan ellos mismos. Así, es posible que los alumnos utilicen las estrategias ganadoras dadas por el profesor sin comprenderlas. En cambio, en el efecto Jourdain el profesor reconoce indicios de conocimientos eruditos en comportamientos triviales o respuestas incorrectas de los alumnos, para evitar reconocer que estos fracasaron en la resolución del problema. No obstante estas diferencias descritas, en ambos efectos del contrato didáctico se evita que los estudiantes produzcan el conocimiento matemático esperado, ya sea porque el docente lo facilita (efecto Topaze) o porque lo da por sabido (efecto Jourdain). 
En contraposición con el modo de accionar docente en estos dos efectos, se encuentra otra forma de intervenir del profesor: proponer problemas que sean aceptados por los alumnos como suyos. Para lograr que los estudiantes asuman esta responsabilidad, Brousseau $(1986,1994,2007)$ sostiene que no es suficiente comunicar los problemas sino que se deben gestionar condiciones para su devolución. Esta devolución implica que el docente no intervenga ofreciendo los conocimientos que permiten resolver los problemas ya que, si así lo hace, el alumno no habrá realizado sus propias elecciones para obtener la solución. De ello se trata la paradoja de la transmisión de las situaciones descrita por Brousseau (1986): si el profesor revela los resultados que espera del problema matemático, los estudiantes pierden oportunidad de alcanzarlos por su propia cuenta y, por tanto, de aprender el contenido disciplinar.

En paralelo con la función docente de devolución, Brousseau $(1994,2007)$ identifica en sus investigaciones la necesidad de los profesores de intervenir para institucionalizar conocimientos. En las fases de institucionalización se otorga el status de saberes legítimos a los conocimientos construidos por los alumnos en las situaciones planteadas.

Habiendo descrito las funciones de devolución e institucionalización, diremos para finalizar este subapartado que gestionar el tiempo es otra labor que le incumbe al docente dentro del contrato didáctico. Un modo de gestionar el tiempo es la organización de una memoria didáctica que, según hallan Brousseau y colaboradores (Brousseau, 1994, 2007; Brousseau y Centeno, 1991), contempla, entre otras acciones, impulsar que los recuerdos de los estudiantes se reactiven en conocimientos movilizables para una nueva situación de aprendizaje.

\subsubsection{Acción conjunta: clausula proprio motu, reticencia, definición y regulación}

Algunos planteos de la teoría de las situaciones didácticas, expuestos en el anterior subapartado, fueron retomados y reformulados por otros investigadores. En este subapartado nos interesa destacar la teoría de la acción conjunta desarrollada inicialmente por Gérard Sensevy, de la cual tomamos nociones para analizar datos en este estudio doctoral.

Este investigador concibe la acción didáctica como necesariamente conjunta y organizada alrededor del saber a ser transmitido (Sensevy, 2007). Posteriormente, para conceptualizar la estructura básica de las interacciones didácticas, Sensevy (2012) recurre al paradigma de la acción conjunta utilizado en las neurociencias y la ciencia cognitiva e identifica tres conceptos que la compondrían: la atención conjunta (necesidad de que los participantes sostengan atención hacia los mismos objetos), las posibilidades conjuntas 
(reconocer las mismas posibilidades de acción) y el trasfondo común (compartir suficientes concepciones para posibilitar la comunicación).

Esta acción didáctica conjunta es entendida por este investigador como una especie de juego en el cual el alumno, para ganarlo, debe producir estrategias por su propio movimiento (proprio motu). En concreto, se trataría de un juego cooperativo del tipo ganador-ganador, ya que si el estudiante lo gana, el docente también, dado que logra su objetivo de que éste aprenda. Por alcanzar ese fin mediante el cumplimiento de la cláusula proprio motu, Sensevy (2007, 2012) advierte que el profesor debe sostener una reticencia a mostrar su saber, es decir, no tiene que indicar a los alumnos cómo ganar el juego didáctico. Como se verá, el Capítulo 6 analiza datos teniendo en cuenta la cláusula proprio motu y la reticencia docente en las clases observadas, nociones que este investigador considera como componentes estructurales de la relación didáctica y, por ende, fundamentales para las descripciones de los procesos de enseñanza-aprendizaje.

Así planteado, el juego didáctico requiere que el profesor efectúe una devolución del problema, para que los estudiantes lo jueguen verdaderamente. Algunos efectos de la negociación del contrato didáctico, que describimos en el subapartado precedente, hacen que el juego pierda pertinencia. De acuerdo con Sensevy (2007), a través del efecto Topaze el docente hace trampa al momento de la producción de estrategias ganadoras y mediante el efecto Jourdain lo hace al momento de su evaluación.

Sin embargo, la reticencia del docente requerida por el juego didáctico no implica que éste se abstenga de intervenir en las situaciones de enseñanza. Además de las funciones de devolución e institucionalización conceptualizadas por Brousseau, el profesor también define el medio y las tareas de aprendizaje, indicando sus reglas específicas, y regula la actividad de los alumnos en pos de los objetivos didácticos (Rickenmann, 2006, Sensevy, 2007). Definido el medio, tal como señala Sensevy (2012), es esencial la orientación y supervisión del docente para promover que los alumnos diriman los obstáculos con los que se van encontrando.

Tomando las consideraciones teóricas descritas en estos dos subapartados, analizamos en el Capítulo 6 las interacciones de clase en torno a contenidos disciplinares sobre los que se propone leer y escribir en las materias indagadas. Para ello, establecimos como ejes principales el medio y el contrato didáctico de las situaciones de enseñanza observadas. Precisamente, Sensevy (2007) sostiene que la acción didáctica necesita ser estudiada empíricamente in situ, teniendo en cuenta su carácter de acción conjunta y a través de la 
descripción del contrato didáctico y del medio en su doble carácter de sistema antagonista y contexto cognitivo de la acción.

\subsubsection{Elementos de las situaciones didácticas: tareas, consignas y materiales de lectura}

En el análisis de prácticas de enseñanza que incorporan leer y escribir en las materias, es fundamental la consideración de cuáles son las tareas, las consignas y los materiales de lectura propuestos a los estudiantes. Los modos en que se producen y se utilizan los textos en las aulas, condicionados por estos elementos de las situaciones didácticas, influyen en las maneras de comunicar, construir y aprender conocimientos.

Por tareas de aprendizaje entendemos, siguiendo a Sensevy (2007), "lo que hay que hacer" (p.25), es decir, aquello que responde a las consultas de los alumnos respecto de qué se espera que realicen en clase. Por ende, las tareas son prescripciones de lo que se debe hacer, a diferencia de lo que se hace efectivamente, para lo cual reservamos el termino de actividad (Pastré, 2011). Dado que las tareas que el docente propone condicionan los comportamientos de los estudiantes, Rickenmann (2006) sostiene que el análisis de estos puede dar indicios acerca del tipo de relación que establecieron o están estableciendo con el saber en juego. En línea con estas ideas, en el Capítulo 6 categorizamos las acciones docentes identificadas en la tarea que se planteó en forma mayoritaria en las clases observadas (leer para responder cuestionarios) a la vez que describimos y analizamos los comportamientos de los alumnos.

Otro elemento central en las situaciones didácticas son las consignas que pautan estas tareas. Con vistas a nuestro objeto de análisis, nos centramos en las consignas de lectura y escritura propuestas en las clases observadas. La importancia de examinar las consignas radica, según Aisenberg (2005a, 2010), en que éstas son herramientas fundamentales que mediatizan la interacción de los alumnos con los textos.

Particularmente en la enseñanza de las Ciencias Sociales, los investigadores franceses Claude Basuyau y Simonne Guyon (1994) identifican como predominantes las consignas de descomposición que requieren identificar y reproducir porciones del texto. Tal como muestran estudios didácticos en el nivel primario, este tipo de consignas originan en los estudiantes lecturas superficiales para localizar la información puntual que las responde (Aisenberg, 2005a, 2010; Benchimol, Carabajal y Larramendy, 2008; Lerner, Aisenberg y Espinoza, 2009). Aun más, la investigadora mexicana Elsie Rockwell (1995) halla que esta localización de respuestas se ve facilitada porque algunas preguntas que los profesores de Ciencias Sociales plantean en cuestionarios reproducen frases textuales de los libros 
indicados para leer. Si bien localizar información es un quehacer lector imprescindible, tal como afirma Aisenberg (2004), resulta insuficiente para aprender contenidos a través de la lectura porque permite contestar las preguntas sin necesidad de entender el texto, a través de una correspondencia término a término entre las preguntas y los párrafos del material. Esto fue comprobado por una investigación didáctica que realizó entrevistas de lectura a estudiantes del nivel primario, quienes tras leer un texto para localizar información, afirman no entender o dan explicaciones distantes de la idea allí planteada (Aisenberg, 2005b).

Una variedad de estudios coincide que en la enseñanza general se pide mayoritariamente a los estudiantes actividades reproductivas. Al respecto, la investigadora Mariana Miras (2000) identifica que las propuestas áulicas más usuales exigen una sola respuesta considerada correcta y alientan una escritura mecánica. En relación con alumnado proveniente de sectores socioeconómicos desfavorecidos, Wells (1987) señala que, como se busca prepararlos para las demandas sociales que los esperan cuando finalicen la escolaridad, generalmente se les proponen actividades que recrean los usos del lenguaje escrito en la vida cotidiana: leer un periódico, escribir una solicitud de empleo, completar un formulario o seguir instrucciones para usar un dispositivo. Sin embargo, para este investigador esto implica perpetuar las desigualdades existentes, porque no se ofrecen a estos estudiantes oportunidades de situarse como pensadores creativos y críticos, a través de usos epistémicos del lenguaje (ver subapartado 2.2.2). Corroborando este señalamiento de Wells, otros investigadores hallan que en escuelas secundarias a las que asisten estos estratos predomina la propuesta de tareas que exigen reproducir contenidos, frecuentemente en formato de cuestionarios que los estudiantes deben contestar (Belossi y Palacios de Caprio, 2004; Krichesky y Duque, 2011a). Específicamente en el área de las Ciencias Sociales, estudios identifican en el nivel primario una prevalencia de cuestionarios (Siede, 2010) y tareas con consignas puntuales como identificar, situar, enumerar hechos, acontecimientos, lugares, fechas o nombres (Benejam y Quinquer, 2000).

Además de estas consignas de descomposición o localización, existen otras consignas de lectura en la enseñanza de las Ciencias Sociales, que incitan a comprender el sentido del texto en su totalidad mediante la construcción de ideas globales, explicaciones o relaciones (Aisenberg, 2005a, 2010). Para ser contestadas, estas consignas requieren un conocimiento general del tema, por lo que suelen resultar complejas de entender para los estudiantes. No obstante, Aisenberg (2010) afirma que en Historia estas consignas, al direccionar la construcción de una representación integrada de la situación histórica, promueven una modalidad de lectura necesaria para aprender la disciplina. 
Otros trabajos también identifican distintos tipos de consignas en la escuela secundaria y la universidad. En el nivel universitario, Carlino (2005) distingue consignas que piden información localizable en el texto y otras que exigen reconstruir ideas dentro de un mismo material o hacerlo a partir de relacionar varios entre sí. Para responder al primer tipo alcanza con subrayar una parte del texto mientras que, para el segundo tipo, se necesita comprender el texto como un todo y/o vincular las ideas allí presentes con las de otros materiales. En el nivel secundario, Dysthe (1996) diferencia dos tipos de consignas de lectura. Por un lado, preguntas diseñadas por los docentes con el objetivo de guiar la revisión de puntos centrales de los libros de texto, que pueden resolverse directamente con la información allí disponible. Este tipo de preguntas se asemejan a las consignas de descomposición descritas anteriormente. Por el otro lado, preguntas que no tienen respuestas prefijadas, cuya resolución demanda a los estudiantes pensar y reflexionar por sí mismos, enlazando los conceptos disciplinares con sus experiencias personales.

Considerados así distintos tipos de consignas, pasaremos ahora a examinar otro elemento que compone las situaciones didácticas: los materiales de lectura. Al respecto, podemos diferenciar manuales o libros de texto, materiales curriculares armados por los profesores y otros textos no producidos específicamente para los estudiantes pero que se proponen para ser leídos y trabajados en el aula. Denominaremos a los dos primeros manuales y materiales curriculares- como textos escolares. Pese a que los tres tipos de materiales de lectura mencionados poseen características distintas, que indudablemente influyen en las maneras de leerlos, investigadores como Prat e Izquierdo (2000) y Rockwell (2001) acuerdan en que su funcionalidad depende del uso que se les otorgue en las clases. Por este motivo, en el Capítulo 6 analizamos no solo la materialidad de los textos (Bourdieu y Chartier, 2010; Chartier, 2005, 2010), es decir, sus características en tanto soportes -aspecto físico, disposición del texto, tamaño, extensión y disponibilidad-, sino también el uso que de ellos se hace en las clases indagadas.

Tal como se verá en el análisis didáctico que presenta el Capítulo 6, los materiales de lectura mayormente propuestos en las clases observadas fueron manuales y módulos escolares. En cuanto a los manuales, la investigadora argentina Graciela Carbone (2003) relata que adquieren amplia difusión en el último cuarto del siglo XIX, junto con la obligatoriedad escolar y la necesidad política de consolidar los sistemas nacionales de educación pública mediante la impartición de conocimientos mínimos a toda la población en tiempos factibles. En razón de ello, los contenidos de los manuales se presentan mediante una progresión definida y bajo una secuencia específica (Carbone, 2003; Wells, 1990b) 
acompañados por recursos gráficos, iconográficos y analítico-sintéticos como clasificaciones, esquemas y cuadros sinópticos. Muchos manuales, al presentar contenidos de un campo de estudio en forma simplificada y breve, eliminan las discusiones teóricas y los problemas no resueltos dentro de la ciencia (Carlino, 2005) a la vez que homogeneízan formas discursivas y borran las convenciones textuales y gráficas de los materiales en los que se basan (Tolchinsky, 2008). De acuerdo con el relevamiento de trabajos que examinan libros de texto, efectuado por Moje, Stockdill, Kim y Kim (2011), en Historia y Estudios Sociales estos materiales utilizan un lenguaje denso que combina vocabulario específico de las disciplinas con una estructura narrativa basada en términos de uso cotidiano.

Distintos autores señalan la predominancia de los manuales por sobre otros materiales de lectura a lo largo de la escolaridad obligatoria (Carbone, 2003; Castedo, Laxalt y Usandizaga, 2010; Lerner, 2001; Siede, 2010). Advertidos de esta predominancia, algunos investigadores plantean como necesario que los docentes propongan trabajar con una multiplicidad y diversidad de textos, entre los que se incluyan manuales pero también materiales de circulación social como notas periodísticas, artículos de divulgación, textos literarios y de información científica (Castedo, Laxalt y Usandizaga, 2010; Lerner, 2001; Lerner y otros, 1996; Tolchinsky, 2008). Estos materiales de circulación social, al no ser particularmente escolares como los manuales, suelen denominarse como "auténticos" (Lerner y otros, 1996; Tolchinsky, 2008) o "del mundo real" (Moje y Speyer, 2008; Moje y otros, 2011). Cabe resaltar que, dado que usualmente no se plantea su lectura en la escuela, estos materiales conllevan para los alumnos desafíos intrínsecos a todo texto novedoso para el cual no cuentan con experiencia previa (Ferreiro, 2001). Aun más, como no están dirigidos a estudiantes, los materiales de circulación social, tal como advierten Lerner (2001) y Lerner y otros (1997), son complejos de comprender porque dan por hecho que sus destinatarios disponen de ciertos conocimientos previos. Así, omiten algunas informaciones que, sin embargo, los alumnos necesitarían para entenderlos. Por este motivo, estas investigadoras en didáctica de las prácticas del lenguaje en el nivel primario proponen que los docentes acompañen a los estudiantes en la lectura de estos textos "difíciles" mediante intervenciones en las que aporten información suplementaria, hagan notar aspectos inadvertidos y ayuden a poner en práctica quehaceres propios de lectores competentes, tales como releer para repensar una cuestión, hacerle preguntas al texto y recurrir a otros materiales para entender mejor.

La descripción que efectuamos en este subapartado respecto de elementos que componen las situaciones didácticas, nos permite en el Capítulo 6 analizar cómo entran a jugar las consignas y los materiales de lectura en la tarea de leer para responder cuestionarios. 


\subsection{Funciones de la lectura y la escritura}

En esta tesis examinamos cómo se enseñan contenidos disciplinares en el nivel secundario con ayuda de la lectura y la escritura. Si bien leer y escribir son valiosas herramientas para aprender contenidos en la escuela, el modo en que se proponga comprender y producir textos puede activar usos reproductivos o epistémicos, que repercuten en el acceso, la participación y la apropiación del conocimiento. Con vistas al análisis didáctico que presentamos en el Capítulo 6, describimos la función reproductiva (2.2.1) y la función epistémica (2.2.2) de la lectura y la escritura.

\subsubsection{Leer y escribir para reproducir conocimiento: función reproductiva}

En algunas ocasiones, las personas utilizamos la lectura como una actividad extractiva, por ejemplo, cuando leemos un texto en búsqueda de una información determinada. También empleamos la escritura como canal de comunicación al copiar datos y al responder preguntas de un examen transcribiendo información memorizada. En estos casos, leer y escribir adoptan una función reproductiva.

En estrecha relación con los usos reproductivos de la lectura y la escritura, interesa subrayar que trabajos de distintas disciplinas conceptualizan la repetición textual, la copia, la imitación y la memorización como valiosas estrategias de aprendizaje. Desde la lingüística aplicada, Guy Cook (1994) destaca como fundamental para la adquisición del lenguaje el habla para uno mismo, que involucraría un discurso íntimo, repetitivo y redundante. Además, de acuerdo con este investigador, la repetición oral favorecería la comprensión dado que repetir de memoria ciertos pasajes de un texto, aunque no se entiendan completamente, permite sostenerlos en la memoria para ir comprendiéndolos de a poco. También diversos trabajos en psicología resaltan el papel de la repetición textual y la copia en la escuela en tanto representarían señales de que se ha puesto en marcha un proceso de aprendizaje. Tal como muestra el estudio de la investigadora española Ana Teberosky (1990), cuando se comienzan a producir textos en la escuela primaria, los niños recurren a la literalidad como garantía de autenticidad. Es decir, escriben en forma similar a los textos fuentes porque buscan reasegurar la validez de su producción con "las palabras de otros". Por este motivo, no logran "escribir con sus propias palabras" sino reproducir términos y expresiones del material leído. En concordancia con ello, estudios nacionales identifican que, para escribir resúmenes, estudiantes del nivel primario copian palabras de los textos fuentes con pocas transformaciones (Kaufman y Perelman, 1999; Perelman y Castorina, 2005). Esta tendencia a 
la literalidad, según la investigadora Flora Perelman (2008), representa un paso necesario en el camino para la apropiación del lenguaje disciplinar que, tras el entrecruzamiento con el propio lenguaje, puede dar origen a las llamadas "propias palabras". Este contraste entre reproducir y usar las "propias palabras" también fue teorizado por Mijaíl Bajtín (1991), quien diferencia dos modos de apropiación de las palabras de otros en la escuela: "recitar de memoria" y "decir con las propias palabras". A diferencia de la reproducción en la que se basa el recitado de memoria, según este autor, cuando los estudiantes utilizan las "propias palabras" narran a dos voces, esto es, emplean sus palabras (su voz) para remitir a lo que otros autores dijeron (voz del autor), evitando posibles tergiversaciones del sentido. Por ello, de acuerdo con Bajtín, “decir con las propias palabras" implica un uso creativo de palabras ajenas, que modifica y cuestiona el discurso de la autoridad que encarna el docente y/o los autores de los textos leídos.

Existe un grupo de estudios que también identifica copias en las producciones escritas de alumnos de otros niveles educativos. En sus ensayos acerca del plagio universitario, la investigadora Rebecca Moore Howard $(1995,1999)$ distingue una operación denominada patchwriting, en la cual los estudiantes reproducen frases enteras, combinan oraciones, eliminan palabras que consideran irrelevantes, utilizan sinónimos, y cambian la gramática y la sintaxis de los textos fuentes. De acuerdo con Hull y Rose (1989), los alumnos realizan estas acciones para mostrar a los profesores cierto conocimiento del texto leído sin recurrir a su copia exacta. Respecto del patchwriting, diversos trabajos concluyen que es una estrategia común que emplean los estudiantes del nivel secundario y universitario en el proceso de aprender a usar fuentes, apropiarse de convenciones del lenguaje académico, formar parte de una comunidad discursiva disciplinar y construir una identidad de autor (Abasi, Akbari y Graves, 2006; Guerin, 2008; Pecorari, 2003; Villalva, 2006). En línea con ello, Roz Ivanič (1998) sostiene, a partir del análisis de ensayos universitarios, que la dependencia de los textos fuente es un modo que los alumnos tienen de identificarse con el discurso académico, por lo que resulta difícil delimitar cuando ha sucedido un plagio, una imitación o la adquisición de un nuevo discurso.

Pese a los planteos expuestos que consideran al patchwriting como un paso necesario en el aprendizaje discursivo y conceptual, Howard $(1995,2001)$ advierte que los alumnos también apelan a ese recurso cuando no comprenden lo leído y no tienen otra manera de referir a esas ideas. En concordancia con ello, investigaciones en didáctica de la Historia hallan que estudiantes del nivel primario, al poseer escaso conocimiento sobre un tema, enfrentan la producción de escritos mediante el uso de sinónimos y la reproducción de frases 
de los textos fuente (Aisenberg y Lerner, 2008) y contestan las preguntas de cuestionarios basándose en indicadores textuales que les permiten identificar las respuestas aun sin entenderlas (Benchimol, Carabajal y Larramendy, 2008).

Hasta aquí hemos reseñado estudios que evidencian que las reproducciones de palabras y frases de textos fuente en escritos de alumnos pueden deberse tanto a un proceso de aprendizaje discursivo y conceptual como a la incomprensión sobre lo leído. No obstante, diversos investigadores sostienen que, en ambos casos, estas copias no deben ser sancionadas sino tomadas como una oportunidad pedagógica para enseñar a los estudiantes a comprender mejor los textos que se leen, ayudarles a utilizar el lenguaje específico de las disciplinas, trabajar su pertenencia a una comunidad discursiva y motivar el surgimiento de su propia voz en las producciones escritas (Howard, 1995, 2001; Hull y Rose, 1989; Pecorari, 2003, 2008; Pecorari y Petrić, 2014).

\subsubsection{Leer, escribir y dialogar para construir conocimiento: función epistémica}

En este subapartado describimos algunas investigaciones que, desde diferentes disciplinas, han contribuido a entender la potencialidad epistémica de la lectura, la escritura y el diálogo, esto es, la posibilidad que ofrecen estas prácticas para tomar conciencia, construir y transformar conocimientos.

En el marco de la psicología cognitiva, interesa resaltar los modelos de escritura propuestos por Linda Flower y John Hayes $(1980,1981)$ y Marlene Scardamalia y Carl Bereiter (1992) a partir de estudios que analizan protocolos de pensamiento en voz alta. En el modelo de Flower y Hayes intervienen tres componentes: el contexto de producción, la memoria a largo plazo del individuo (que incluye el conocimiento del tópico y la audiencia) y el proceso de escritura (que involucra la planificación del texto, su textualización y su revisión). De acuerdo con los hallazgos de estos investigadores, cuando en la planificación los escritores definen una representación integrada del problema retórico que deben resolver -que considera la situación retórica y los objetivos planteados- pueden no solo recuperar ideas de su memoria sino también organizarlas de otro modo y generar nuevas; en definitiva, activar la función epistémica de la escritura. Por su parte, el modelo de Scardamalia y Bereiter (1992) describe dos procesos de composición escrita: "decir el conocimiento" y "transformar el conocimiento". Cuando un escritor "dice" el conocimiento no planifica lo que escribe sino que textualiza directamente, partiendo de una representación mental acerca del tema y el género sobre el que debe escribir, y basándose en los saberes almacenados en su memoria. En relación con el proceso de "decir el conocimiento", Flower (1979) advierte que 
quienes lo llevan a cabo emplean una "prosa basada en el escritor", es decir, guiada por el curso de pensamiento del autor, en la cual prescinden de revisar el texto para adaptarlo a las necesidades del lector. Al respecto, Miras (2000) añade que generalmente escriben de ese modo aquellos que no conocen en profundidad cierta temática y se limitan a reproducir el conocimiento que poseen. Dado que al "decir el conocimiento" no se consideran aspectos retóricos, éste se transcribe sin reelaborarse, lo cual implica un uso reproductivo de la escritura. En cambio, el otro proceso de composición escrita, "transformar el conocimiento", involucra un plan previo de escritura y la consideración simultánea de problemas de significado, expresión y organización del texto (Scardamalia y Bereiter, 1992). Por este motivo, este proceso implica una interacción dialéctica entre dos espacio-problema: el retórico (referido a los objetivos discursivos) y el semántico (respecto al contenido sobre el que se escribe). A través de esta interacción dialéctica, el escritor se descentra de su propio punto de vista para considerar la situación comunicativa en la que se escribe y adecúa el conocimiento a la perspectiva del destinario mediante la planificación y revisión del texto. Estos movimientos de ajuste de lo escrito, según Paula Carlino (2005), pueden originar que el tema se piense en forma novedosa. En consecuencia, el proceso de "transformar el conocimiento" promueve un uso epistémico de la escritura: el escritor avanza en sus conocimientos discursivos y conceptuales; en palabras de Miras (2000, p.74), "no solo aprende acerca de lo que escribe, sino que también aprende a escribir".

Además de estudios con perspectivas cognitivas, existen investigaciones con enfoques socioculturales que abordan la potencialidad epistémica de leer y escribir. Oponiéndose a considerar la literacidad como una competencia única y homogénea, Wells (1987, 1990b) propone un modelo compuesto por cinco niveles (performativo, funcional, informacional, recreacional y epistémico) que estarían presentes en cada evento letrado. El primer nivel concibe al lenguaje como un código a ser descifrado. El segundo enfatiza el uso del lenguaje para actuar y comunicarse con otros en la vida cotidiana. El tercer nivel focaliza la lectura y la escritura en tanto canales de acceso y comunicación del conocimiento. El cuarto destaca el placer que se experimenta al involucrarse con textos y explorar el mundo a través de ellos. Finalmente, el nivel epistémico alude al poder de leer y escribir como instrumentos de pensamiento y desarrollo de nuevos conocimientos a través del diálogo que se produce entre el texto y el lector o escritor. Con relación a este último nivel, Wells (1990a, 1990b) destaca el potencial epistémico de la escritura por sobre la lectura. Según este investigador, se lee en forma epistémica cuando se interrogan activamente los textos para comprenderlos, se consideran interpretaciones alternativas y se busca evidencia al respecto en los materiales 
leídos. Sin embargo, Wells señala que las representaciones mentales creadas en la lectura tienden a desvanecerse, a diferencia de la escritura, que permite retornar a las ideas escritas y retrabajarlas. Ello sucede debido a que los escritos comportan un soporte externo y permanente que puede registrar el proceso de pensamiento. Esta posibilidad de "volver" sobre el propio escrito y reflexionar sobre éste para reorganizar el propio pensamiento también fue resaltada por investigadores como David Olson (1997) y Ana Teberosky (1997, 2001), entre otros.

Siguiendo los planteos de Wells, la potencialidad epistémica de escribir radica en beneficios propios del proceso dialéctico de componer un texto: planificar, hacer borradores, releer y revisar. Dado que el escritor se encuentra distante de sus lectores en términos de tiempo y espacio, no puede verificar si las interpretaciones que éstos realizan de su texto coinciden con sus intenciones. En función de ello, si organiza su texto seleccionando qué información incluir y cómo expresarla de acuerdo con la audiencia, esta actividad pondrá en marcha la interacción entre el espacio-problema retórico y el espacio-problema semántico, conceptualizada por Scardamalia y Bereiter (1992). Emprender esta organización del texto a través de la reflexión y el pensamiento crítico-constructivo, según Wells (1987, 1990a), puede incitar a que el autor transforme sus ideas y conocimientos.

Los aportes descritos hasta aquí abren camino para pensar los aprendizajes disciplinares que pueden impulsarse a través de usos epistémicos de la lectura y la escritura. Trabajar los textos en forma epistémica, de acuerdo con Wells (1990b), implica que los docentes ayuden a los estudiantes a examinarlos críticamente considerando distintas interpretaciones posibles, en contraposición con entenderlos como portadores de significados ya dados y autoevidentes. Según este investigador, el trabajo epistémico requiere la participación de los alumnos junto con sus profesores en actividades en las que se hable sobre los textos leídos o producidos, de forma que se externalicen las actividades mentales involucradas en dicha comprensión y producción, inobservables de otro modo. Además de permitir esta externalización, Wells (1990a, 1993) señala que la interpenetración entre discursos orales y escritos ofrece otra potencialidad epistémica. Hablar sobre lo leído o producido permite aprender sobre contenidos disciplinares al mismo tiempo que se aprende acerca del lenguaje escrito. En efecto, este investigador identifica que discutir en clase respecto a lo leído, comparando interpretaciones individuales a fin de construir una interpretación colectiva, puede promover que los alumnos clarifiquen y desarrollen su propia comprensión. Por ello, Wells enfatiza la importancia de participar conjuntamente en actividades letradas, creando en las clases comunidades de pensadores letrados. Otro ejemplo 
que evidencia la importancia de dialogar acerca de lo leído es un estudio cualitativo que Wells (1993) llevó a cabo en clases de Ciencias Naturales en una escuela primaria canadiense, en donde encuentra que los profesores logran tender puentes entre los significados abstractos de los textos disciplinares y la propia experiencia de los estudiantes. Estos puentes se establecen cuando se ofrecen paráfrasis, explicaciones o ejemplos orales para contextualizar la información escrita en un lenguaje más familiar.

Otra investigadora que centra sus estudios en la interacción entre el discurso oral y el escrito es la noruega Olga Dysthe. De acuerdo con esta investigadora, dicha interacción incrementa la dialogicidad y la pluralidad de voces en las clases, lo que genera más oportunidades de aprendizaje que solo hablar o escribir. Retomando a Mijaíl Bajtín, Dysthe $(1996,2013)$ sostiene que un intercambio es dialógico cuando voces divergentes entran en tensión por los distintos puntos de vista que conllevan, se construyen nuevos significados y la comprensión de los participantes se ve modificada. Toda clase contiene múltiples voces que pueden originar estos intercambios dialógicos, ya que se compone por alumnos con diferencias sociales, culturales y lingüísticas; empero, es el docente quien debe crear condiciones para la participación de esas distintas voces (Dysthe, 2013; Dysthe, Bernhardt y Esbjørn, 2013).

Algunos estudios naturalistas que desarrolló Dysthe $(1996,2013)$ muestran cómo se integra la escritura con el habla a través del uso de producciones de los estudiantes como base para las discusiones orales. En una clase de Historia del nivel secundario, esta investigadora registra que el profesor toma extractos de trabajos de investigación realizados por los alumnos para debatir con ellos cómo se debe escribir la sección introductoria. Así, esta escritura de los estudiantes posibilita no solo que el docente tenga material para supervisar y brindar feedback sino que se discuta sobre el género a partir de textos de los pares. En relación con las discusiones orales, Dysthe (1996) observa en clases de Ciencias Sociales que, para incrementar la dialogicidad, los profesores pueden intervenir de diversas formas: aportando información basada en su conocimiento especializado, estimulando a los alumnos a que expliciten sus opiniones sobre un tema y visibilicen las diferencias entre éstas, y expresando la propia visión para desafiar sus posturas. Según sus hallazgos, para impulsar el diálogo también es importante que los profesores no respondan las intervenciones de los estudiantes rápidamente con comentarios evaluativos del tipo "bueno" o "bien”, dado que así cierran en forma anticipada las discusiones posibles.

En conjunto, las conclusiones a las que llegan los estudios de Wells y Dysthe coinciden en que los docentes ejercen un rol central para activar (o no) la función epistémica 
de hablar, leer y escribir. Con ello concuerda el estudio etnográfico de Rockwell (1995) en clases de Historia del nivel primario, que muestra que los docentes pueden intervenir oralmente transformando el sentido del texto escrito. En concreto, esta investigadora halla que determinadas exposiciones docentes anticipan, seleccionan, complementan y reordenan los contenidos abordados en los materiales, brindando a los estudiantes un esquema particular de interpretación en línea con la perspectiva del profesor. Además, en los intercambios orales sobre los textos, Rockwell identifica preguntas de los docentes cuyas respuestas se encuentran implícitamente sugeridas, de forma que no motivan a los alumnos a reflexionar sobre los temas trabajados porque resultan fáciles de contestar, incluso, sin comprender el contenido. No obstante, en estos intercambios comandados por los profesores, esta investigadora también registra momentos de ruptura en los que se asoma la voz de los estudiantes para explicitar sus propias interpretaciones sobre los contenidos.

Sintetizando pues, diremos para terminar este subapartado que los distintos modos descritos de interrelacionar o no la lectura, la escritura y la oralidad permiten delimitar formas de enseñanza situadas en un continuo entre monologicidad y dialogicidad (Dysthe, 1996; Wells, 2006). Predomina la monologicidad en las propuestas de escribir en forma individual y en los hogares, sin que luego se debata sobre lo escrito, en las clases en las que los docentes formulan preguntas únicamente para comprobar que los estudiantes están comprendiendo sus explicaciones, y en las discusiones donde no se facilita que otras voces participen y se impone una sola respuesta autorizada (Dysthe, 2013). En oposición a ello se ubican situaciones correspondientes a modos de enseñanza dialógicos, en las que los textos y las discusiones orales se utilizan como dispositivos para pensar en clase. Estas situaciones no solo promueven la función epistémica de la lectura, la escritura y la oralidad sino que, al valorar la palabra de los estudiantes como contribución valiosa, los habilitan como pensadores y promueven su autoconfianza académica (Dysthe, 1996).

\subsection{Leer y escribir para aprender contenidos en materias del nivel secundario}

En este apartado reseñamos algunos estudios que abordan la lectura y la escritura como herramientas para aprender en Historia, Geografía y Economía. A través de esta revisión examinamos aspectos relativos a las especificidades de los contenidos tratados en las tres asignaturas indagadas en el presente trabajo doctoral e identificamos modos posibles en que leer y escribir contribuyen a la elaboración cognoscitiva de dichos contenidos en el nivel secundario. 
Este relevamiento de investigaciones sobre los modos de pensar, leer y escribir característicos de estas disciplinas permite tener presente las prácticas de referencia de cada campo del saber sobre el cual los estudiantes aprenden. Al mismo tiempo, conocer qué se estudió respecto a leer y escribir para aprender en asignaturas similares a las que estudiamos en este trabajo favorece la puesta en relación de los resultados de esta tesis con los de otras indagaciones.

Como se verá en los próximos subapartados, las elaboraciones teóricas y estudios empíricos hallados en la base de datos Academic Search Premier arrojó diferente cantidad de resultados en las búsquedas booleanas en inglés realizadas a partir de las combinaciones posibles de las palabras clave "writing", "reading", "literacy" con los nombres de las asignaturas en cuestión. Cabe recalcar que en el campo atinente al resumen de los artículos ${ }^{1}$ se realizaron búsquedas sucesivas de esas palabras clave bajo los parámetros "secondary", "high school" y "K-12"2. Específicamente, la búsqueda de dichas palabras clave junto con "history" identificó 111 publicaciones. En contraste, fueron pocos los artículos obtenidos a través de la combinación de los términos clave mencionados con "economics" (76), "business" (32) y "geography" (9) ${ }^{3}$. Esta diferencia da la pauta de que existe un mayor volumen de investigaciones publicadas en revistas internacionales sobre leer y escribir para aprender Historia en el nivel secundario, en comparación con leer y escribir para aprender en Geografía y Economía.

La búsqueda en la base de datos indicada se complementó con la revisión de libros y otras publicaciones (como por ejemplo: Cartolari, 2014; Cartolari y Carlino, 2011, y textos correspondientes al programa curricular de Didáctica del nivel medio de la Facultad de Filosofía de la Universidad de Buenos Aires) recomendadas por colegas del GICEOLEM especialistas en leer y escribir para aprender en Ciencias Sociales. Conjuntamente, se sumó la búsqueda en Internet de revistas sobre didáctica de la Historia, la Geografía y la Economía y publicaciones referidas a la lectura y escritura en esas materias del nivel secundario.

A continuación, describimos los principales aportes de los artículos y publicaciones halladas al respecto de cada área disciplinar.

\footnotetext{
${ }^{1}$ Escogimos circunscribir la búsqueda al campo del resumen debido a que, tal como requieren las revistas científicas a los autores de los trabajos, éste condensa la información relevante de las investigaciones e incluye los términos claves de éstas.

${ }^{2}$ Denominación utilizada en los Estados Unidos, Canadá, Corea del Sur, Turquía, Australia y Filipinas para referir al conjunto de la educación primaria y secundaria. "K" remite al jardín de infantes (kindergarten) y "12" al último grado que abarca este espectro educativo, es decir, el último año de la secundaria.

${ }^{3}$ Entre paréntesis se identifica el máximo numérico de artículos que arrojaron las combinaciones en las búsquedas booleanas.
} 


\subsubsection{Leer y escribir en Historia}

En Historia se distingue una concepción positivista, predominante en el siglo XIX, que entiende la disciplina como una enumeración descriptiva y narrativa de acontecimientos motivados en forma coyuntural y personalista por ciertos "héroes" (Gojman, 1994; Prats, 2000; Prats y Santacana, 2001). La concepción contemporánea, en cambio, resalta la Historia como un entramado complejo en el que los fenómenos se encuentran entrelazados por explicaciones causales (Prats, 2000; Topolsky, 1985, citado en Gojman, 1994).

Con base en esta última concepción, el "hacer disciplinar" de los historiadores consiste en explicar y atribuir causas a los hechos a partir de lecturas múltiples (Carr, 1964; Jenkins, 2003). Partiendo de esta idea, investigadores analizan protocolos de pensamiento en voz alta para identificar estrategias de lectura que historiadores profesionales y alumnos del nivel secundario y universitario utilizan al abordar textos históricos (Wineburg, 1991, 1998, 2007; Wineburg, Reisman y Fogo, 2007). De esta forma, Wineburg (1991) distingue tres estrategias que emplean los lectores avanzados en la disciplina, a diferencia de los principiantes. La primera estrategia es identificar y evaluar al autor-evaluando su posición, motivación y forma de participar en los sucesos- y a la fuente -valorando el tipo de documento y la fecha en la que fue escrito-. Esta evaluación de datos, que no está explícita en el texto, según Wineburg (1991) configura un marco interpretativo crucial para construir significado. En relación con esta estrategia, Prats y Santacana (2001) coinciden en que situar la procedencia y la época o lugar en que habitaban/habitan los autores es fundamental para entender su visión de los hechos. La segunda estrategia identificada es contextualizar en tiempo y espacio los hechos relatados y, a la vez, examinar las hipótesis y explicaciones del autor, lo que demanda conocimientos históricos por parte del lector. La contextualización en formaciones sociales específicas también fue señalada por Prats y Santacana (2001) como necesaria para alcanzar una comprensión mayor de las múltiples causas y consecuencias de los sucesos históricos. Las dos estrategias descritas (identificar y evaluar al autor y la fuente y contextualizar en tiempo y espacio) resultan decisivas para concebir las fuentes como evidencia histórica en la reconstrucción del pasado. Entender las fuentes de ese modo representa uno de los parámetros centrales que Seixas (2006) y Seixas y Peck (2004) establecen respecto del modo de pensar en Historia. Finalmente, la tercera estrategia que emplean lectores avanzados en Historia es corroborar la información mediante la comparación de distintos documentos entre sí. De esta forma, es posible determinar si hay acuerdo, validación, contraposición o complementación entre fuentes. 
En cuanto a estas tres estrategias de lectura en la disciplina, Wineburg (1991) advierte que no es sencillo para estudiantes del nivel secundario y universitario ponerlas en marcha. En efecto, enfrentarse a textos históricos conlleva dificultades de comprensión que son inherentes al proceso de construcción del conocimiento específico en el área.

Una característica de los textos históricos, que puede implicar dificultades para entenderlos, son los vaivenes temporales. Respecto de las cronologías y las duraciones temporales, Carretero, Pozo y Asensio (1997) hallan que a los alumnos del nivel secundario se les dificulta contextualizar acontecimientos históricos y comparar situaciones sociales de distintos momentos. En concordancia con ello, en el nivel primario investigaciones didácticas identifican que a los estudiantes les cuesta entender textos históricos en los cuales los autores presentan las ideas realizando entrecruzamientos temporales entre el pasado y la actualidad, sin seguir el orden cronológico de los sucesos (Aisenberg, 2008; Benchimol, Carabajal y Larramendy, 2008; Lerner, Aisenberg y Espinoza, 2009, 2012).

Simultáneamente, investigadores del área sostienen que determinados conceptos históricos presentan desafíos para ser entendidos por alumnos del nivel secundario. Ciertos conceptos, como feudalismo, revolución burguesa y mercantilismo, requieren ser trabajados en forma profunda en clase para poder ser definidos y empleados no desde el sentido común sino desde una perspectiva histórica (Prats, 2000). Asimismo, en el nivel secundario otros conceptos, como monarca, iglesia, aristócrata y democracia, suelen darse por sabidos porque se utilizan en el lenguaje cotidiano (Taylor y Young, 2003); empero, debe advertirse que en los textos estos cobran distintas significaciones según los escenarios espacio-temporales a los que se remitan (Prats, 2000). En efecto, Hudson (1996) halla que en las respuestas de exámenes escritos algunos alumnos del nivel medio son capaces de utilizar adecuadamente términos históricos sin comprenderlos en forma precisa.

Dificultades para entender conceptos históricos, como las mencionadas hasta aquí, dan cuenta de la importancia de trabajar en clase haciendo explícitos los conocimientos previos de los estudiantes acerca de la Historia y del mundo social. Específicamente en esta disciplina, Moje (2010) y Moje y Speyer (2008) resaltan la importancia de conocer ciertos conceptos y hechos históricos para encarar una lectura crítica disciplinar, en tanto resultan esquemas asimiladores en la construcción de significados que realizan los alumnos. El estudio que Moje y Speyer (2008) llevaron a cabo en un bachillerato estadounidense al que asisten alumnos predominantemente latinos aporta resultados en esa dirección. Estas investigadoras propusieron a los estudiantes analizar leyes migratorias a lo largo de la historia. Sin embargo, notaron que la falta de conocimiento de los alumnos sobre el período 
histórico al que referían las leyes dificultó que interpretaran su intención de excluir algunos grupos migratorios y privilegiar otros. Por este motivo, las investigadoras decidieron efectuar un "trabajo de reparación" (Moje, 2010, p.79), esto es, dedicar tiempo de clase para construir junto con los estudiantes dicho conocimiento histórico, que debía haber sido trabajado en años anteriores de la escolaridad. Pese a que evalúan la experiencia como positiva porque los alumnos pudieron comprender la importancia histórica de esas leyes, Moje y Speyer notan que el "trabajo de reparación" que realizaron obstaculizó que se trabajasen temas correspondientes al programa curricular del año en cuestión.

En coincidencia con la importancia otorgada a los conocimientos previos, la investigación de Aisenberg y otros (2009) muestra que estudiantes del nivel primario comprenden las ideas centrales de textos históricos difíciles cuando tienen una inmersión previa en el tema. Dicha inmersión puede ofrecerse a los alumnos mediante una presentación del contenido por parte del docente -en la cual se haga referencia a diversos textos que abordan la polémica sobre dicho tema- y una propuesta de lectura individual y de relectura y discusión en conjunto con el resto de la clase. Al respecto, Aisenberg y Lerner (2008) observan que este trabajo intenso de lectura previa funciona como marco para que los estudiantes escriban síntesis personales sobre la problemática histórica, guiados y monitoreados por el profesor. Tal como identifican estas investigadoras, las producciones escritas de los alumnos resultan diversas: la mayor parte se centra en la problemática central, otras abordan solo algunos aspectos pertinentes y el resto consta de partes copiadas de los textos leídos.

Otra particularidad de los textos históricos es la intertextualidad. Trabajar con la intertextualidad es una vía para enseñar Historia mientras se enseña en qué consiste la naturaleza del proceso de conocimiento histórico. Justamente, las conexiones existentes entre distintos textos y fuentes, cuando proponen perspectivas conflictivas o divergentes, posibilitan una mirada más amplia y profunda de los temas (Cardoso, 1985; Jenkins, 2003; Lenski, 1998). Sin embargo, algunas investigaciones remarcan que los estudiantes del nivel secundario y universitario leen documentos solo para extraer hechos o listar argumentos, sin relacionarlos entre sí (Afflerbach y VanSledright, 2001; Hynd-Shanahan, Holschuh y Hubbard, 2004; Wineburg, 1991). En ocasiones, los docentes de Historia del nivel medio no contribuyen a revertir esta situación dado que, tal como afirman Leinhardt y Stanion (1994), se encuentran más preocupados por enseñar los contenidos de su materia que por visibilizar que la disciplina implica el diálogo con el pasado y sus intérpretes. 
Producir conocimiento en Historia, entonces, significa reconstruir el pasado desde cierto posicionamiento, lo que promueve que existan múltiples y divergentes historias dentro de la disciplina (Gojman, 1994). En relación con ello, estudios en didáctica de la Historia analizan intervenciones docentes en el nivel primario que enseñan a identificar las visiones de los hechos históricos que enuncian los autores de los textos que se leen (Aisenberg y otros, 2009; Aisenberg, 2010; Lerner, Aisenberg y Espinoza, 2009, 2012; Torres, 2008). De acuerdo con los resultados de estos trabajos, para posibilitar esta identificación es fundamental que los estudiantes aprendan, a través de la lectura de múltiples materiales complementarios, opuestos o que resalten otros aspectos de los temas-, que el relato de los acontecimientos se construye según cierta perspectiva de los autores. Intervenciones docentes en esa dirección ayudan a evitar que los alumnos del nivel primario equiparen una narrativa puntual con "lo que de verdad pasó" (Lerner, Aisenberg y Espinoza, 2012, p.533) y en el nivel secundario descarten perspectivas alternativas por considerarlas falsas (Barton y Levstik, 2004) o inadecuadas a la realidad (Carretero, Pozo y Asensio, 1997).

El trabajo conjunto entre docente y alumnos, destinado a reflexionar, criticar y debatir la información provista por los libros de texto de Historia-que suelen verse como autoridades incuestionables-, impulsa la comprensión de las distintas perspectivas históricas. Al respecto, Bain (2006) observa en sus clases la necesidad de estimular a los alumnos del nivel secundario a "sospechar" de los textos del modo que lo harían investigadores históricos. En línea con esta observación, Prats y Santacana (2001) subrayan la importancia de utilizar en clase métodos de trabajo similares a los que emplean los historiadores. Para conocer la historia recurrimos a fuentes, ya que los hechos del pasado no pueden ser reproducidos, pero sobre éstas es necesario efectuar un trabajo de comparación, análisis y crítica (Prats, 2000). En cuanto a cuestionar la "verdad" sobre el pasado, se resalta como fundamental que los profesores también presenten sus propias perspectivas como interpretaciones posibles (Taylor y Young, 2003), evitando que los estudiantes las consideren incuestionables, tal como algunos estudios muestran que sucede en el nivel secundario (Evans y Pate, 2007; Shemilt, 1980).

Ahora bien, investigaciones aseguran que la intertextualidad en la disciplina trae aparejada dificultades a la hora de producir escritos. El trabajo de Young y Leinhardt (1998) evidencia que a los estudiantes de los últimos años del nivel secundario se les complica integrar en una producción escrita las explicaciones sobre un mismo proceso histórico leídas en distintos documentos. No obstante, los profesores pueden ayudar a mejorar los escritos de sus alumnos. Tal como muestran diversos estudios, cuando los docentes dan lugar a 
discusiones colectivas -en las que los estudiantes pueden expresar lo comprendido sobre un tema- y promueven la producción de textos intermedios otorgando feedback, ayudan a visibilizar que los materiales leídos son determinadas argumentaciones y no la "verdad" oficial acerca de lo sucedido (Ferretti, MacArthur y Okolo; De La Paz, 2005; HyndShanahan, Holschuh y Hubbard, 2004).

Dado que se centra en el nivel secundario, resulta interesante pormenorizar la investigación de De La Paz (2005) sobre la influencia de los profesores en los modos en que los estudiantes escriben ensayos argumentativos sobre eventos históricos. En dicho estudio un grupo experimental de estudiantes de octavo grado recibe durante dos semanas la enseñanza explícita de estrategias de razonamiento histórico y de escritura argumentativa, inicialmente andamiadas por el docente y progresivamente transferidas a los alumnos para su uso independiente. La estrategia de razonamiento histórico motiva a que los estudiantes evalúen la credibilidad de cada fuente y analicen la presencia del autor en cada suceso. Por su parte, la estrategia de escritura promueve que los alumnos suspendan los juicios y consideren argumentos opuestos. El análisis del pre y post test administrado revela que las producciones escritas de los estudiantes del grupo experimental, a diferencia de los alumnos del grupo control, presentan mayor longitud, cantidad de argumentos y precisión de los contenidos históricos.

En suma, las investigaciones citadas demuestran que, para identificar las distintas visiones posibles sobre la Historia, a lo largo y ancho del sistema educativo, es fundamental que el docente organice y acompañe la lectura seleccionando distintos materiales (polémicos o complementarios) sobre un mismo tema y, al mismo tiempo, oriente a los alumnos a delimitar las posturas de los autores y compararlas entre sí. Lo anterior contrasta con las situaciones habituales descritas por Aisenberg (2005a, 2005b, 2010) y Carlino (2005), en las que se deja que los estudiantes trabajen con los textos sin ayuda, porque no se visibiliza la necesidad de enseñar a leer al interior de cada disciplina.

\subsubsection{Leer y escribir en Geografía}

Dentro del campo de la didáctica de la Geografía, se ha propuesto en las últimas décadas que la enseñanza de esta disciplina exceda la simple clasificación y descripción de los espacios y los cambios naturales de la superficie terrestre, lo cual ha sido el enfoque tradicional hasta mediados del siglo XX. En ese sentido, distintos académicos del área plantean evitar la clásica división entre geografía física y geografía humana, para impulsar la comprensión de los fenómenos socio-territoriales incorporando la acción del hombre en ellos (Finocchio y 
García, 1995; Gurevich, 1994, 1998). Esta comprensión requiere, según Gurevich (1998), que los estudiantes otorguen significado a la motivación del accionar humano sobre los espacios, así como a las razones y causas que explican las configuraciones territoriales.

Pese a esta propuesta de cambio en la enseñanza de la Geografía, se ha demostrado que el enfoque tradicional sigue siendo predominante: en las clases se trabajan meras categorías descriptivas y clasificatorias de los distintos ambientes y cambios naturales ocurridos en el planeta. Al respecto, la investigación realizada por Alexandre (2009) muestra, a partir de entrevistas a estudiantes de profesorado de Geografía en Portugal, que prima un enfoque descriptivo y fáctico en la enseñanza de esta disciplina. Los entrevistados aducen que aprender Geografía implica conocer las características de diferentes espacios -como regiones y continentes- y clasificarlos. Similares resultados alcanzan Molin y Grubbström (2013) a través de observaciones, entrevistas y análisis de test administrados a estudiantes del nivel secundario en Suecia. Así, identifican que, según los alumnos, los docentes enseñan Geografía privilegiando las habilidades para leer mapas y usar escalas y el conocimiento de los nombres de países y regiones. Esto deja en segundo plano la enseñanza de las relaciones entre diferentes espacios que, de acuerdo con estos investigadores, ayudaría a comprender cuestiones más profundas concernientes a este campo disciplinar, tales como las consecuencias de las injusticias sociales, la relación entre los modos de trabajo y el desarrollo sustentable, etcétera. En consecuencia, Molin y Grubbström notan que estos alumnos entrevistados presentan dificultades para alcanzar un razonamiento geográfico sofisticado.

Considerando que lo que se dice hacer en clase puede distar de lo que realmente sucede, Hugonie (2004) observó clases de Geografía en el nivel secundario francés para identificar las actividades propuestas por los docentes. Sus hallazgos también confirman la predominancia del enfoque tradicional en la enseñanza de la Geografía, señalada por las investigaciones citadas anteriormente. En concreto, Hugonie encuentra que la mayoría de las actividades apunta a captar información bruta de documentos, tablas y gráficos referidos a países, localizar ciertas zonas en mapas, y observar y describir fotografías de paisajes. Al entrevistar a los profesores de dichas clases, este investigador recaba que estos consideran al conocimiento geográfico simplemente como una colección de aspectos observados directamente en la superficie terrestre. Es a partir de esta concepción de la geografía que, según Hugonie, los docentes no proponen actividades para reflexionar acerca de las relaciones entre los elementos de la Tierra y los usos que las sociedades les otorgan.

Particularmente en nuestro país, Quintero (2001) identifica en manuales de Geografía del nivel primario y secundario dos tradiciones de enseñanza que otorgan primacía a la 
noción de Estado: la geografía regionalista y la geopolítica. La primera tradición entiende los territorios como las bases naturales de los Estados y no como espacios socialmente constituidos por la acción histórica, mientras que la segunda visualiza a los Estados como organismos espaciales condicionados por su ubicación en los mapas mundiales. Además de los manuales, los docentes también sostienen enfoques curriculares con el Estado como eje central. La encuesta que Denkberg y Fernández Caso (2004) administraron a participantes de una formación para capacitadores de docentes en el área de Ciencias Sociales muestra que, aunque existe diversidad de perspectivas sobre la enseñanza de la disciplina, todas sitúan al Estado Nacional como unidad privilegiada de organización curricular.

En paralelo, otra investigación sobre textos escolares diseñados para la enseñanza secundaria del país muestra que el concepto de globalización -central en Geografía a partir de la década de los 90- se presenta, en la mayoría de estos materiales, en forma deshistorizada y carente de controversias en torno a su surgimiento (Hollman, 2005). Por lo tanto, este concepto aparece como un hecho dado y autoevidente, lo cual obstaculiza la posibilidad de discutir acerca de las relaciones sociales de producción capitalistas a nivel global.

Con respecto a los modos de enseñanza de la Geografía, encontramos algunos trabajos que señalan la importancia de las propuestas de leer y escribir para aprender en la disciplina. Sosteniendo que en las universidades se ignoran los estudios empíricos que avalan la enseñanza de la escritura en Geografía, Libbee y Young (1983) retoman el modelo de escritura de Flower y Hayes (ver subapartado 2.2.2) y hacen hincapié en la importancia del feedback docente como un modo de ayudar a los estudiantes a avanzar en sus escritos, ofreciéndoles la perspectiva del lector. Con base en ello, estos investigadores describen actividades de escritura para enseñar a los estudiantes a pensar como geógrafos. Entre dichas actividades, se distinguen pre-escrituras con consignas como las siguientes: ¿qué preguntas se hacen los geógrafos?, ¿qué tipo de evidencia usan?, ¿cuáles son los problemas comunes que enfrentan al presentar conocimientos en esta área?, ¿cuáles son las limitaciones de las perspectivas geográficas? Pese a que el artículo de Libbee y Young puntúa estos interrogantes para las pre-escrituras, no otorga respuestas posibles, que definirían en parte la especificidad del conocimiento geográfico. En simultáneo con las pre-escrituras, estos investigadores resaltan la importancia de alentar a los estudiantes a usar fuentes primarias y trabajar con datos para crear distribuciones ${ }^{4}$, analizarlas y comparar patrones. Otras recomendaciones que realizan Libbee y Young son de nivel más general, no específicas de la

\footnotetext{
${ }^{4}$ A pesar de que el artículo no lo aclara, suponemos que con "distribuciones", los autores refieren a los patrones de distribución de los elementos geográficos sobre la superficie terrestre, aspecto que aborda la Geografía.
} 
disciplina, aunque vale la pena mencionarlas porque muestran que ciertas intervenciones docentes utilizadas para ayudar a aprender en otros campos del saber también son sugeridas por estos geógrafos y especialistas en educación. Tales intervenciones son: que los docentes ayuden a los estudiantes a delimitar un área de interés para escribir, que promuevan múltiples revisiones y reescrituras de borradores, que alienten a pensar sobre los comentarios recibidos y que evalúen la producción final asignando una calificación que tenga en cuenta la totalidad del proceso.

La potencialidad de leer y escribir para aprender contenidos en Geografía también se evaluó en el nivel universitario a través de diarios de los alumnos. En sus clases, Fouberg (2000) propone seis tipos de tareas de escritura con el fin de que los estudiantes aprendan a pensar geográficamente. El primer tipo de tarea requiere que los estudiantes respondan en clase una pregunta dada por el docente, como por ejemplo: "Pensando en nuestros debates sobre el mercantilismo, la exploración, el Renacimiento, la Reforma y la primera ola de colonialismo, explicar por qué Europa fue el colonizador en lugar del colonizado" (Fouberg, 2000, p.199). También pide que los alumnos lean artículos de revistas académicas y capítulos de libros incluidos en el cuadernillo de la materia y que, en sus hogares, contesten en sus diarios un interrogante al respecto. Un tercer tipo de escritura exige que, tras la lectura de novelas relacionadas con ejes temáticos de la asignatura, los estudiantes formulen preguntas acerca de conceptos geográficos y las respondan en sus diarios, valiéndose de ejemplos de las novelas. Asimismo, buscar noticias actuales relacionadas con tópicos o conceptos de la materia y explicar dónde suceden esos eventos y porqué ocurren allí y no en otro lugar de mundo, es otra de las tareas de escritura propuestas para los diarios. Finalmente, Fouberg plantea a los estudiantes escrituras más extensas. Por un lado, un ensayo en el que deben estudiar un paisaje cultural, entrevistar actores como guardaparques, profesores y miembros de sociedades históricas, hacerse tres preguntas sobre el mismo y responderlas. Por el otro lado, un ensayo reflexivo en el que los alumnos tienen que leer las escrituras previas que realizaron en sus diarios y explicar si y porqué estas les sirvieron para aprender en la asignatura, recurriendo a citas y ejemplos de sus producciones anteriores. La encuesta administrada al final del semestre a los estudiantes revela que la mayoría de estos privilegia como útiles para aprender conceptos geográficos las dos primeras tareas de escritura descritas (responder preguntas acerca de temas debatidos en clase o sobre temas leídos en artículos académicos y capítulos de libros), dado que estas ya especifican consignas y materiales: preguntas del docente y textos o lo discutido en clase como base para contestarlas. 
Otro estudio que muestra la potencialidad de leer y escribir para aprender los contenidos de esta disciplina es el de Salinas, Fránquiz y Reidel (2008), quienes documentan y analizan las prácticas de enseñanza de una docente de Geografía en una escuela secundaria estadounidense con población inmigrante. Mediante entrevistas, observaciones de clase y recolección de documentos encuentran que la profesora toma el conocimiento previo de sus alumnos como base para construir nuevos conocimientos geográficos. Concretamente, la docente los hace participar oralmente con preguntas que requieren comparar, contrastar, analizar y sintetizar temas. Por ejemplo, al trabajar en sus clases los movimientos expansionistas europeos a partir del siglo XVI y sus efectos sobre la vida de las tribus nativas norteamericanas, la profesora inquiere: “¿cómo los nativos se sintieron acerca de estos extranjeros?”, “qqué cosas buenas podrían haber sucedido cuando estas culturas se reunieron?” o “qqué cosas no tan buenas podrían haber sucedido?” (Salinas, Fránquiz y Reidel, 2008, p.73). En forma simultánea, la profesora propone que en pequeños grupos los estudiantes completen en una tabla de doble entrada -que han comenzado a realizar en conjunto en el pizarrón- los efectos negativos y positivos de ese encuentro cultural, para luego compartir la producción con el resto de los compañeros. En otra clase relativa a la expansión española sobre Latinoamérica, esta docente pide a los estudiantes que grafiquen una línea de tiempo respecto a los movimientos migratorios de sus antecesores. Al analizar estas prácticas de enseñanza, Salinas, Fránquiz y Reidel (2008) resaltan que las estrategias empleadas por la docente satisfacen las necesidades educativas de alumnos inmigrantes desde un enfoque cultural superador, no solo centrado en la relación entre las personas y los territorios, sino también en variables de poder, raza, clases sociales y género.

Finalmente, la potencialidad de la lectura y la escritura para aprender en Geografía fue también examinada en el nivel primario por trabajos como el de Hinde y otros (2007). Este estudio analiza los efectos de un programa de literacidad, denominado Geoliteracy ${ }^{5}$, que versa sobre la comprensión lectora en esta área del conocimiento. Dicho programa, producido por profesores expertos en cartografía, consta de materiales de clase con actividades creativas que integran contenidos de geografía con lectura y escritura. Para el estudio citado, los investigadores dispusieron que un grupo de docentes enseñe siguiendo el programa Geoliteracy y otro grupo lo haga de modo usual. Los pre y post test que se administraron a

\footnotetext{
${ }^{5}$ El programa incluye 85 clases diseñadas para el espectro educativo desde jardín de infantes hasta octavo grado de la educación primaria (denominado K-8). Por ejemplo, para cuarto y quinto grado se propone una clase llamada "Un río a través del tiempo", que plantea a los alumnos investigar, mediante fuentes primarias, los efectos que tuvo la construcción de represas en el río Gila sobre el estilo de vida de los indios Pima, agricultores que utilizaban sus aguas para regar cultivos. Véase: http://alliance.la.asu.edu/geoliteracy/ELL/ELLCD/LessonHomePages/warrenriver.html
} 
los estudiantes no evaluaron el conocimiento informacional de Geografía sino los modos de leer pertinentes y necesarios para aprender esta materia, que el programa busca reforzar: establecer causas y efectos, secuenciar, identificar la idea principal, resumir, hacer inferencias y conclusiones, seguir directivas e interpretar representaciones gráficas. A través de un análisis estadístico de estos instrumentos, Hinde y otros (2007) identifican que los estudiantes que participaron en el programa Geoliteracy obtienen puntajes más altos en los test de comprensión lectora, en comparación con el grupo control. Además, los profesores participantes notan que estos alumnos se encuentran más motivados para leer o aprender sobre los contenidos.

Los estudios reseñados hasta aquí, que muestran formas novedosas de enseñar Geografía con ayuda de la lectura y la escritura, contrastan con la investigación realizada por Shepherd y Bleasdale (1993). Estos investigadores analizan en el Reino Unido el uso de course readers (colecciones de textos provenientes de libros, revistas y diarios) para alentar y apoyar la lectura en la disciplina. La mayoría de los estudiantes, a través de un cuestionario que se administra, revela no percibir cambios en el estilo de enseñanza docente a partir del uso en clase de estos materiales. Tal como concluyen los investigadores, el solo hecho de incorporar un recurso original no garantiza por sí mismo cambios en la enseñanza ni comporta una solución a los problemas relativos a la lectura de los estudiantes.

En conjunto, las investigaciones sintetizadas en el presente subapartado evidencian que aprender Geografía implica no solo poder clasificar superficies terrestres sino también comprender los fenómenos socio-territoriales teniendo en cuenta las diferencias sociales, económicas y étnicas de las poblaciones y las desigualdades existentes en función de ellas. Si bien predomina un enfoque tradicional en la enseñanza de esta disciplina, distintos estudios muestran que cuando los docentes proponen actividades $y / 0$ materiales que integran contenidos geográficos con lectura y escritura, y cuando estimulan producciones escritas en las que se piensa como geógrafos, los estudiantes aprenden más y mejor acerca de los temas del área.

\subsubsection{Leer y escribir en Economía}

De acuerdo con distintos investigadores, en la enseñanza de la Economía predomina el paradigma neoclásico por sobre otras corrientes de pensamiento económico, tales como la escuela keynesiana, la escuela marxista, el estructuralismo latinoamericano o la teoría de la dependencia (Aronskind, 2011; Cataño, 2001; Corredor, 2005; López Accotto y de Amézola, 2004; Rodas, 2011; Urquiza, Wainer y Martínez, 2011). Particularmente en nuestro país, 
estudios empíricos corroboran dicha hegemonía en planificaciones docentes de escuelas secundarias bonaerenses (Urquiza, Wainer y Martínez, 2011) y en manuales de economía para el nivel (Rodas, 2011).

Sostenido por economistas como Willam Jevons, Leon Walrras y Lionel Robbins, el paradigma neoclásico se vincula con la ideología neoliberal y se asocia con las Ciencias Exactas. Por ello, este paradigma aborda los fenómenos económicos exclusivamente a partir de modelos matemáticos (Aronskind, 2011; Corredor, 2005; Rodas, 2011), sin considerar su determinación histórica (Dubrovsky, 2011; López Accotto y de Amézola, 2004; Urquiza, Wainer y Martínez, 2011). Desde este paradigma, el análisis económico que se propone en las escuelas, entonces, se reduce a la relación hombre-recursos que tiende a mostrar la necesidad del equilibrio entre estos dos factores (Corredor, 2005). Así, los conceptos clave sobre los que se basa una enseñanza orientada bajo ese paradigma son: microeconomía, macroeconomía, oferta y demanda y satisfacción de necesidades (Rodas, 2011; Tobío, 2011; Urquiza, Wainer y Martínez, 2011).

En contraposición con el paradigma neoclásico, los enfoques críticos proponen entender la realidad económica como producto de la actividad humana e incorporar en su análisis las relaciones sociales, los intereses económicos y la dominación de clases (Urquiza, Wainer y Martínez, 2011). Esta postura es sostenida, por ejemplo, por la revista Real-World Economics Review, conformada por un grupo de estudiantes de escuelas de economía francesas que, desde el año 2000, claman por un pluralismo en la enseñanza de la disciplina (Corredor, 2005).

Existen pocos estudios específicos sobre enseñanza de la lectura y la escritura para aprender en Economía. Dicha escasez puede relacionarse con dos factores. Por un lado, con el hecho de que los desarrollos en didáctica de la Economía son incipientes, tal como advierten López Accotto y de Amézola (2004) y, por el otro lado, con el papel secundario que adquiere la Economía en el currículum escolar de Ciencias Sociales, según sostienen Travé (1999) y Travé y Estepa (1997). En efecto, estos dos factores han sido corroborados por Travé y Pozuelos (2008) en una investigación con docentes de una escuela primaria española situada en un contexto socioeconómico desfavorecido. Dicho estudio identifica dificultades en los profesores a la hora de diseñar, desarrollar y reflexionar sobre una unidad didáctica cuyos contenidos centrales son nociones económicas. Los investigadores describen que estos docentes poseen escasa formación en didáctica de la Economía, ubican la disciplina dentro del campo de las Matemáticas -y no dentro del área de las Ciencias Sociales-, tienden a seleccionar actividades de los manuales sin cuestionar los objetivos y contenidos de 
enseñanza, y creen que proponer tareas de investigación escolar se reduce a que los estudiantes busquen información bibliográfica por sí mismos.

Entre los escasos estudios respecto a leer y escribir para aprender en esta disciplina, hallamos uno que recomienda estrategias para promover la escritura de los alumnos. En dicha investigación, Stowers y Barker (2003) muestran que el entorno empresarial y las comunicaciones mediadas por la tecnología demandan que los profesionales escriban correctamente cartas, folletos, memos, reportes y propuestas. Al respecto, las estrategias de enseñanza en Economía que proponen son: establecer objetivos claros para la asignatura, invertir tiempo para discutir con los estudiantes sobre la tarea de escritura (dando lugar a borradores y sus revisiones), aclarar las expectativas respecto a ésta, establecer conexiones entre las tareas indicadas y los objetivos del curso, estimular a que los alumnos consideren la audiencia para la cual escriben y fomentar el feedback en la evaluación de los escritos a través de la revisión entre pares. No obstante, nuestra lectura crítica de este estudio advierte que estas estrategias no enfocan la especificidad disciplinar, ya que su generalidad hace que puedan emplearse también para otras áreas. Únicamente en relación con la última estrategia, fomentar el feedback, Stowers y Barker mencionan la importancia que adquiere con vistas a la vida profesional que desempeñarán los alumnos en tanto hombres y mujeres de negocios, dado que allí constantemente se les exigirá revisar escritos preparados por empleados o por superiores para su evaluación y/o sugerencias.

Otra serie de indagaciones que aborda la escritura para aprender Economía enfoca la utilidad de una estrategia de enseñanza denominada one-minute-paper para favorecer el aprendizaje en la disciplina y otras materias relacionadas (Almer, Jones y Moeckel, 1998; Chizmar y Ostrosky, 1998; McElroy y Coman, 2002; Stead, 2005). Tal estrategia consiste en dar a los estudiantes una consigna de escritura que pide responder dos preguntas en los últimos minutos de clase: a) ¿Qué es lo más importante que aprendiste hoy? y b) ¿Cuál es la principal pregunta que te quedó sin respuesta? Las investigaciones citadas concluyen que el uso de esta estrategia ofrece al docente un feedback detallado acerca de qué están aprendiendo los alumnos, incentiva que participen en clase y colabora con el aprendizaje de contenidos disciplinares.

Dentro del conjunto de estas investigaciones, Chizmar y Ostrosky (1998) realizan un estudio en cursos universitarios de Introducción a la Economía en los que implementan el one-minute-paper. Mediante un pre-test, miden el conocimiento inicial de los alumnos sobre principios económicos $\mathrm{y}$, luego, a través de un post-test, su conocimiento al término del semestre. Así, estos investigadores determinan que esta estrategia ayuda a enriquecer el 
conocimiento económico de los estudiantes. De modo similar, otros estudios muestran un incremento en los resultados de los post-test de estudiantes universitarios de contabilidad (Almer, Jones y Moeckel, 1998) y contabilidad de gestión (McElroy y Coman, 2002), cuyos profesores plantean el uso del one-minute-paper. Por su parte, el trabajo de Stead (2005) recaba opiniones de alumnos de una universidad del Reino Unido acerca del one-minutepaper e identifica que la mayoría de los estudiantes de licenciatura en Ciencias Económicas consideran valioso el uso en clase de esta estrategia. En especial, los alumnos señalan la oportunidad de expresar sus dudas al docente y recibir su feedback como los principales beneficios.

Pese a que los trabajos reseñados muestran al one-minute-paper como una manera posible de aprovechar la escritura para favorecer mejores aprendizajes, el estudio de Becker y Watts (2001) halla que docentes de Economía en la universidad recurren a las clases expositivas como principal método de enseñanza. Estos investigadores identifican, a través de encuestas, que los profesores no proponen a los alumnos tareas para realizar en pequeños grupos ni escrituras como el one-minute-paper. Para Becker y Watts, si se utilizaran otros métodos, podría promoverse en los estudiantes mayor interés por la asignatura y mejores rendimientos académicos. En la misma línea, Stead (2005) comprueba, mediante cuestionarios a profesores de Economía e Historia Económica de universidades del Reino Unido y de los Estados Unidos, que el one-minute-paper no se utiliza ampliamente debido a que se ignora su existencia o se cree que insume mucho tiempo analizar y contestar las respuestas de los estudiantes.

Reconociendo esta predominancia de las clases expositivas, Salemi, Siegfried, Sosin, Walstad y Watts (2001) sitúan al estudio de los métodos de enseñanza actuales como prioritario en la investigación sobre la enseñanza y el aprendizaje de la Economía. En su artículo, los autores también sostienen que es fundamental promover aprendizajes activos en los estudiantes, proponiendo tareas que los fuercen a pensar como economistas y en las que deban usar ideas económicas para contestar preguntas y resolver problemas.

En síntesis, las investigaciones descritas hasta aquí sobre formas de conocer en Economía y modos de aprovechar la lectura y la escritura como herramientas para aprender los contenidos de esta disciplina, evidencian que se trata del área con mayor vacancia de investigaciones respecto de esta temática. La mayoría de los estudios se centra en la descripción de estrategias generales (como el one-minute-paper) que no direccionan la especificidad del conocimiento disciplinar en juego. 


\section{Metodología}

¿Cómo investigar prácticas de enseñanza que entrelazan leer y escribir en materias del nivel secundario sin simplificar su complejidad? ¿Cómo hacerlo en tres asignaturas diferentes y en un curso escolar con alumnado de cierta procedencia socioeconómica? Este capítulo describe y fundamenta las decisiones metodológicas que se tomaron a lo largo del proceso investigativo a fin de enfrentar estos desafíos. En principio, puntualizamos los objetivos de investigación, que justifican la elección del diseño del estudio. Luego, relatamos la selección de la institución y de los casos, y detallamos los instrumentos de recolección de datos y los procedimientos que utilizamos para su registro. Por último, describimos el modo en que analizamos la empiria y efectuamos algunas consideraciones acerca de la validez del presente estudio.

\subsection{Objetivos de la investigación}

El objetivo principal del presente trabajo es identificar y comprender las prácticas de enseñanza que favorecen u obstaculizan que leer y escribir se conviertan en herramientas de acceso, participación y apropiación del conocimiento en asignaturas de escuelas secundarias a las que asisten alumnos de sectores socioeconómicos desfavorecidos.

Dado este objetivo principal, los objetivos específicos que guían nuestro estudio son los siguientes:

a) Caracterizar las tareas de lectura y escritura llevadas a cabo en asignaturas de una escuela secundaria a la que asisten alumnos de sectores socioeconómicos desfavorecidos.

b) Establecer las demandas y expectativas de los docentes en relación con las tareas de lectura y escritura en sus materias.

c) Comprender los desafíos que enfrentan los estudiantes a la hora de participar en las tareas de lectura y escritura para aprender contenidos, teniendo en cuenta su procedencia socioeconómica.

d) Describir y caracterizar las intervenciones docentes que se presentan en las asignaturas estudiadas y establecer cuáles de ellas valoran los estudiantes como ayudas para desarrollar las tareas pedidas. 
e) Identificar las perspectivas de docentes y alumnos acerca de la lectura y la escritura, su enseñanza y aprendizaje, y su relación con los contenidos disciplinares.

Nuestro énfasis en la comprensión de las prácticas de enseñanza mediadas por la lectura y la escritura, que se desarrollan en un contexto específico, responde a una concepción del leer y escribir como actividades condicionadas por las estructuras sociales (Barton y Hamilton, 2004; Kalman, 2003; Rockwell, 1982; Street, 1984). Por lo tanto, consideramos que la enseñanza de contenidos con ayuda de la lectura y la escritura en asignaturas de una institución, situada en determinado contexto y que atiende población desfavorecida socioeconómicamente, adquiere características propias. Nos preguntamos, entonces, cómo se incluyen las prácticas de enseñanza mediadas por lectura y escritura en materias de escuelas secundarias a las que asisten alumnos provenientes de estos sectores socioeconómicos. Comprender tal objeto de estudio requiere un abordaje metodológico que permita dar cuenta de su complejidad y singularidad. A continuación describimos el diseño que escogimos para nuestro estudio, a fin de abordar dichos aspectos.

\subsection{Diseño del estudio}

Para alcanzar los objetivos descritos, el presente estudio adopta una metodología cualitativa, ya que busca comprender procesos y significados prescindiendo de las mediciones numéricas de los estudios cuantitativos (Denzin y Lincoln, 2005). Concebimos el diseño de esta investigación cualitativa a partir de un modelo interactivo en el que sus componentes interactúan y se interconectan permitiendo cambios y ajustes en la misma (Maxwell, 2005). De acuerdo con Mendizábal (2006), esta flexibilidad permite advertir durante la investigación las situaciones inesperadas que requieren reorganizar el trabajo.

Para responder al interrogante que guía nuestro trabajo - explicitado en el subapartado anterior-, y en vista de la escasez de investigaciones nacionales que enfoquen cómo se enseñan contenidos disciplinares con ayuda de la lectura y la escritura en las materias del nivel secundario argentino (ver Capítulo 1), decidimos diseñar un estudio de casos (Stake, 2000, 2010). En este tipo de estudios, se exploran estratégicamente ciertos casos para su abordaje intensivo y en profundidad (Creswell, 2007; Flyvbjerg, 2006; Neiman y Quaranta, 2006; Stake, 2000, 2010; Yin, 2003). Por esta razón, de acuerdo con Yin (2003), los estudios de casos son apropiados para contestar preguntas acerca del cómo de un fenómeno, tal como nos propusimos indagar. 
En concreto, siguiendo a Stake (2000, 2010), nuestra investigación puede catalogarse como un estudio de casos instrumental ya que los casos se escogieron deliberadamente, como instrumentos para responder a los interrogantes planteados. Tal como detallan los próximos subapartados, para desarrollar este estudio seleccionamos tres asignaturas de una escuela secundaria que recibe alumnos de sectores socioeconómicos desfavorecidos, como "casos" que ilustran modos posibles de incluir a la lectura y la escritura en la enseñanza de contenidos. Se trata, por tanto, de un estudio naturalista de carácter descriptivo-interpretativo que selecciona intencionalmente asignaturas del repertorio habitual de prácticas pedagógicas. Como "unidad de análisis", tomamos al sistema didáctico, esto es, las interacciones entre los estudiantes, los docentes y los contenidos disciplinares (ver apartado 2.1 del Capítulo 2). Valiéndonos de esa unidad de análisis, apuntamos a obtener una comprensión situada y significativa de las prácticas de enseñanza de contenidos disciplinares mediadas por la lectura y la escritura en tres materias del nivel, que preserve la especificidad, singularidad y complejidad de cada caso.

\subsection{Selección y acceso a la institución}

El principal criterio que establecimos para delimitar la institución escolar en la cual llevar a cabo el trabajo de campo, de acuerdo con el objetivo principal de esta tesis, fue que recibiera alumnos de sectores socioeconómicos desfavorecidos.

Al iniciar la búsqueda de escuelas con esa característica, localizamos en el ámbito de la Ciudad de Buenos Aires un establecimiento de gestión estatal cuyas autoridades estaban dispuestas a abrirnos sus puertas para desarrollar el estudio. De esta manera, se saldaba un desafío que, según Creswell (2007), resulta determinante para la viabilidad de estudios cualitativos como el nuestro: el acceso a los lugares donde se van a recoger datos. Dicha escuela, además de atender estudiantes provenientes de esos sectores, lleva adelante un proyecto institucional que considera el entorno sociocultural de los estudiantes y propone programas específicos para su ingreso, permanencia y egreso (ver subapartado 4.1.2 del Capítulo 4).

Visitamos el establecimiento escolar en el mes de agosto del año 2010 y tuvimos un encuentro con el rector a cargo. En esa oportunidad, recorrimos las instalaciones y describimos las tareas de investigación que deseábamos realizar. El rector brindó su autorización para el estudio y, a fin de que nos interioricemos acerca de la historia de la escuela y sus proyectos actuales, facilitó dos documentos institucionales: el Proyecto Escuela y el Proyecto Institucional Inclusivo. Garantizadas las condiciones de accesibilidad, 
acordamos comenzar la investigación al año siguiente, junto con el inicio del nuevo ciclo lectivo.

\subsection{Selección de los casos}

Con vistas a la selección de asignaturas como casos a investigar, llevamos a cabo un estudio piloto. Este estudio permitió no solo explorar diversos años y materias para definir los casos sino también familiarizarnos con la institución y sus integrantes y poner a prueba las herramientas destinadas a recolectar información.

A los fines de comenzar el estudio, nos pusimos en contacto con la nueva rectora, quien reemplazó al anterior directivo ante su jubilación. En el mes de abril del año 2011, concertamos un encuentro para presentarnos y detallar el plan de actividades del trabajo de campo. Respondiendo a nuestro pedido de contacto con profesores, la rectora ofreció los correos electrónicos de dos docentes del área de Ciencias Sociales que dictaban clases en el turno de la mañana.

Tras el envío de correos que explicitaban nuestra intención de observar prácticas de enseñanza, contestó uno de los docentes e informó que dictaba clases de Historia en segundo y de Estudios Sociales Argentinos en quinto año. Bajo el supuesto de que en el último tramo de la escolaridad secundaria encontraríamos alumnos "desganados" y con menor voluntad para cumplimentar las actividades diarias, optamos por iniciar el estudio piloto en segundo año. En la primera clase observada de Historia, resultó ardua la tarea de identificar propuestas docentes en relación con la comprensión y producción de textos porque la mayor parte del tiempo los estudiantes hablaron entre sí en torno a temas ajenos a la materia, mientras que el profesor pidió silencio para formular actividades. Luego de esta observación, y ante nuestro pedido, el docente nos puso en contacto con otra profesora del área, que también dictaba clases en Historia pero en tercer año. En las tres clases observadas en dicho año, encontramos un panorama similar al de segundo año: cuando la docente intentó exponer oralmente un tema, debió interrumpirse para pedir que los estudiantes hicieran silencio, apagasen la música y/o dejasen de navegar por redes sociales desde las netbooks ${ }^{6}$.

En paralelo con estas observaciones piloto en segundo y tercer año, conversamos con otros actores institucionales que definieron a estos primeros años como un período en el cual los alumnos exhiben problemáticas que ocupan la centralidad del quehacer áulico y los esfuerzos educativos se concentran en socializar a los alumnos en normas institucionales que

\footnotetext{
${ }^{6}$ Los estudiantes de esta institución poseían netbooks propias, producto de la entrega que efectuó el Gobierno Nacional en el marco del programa Conectar Igualdad.
} 
aseguren la convivencia y la disciplina necesaria para una enseñanza más sistemática. Más adelante, en el subapartado 4.1.3 del Capítulo 4, nos concentramos en la descripción de las características que presentan los estudiantes en ese tramo inicial del nivel.

Considerando estos comentarios de los actores institucionales, y la dificultad para recoger datos sobre la enseñanza de contenidos con ayuda de la lectura y la escritura en esos cursos, deliberamos junto con el equipo de investigación acerca de las posibilidades de alcanzar los objetivos de la tesis indagando en años superiores. Las circunstancias descriptas en segundo y tercer año entorpecían la identificación de las intervenciones docentes y los desafíos que hallaban los estudiantes para leer y escribir en las materias. Observar un encuadre de trabajo establecido en esos cursos parecía requerir un estudio longitudinal que acompañara su tránsito por el proceso de socialización de normas referido por los actores institucionales. Por ello, y teniendo en cuenta los plazos previstos para la recolección de datos de esta tesis, decidimos indagar en cursos del tramo final del nivel secundario. Recurrimos nuevamente al primer docente contactado para observar sus clases de Estudios Sociales Argentinos en quinto año. En la primera clase observada registramos un panorama distinto al de los otros años: identificamos que los estudiantes charlaron entre sí mientras efectuaron una tarea de lectura y escritura (leer un texto de un cuadernillo y responder preguntas de un cuestionario). En esas condiciones, logramos registrar intervenciones del profesor para guiar la lectura y consultas orales por parte de los alumnos. Dado que prometía un escenario viable para recoger y analizar datos sobre cómo se enseñan contenidos mediante la lectura y la escritura, decidimos profundizar la indagación en ese año y delimitar dicha materia como un primer caso (en adelante Asignatura A). La elección de indagar asignaturas en quinto año también brindaba la posibilidad de aproximarnos al conocimiento de los usos de la lectura y la escritura propuestos y ejercidos en un momento excepcional de la escolaridad secundaria: su último tramo. Esta elección, finalmente, acordaba con los criterios que Stake (2000, 2010) señala como fundamentales para la selección de los casos a investigar: la accesibilidad y la posibilidad de aprendizaje que ofrece.

A la par que incrementamos las observaciones en la Asignatura A, decidimos incorporar otras materias de quinto año a nuestro estudio. Dado que consideramos que los distintos campos de conocimiento exigen modos específicos de comprender y producir textos, y para establecer contrastes posibles entre las prácticas de enseñanza observadas, decidimos circunscribir la búsqueda al área de las Ciencias Sociales, a la que pertenecía la asignatura ya escogida. Contactamos en la institución con otro docente del área $\mathrm{y}$, a fines de junio del año 2011, comenzamos a observar sus clases de Geografía Económica, delimitando un nuevo 
caso que denominamos Asignatura $B$. Luego, en vista de incluir una tercera materia, consultamos el programa escolar de quinto año exhibido en la preceptoría. Notamos que, dado que la escuela posee orientación comercial, existe una predominancia de materias contables, y solo las Asignaturas A y B corresponden a las Ciencias Sociales. Considerando la importancia de ampliar el número de casos en estudio, preseleccionamos otras dos asignaturas pertenecientes al área Jurídico-Contable. Así, a fines de agosto del año 2011 contactamos a las docentes a cargo de esas asignaturas y obtuvimos su permiso para observar clases. En la primera materia observada, Administración, registramos como tarea principal la resolución de problemas numéricos a través de la aplicación de fórmulas. Debido a que esta asignatura parecía ajustarse exclusivamente al campo contable, pensamos con el equipo de investigación que ello reduciría las posibilidades de relacionar esas tareas con las efectuadas en las Asignaturas A y B. Sumado a ello, otra circunstancia antepuso un obstáculo a la posibilidad de observar la progresión de actividades de enseñanza en dicha materia: la docente comentó que, dado que también estaba a cargo de Contabilidad - otra asignatura del área Jurídico-Contable en quinto año-, solía alternar las ocasiones en que dictaba una u otra en función de repasar o continuar con algún contenido disciplinar específico.

A diferencia de ello, cuando presenciamos clases en la otra asignatura preseleccionada del programa, Legislación Fiscal, notamos actividades relacionadas con temas de economía, ciudadanía y cultura fiscal, que dejaron en segundo plano el cálculo de impuestos. En la primera observación realizada, registramos lectura en pequeños grupos y una puesta en común mediada por la docente, lo que sugería la presencia en la asignatura de tareas de lectura y escritura para aprender contenidos. Por estos motivos, determinamos que dicha materia conformaría el tercer caso en estudio y la denominamos como Asignatura $C$.

Todas las decisiones metodológicas que tomamos, reseñadas en este subapartado, permitieron delimitar tres casos para nuestro estudio: Estudios Sociales Argentinos (Asignatura A), Geografía Económica (Asignatura B) y Legislación Fiscal (Asignatura C). Estos casos fueron seleccionados en forma intencional para estudiarlos en profundidad por su posibilidad de aportar entendimiento a la problemática de investigación (Creswell, 2007, Patton, 1990). De acuerdo con Rockwell (1995), al mantener ciertas características constantes (se dictan en un mismo curso de quinto año) y otras características variables (abordan contenidos disciplinares específicos y están a cargo de distintos docentes), estos casos poseen una estructura que permite su contraste analítico, tal como se mostrará en el Capítulo 6. 


\subsection{Procedimiento e instrumentos de recolección de datos}

En los siguientes subapartados describimos los distintos instrumentos que utilizamos para recoger datos en el trabajo de campo: observación de clases, entrevista a actores institucionales y recolección de documentos, materiales de lectura y producciones escritas. Conjuntamente, detallamos el procedimiento de registro y transcripción de los datos.

\subsubsection{Observación de clases}

Desde hace varias décadas, diversos investigadores recalcan el valor de la observación como técnica de recolección de datos en el campo educativo (De Ketele, 1984; Fernández Enguita, 1985; Guber, 2001; Poggi, 1995; entre otros). Específicamente en los estudios de caso, observar clases resulta un medio privilegiado para obtener información durante el trabajo de campo (Stake, 2010). Aun más, de acuerdo con Gloria Edelstein (2011), una de las principales referentes del país en cuanto a la formación docente, este instrumento resulta una vía privilegiada para indagar prácticas de enseñanza, tal como nos propusimos en esta tesis.

Para observar clases en nuestra investigación, decidimos no utilizar guías que prefigurasen categorías sobre las cuales obtener datos. En cambio, concurrimos al aula de quinto año dispuestos a registrar lo que aconteciera, haciendo foco en la unidad de análisis delimitada, esto es, las interacciones entre el profesor y los estudiantes en torno a la lectura y la escritura de contenidos disciplinares.

A lo largo de siete meses -mediados de mayo hasta fines de noviembre del año 2011realizamos un seguimiento sistemático de las clases en las materias escogidas como casos (Asignaturas A, B y C). En total, presenciamos 39 clases: 11 en la Asignatura A, 17 en la Asignatura B y 11 en la Asignatura C. Respecto de la frecuencia y duración de dichas clases, el plan de estudios de quinto año dispone que a la Asignatura A le corresponde un dictado semanal de dos horas cátedra ${ }^{7}$, a la Asignatura $\mathrm{B}$ dos horas cátedra dos veces por semana y a la Asignatura $\mathrm{C}$ tres horas cátedra dos veces por semana. Sin embargo, observamos durante el trabajo de campo que la duración de las clases fue menor a la estipulada. En la Asignatura A, dictada en las primeras horas de la jornada escolar, el docente solía demorar el comienzo de las clases debido a que los alumnos entraban tarde a la institución. Por su parte, los profesores de las Asignaturas B y C -dictadas en las últimas horas-, frente al pedido de los estudiantes, daban cierre a las clases entre quince minutos y media hora antes de completar las horas cátedra correspondientes. Por tanto, de acuerdo con lo que indican las grabaciones de audio,

\footnotetext{
${ }^{7}$ Se denomina hora cátedra al lapso de 40 minutos de clase.
} 
el promedio aproximado de horas de clase observadas en la Asignatura A y la Asignatura C fue de 59 minutos y en la Asignatura B de 41 minutos. La Tabla 1 ilustra la duración real de las clases presenciadas en cada materia. Aclaramos al lector que en dicha tabla, y a lo largo de toda la tesis, denominamos Clase 1 a la primera clase observada, y así sucesivamente con las restantes clases.

Tabla 1. Duración de las clases observadas en las asignaturas

\begin{tabular}{|c|c|c|c|}
\hline & Asignatura A & Asignatura B & Asignatura C \\
\hline Clase 1 & $1 \mathrm{~h}$ & $56 \min 55 \mathrm{~s}$ & $1 \mathrm{~h} 3 \min 9 \mathrm{~s}$ \\
\hline Clase 2 & $1 \mathrm{~h} 36 \mathrm{~s}$ & $37 \min 20 \mathrm{~s}$ & $34 \min 52 \mathrm{~s}$ \\
\hline Clase 3 & $1 \mathrm{~h} 7 \min 53 \mathrm{~s}$ & $37 \mathrm{~min} 51 \mathrm{~s}$ & $1 \mathrm{~h} 41 \min 1 \mathrm{~s}$ \\
\hline Clase 4 & $1 \mathrm{~h} 11 \min 54 \mathrm{~s}$ & $48 \min 52 \mathrm{~s}$ & $1 \mathrm{~h} 17 \min 49 \mathrm{~s}$ \\
\hline Clase 5 & $49 \min 57 \mathrm{~s}$ & $39 \min 8 s$ & $1 \mathrm{~h} 9 \min 39 \mathrm{~s}$ \\
\hline Clase 6 & $40 \min 36 \mathrm{~s}$ & $41 \min 32 \mathrm{~s}$ & $1 \mathrm{~h} 27 \min 14 \mathrm{~s}$ \\
\hline Clase 7 & $59 \min 49 \mathrm{~s}$ & $45 \min 39 \mathrm{~s}$ & $1 \mathrm{~h} 12 \min 38 \mathrm{~s}$ \\
\hline Clase 8 & $1 \mathrm{~h} 4 \min 45 \mathrm{~s}$ & $42 \min 18 \mathrm{~s}$ & $1 \mathrm{~h} 49 \min 16 \mathrm{~s}$ \\
\hline Clase 9 & $59 \mathrm{~min}$ & $47 \min 10 \mathrm{~s}$ & $1 \mathrm{~h} 10 \min 42 \mathrm{~s}$ \\
\hline Clase 10 & $1 \mathrm{~h} 3 \min 31 \mathrm{~s}$ & $11 \min 8 s$ & $53 \min 2 \mathrm{~s}$ \\
\hline Clase 11 & $1 \mathrm{~h} 38 \mathrm{~s}$ & $33 \min 17 \mathrm{~s}$ & $55 \min 17 \mathrm{~s}$ \\
\hline Clase 12 & - & $43 \min 6 s$ & 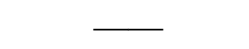 \\
\hline Clase 13 & $\longrightarrow$ & $29 \min 41 \mathrm{~s}$ & \\
\hline Clase 14 & - & $40 \min 48 \mathrm{~s}$ & - \\
\hline Clase 15 & - & $58 \min 4 \mathrm{~s}$ & - \\
\hline Clase 16 & - & $38 \min 21 \mathrm{~s}$ & $\longrightarrow$ \\
\hline Clase 17 & $\longrightarrow$ & $43 \min 13 \mathrm{~s}$ & $\longrightarrow$ \\
\hline Total & 10 h $58 \mathrm{~min} 39 \mathrm{~s}$ & 11 h $34 \mathrm{~min} 23 \mathrm{~s}$ & 13 h $14 \min 39 s$ \\
\hline
\end{tabular}

Otras circunstancias hicieron que se redujera no solo la duración de clases observadas sino también la frecuencia y cantidad de clases presenciadas. Desde los inicios del trabajo de campo, planificamos sostener una presencia sistemática en las clases a fin de observar una progresión secuenciada de las actividades de lectura y escritura desarrolladas en las tres materias de quinto año. Sin embargo, este objetivo se vio obstaculizado por reiteradas suspensiones de clases. Durante nuestra estadía en la institución, fueron suspendidas en total 37 clases por diversos motivos. En su mayoría, estos fueron explicitados por los profesores: ausencias docentes (por licencias, por concurrir a votación de representantes en las Juntas de Clasificación y por razones personales) ${ }^{8}$, salidas educativas, actividades tutoriales (jornadas colectivas o tutorías en cursos específicos) ${ }^{9}$, paros docentes, actos escolares (superpuestos con el horario de clases), simulacros de evacuación y tareas de limpieza y desinfección tras jornadas electorales en los que la escuela ofició como sede de votación. En otras ocasiones,

\footnotetext{
${ }^{8}$ El Estatuto docente establece como un derecho del personal docente el goce de licencias, justificaciones y franquicias. Entre los motivos posibles se encuentran las ausencias por razones particulares, afecciones comunes o largo tratamiento.

${ }^{9}$ Bajo esta categoría agrupamos dos actividades: jornadas colectivas para todos los docentes-tutores (que involucran la suspensión de clases en toda la institución) y tutorías con algún curso en particular en las que un profesor-tutor debe ausentarse de su clase en otro curso.
} 
los docentes de las asignaturas comunicaron directamente a la investigadora la suspensión de clases pero omitieron los motivos, por lo que no consideramos pertinente indagarlos y los clasificamos como "no informados". En la Tabla 2, contabilizamos las clases suspendidas de acuerdo con los motivos descritos.

Tabla 2. Motivos de suspensión de clases en las asignaturas observadas

\begin{tabular}{cc}
\hline Motivos de suspensión & Cantidad de clases \\
\hline Ausencias del docente & 15 \\
No informados & 6 \\
Salidas educativas & 5 \\
Actividades tutoriales & 3 \\
Paros docentes & 3 \\
Actos escolares & 2 \\
Tareas de limpieza y desinfección & 2 \\
Simulacros de evacuación & 1 \\
\hline Total & 37 \\
\hline
\end{tabular}

Tal como muestra la Tabla 2, la mayor cantidad de clases suspendidas se debe a las ausencias docentes. Esto coincide con los hallazgos de investigaciones realizadas en escuelas secundarias con alumnado de sectores socioeconómicos desfavorecidos, que identifican irregularidades en la asistencia a clase de los profesores (Belossi y Palacios de Caprio, 2004; Jacinto y Terigi, 2007; Krichesky y Duque, 2011b; Krichesky y otros, 2008), aunque no especifican los motivos de éstas.

Otro dato que se desprende de la Tabla 2 es que el número total de clases suspendidas (37) se asemeja al número total de clases observadas (39). En concreto, se suspendieron catorce clases en la Asignatura B, trece en la Asignatura C y diez en la Asignatura A. No obstante este elevado número de clases suspendidas, vale aclarar que aquellas ocasionadas por salidas educativas y actividades tutoriales (ocho en total) encuentran justificación en el proyecto político-pedagógico de la escuela, que pauta una diversidad de iniciativas para la inclusión educativa de los alumnos, entre las que se encuentran la propuesta de experiencias didácticas y recreativas fuera de la institución escolar y el seguimiento de las problemáticas de los cursos a través de tutorías (ver subapartado 4.1.2 de Capítulo 4).

\subsubsection{Entrevista}

Otra herramienta que utilizamos en el trabajo de campo para recoger datos es la entrevista. Efectuamos entrevistas semiestructuradas y en profundidad a los docentes a cargo de las tres asignaturas observadas, a los alumnos de quinto año y al ex rector de la institución.

En particular, las entrevistas a los docentes requirieron dos encuentros distintos. En el primero, indagamos sus datos personales y de formación, tales como edad, título de base, 
otros títulos y estudios en curso, antigüedad en la docencia y en la institución, materias dictadas, cargos en la escuela, otros establecimientos donde se desempeñan y cantidad total de horas de trabajo. Luego de una pregunta introductoria - “¿Qué tienen que hacer los alumnos para aprender en esta materia?"- nos concentramos en aspectos prefijados en un guion de entrevista, relativos a las tareas de lectura y escritura que proponen en sus clases y las perspectivas que sostienen respecto de leer y escribir para aprender en sus materias (ver Anexo 1). Posteriormente, en el segundo encuentro, orientamos las preguntas en función de ciertas tareas de comprensión y producción textual que observamos en sus clases y las intervenciones que registramos los profesores habían realizado. En simultáneo, interrogamos los criterios para seleccionar los materiales de lectura en sus asignaturas y ahondamos en su compromiso institucional y en las normas de trabajo que establecen en el curso. En total, se llevaron a cabo seis entrevistas (dos con cada docente) de una duración promedio de 44 minutos.

De acuerdo con las posibilidades y preferencias de cada profesor, fuimos variando los lugares donde llevamos a cabo las entrevistas. Los docentes de las Asignaturas A y C escogieron ser entrevistados en la misma institución, en espacios que estuviesen desocupados al momento de la entrevista. Por su parte, el profesor de la Asignatura B pidió realizar uno de los encuentros en la sala de profesores y otro en la Dirección de una escuela pública porteña donde se desempeña como vicerrector. En la Tabla 3 se especifica la duración de cada entrevista efectuada a los profesores de las asignaturas observadas.

Tabla 3. Duración de las entrevistas realizadas a los docentes

\begin{tabular}{|c|c|c|c|}
\hline $\mathrm{N}^{\circ}$ de entrevista & Docente & Duración & Total \\
\hline 1 & \multirow{2}{*}{ Asignatura A } & 53 min 9 s (Primera entrevista) & \multirow{2}{*}{$1 \mathrm{~h} 30 \min 9 \mathrm{~s}$} \\
\hline 2 & & 37 min (Segunda entrevista) & \\
\hline 3 & \multirow{2}{*}{ Asignatura B } & 39 min $47 \mathrm{~s}$ (Primera entrevista) & \multirow{2}{*}{$1 \mathrm{~h} 24 \min 59 \mathrm{~s}$} \\
\hline 4 & & $45 \min 12 \mathrm{~s}$ (Segunda entrevista) & \\
\hline 5 & \multirow{2}{*}{ Asignatura $\mathrm{C}$} & $45 \min 39 \mathrm{~s}$ (Primera entrevista) & \multirow{2}{*}{$1 \mathrm{~h} 31 \min 8 \mathrm{~s}$} \\
\hline 6 & & $45 \min 29 \mathrm{~s}$ (Segunda entrevista) & \\
\hline
\end{tabular}

En cuanto a las entrevistas a los catorce alumnos de quinto año, a medida que nos interiorizamos de sus situaciones de vida, advertimos la dificultad para hallar un momento adecuado y disponible para realizarlas. La mitad de ellos trabajaban a contraturno y algunos, al concluir la jornada escolar, se marchaban rápidamente a sus empleos. Incluso, la escuela 
permitía que los estudiantes se retiraran antes de finalizar el horario escolar para llegar a tiempo a sus trabajos. Debido a estas circunstancias, pedimos autorización al profesor de la Asignatura A - cuya materia se dictaba en las primeras horas de la mañana-, para entrevistar alumnos durante sus clases. Aunque esta alternativa posibilitó entrevistar nueve estudiantes, no conseguimos hallar el momento oportuno para hacerlo con los cinco restantes, que tenían permiso institucional para ingresar una vez iniciado el horario escolar porque trabajaban de noche o formaban parte del programa Retención Escolar de alumnas/os madres/padres y embarazadas (ver subapartado 4.1.2 del Capítulo 4). Finalmente, con el aval de la docente de la Asignatura $\mathrm{C}$, pudimos entrevistar a estos estudiantes durante las últimas horas del turno mañana, correspondientes a sus clases. Cabe aclarar que, en ambas materias, acordamos el retiro de los alumnos cuando no fuera imprescindible la presencia del curso completo en la clase. $^{10}$

En todos los casos, propusimos a los estudiantes ser entrevistados en duplas. Esta decisión se basó en otros estudios desarrollados dentro del GICEOLEM (por ejemplo, Di Benedetto, 2012), que mostraron que entrevistar a los alumnos junto con algún/algunos compañero/s favorece la interacción y el diálogo entre ellos. En especial, considerando que debíamos interrogar adolescentes, invitarlos a responder preguntas de a pares parecía una forma efectiva de promover su participación y evitar que sintieran vergüenza o timidez de estar a solas con la entrevistadora. Efectivamente, en la primera entrevista llevada a cabo con dos alumnas percibimos, por un lado, que se sintieron cómodas por estar con una compañera $y$, por el otro, que se produjo un interesante intercambio de opiniones entre ambas: en algunas preguntas disintieron y aportaron visiones diferentes y en otras acordaron y complementaron sus respuestas. Por esta razón, resolvimos mantener esta modalidad. Lo oportuno de esta decisión volvió a corroborarse en las siguientes entrevistas: continuaron suscitándose significativos diálogos entre los estudiantes que, creemos, no se hubieran producido de haberlos convocado individualmente.

Las entrevistas a los alumnos se desarrollaron en el comedor escolar contiguo al aula de quinto año. Antes del horario del almuerzo, este espacio permanecía vacío, por lo que aseguró, tal como sugiere Creswell (2007), un ambiente libre de distracciones para efectuar las entrevistas. Elaboramos para esos encuentros un guion de preguntas que comenzaba requiriendo datos personales y de formación tales como edad, barrio de residencia, trayectoria

\footnotetext{
${ }^{10}$ Por ejemplo, en la Asignatura A entrevistamos estudiantes cuando el docente organizó espacios donde comentó en forma individual las correcciones de trabajos prácticos. En la Asignatura C, lo hicimos en la clase en la cual la profesora tomó un recuperatorio escrito a algunos estudiantes y en la clase donde comentó individualmente con los alumnos las calificaciones obtenidas en el segundo trimestre.
} 
escolar, situación laboral y máximo nivel educativo alcanzado por la familia (ver Anexo 2). Nos interesaban estas cuestiones para poder construir un perfil socioeducativo de cada alumno. El guion continuaba con una pregunta similar a la efectuada a los docentes, “¿Qué tienen que hacer para aprender en las materias?", y luego se abocaba a indagar las tareas de lectura y escritura exigidas por los docentes cuyas asignaturas observamos. Pese a que preestablecimos dichas temáticas centrales para abordar durante la entrevista, convenimos estar atentos al surgimiento de otras que pudiesen introducir los alumnos.

Del modo descrito, se condujeron siete entrevistas de una duración promedio de 43 minutos cada una. Aunque en su mayoría se realizaron a duplas de estudiantes que así se agruparon por decisión propia, hubo dos excepciones: la entrevista a un trío de estudiantes, que pidió ser entrevistado de ese modo, y la última entrevista, efectuada en forma individual a una alumna embarazada de ocho meses, que llevaba alrededor de un trimestre ausentándose a clase. La Tabla 4 muestra la secuencia de entrevistas realizadas, especificando qué alumnos participaron y la duración de las mismas.

Tabla 4. Duración de las entrevistas realizadas a los alumnos de quinto año

\begin{tabular}{|c|c|c|}
\hline $\mathrm{N}^{\circ}$ de entrevista & Alumnos & Duración \\
\hline 1 & Claudia y Marisa & $28 \min 36 \mathrm{~s}$ \\
\hline 2 & Carla y Lorena & $34 \min 17 \mathrm{~s}$ \\
\hline 3 & Daiana y Fabiana & $38 \min 33 \mathrm{~s}$ \\
\hline 4 & Ernesto, Ariana y Yésica & $36 \min 12 \mathrm{~s}$ \\
\hline 5 & Nadia y Lautaro & $1 \mathrm{~h} 1 \min 34 \mathrm{~s}$ \\
\hline 6 & Martín y Denise & $1 \mathrm{~h} 1 \min 13 \mathrm{~s}$ \\
\hline 7 & Guadalupe & $41 \mathrm{~min} 33 \mathrm{~s}$ \\
\hline 7 entrevistas & 14 alumnos & $5 \mathrm{~h} 1 \mathrm{~min} 58 \mathrm{~s}$ \\
\hline
\end{tabular}

Nota: Los nombres de los alumnos son seudónimos que preservan su identidad.

Por último, además de entrevistar a los docentes y los alumnos de quinto año, realizamos una entrevista con el ex rector de la institución. La decisión de entrevistarlo se debió a que, a medida que comenzamos a analizar los datos del trabajo de campo, y a fin de entender algunas acciones didácticas de los docentes, advertimos la necesidad de profundizar la información relativa a la historia institucional y los objetivos pedagógicos de la escuela. Por estas cuestiones, convenimos interrogar a quien fuera el director de la institución durante dieciocho años. La entrevista se realizó en el mes de septiembre del año 2012 en un bar céntrico de la Ciudad de Buenos Aires y duró alrededor de una hora y 38 minutos. En concreto, las preguntas giraron en torno a su trayectoria en la escuela, su concepción de la labor pedagógica necesaria para el trabajo diario con alumnos de estos sectores socioeconómicos, los aprendizajes que considera fundamentales promover y su punto de vista acerca del lugar que ocupa la lectura y la escritura en ellos (ver Anexo 3). 


\subsubsection{Recolección de documentos, materiales y producciones}

En el trabajo de campo también recopilamos documentos institucionales, materiales de lectura y producciones escritas de los alumnos.

Anteriormente mencionamos que recabamos dos documentos institucionales en el primer encuentro que tuvimos con el entonces rector de la escuela. Uno de estos documentos es el Proyecto Institucional Inclusivo, elaborado en el mes de junio del año 2009, que recopila fragmentos de otros documentos de trabajo de la escuela a fin de puntualizar los fundamentos teórico-ideológicos que sustentan su proyecto de educación popular. El otro documento es el Proyecto Escuela, que incluye datos identificatorios de la escuela, una breve fundamentación del proyecto escolar, sus objetivos y líneas de acción, y la programación de las actividades para el ciclo lectivo. El formato de este último documento se basa en las indicaciones del Ministerio de Educación para su elaboración y envío a la supervisión del distrito escolar. Para ahondar en la información que presentan estos documentos, remitimos al lector al subapartado 4.1.2 del Capítulo 4.

Respecto de las planificaciones docentes, solo obtuvimos la correspondiente a la Asignatura A. El profesor de la Asignatura B informó que no había armado formalmente la planificación para el año lectivo, aunque nos comentó oralmente los contenidos que pensaba abordar en el curso. Por su parte, la docente de la Asignatura C prometió enviárnosla por correo electrónico pero, hasta el momento presente, no la recibimos.

En relación con los materiales de lectura, fotocopiamos los textos que los docentes de las asignaturas propusieron para trabajar con los alumnos en las clases observadas. En la Asignatura A fotocopiamos el cuadernillo de textos de la materia y un cuestionario escrito sobre el modelo nacional agroexportador que el docente entregó a los estudiantes. En la Asignatura B lo hicimos con capítulos de manuales de Geografía e Historia Mundial que se trabajaron en clase, tres artículos periodísticos y un extracto de página web que el docente repartió sobre el bloque regional UNASUR. Finalmente, en la Asignatura C fotocopiamos apartados del módulo de Cultura Fiscal utilizado en las clases y un cuestionario escrito con preguntas sobre capacidad contributiva que la profesora dio a los alumnos.

Por último, recopilamos diversas producciones escritas de los alumnos: carpetas, trabajos prácticos y evaluaciones. En cuanto a las carpetas, solo logramos fotocopiar dos, pertenecientes a las alumnas Yésica y Marisa. El resto de los estudiantes no accedió al pedido de fotocopiar sus carpetas, argumentando que las tenían "incompletas" y/o "desprolijas". Además de esas dos carpetas, recopilamos dieciséis trabajos prácticos realizados para la 
Asignatura A, que los estudiantes enviaron en forma digital al docente. También fotocopiamos diez parciales de la Asignatura C, corregidos y calificados numéricamente por la docente, correspondientes al número de alumnos que se presentó a rendir. Cabe aclarar que esta materia fue la única que durante el período de clases observado evaluó contenidos disciplinares a través de un examen presencial y escrito.

\subsubsection{Registro y transcripción de datos}

Para el registro de datos en el trabajo de campo utilizamos en forma simultánea un grabador digital y un cuaderno de notas. En las observaciones de clase, con vistas a registrar las intervenciones verbales tanto de los alumnos como de los docentes, colocamos el grabador en un banco libre del centro del aula. La investigadora se ubicó en una silla hacia el extremo izquierdo del pizarrón, lugar que ofrecía una visión panorámica del curso. Luego de cada clase observada, almacenamos los archivos de sonido en la computadora, identificándolos con el nombre de la asignatura y el número y la fecha de observación correspondientes. Del mismo modo procedimos para registrar el audio de las entrevistas: utilizamos el grabador y lo ubicamos entre los interlocutores. Tras dichos encuentros, almacenamos los archivos en la computadora con los nombres de los entrevistados y la fecha de realización. La duración total del material audiograbado de clases ( $35 \mathrm{~h} 47 \mathrm{~min} 41 \mathrm{~s}$ ) y de entrevistas (11 h 6 min $14 \mathrm{~s}$ ) es de 46 h $53 \min 55 \mathrm{~s}$.

Por su parte, el cuaderno de notas sirvió para apuntar información que el grabador no podía captar. Esto permitió registrar datos como: el lenguaje no verbal (gestos, miradas, cambios de entonación, etc.) de alumnos y docentes en las clases y las entrevistas, las interacciones entre actores institucionales que observamos en espacios extra-áulicos (pasillos, recreos, sala de profesores y alrededores de la escuela) y nuestras impresiones como investigadores. Particularmente en las observaciones de clase, también utilizamos el cuaderno de notas para graficar un croquis con la disposición de los bancos -que usualmente se mantenía en cada clase- y la ubicación de los alumnos en ellos -que solía variar-. Contabilizando desde los primeros asientos del lado derecho del aula, numeramos a los estudiantes correlativamente (A1, A2, A3, etc.) en cada clase, para luego vincular sus intervenciones verbales, registradas por el grabador, con otros datos anotados en el cuaderno. A medida que nos familiarizamos con sus nombres, los apuntamos bajo dicha nominación alfanumérica. Igualmente reprodujimos en el cuaderno las anotaciones que durante las clases observadas efectuaron los profesores en el pizarrón (cuadros sinópticos, gráficos, líneas de tiempo, cuestionarios de preguntas, definiciones teóricas, recordatorios de fechas, etcétera.). 
Para la transcripción de los datos empleamos un procesador de textos en el que desgrabamos los audios obtenidos. Generamos así documentos con los audios transcritos, en los que incorporamos las anotaciones del cuaderno, a fin de posibilitar un análisis integral de aspectos verbales y no verbales de las observaciones de clases y las entrevistas. En cada registro de clase, identificamos las intervenciones de los alumnos con una nominación alfanumérica y las intervenciones de los docentes con la letra " $\mathrm{D}$ ". De modo similar, en las desgrabaciones de entrevistas reiteramos estas nominaciones y utilizamos la letra " $R$ " para el ex rector y la letra "E" para la entrevistadora. La información relativa a datos personales y de formación, obtenida en las entrevistas, se transcribió a modo de tablas al inicio de los documentos del procesador de textos.

\subsection{Estrategias utilizadas para el análisis de datos}

Para el análisis de los datos descritos se utilizaron estrategias cualitativas de categorización y contextualización, que examinan relaciones de similitud y contigüidad, respectivamente (Maxwell y Miller, 2008). Durante todo el proceso de análisis, nos basamos en una lógica dialéctica que supone un interjuego entre teoría y empiria (Maxwell, 1992). Es decir, no adecuamos los datos a categorías preconstruidas sino que efectuamos categorizaciones y contextualizaciones preliminares partiendo de los datos, luego exploramos el marco conceptual y nuevamente, volvimos a los datos para refinar el análisis, y así sucesivamente.

A través del modo expuesto, obtuvimos dos tipos de resultados, que se presentan en la segunda parte de esta tesis. El primer conjunto de resultados consta de un análisis de las acciones desarrolladas por directivos y docentes para propiciar la permanencia escolar (Capítulo 4) mientras que el segundo constituye un análisis didáctico de las intervenciones docentes relacionadas con la tarea de leer para responder cuestionarios, mayoritariamente propuesta en las clases observadas (Capítulo 5). Si bien nuestro objeto de indagación son las prácticas de enseñanza de contenidos mediadas por la lectura y la escritura en las materias, nos vimos en la necesidad de efectuar un análisis de las acciones institucionales e interpersonales que fomentan la permanencia escolar dado que, al comenzar las lecturas y relecturas de las transcripciones de los datos, identificamos en forma recurrente alusiones a dicha temática por parte de los actores y situaciones que referían a la misma. Por ello, categorizamos esos datos efectuando triangulaciones entre las transcripciones de entrevistas, los registros de clase y la información de los documentos institucionales, y las relacionamos con la bibliografía disponible al respecto, presentada en el apartado 1.2 del Capítulo 1. 
En cuanto al análisis didáctico, para iniciarlo leímos en forma transversal los registros de las 39 clases observadas y efectuamos un recorte de aquellas 37 en las que se registraron actividades de lectura y escritura: 11 clases en la Asignatura A, 16 clases en la Asignatura B, y 10 clases en la Asignatura $C .{ }^{11}$ En esas 37 clases seleccionadas en las que registramos comprensión y producción de textos, se identificó la tarea de lectura y escritura propuesta en forma predominante por los docentes de las tres materias: leer para responder cuestionarios, en la cual escogimos concentrar el análisis. Confirmamos esta primacía a través del armado de viñetas que, tal como sugieren Miles y Huberman (1994), presentan una reconstrucción sintética y narrativa de eventos representativos, en nuestro caso, de las principales tareas respecto de leer y escribir contenidos propuestas en cada clase observada (ver Anexo 4).

Dada esta elección por concentrarnos en la tarea de leer para responder cuestionarios, quedaron fuera del análisis didáctico cinco clases en las que, en su totalidad, se llevaron a cabo tareas planteadas minoritariamente por los profesores durante el período observado (no sucedieron más de una o dos veces durante los siete meses de recolección de datos del trabajo de campo) mientras que otras clases permanecieron dentro del corpus de análisis recortando solo los episodios relativos a la tarea escogida. Remarcamos al lector que las tareas propuestas en forma minoritaria por los docentes ${ }^{12}$, si bien se excluyen de esta tesis doctoral, serán analizadas durante la beca posdoctoral. Finalmente, omitimos de las clases seleccionadas aquellos fragmentos en los que no se hace referencia a la lectura y escritura de contenidos disciplinares ${ }^{13}$ que, sin embargo, se utilizan como material empírico para el análisis de las acciones que fomentan la permanencia escolar (ver Capítulo 4). De acuerdo

\footnotetext{
${ }^{11}$ Solamente excluimos del análisis dos clases observadas: la Clase 13 en la Asignatura B y la Clase 6 en la Asignatura C. En la primera, no se trabajaron actividades de lectura y escritura para aprender contenidos sino que el docente, a pedido de la rectoría, dio una charla sobre orientación vocacional. La otra clase que excluimos estuvo dedicada a la devolución oral de las notas del trimestre. La profesora conversó individualmente con los alumnos y expresó su apreciación personal acerca del desempeño en la materia.

${ }^{12}$ Estas tareas propuestas en forma minoritaria fueron: escribir en forma domiciliaria un trabajo práctico de investigación (Clase 1 y 2 en Asignatura A), recibir comentarios individuales sobre las correcciones de un trabajo práctico de investigación (Clase 3 en Asignatura A), recibir un comentario general acerca de aspectos comunes de los trabajos prácticos de investigación (Clase 4 en Asignatura A), leer conjuntamente un texto en voz alta, parte por parte, discutiendo acerca de los fragmentos leídos (Clase 4 en Asignatura A), ver un video y discutir oralmente las respuestas a un cuestionario (Clase 6 en Asignatura A), ver repetidas veces un fragmento de documental para responder un cuestionario por escrito (Clase 4 y 5 en Asignatura B), leer textos diferentes en pequeños grupos y exponer lo comprendido ante el resto de los compañeros (Clase 1 en Asignatura C), responder una evaluación escrita y presencial (Clase 4 en Asignatura $\mathrm{C}$ ) y responder un recuperatorio escrito $\mathrm{y}$ presencial (Clase 5 en Asignatura C).

${ }^{13}$ Se trata de fragmentos correspondientes a: conversaciones de actores institucionales como preceptores y secretarios con los alumnos del curso; comentarios y diálogos informales de los docentes con la investigadora; conversaciones de los profesores con los alumnos respecto a temas diversos (como los estudios superiores, actos y eventos escolares, necesidad de esforzarse y ser responsables, organización de salidas recreativas y/o didácticas, y vida cotidiana); conversaciones entre los alumnos en voz alta respecto a temas ajenos a la materia; e interacciones orales de los alumnos con la investigadora.
} 
con el procedimiento descrito, quedó conformado un corpus de 32 clases como base empírica para el análisis didáctico.

A partir de este corpus, efectuamos lecturas y relecturas de los registros de clase, para identificar intervenciones de los profesores en torno a la tarea de leer para responder cuestionarios, y las nombramos inicialmente con etiquetas descriptivas. En principio, para su análisis, dividimos estas intervenciones en tres grandes categorías: antes, durante y después de la tarea. Posteriormente, y en línea con el marco conceptual delineado, refinamos esta división de acuerdo con tres funciones docentes que distinguimos que los profesores ejercieron en forma predominante durante esta tarea: definición del medio, gestión del medio y evaluación de la tarea. Mediante una tabla del programa Excel, comenzamos un proceso de categorización de la empiria seleccionada guiándonos por nuestro marco conceptual, que condujo a delimitar categorías y subcategorías de las intervenciones docentes identificadas. Al mismo tiempo, valiéndonos de una estrategia contextualizadora, distinguimos el comportamiento de los estudiantes ante cada una de estas intervenciones. Así, teniendo en cuenta simultáneamente cómo actuaron profesores y alumnos en dicha tarea, buscamos abordar la acción conjunta (Sensevy, 2007) en relación con los contenidos disciplinares abordados en las materias observadas. Dicho análisis requirió retornar a los datos empíricos, probar en los registros de clase las categorías y subcategorías preconstruidas y releer el marco conceptual para ajustarlas. Una vez estabilizadas las categorías y subcategorías, mediante ese ir y venir entre datos-teoría, procedimos a contabilizar las intervenciones docentes que engloban, de acuerdo con la cantidad de veces ocurridas en cada clase. Por ejemplo, si en un registro de clase identificamos que el profesor da una consigna para realizar en los hogares y la reitera dos veces, contabilizamos tres intervenciones respecto de "da consignas domiciliarias". Del modo descrito, categorizamos 354 intervenciones docentes. Tal como se verá en el Capítulo 5, algunas intervenciones corresponden solo a un turno de habla de los docentes (por ejemplo, las pertenecientes a la categoría "Define la tarea") mientras que otras abarcan distintos turnos de habla de los profesores, intercalados con turnos de habla de los alumnos (por ejemplo, las pertenecientes a la categoría "Establece significados compartidos"). Por último, cabe resaltar que la categorización resultante fue producto de una triangulación de los registros de clase con información proveniente de las entrevistas, los documentos institucionales y las producciones escritas de los estudiantes.

Para concluir este subapartado respecto de las estrategias utilizadas para examinar datos, diremos que nuestro énfasis en las acciones de los profesores remite a una concepción 
del análisis didáctico similar a la que sostienen Lenzi y Castorina (2000, p.271): como el estudio de "las condiciones de posibilidad de transformación de los conocimientos de los alumnos debidas al tipo de intervención del docente". Aunque no utilizamos métodos para indagar los procesos cognoscitivos de los estudiantes, que informen si hubo aprendizaje (o no) de contenidos disciplinares, consideramos que los datos que muestran los registros de clase dan indicios acerca de su trabajo intelectual. De esta forma, creemos que nuestro estudio, pese a que no puede determinar el producto de aprendizaje, al examinar las interacciones entre docentes, alumnos y saberes disciplinares en las clases observadas, analiza el potencial educativo (Dysthe, 2013) de ciertas prácticas de enseñanza de contenidos mediadas por la lectura y la escritura, esto es, las posibilidades de aprendizaje que crean y aquellas que cierran.

\subsection{Consideraciones sobre la validez del estudio}

Para garantizar la validez y fiabilidad de la investigación, hemos tenido en cuenta distintos criterios. En principio, siguiendo a Denzin (1970), recurrimos a diferentes tipos de triangulación: de datos, metodológica, teórica y de investigadores. Los dos primeros tipos se encuentran en estrecha relación: dado que utilizamos distintos métodos para recabar datos (observación de clases, entrevista y recolección de documentos), fue posible confrontar la información obtenida en cada uno de ellos. En cuanto a la triangulación teórica, que refiere al vínculo entre distintas posturas teóricas, el Capítulo 2 anticipa lo que luego podrá verse en los dos capítulos de resultados: la inclusión de enfoques didácticos y socioculturales para analizar datos. Finalmente, aseguramos la triangulación de investigadores provenientes de distintas disciplinas a partir de distintos eventos: las jornadas internas de trabajo con los participantes del Proyecto PICT 2010-0893 (“Escribir y leer para aprender en universidades e institutos de formación docente. Concepciones y prácticas en cátedras de diversas áreas disciplinares"), las reuniones quincenales con los integrantes del GICEOLEM y los encuentros con investigadores externos que asisten como invitados a esas reuniones. En dichos eventos, nuestros datos $\mathrm{y}$ análisis preliminares fueron triangulados con las perspectivas de otros investigadores, que funcionaron como auditores del proceso de investigación (Mendizábal, 2006) y ofrecieron interpretaciones alternativas (Stake, 2010).

Al ser un estudio de casos, los resultados de esta investigación no pueden generalizarse a otros universos o poblaciones. En concreto, no podemos afirmar que nuestros resultados acerca de las prácticas de enseñanza de contenidos mediadas por la lectura y escritura en una escuela secundaria con alumnado de sectores socioeconómicos 
desfavorecidos, alcanzados a partir del análisis de tres casos particulares, serán idénticos a los obtenidos en estudios en otras instituciones de características similares. Sin embargo, investigadores como Anguera (1995, citado en Lenzi y Castorina, 2000), afirman que los estudios de casos puede posteriormente compararse con otros para identificar regularidades y especificidades de un contexto y deslindar lo generalizable a otras situaciones.

En suma, en este capítulo hemos descrito las decisiones metodológicas tomadas en nuestra investigación para abordar la complejidad de las prácticas de enseñanza que entrelazan lectura y la escritura para aprender contenidos en una escuela secundaria a la que asiste población desfavorecida socioeconómicamente. En el próximo capítulo presentamos la definición y caracterización del contexto y la población de la escuela en la cual desarrollamos el estudio, cuya selección se argumentó a lo largo de este capítulo metodológico. 



\section{Definición y caracterización del contexto y la población}

En el capítulo anterior, definimos el diseño de este trabajo como un estudio de casos. De acuerdo con Mitchell (1984), para alcanzar una comprensión de los casos en ese tipo de estudios, es fundamental entender las particularidades y las circunstancias que los rodean. Ciertamente, respecto de la acción didáctica que pretendemos describir y comprender como objetivo principal de este estudio, Sensevy (2007) sostiene que su análisis requiere la comprensión del entorno en la que se desarrolla.

Teniendo en cuenta las consideraciones precedentes, en el presente capítulo ofrecemos una extensa descripción narrativa del contexto de la escuela y la población que allí concurre, sin olvidar que todo registro descriptivo presenta algún nivel de interpretación por parte del investigador (Rockwell, 1987). Para efectuar esta descripción y caracterización nos valemos de índices oficiales y datos obtenidos en el trabajo de campo.

En principio, abordamos algunas características de la institución: relatamos la historia de su creación, describimos la zona geográfica en la que se sitúa, detallamos su proyecto político-pedagógico y caracterizamos las diferencias identificadas entre alumnos de los dos tramos del nivel secundario: el ciclo básico y el ciclo superior. Por último, nos centramos en la población que concurre al curso de quinto año en el que indagamos: aportamos una caracterización de los catorce alumnos y los tres docentes que participaron de este estudio. Para finalizar, sintetizamos la información presentada en este capítulo.

\subsection{La institución escolar}

En los próximos tres subapartados describimos la escuela pública que abrió sus puertas para nuestro estudio. Primero, reseñamos la historia de su creación y describimos la zona geográfica en el que se ubica. Luego, describimos las líneas teóricas en las que se sustenta su proyecto político-pedagógico y las acciones que se desarrollan a partir de éste. Finalmente, destacamos las diferencias que se presentan entre los estudiantes que cursan el ciclo básico de la escolaridad secundaria (primero, segundo y tercer año) y aquellos que cursan el ciclo superior (cuarto y quinto año).

\subsubsection{Historia de su creación y zona geográfica}

La historia de cómo se creó esta escuela se encuentra estrechamente ligada a la historia del barrio en el que vive la mayoría de los alumnos. En los años 40 llegaron al extremo norte de 
la Ciudad de Buenos Aires migrantes del interior del país atraídos por el crecimiento industrial y se instalaron en los alrededores de una fábrica electrónica, conformando una villa. En 1957, sus hogares quedaron destruidos por un incendio y debieron mudarse a un albergue mientras el gobierno construía viviendas en un terreno cercano. Estos trabajadores ocuparon esas nuevas viviendas de lo que se denomina como "barrio de relocalización de villa". Hoy en día, este barrio se encuentra conformado por seis manzanas entre las que conviven casas de material - pertenecientes a vecinos que lo habitan desde su origen- con ranchos de chapa y madera de nuevos habitantes. A lo largo de esta tesis, para preservar el anonimato, lo nombraremos como "El Barrio".

Fueron los vecinos de dicho barrio quienes, tal como relata el Proyecto Escuela -uno de los documentos institucionales recogidos en el trabajo de campo-, impulsaron la creación de la escuela, buscando mejorar las condiciones educativas de los jóvenes habitantes. Al reclamar por un espacio de escolarización, estos vecinos recibieron el apoyo de un grupo de religiosas católicas que vivían allí desde hacía quince años. Finalmente, el pedido fue concretizado en el año 1990 a través de un decreto municipal que creó una serie de escuelas medias en distintos barrios, para atender a la creciente población de contextos socioeconómicos desfavorecidos (Juarros y Cappellacci, 2009; Tiramonti, 2009). A estas instituciones se las denomina "históricas" debido a que fueron las primeras escuelas de origen propiamente municipal. A fines del año 1992, otras instituciones se sumaron a la órbita municipal, a partir de la transferencia a las jurisdicciones de los establecimientos educativos que dependían del Ministerio de Educación de la Nación (Bravo, 1994).

La zona geográfica en la que se ubica la escuela presenta fuertes contrastes socioeconómicos. El establecimiento escolar se erigió en un suburbio tradicional conformado mayoritariamente por sectores de clase "media" y "media alta" (Sabarots, 2007), que limita con "El Barrio". En efecto, de acuerdo con estadísticas producidas por el Gobierno de la Ciudad de Buenos Aires, el distrito escolar correspondiente posee un 3\% de población con Necesidades Básicas Insatisfechas ${ }^{14}$ (2001) y un promedio de 0,15 en el Índice de Vulnerabilidad Social ${ }^{15}$ (2009). Ambos números se consideran valores bajos en comparación

\footnotetext{
${ }^{14}$ Este método de medición de pobreza entiende este fenómeno como carencia de bienes o servicios materiales. Evalúa los siguientes indicadores: hacinamiento (hogares con más de 3 personas por cuarto), vivienda (hogares que habiten en viviendas como pieza de inquilinato, vivienda precaria u otro tipo), condiciones sanitarias (hogares sin retrete), asistencia escolar (hogares con algún niño en edad escolar que no asista a la escuela) y capacidad de subsistencia (hogares con 4 o más personas por miembro ocupado y, además, cuyo jefe tenga baja educación).

${ }^{15}$ El IVS es un índice evalúado que asigna a cada hogar un puntaje en función de su condición frente a un conjunto de características. Cada una de las siguientes dimensiones aporta un peso al puntaje total y puede subdividirse según la intensidad o profundidad del déficit: hacinamiento (moderado o crítico), material de la
} 
con otros distritos escolares. Por el contrario, "El Barrio" tiene una puntuación muy crítica de IVS y es considerado una "mancha" sobre el "fondo de valores bajos y moderados" que presenta la franja norte de la Ciudad (GCBA, 2009, p.11), lo que evidencia el contraste socioeconómico al que hicimos referencia. Debido a que la mayoría de la matrícula escolar proviene de ese asentamiento, la escuela ha sido categorizada como Zona de Acción Prioritaria dentro de la jurisdicción. Es decir que, dadas las condiciones de vulnerabilidad socioeducativa de gran parte de sus alumnos, esta institución se incluye dentro de un programa especial que recibe atención gubernamental prioritaria para sostener las trayectorias escolares.

\subsubsection{Proyecto político-pedagógico}

Según el documento Proyecto Escuela, un $60 \%$ de la matrícula escolar de esta institución se compone de jóvenes que viven en "El Barrio" y presentan problemáticas de sobreedad, repitencia, pobreza, marginación, adicciones y situaciones de judicialización. El resto de la matrícula se conforma por adolescentes provenientes de barrios cercanos de la Ciudad y del Conurbano bonaerense.

Teniendo en cuenta estas características del alumnado, la escuela lleva adelante un proyecto de educación popular cuyo objetivo primordial es "propiciar la inclusión, la permanencia y el aprendizaje de calidad". Este objetivo y sus fundamentos se describen en los dos documentos recabados en el trabajo de campo: el Proyecto Institucional Inclusivo y el Proyecto Escuela. Ambos documentos describen a la institución como parte de un contexto socio-histórico específico en el cual gran parte de los jóvenes se encuentra en situación de riesgo por la ausencia de políticas sociales que velen por sus derechos. Por ello, estos documentos convocan a los docentes a rechazar esta realidad injusta, y los incitan a asumir un compromiso ético-político por intentar cambiar esas condiciones sociales, promover el desarrollo personal de los estudiantes y facilitar su futura inserción laboral.

Para alcanzar el objetivo mencionado, el proyecto político-pedagógico propone dos principios de trabajo que se detallan en los documentos: "pedagogía sin violencia" y “pedagogía de la presencia". Estos principios, tomados de los pedagogos latinoamericanos Paulo Freire y Antonio Gomes Da Costa, postulan que los educadores deben sostener una

vivienda (déficit moderado o crítico), carga de dependencia por jubilado ( 2 o más personas en hogares sin ocupados), carga de dependencia por ocupado ( 5 o más personas en hogares sin jubilados), hogares que no reciben ingresos por trabajo ni jubilación ni pensión, hogares con al menos un integrante sin cobertura exclusiva del sistema público de salud, hogares con un promedio de años de escolarización de la población de 18 años y más, menor a 7, y hogares con un promedio de años de escolarización de la población de 18 años y más, entre 7 y menos de 12 . 
mirada especial con los jóvenes signados por la discriminación y la marginación social. Así, proponen que las preocupaciones y demandas de estos jóvenes sean atendidas en el marco de un vínculo de diálogo y respeto mutuo donde se rescate lo positivo y se visualice el potencial de cada estudiante. Del mismo modo, estos principios sugieren entender los conflictos como una posibilidad de intervenir con calma, escucha y afecto, excluyendo modos agresivos. Esto requiere que los adultos se constituyan en referentes significativos, construyan su autoridad paulatinamente y fortalezcan la confianza de los alumnos en sí mismos. En línea con estos principios, en nuestro encuentro inicial en la institución, el entonces rector sostuvo que quienes encaran el mayor desafío para la inclusión de estos jóvenes son los docentes, mientras que los directivos acompañan dicho proceso. De cara a ello, el Proyecto Institucional Inclusivo propone generar en la escuela un ambiente de apoyo y quehacer colectivo en el cual las problemáticas emergentes sean encaradas conjuntamente por directivos y profesores.

Estos principios político-ideológicos descritos sostienen múltiples acciones que se desarrollan en la institución y se pormenorizan en el Proyecto Escuela. En dicho documento figuran distintos programas nacionales y municipales que funcionan en la escuela (Programa Todos a Estudiar ${ }^{16}$, Club de Jóvenes $^{17}$, Programa de Fortalecimiento de la Escuela Media ${ }^{18}$, Retención Escolar de alumnas/os madres/padres y embarazadas ${ }^{19}$ y Campamentos $^{20}$ ) que se complementan con otros proyectos originados en la comunidad barrial (como la Red Interinstitucional $^{21}$ ) y surgidos desde la propia escuela (Tutorías en el ciclo superior, Terminalidad escolar, Apoyo escolar, y proyectos específicamente curriculares).

Con el fin de mostrar cómo la escuela se propone alcanzar la inclusión, la permanencia y el aprendizaje de calidad formulada en el proyecto político-pedagógico, nos

\footnotetext{
${ }^{16}$ El Programa Nacional "Todos a Estudiar" fomenta la inclusión educativa y social de adolescentes que se encuentran fuera del sistema escolar. Para ello, promueve la cogestión entre el Estado y organizaciones sociales y otorga apoyo económico a través de becas escolares y subsidios para proyectos y equipamiento.

${ }^{17}$ Los Clubes de Jóvenes funcionan los días sábados con un coordinador responsable y docentes a cargo del grupo. Proponen espacios educativos para que los adolescentes revaloricen el uso del tiempo libre, desde la recreación, el deporte y distintas expresiones culturales y artísticas.

${ }^{18}$ El Programa Fortalecimiento Institucional de la Escuela Media ofrece horas destinadas al trabajo institucional ("módulos institucionales") y asistencia técnica para el asesoramiento y el acompañamiento de proyectos de inclusión educativa.

${ }^{19}$ El Programa Retención escolar de alumnas/os madres/padres y embarazadas crea en un dispositivo de trabajo institucional que incluye estrategias para la inclusión de las alumnas embarazadas, madres y de los alumnos padres.

${ }^{20}$ El Programa Campamentos escolares promueve la organización y puesta en marcha de campamentos educativos para alumnos de escuelas que atienden a poblaciones socialmente vulnerables, aportando capacitación docente, recursos organizativos y materiales.

${ }^{21}$ Esta Red nuclea distintas instituciones barriales como el centro cultural, la escuela secundaria, el centro comunitario, el jardín maternal, el centro de salud y la escuela nocturna para adultos.
} 
interesa detallar algunos de los proyectos mencionados. Por ejemplo, las Tutorías en el ciclo básico -pertenecientes a la planta orgánica funcional de todas las escuelas públicas de la Ciudad de Buenos Aires- proponen familiarizar a los alumnos en la modalidad de trabajo y convivencia propia del nivel medio. El Proyecto Escuela describe las distintas tareas que se planifican para ello: relevar necesidades, intereses y conflictos de los cursos, entrevistar familias y alumnos, concientizar sobre hábitos y técnicas de estudio, realizar actividades de integración grupal, entre otras. De acuerdo con este documento, en el ciclo superior las Tutorías se postulan como espacios de reflexión para que los estudiantes puedan anticipar su inserción en el mundo del trabajo y en estudios superiores. Con esa finalidad, se planea durante esos encuentros recabar sus expectativas en relación con estos ámbitos, organizar charlas para debatir experiencias con ex-alumnos, incentivar el interés por cuestiones político-sociales y fortalecer la formación ciudadana.

Por su parte, Terminalidad escolar y Apoyo escolar son dos proyectos institucionales que apuntan a la conclusión del trayecto educativo del nivel. En las entrevistas, los docentes de las Asignaturas A y C, que participan de ambos proyectos, refieren sus objetivos y modalidades de funcionamiento. Según lo que relatan, el proyecto Terminalidad escolar apunta a identificar alumnos que hayan finalizado la cursada y adeuden materias para obtener su título. Se ofrece a estos jóvenes sesiones de tutoría con profesores del área correspondiente a las materias adeudadas. Los docentes a cargo de esas tutorías van evaluando su desempeño a través de trabajos prácticos presenciales o domiciliarios hasta que determinan que están en condiciones de rendir la materia. En el caso del Apoyo escolar, se trabaja con estudiantes regulares en riesgo de abandono, repitencia o que deban materias en calidad de previas. Estos alumnos combinan horarios con los profesores para revisar los contenidos de las asignaturas en las que acarrean dificultades.

Habiendo descrito los lineamientos teóricos del proyecto político-pedagógico, en el siguiente subapartado describimos las diferencias que identificamos entre los alumnos del ciclo básico y del ciclo superior del nivel.

\subsubsection{Tramos escolares: diferencias entre ciclo básico y ciclo superior}

A lo largo del trabajo de campo en la institución, recogimos diversos datos que permiten reconstruir diferencias entre los estudiantes de los dos tramos reconocidos en la escolaridad secundaria. Aunque la Ley de Educación Nacional define para el nivel dos ciclos de formación, básico y orientado, para la presente descripción escogimos utilizar la 
denominación que se desprende de los documentos de la propia institución: "ciclo básico" para primero, segundo y tercer año y "ciclo superior" para cuarto y quinto año.

En principio, identificamos que para estos ciclos existen marcadas diferencias en términos de distribución edilicia. En esta escuela se destinan las aulas de planta baja (cercanas a la preceptoría y la rectoría) para el ciclo básico y las del primer piso (contiguas al comedor escolar) para el ciclo superior. Por otro lado, estos dos ciclos se diferencian en relación con los procesos de integración de los alumnos. En el ciclo básico, tal como describen en encuentros informales la rectora, la preceptora de quinto año y la portera de la institución, los estudiantes atraviesan un período de socialización de las pautas de convivencia institucional. En primero y segundo año, de acuerdo con comentarios de docentes que registramos en la sala de profesores, las transgresiones de los alumnos a las normas son reiteradas y requieren sanciones disciplinarias como llamados de atención, suspensiones y, excepcionalmente, cambios de turno de cursada. Esto coincide con los hallazgos del estudio realizado por Dabenigno y otros (2010), en el cual directivos y docentes de escuelas secundarias resaltan las dificultades que aparecen en los primeros años del nivel para asegurar la convivencia institucional. Estas transgresiones también pueden relacionarse con el hecho de que, antes de ingresar a la escuela, estos jóvenes atraviesan problemáticas de gravedad. Así lo explica el docente de la Asignatura B, uno de los profesores con mayor antigüedad en la institución:

\begin{abstract}
"Hay pibitos [chicos] $]^{22}$ que están "de fierro" [armados] todos los días. [...] Están dirimiendo qué hacen, si son pibes “chorros" [ladrones], si no son pibes "chorros", si voy a la escuela, si no voy, si me fumo toda la marihuana [...] o no la fumo [...], si me empastillo o me empastillo poco, digamos, otras cuestiones. Y cuando los pibes llegan a quinto año, es todo un proceso que se dio. En principio sobrevivieron y después resolvieron y eligieron estar en la escuela. [...] El abordaje institucional es ese, en principio, entender que esa escuela, en muchos casos, es una alternativa de vida. [...] Los pibes están dirimiendo eso: si viven o mueren. Te digo porque he ido a más de un entierro de pibes de la escuela."
\end{abstract}

(Entrevista al profesor de la Asignatura B)

En el fragmento de entrevista precedente, el profesor de la Asignatura B, quien ha dictado clases en ambos ciclos, marca un contraste entre los primeros años en los que algunos

\footnotetext{
${ }^{22}$ En los fragmentos provenientes de entrevistas y observaciones de clases que se incluyen la presente tesis, los corchetes realizan aclaraciones necesarias para entender el discurso de los participantes e indican información no verbal. Por su parte, los puntos suspensivos entre corchetes señalan que hemos omitido parte del discurso, que resulta irrelevante a los fines del análisis.
} 
alumnos atraviesan problemáticas de drogadicción y/o delincuencia, y los últimos años, en los que "sobrevivieron" dichas situaciones y "eligieron" asistir a clase. Para resaltar la gravedad del proceso que viven los jóvenes antes de optar por la escuela como "alternativa de vida", este docente comenta haber concurrido a entierros de éstos.

Dentro de esta etapa de socialización de pautas que representaría el ciclo básico, primer año aparece como el principal exponente de dificultades. En el encuentro que tuvimos para comenzar el estudio piloto, la rectora caracterizó los cursos de los turnos mañana y tarde de ese año como "complicados" por los desafíos que allí enfrenta el cuerpo docente para favorecer dicho proceso. En este punto, su visión se asemeja a la de directivos de establecimientos secundarios entrevistados por Coler y otros (2011), que caracterizan el primer año del nivel como problemático y cargado de dificultades porque representa una bisagra entre la escuela primaria y la escuela secundaria, en la cual los jóvenes deben aprender el oficio de ser alumnos y comprender las normas de la nueva institución.

Efectivamente, durante el trabajo de campo registramos en el cuaderno de notas tres episodios que parecen ilustrar la caracterización que tanto el docente de la Asignatura B como la rectora de la institución hacen respecto de las problemáticas que atraviesan algunos estudiantes en el ciclo básico. El primer episodio lo observamos a dos cuadras de la institución, una vez finalizada la jornada escolar. Al salir del establecimiento, advertimos que agentes policiales habían demorado a alumnos de primero y segundo año por motivos desconocidos. Rápidamente, la rectora se hizo presente en el lugar para conversar con los efectivos acerca de lo sucedido, tras lo cual estos permitieron a los estudiantes retirarse a sus hogares. Otro suceso que guarda relación con las características atribuidas a este ciclo básico fue una tutoría organizada en forma $a d$ hoc en primer año. Según lo que informó el docente de la Asignatura A -tutor a cargo de aquel curso-, se había decidido llevar a cabo dicha tutoría luego de conocerse que durante el fin de semana una estudiante de ese año había sido asesinada en "El Barrio" y que, por el hecho, se encontraba detenido su novio, otro alumno de la escuela. El hecho se produjo en julio del año 2011 y fue tapa de diversos periódicos de circulación nacional. El tercer episodio ocurrió cuando nos encontrábamos en la sala de profesores esperando para entrevistar al docente de la Asignatura A. La profesora de Biología de primer año ingresó a la sala llorando y relató que acababa de sancionar a un alumno y que éste la había insultado delante del resto del curso. Señaló que ese estudiante, el mes anterior, también la había increpado simulando con su mano un arma de fuego mientras le presionaba la sien y le preguntaba si estaba segura de que él no sería capaz de dispararle. En ese momento del relato, la docente de Historia de tercer año, que se encontraba presente en la 
sala de profesores, añadió que los primeros años eran cursos "difíciles" y comentó que ese mismo joven ya había sido suspendido por cortarle el pelo al hijo pequeño de una compañera, sin requerir autorización de la madre.

En contraste con el proceso de socialización de pautas de convivencia que caracteriza el ciclo básico, el ciclo superior del nivel representa una etapa distinta para los estudiantes. En este ciclo los alumnos se disponen a continuar y completar su trayectoria escolar, tal como comenta el profesor de la Asignatura B en el siguiente fragmento de entrevista.

"En quinto [año] hay todo un proceso que el pibe [alumno] hizo en la escuela. O sea, [un proceso] que comienza en primer año y va generando la formación intelectual del pibe para llegar a quinto año desde otro lugar [...]. Estos pibes están receptivos a que vos puedas trabajar bien con ellos [...] porque tienen internalizado todo un proceso que hicieron, entonces vos podés poner pautas y ese encuadre que los pibes necesitan, en definitiva."

(Entrevista al profesor de la Asignatura B)

Según las afirmaciones del docente de la Asignatura B, en quinto año los alumnos habrían desarrollado cierta "formación intelectual" que los haría "receptivos" al establecimiento de un encuadre y pautas de trabajo en clase. Con ello concuerda la preceptora de quinto año, quien sostuvo en una conversación de pasillo que en el curso los estudiantes "ponen empeño" y tienen compromiso con las tareas académicas. En efecto, percibimos en nuestro trabajo de campo dicho encuadre en quinto año, lo que contrastó con las observaciones de clase en cursos del ciclo básico. En razón de ello, tal como relata el apartado 3.4 del Capítulo, escogimos como casos a indagar tres asignaturas de quinto año.

Por último, un aspecto conductual diferencia a los estudiantes del ciclo superior de los alumnos del ciclo básico: estos serían capaces de cuestionar las decisiones institucionales en forma organizada y sin infringir las normas. En la entrevista que realizamos la docente de la Asignatura $\mathrm{C}$ relata un ejemplo al respecto: ante el rumor de que el curso de quinto año sería trasladado a un aula en planta baja, los alumnos citaron a la rectora y expresaron su deseo de permanecer en el primer piso. Finalmente, los directivos desistieron de su intención. También en el trabajo de campo presenciamos un episodio en el que alumnos de cuarto y quinto año se agruparon para manifestar su descontento ante una sanción disciplinar. Debido a que algunos estudiantes -que no habían sido identificados- habían fumado marihuana durante un recreo en un aula del primer piso, los directivos ordenaron que, a partir de entonces, los alumnos del ciclo superior descendieran obligatoriamente al patio en los recreos. Tras debatir con la rectora, y tal como pretendían, los estudiantes lograron que se revocara esa imposición. 
Hemos descrito, en los tres subapartados anteriores, características de la institución escolar escogida para este trabajo doctoral y de la población general que allí asiste. En el próximo apartado nos concentramos en la población del curso de quinto año en el cual observamos clases.

\subsection{La población del curso escogido}

Este apartado presenta una caracterización de la población del curso escogido para la investigación: los catorce alumnos de quinto año y los tres docentes de las asignaturas seleccionadas. Brindando información relativa a los participantes del estudio, buscamos contribuir a la comprensión de algunas condiciones de las que surgen los resultados presentados en esta tesis.

\subsubsection{Caracterización de los alumnos}

El curso de quinto año está compuesto por 14 estudiantes: once mujeres y tres varones cuyas edades oscilan entre los 17 y 22 años. Ocho de ellos habitan en edificios de los alrededores de la escuela, cuatro en "El Barrio" y otros dos en barrios limítrofes.

En relación con las trayectorias escolares, hallamos que cinco alumnos iniciaron su escolaridad secundaria en la escuela indagada mientras que nueve lo hicieron en otras instituciones. Doce estudiantes desarrollaron trayectorias escolares discontinuas producto de repitencias (10) y/o abandonos (2), por lo que presentan sobreedad. Por este motivo, solo dos de los catorce alumnos del curso poseen la edad "esperada" para quinto año, dado que cumplieron la progresión lineal prevista por el sistema educativo: un grado por año. Entre los diez alumnos repitentes, ocho recursaron años en el ciclo básico del nivel, un estudiante en el ciclo superior y otra alumna en el nivel primario. La concentración de repitencias en los primeros años del nivel secundario coincide con los indicadores de la problemática relevados por Coler y otros (2011) en escuelas públicas de la Ciudad de Buenos Aires. Por su parte, las dos estudiantes que abandonaron lo hicieron en el ciclo superior del nivel. Los datos descritos se presentan en la Tabla 5 . 
Tabla 5. Trayectorias escolares de los alumnos de quinto año

\begin{tabular}{|c|c|c|c|c|c|}
\hline Característica & $\begin{array}{l}\text { Alumnos } \\
\text { de quinto }\end{array}$ & & $\begin{array}{l}\text { Total de } \\
\text { alumnos }\end{array}$ & & $\begin{array}{l}\text { Total de } \\
\text { alumnos }\end{array}$ \\
\hline $\begin{array}{c}\text { Inicio de la escolaridad } \\
\text { secundaria en otras escuelas }\end{array}$ & $9 / 14$ & & 9/9 & & 9/9 \\
\hline $\begin{array}{l}\text { Inicio de la escolaridad } \\
\text { secundaria en esta escuela }\end{array}$ & $5 / 14$ & & $5 / 5$ & & $5 / 5$ \\
\hline $\begin{array}{c}\text { Trayectorias escolares } \\
\text { continuas }\end{array}$ & $2 / 14$ & & $2 / 2$ & & $2 / 2$ \\
\hline \multirow{4}{*}{$\begin{array}{l}\text { Trayectorias escolares } \\
\text { discontinuas }\end{array}$} & \multirow{4}{*}{$12 / 14$} & \multirow{3}{*}{ Repitencias } & \multirow{3}{*}{$10 / 12$} & Ciclo básico & $8 / 10$ \\
\hline & & & & Ciclo superior & $1 / 10$ \\
\hline & & & & Nivel primario & $1 / 10$ \\
\hline & & Abandono & $2 / 12$ & Ciclo superior & $2 / 2$ \\
\hline
\end{tabular}

En cuanto a la composición familiar, contabilizamos que ocho alumnos conviven con ambos progenitores, cinco solo su madre y una con su abuela. El máximo nivel educativo que alcanzaron los integrantes de estas familias es variado. Pese a ello, podemos afirmar que la mayoría de los estudiantes de quinto año no conforma una "primera generación" que concurre al nivel secundario, ya que otros integrantes de sus familias lo han hecho previamente. Del grupo total de estudiantes, cinco tiene al menos uno de sus padres con título secundario, entre los que se halla una madre también con título terciario (profesorado de educación inicial). De los nueve alumnos que no poseen progenitores con título secundario, siete tienen hermanos mayores que concluyeron el nivel y/o padres que concurrieron durante un tiempo.

Otro aspecto que caracteriza al curso es que gran parte de los alumnos trabaja en actividades informales. Siete estudiantes lo hacen a contraturno en forma precarizada y/o temporaria en locales de comidas rápidas, pizzerías, servicio de delivery, changas, cuidado de niños y paseo de mascotas.

La maternidad y la paternidad adolescente también se presentan en quinto año. De los catorce alumnos, hay tres madres (una de ellas embarazada nuevamente) y un padre con niños pequeños de entre año y medio y cuatro años. Al incorporar el programa Retención escolar de alumnas madres/embarazadas y padres en escuelas medias y técnicas de GCBA (ver subapartado 4.1.2), la escuela promueve un régimen especial de ausencias para estos jóvenes y pauta un horario de entrada a clase flexible.

A continuación, la Tabla 6 muestra un breve perfil socioeducativo de cada alumno de quinto año, que elaboramos en función de los datos recabados en las entrevistas y las 
observaciones de clase. Con estos perfiles buscamos mostrar que, a pesar de indagar en una escuela que recibe mayoritariamente población de sectores socioeconómicos desfavorecidos, en el curso indagado las situaciones de vida y las características socioeducativas de los alumnos son heterogéneas.

Tabla 6. Perfiles socioeducativos de los alumnos de quinto año

\begin{tabular}{|c|c|c|}
\hline Alumno & Edad & Perfil \\
\hline Ariana & 22 años & $\begin{array}{l}\text { Es la alumna con mayor edad del curso. Vive en un barrio aledaño a la escuela. Su } \\
\text { madre es niñera, su padre encargado de edificio y su hermano empleado en un } \\
\text { local de comidas rápidas. Abandonó la escuela comercial a la que asistía y trabajó } \\
\text { durante cuatro años. Buscaba trabajo pero desistió porque solo obtenía propuestas } \\
\text { para la mañana, turno en el que asiste a la escuela. Quiere estudiar Administración } \\
\text { de Empresas e intentó adelantar algunas materias inscribiéndose en el programa } \\
\text { UBA XXI (Programa de Educación a Distancia de la Universidad de Buenos } \\
\text { Aires) pero le pareció "muy difícil" y lo dejó. }\end{array}$ \\
\hline Carla & 17 años & $\begin{array}{l}\text { Vive con su familia dentro de la escuela ya que su madre es la portera. No repitió } \\
\text { ningún año escolar. Trabaja cuatro horas diarias en una pizzería cercana. Desea ser } \\
\text { maestra jardinera. }\end{array}$ \\
\hline
\end{tabular}

Proviene de un país limítrofe, donde repitió cuarto y quinto grado en la escuela Claudia 20 años hermana mayor y su sobrino pequeño. Trabaja cuidando una niña durante las tardes. Le gustaría ser chef y también farmacéutica, pero le parecen "muy largos" los seis años que requiere esta última carrera.

\begin{tabular}{|c|c|c|}
\hline Daiana & 18 años & $\begin{array}{l}\text { Repitió segundo año en una institución privada y religiosa de la zona y se cambió } \\
\text { a esta escuela pública. Vive en "El Barrio" con sus padres y su hermano menor. } \\
\text { Busca empleo y se anotará para cursar el profesorado de educación inicial. }\end{array}$ \\
\hline Denise & 18 años & $\begin{array}{l}\text { Antes de ingresar a la institución, concurrió a un establecimiento con orientación } \\
\text { bachiller y luego a una escuela comercial donde repitió tercer año. Vive con sus } \\
\text { padres y hermanos. Trabajó durante un tiempo en un quiosco pero luego renunció. } \\
\text { Quiere estudiar peluquería o maquillaje. }\end{array}$ \\
\hline Ernesto & 19 años & $\begin{array}{l}\text { Habita en un barrio aledaño a la escuela con sus padres y tres hermanos, uno de } \\
\text { los cuales estudia Odontología. Repitió dos veces tercer año y anteriormente cursó } \\
\text { en una escuela técnica. }\end{array}$ \\
\hline Fabiana & 19 años & $\begin{array}{l}\text { Dejó la escuela durante el año que vivió en el interior del país por problemas } \\
\text { familiares. Actualmente reside cerca de la escuela con sus padres, dos hermanos } \\
\text { mayores y una hermana menor. Le gustaría ser profesora de Literatura. }\end{array}$ \\
\hline Guadalupe & 20 años & $\begin{array}{l}\text { Trabaja en un local de comidas rápidas, aunque se encuentra de licencia por } \\
\text { embarazo. Próximamente, planea conseguir trabajo como empleada de un } \\
\text { hipermercado y estudiar para ser maestra jardinera. Tiene un niño de cuatro años y } \\
\text { vive con sus padres, sus tres hermanas, dos sobrinas y su pareja, quien trabaja } \\
\text { como empleado de seguridad de un shopping de la zona. Repitió segundo año en } \\
\text { una escuela normal y tercer año en un bachiller. }\end{array}$ \\
\hline Lautaro & 20 años & $\begin{array}{l}\text { Desde hace seis años, vive en un sector de "El Barrio" que caracteriza como } \\
\text { "tranquilo" dado que, según sus comentarios, en la zona los vecinos trabajan, no } \\
\text { delinquen y tampoco se comercializan ni se consumen drogas. Previamente residía } \\
\text { con su familia en una casona sobre una de las avenidas principales del barrio, pero } \\
\text { se mudaron por problemas financieros. Su madre es enfermera doméstica y su } \\
\text { padre remisero. Repitió dos veces primer año en una escuela técnica. Trabaja ocho } \\
\text { horas diarias haciendo servicio de delivery con su moto. Es padre de una niña de } \\
\text { dos años. Proyecta ser visitador médico. }\end{array}$ \\
\hline Lorena & 19 años & $\begin{array}{l}\text { Tiene un hijo de tres años. Repitió primero y segundo año y se cambió a la escuela } \\
\text { cuando estaba embarazada porque "le quedaba cerca". Vive con su madre y } \\
\text { actualmente trabaja paseando perros. }\end{array}$ \\
\hline Marisa & 19 años & $\begin{array}{l}\text { Repitió primer año dos veces. No trabaja y vive con su madre. Le gustaría estudiar } \\
\text { Matemática o Contabilidad pero también Medicina Forense u Hotelería. }\end{array}$ \\
\hline
\end{tabular}




\begin{tabular}{|c|c|c|}
\hline Martín & 20 años & $\begin{array}{l}\text { Trabaja en un local de comidas rápidas en el que cumple turnos rotativos de cinco } \\
\text { horas diarias. Planea continuar allí ya que, si obtiene el título secundario, } \\
\text { prometieron ascenderlo. Repitió tres veces primer año en otra escuela y espera un } \\
\text { bebé con su pareja. }\end{array}$ \\
\hline Nadia & 19 años & $\begin{array}{l}\text { Repitió cuarto año en la escuela. De acuerdo con su relato, desde que nació vive } \\
\text { en una de las cuadras de "El Barrio" donde es habitual ver personas vendiendo y } \\
\text { consumiendo drogas y son comunes los allanamientos policiales. Tiene un hijo de } \\
\text { casi dos años que su madre cuida por las mañanas para que asista a la escuela. Los } \\
\text { miércoles, cuando ésta trabaja como empleada doméstica, suele ausentarse a clase } \\
\text { para quedarse con el niño. Sus hermanos pequeños concurren a la escuela y su tía } \\
\text { trabaja allí como auxiliar docente. Su padre se encuentra preso. Quiere seguir una } \\
\text { carrera "corta" como profesorado de educación inicial o enfermería para poder } \\
\text { "mantener" a su hijo. }\end{array}$ \\
\hline Yésica & 17 años & $\begin{array}{l}\text { Nunca repitió y es reconocida por los tres profesores participantes de este estudio } \\
\text { como la mejor alumna del curso. Habita en el mismo sector de "El Barrio" que } \\
\text { Nadia, donde convive con su abuela y hermana menor discapacitada. } \\
\text { Anteriormente vivió en el interior del país y concurrió a un colegio primario } \\
\text { privado. Trabaja ocasionalmente realizando changas. }\end{array}$ \\
\hline
\end{tabular}

Como ilustra la Tabla 6, las situaciones de vida y las características socioeducativas de los estudiantes de quinto año son diversas. No obstante ello, en el trabajo de campo identificamos un rasgo que comparten todos los alumnos: el ausentismo a clase. Según diversos investigadores, se trata de una problemática usual con la que se enfrentan las escuelas que atienden a este tipo de sectores socioeconómicos (Jacinto y Freytes Frey, 2004; Jacinto y Terigi, 2007; Krichesky y Duque, 2008; Krichesky y otros, 2008). Cabe aquí hacer una salvedad: aunque estos estudiantes comparten el hecho de faltar a clases en forma reiterada, pueden existir distintos motivos para ello, tales como la maternidad, la superposición entre el horario escolar y el laboral, un trabajo ocasional o el desinterés por la propuesta educativa (Terigi, 2009). En efecto, algunos de estos motivos fueron alegados por los estudiantes en las entrevistas.

Esta problemática del ausentismo puede ilustrarse con datos de nuestro trabajo de campo. Concretamente, el promedio de alumnos presentes en las clases observadas fue nueve. Vale aclarar que los estudiantes que se ausentaron no fueron siempre los mismos, sino que pareció darse una especie de rotación entre quienes faltaron a clase. A continuación, la Tabla 7 muestra la cantidad de estudiantes que asistió a cada clase de las materias indagadas. 
Tabla 7. Cantidad de alumnos asistentes a las clases observadas

\begin{tabular}{cccc}
\hline $\begin{array}{c}\text { Asignatura } \\
\text { Clase observada }\end{array}$ & Asignatura A & Asignatura B & Asignatura C \\
\hline Clase 1 & $9 / 14$ & $7 / 14$ & $9 / 14$ \\
Clase 2 & $7 / 14$ & $8 / 14$ & $10 / 14$ \\
Clase 3 & $9 / 14$ & $9 / 14$ & $8 / 14$ \\
Clase 4 & $10 / 14$ & $13 / 14$ & $10 / 14$ \\
Clase 5 & $7 / 14$ & $10 / 14$ & $11 / 14$ \\
Clase 6 & $10 / 14$ & $11 / 14$ & $8 / 14$ \\
Clase 7 & $13 / 14$ & $9 / 14$ & $12 / 14$ \\
Clase 8 & $11 / 14$ & $9 / 14$ & $8 / 14$ \\
Clase 9 & $6 / 14$ & $12 / 14$ & $9 / 14$ \\
Clase 10 & $11 / 14$ & $3 / 14$ & $8 / 14$ \\
Clase 11 & $8 / 14$ & $6 / 14$ & $6 / 14$ \\
Clase 12 & - & $9 / 14$ & - \\
Clase 13 & - & $10 / 14$ & - \\
Clase 14 & - & $9 / 14$ & - \\
Clase 15 & - & $8 / 14$ & - \\
Clase 16 & - & $6 / 14$ & - \\
Clase 17 & - & - & - \\
\hline Se rasu & - & & - \\
\hline
\end{tabular}

Nota: Se resaltan las clases en las que el grupo de alumnos de quinto año estuvo casi completo (sombreado oscuro) y las clases en las que solo estuvo presente la mitad de los estudiantes del curso o una cantidad menor (sombreado claro)

Tal como evidencia la Tabla 7, en ninguna de las 39 clases observadas estuvieron presentes los catorce estudiantes que conforman el curso de quinto año. Solamente en dos ocasiones (Clase 7 en la Asignatura A y Clase 4 en la Asignatura B), que remarcamos con sombrado oscuro, el grupo estuvo casi completo (13/14), con la ausencia de Guadalupe. Esta alumna, debido a síntomas propios de la etapa final de embarazo, faltó frecuentemente a clase durante el período que observamos. Para marcar el contraste, en sombreado claro resaltamos nueve clases a las que asistió solo la mitad de los estudiantes del curso o una cantidad menor (Clase 2, 5 y 9 en la Asignatura A, Clase 1, 10, 11, 16 y 17 en la Asignatura B y Clase 11 en la Asignatura C). Interesa mencionar que, en una de esas nueve clases, el docente dio autorización para retirarse a los alumnos que hubieran finalizado la actividad de la clase anterior, por lo que solo permanecieron en el aula tres estudiantes (Clase 10 de la Asignatura B), 
Como se verá en la sección de resultados, esta problemática del ausentismo, que exhibe la Tabla 7, impulsa a los directivos y los docentes a encarar acciones para favorecer la permanencia de los estudiantes (Capítulo 4), evitando el abandono escolar, y también a tomar determinadas decisiones didácticas, en relación con consignas y materiales de lectura, para disminuir los efectos de la pérdida de progresión de los temas dictados (Capítulo 5).

\subsubsection{Caracterización de los docentes}

Los profesores de quinto año que participaron de la investigación son dos varones y una mujer de entre 35 y 42 años que dictan materias del área de Ciencias Sociales y del área Jurídico-Contable, respectivamente.

En cuanto a la formación académica y los cargos que desempeñan en la actualidad estos docentes, observamos que son variados. El docente de la Asignatura A posee título docente y ejerce en otras escuelas medias de la Ciudad y la provincia de Buenos Aires. Ha realizado diversos cursos y actualmente cursa una carrera universitaria a distancia. Por su parte, el docente de la Asignatura B también tiene título docente, dicta clases en otras instituciones de nivel medio y terciario y es vicerrector de una escuela secundaria pública. Asimismo, posee otro título terciario y estudios universitarios incompletos. Por último, la profesora de la Asignatura $\mathrm{C}$ no tiene título docente pero se encuentra habilitada para dictar su materia por la certificación de técnica obtenida en la escolaridad secundaria. Trabaja, a su vez, en dos escuelas medias de la Ciudad de Buenos Aires y tiene estudios terciarios y universitarios incompletos. En la institución en la que indagamos clases, los docentes de las Asignaturas A y C integran los proyectos de Terminalidad y Apoyo escolar (ver subapartado 4.1.2), son tutores de cursos y están a cargo de la coordinación de las áreas disciplinares de su incumbencia.

Agrupamos los datos descriptos en este subapartado en la Tabla 8, para facilitar su visualización y comparación. 
Tabla 8. Datos de los docentes participantes de la investigación

\begin{tabular}{|c|c|c|c|c|c|c|}
\hline \multirow[b]{2}{*}{ Docente } & \multirow[b]{2}{*}{ Edad } & \multicolumn{2}{|c|}{ Estudios } & \multicolumn{2}{|c|}{ Antigüedad } & \multirow[b]{2}{*}{ Cargos } \\
\hline & & Terciarios & Universitarios & Docente & $\begin{array}{c}\text { En la } \\
\text { escuela }\end{array}$ & \\
\hline $\begin{array}{c}\text { Asignatura } \\
\text { A }\end{array}$ & 40 & Completo & En curso & 4 años & $\begin{array}{c}2 \text { años y } \\
\text { medio }\end{array}$ & $\begin{array}{c}\text {-Docente nivel } \\
\text { medio } \\
\text {-Tutor } \\
\text {-Coordinador } \\
\text { área Ciencias } \\
\text { Sociales }\end{array}$ \\
\hline $\begin{array}{c}\text { Asignatura } \\
\text { B }\end{array}$ & 42 & Completo & Incompleto & 18 años & 18 años & $\begin{array}{c}\text {-Docente nivel } \\
\text { medio y terciario } \\
\text {-Vicerrector }\end{array}$ \\
\hline $\begin{array}{c}\text { Asignatura } \\
\text { C }\end{array}$ & 35 & Incompleto & Incompleto & 5 años & 5 años & $\begin{array}{c}\text {-Docente nivel } \\
\text { medio } \\
\text {-Tutora } \\
\text {-Coordinadora } \\
\text { área Jurídico- } \\
\text { Contable }\end{array}$ \\
\hline
\end{tabular}

La caracterización de estos tres docentes, mostrada a partir de datos relacionados con su edad, formación académica, antigüedad docente, antigüedad de pertenencia al plantel de la escuela y cargos que poseen; representa un insumo para comprender los recorridos personales a partir de los cuales desarrollan acciones tendientes a fortalecer la permanencia escolar y ejercen prácticas de enseñanza de contenidos disciplinares mediadas por la lectura y la escritura, que serán descritas y analizadas en los capítulos 4 y 5 , respectivamente.

\subsection{Síntesis}

Este capítulo mostró, a partir de la información obtenida en el trabajo de campo, una descripción del contexto y la población que asiste a la escuela en la que indagamos clases. Centrándonos en documentos institucionales que reconstruyen la historia de la escuela, delineamos el impulso comunitario que motivó su creación. Con índices oficiales, describimos las condiciones socioeconómicas del distrito escolar $\mathrm{y}$, específicamente, las respectivas a "El Barrio" del cual proviene la mayoría de la matrícula. Mencionamos también los distintos programas que forman parte del proyecto político-pedagógico de la escuela y describimos cómo buscan atender las particularidades del alumnado. A través de la narración de situaciones que presenciamos y conversaciones que tuvimos con actores institucionales, ilustramos el contraste que estos efectúan entre los estudiantes del ciclo básico y los del ciclo superior del nivel secundario. En el primer ciclo los esfuerzos institucionales se concentran en asegurar la permanencia escolar. Los alumnos, además de presentar problemáticas de gravedad, atraviesan un período de socialización de las pautas de convivencia, por lo que en las clases puede observarse la ausencia de un encuadre de trabajo estable. En cambio, en el 
ciclo superior este proceso ha culminado y los estudiantes se disponen a cumplimentar las actividades áulicas diarias.

En relación con los alumnos y los docentes del curso escogido para este estudio doctoral, hemos brindamos datos relevantes. Enfocamos las trayectorias escolares de los estudiantes, su composición familiar y algunos fenómenos que los atraviesan, tales como su condición de trabajadores, la maternidad y paternidad adolescente y el ausentismo escolar. Para los docentes, focalizamos su antigüedad en el ejercicio de la profesión, su tiempo de pertenencia al plantel institucional, su formación académica y los distintos cargos que poseen.

A través de los dos apartados que contiene este capítulo pusimos foco en determinantes institucionales y contextuales que, tal como se verá en la próxima sección de la tesis, atraviesan las relaciones entre alumnos, docentes y conocimientos. 


\section{SEGUNDA PARTE}

Resultados y conclusiones 



\section{Acciones institucionales y acciones interpersonales que promueven la permanencia escolar}

Cualquier acción pedagógica que quiera impulsarse, como promover que los alumnos lean y escriban para aprender en las asignaturas, requiere lógicamente que estos concurran asiduamente a clases. En otras palabras, la enseñanza precisa la permanencia escolar de los estudiantes. Siguiendo a Dabenigno y otros (2010, p.7), entendemos la permanencia escolar como "el entramado de relaciones y prácticas que se despliegan en el nivel de las instituciones educativas -estén o no formalizadas-para promover que todos los estudiantes logren transitar y completar su carrera escolar, evitando el abandono". Por ello, la permanencia es una condición necesaria que debe considerarse para todo el alumnado, especialmente en poblaciones de sectores socioeconómicos desfavorecidos, que se caracterizan por su alto grado de ausentismo (Jacinto y Freytes Frey, 2004; Jacinto y Terigi, 2007; Krichesky y Duque, 2008; Krichesky y otros, 2008). El ausentismo, además de ser un fenómeno que usualmente precede al abandono escolar, equivale a un menor tiempo de clase, lo que obstaculiza la progresión de la enseñanza de contenidos y repercute, inevitablemente, en las posibilidades de aprendizaje de los estudiantes (Jacinto y Terigi, 2007).

Tal como mostramos en el Capítulo 1, las investigaciones nacionales que estudian la inclusión educativa en escuelas secundarias a las que asisten alumnos provenientes de sectores socioeconómicos desfavorecidos ponen el acento principal en la permanencia. En línea con estos estudios, este capítulo aborda las acciones que llevan a cabo directivos y docentes de la escuela en la que indagamos para propiciar la permanencia de los alumnos. En el Capítulo 3 señalamos que, aunque el objeto de indagación de esta tesis son las prácticas de enseñanza de contenidos mediadas por la lectura y la escritura en las asignaturas, nos vimos en la necesidad de efectuar un análisis de las estrategias que fomentan la permanencia escolar, dado que recurrentemente en las transcripciones de los datos identificamos situaciones y hallamos alusiones de los actores al respecto.

Las acciones que se describen en este capítulo han sido identificadas tanto por la bibliografía (ver apartado 1.2) como por los actores implicados como favorecedoras de la asistencia a clase. En los próximos apartados agrupamos dichas acciones según su carácter institucional o interpersonal. A pesar de esta distinción que efectuamos, a efectos de su presentación, advertimos al lector que estas acciones se hallan fuertemente interrelacionadas y actúan en simultáneo retroalimentándose unas a otras. Para ilustrarlas, nos valemos de 
transcripciones de entrevistas, registros de clase e información de los documentos institucionales. Hacia el final del capítulo, sintetizamos este conjunto de acciones.

Cabe recalcar, antes de comenzar la descripción de estas acciones, que de acuerdo con el documento Proyecto Escuela, el porcentaje de retención de esta institución a la fecha del estudio era del 90\%, levemente superior al promedio del conjunto de escuelas estatales de la Ciudad de Buenos Aires (GCBA, 2011), que incluye a sectores con mayores recursos socioeconómicos. Por tanto, las acciones de carácter institucional e interpersonal que se describen a continuación parecen haber favorecido la permanencia escolar.

\subsection{Acciones de carácter institucional}

De acuerdo con Jacinto y Terigi (2007), los estilos de gestión institucional son un factor fundamental para impulsar la permanencia escolar de adolescentes provenientes de sectores socioeconómicos desfavorecidos. Estas investigadoras señalan que los modelos tradicionales de gestión desconocen las características del entorno escolar. En cambio, otras instituciones adoptan modelos en los que sus integrantes revelan un alto grado de conocimiento de la comunidad de referencia y aceptan que las problemáticas socioeconómicas del alumnado se imponen como cuestiones centrales a ser consideradas, debido a que condicionan las prácticas pedagógicas.

En la escuela en la que indagamos, reconocemos ciertas acciones de los directivos y profesores que van en línea con estos últimos modelos: asumir un compromiso político con un proyecto pedagógico inclusivo y conformar un equipo para abordar problemáticas que atenten contra la permanencia escolar. Al ser llevadas a cabo por todo el plantel docente y directivo en su conjunto, denominamos como de carácter institucional a estas acciones, que se describen en los subapartados subsiguientes.

\subsubsection{Asumir un compromiso con un proyecto pedagógico inclusivo}

Los proyectos y acciones educativas que poseen una dimensión ética, según Cantero (1999), favorecen logros pedagógicos con alumnos de sectores populares. Comprometerse con proyectos de ese estilo representa, de acuerdo con Acosta (2006), una condición para sostener el trabajo en instituciones que reciben a población de sectores socioeconómicos desfavorecidos.

Particularmente en esta escuela identificamos, tanto en el discurso como en las acciones observadas, un compromiso del directivo y los docentes participantes en pos del cumplimiento del proyecto político-pedagógico. Al respecto, anteriormente mostramos que 
su objetivo principal, explicitado en el Proyecto Escuela, es "propiciar la inclusión, la permanencia y el aprendizaje de calidad". En vías de facilitar la consecución de ese objetivo, la institución promovió durante años un espacio de reunión entre profesores y directivos para debatir los principios ético-políticos que dieron origen al proyecto -provenientes de pedagogos latinoamericanos- y vincularlos con situaciones ocurridas en las aulas. Los tres profesores cuyas clases observamos mencionan en las entrevistas haber participado, en algún momento, de estos espacios. Ámbitos formativos y de encuentro como el mencionado, que promueven la reflexión, favorecen el sentimiento de pertenencia institucional del cuerpo docente (Fernández, 1994).

Este objetivo descrito en el Proyecto Escuela aparece condensado en el discurso de integrantes de la institución. A continuación transcribimos algunas expresiones del ex rector que lo denotan:

\begin{abstract}
“Usamos términos como "la inclusión”, “contra la exclusión” [...], no es solamente a favor de la inclusión sino [que] es [inclusión] emancipadora [...]. El eje [del proyecto pedagógico] estaba puesto en, primero, que los chicos tengan escuela. No se puede educar si no están los chicos en la escuela. Dentro de la escuela habrá que pensar [...] las perspectivas culturales, sociales, los modos de vida [...]. “¿Cómo hago para que se quede?” [...]. A nosotros nos interesan los chicos.
\end{abstract} Tienen que estar en la escuela [...]. Les decimos "tenés que quedarte."

(Entrevista al ex rector)

En la cita anterior, este directivo enuncia la permanencia escolar (“tienen que estar en la escuela") como eje fundamental del proyecto pedagógico. Por este motivo, el principal interrogante que el plantel docente y directivo se formularía es cómo hacerla efectiva. La referencia a términos como "inclusión emancipadora" coincide con los principios de trabajo descritos en los documentos institucionales, que se analizan en el subapartado 4.1.2 del Capítulo 4. Tal como enuncia el entrevistado en otra parte de la entrevista, la búsqueda de esta inclusión debe ser encarada a partir del reconocimiento del sentido político de la tarea docente: la capacidad de transformar el futuro de los alumnos.

\footnotetext{
"Uno tiene en este lugar social, un lugar político, [...] sos una persona cuyo quehacer o no hacer tiene que ver con el destino de una comunidad. [...] Lo más importante de tu trabajo es lo conceptual, no lo técnico. Por eso digo que, en realidad, un buen docente es el que descubrió el sentido de su tarea."
}

(Entrevista al ex rector) 
En consonancia con estas afirmaciones, que resaltan la importancia de "descubrir el sentido" de la tarea docente; las acciones y el discurso de los tres profesores participantes de la investigación evidencian el compromiso ético-político que contrajeron en su profesión. Describimos a continuación acciones que ilustran el compromiso de cada docente.

Según comenta en la entrevista, el profesor de la Asignatura A, comprometido con lograr un cambio educativo, tomó el cargo en quinto año -vacante desde hacía dos meses- ya que ningún profesor externo lo había aceptado. Por su parte, el docente de la Asignatura $\mathrm{B}$, desde que ingresó a trabajar en la escuela en el año 1993, ocupó diferentes cargos como preceptor, docente en los dos ciclos del nivel y secretario institucional. En la entrevista relata que presenció los comienzos de la institución, se involucró en la organización de diversas reuniones (relativas a campamentos, tutorías, coordinación de áreas curriculares y junta de directivos), e interactuó recurrentemente con los vecinos de "El Barrio". Dado su largo tiempo de pertenencia al plantel de esta escuela, este profesor menciona que "casi las tuve en brazos" a dos estudiantes que concurren a quinto año, dado que son hijas de una ex alumna y de la portera de la institución. Respecto de la profesora de la Asignatura C, recabamos en la entrevista que ingresó a la escuela tras tomar un puesto para el cual los directivos no conseguían docente. Anteriormente señalamos que, tanto esta docente como el profesor de la Asignatura A, integran proyectos institucionales de Terminalidad y Apoyo escolar. Formar parte de tales proyectos, que ofrecen ayudas pedagógicas para favorecer la permanencia y la culminación del nivel, también muestra el compromiso de estos profesores con el proyecto político-pedagógico de la escuela.

Las actividades descritas, que realizan o realizaron estos docentes, revelan una elección personal por trabajar en esta institución y concretar el proyecto político-pedagógico inclusivo. En este punto, se diferencian de aquellos profesores que, tal como hallan Foglino, Falconi y López Molina (2008), ingresan a escuelas que atienden a estos sectores como portal de entrada a la profesión, pero enseñan en esas instituciones sin un deseo que lo sostenga. También contrastan con los docentes que adoptan una "actitud de huida" (Cantero, 1999, p. 34) de estas instituciones, rehusando trabajar allí debido a las problemáticas que encuentran.

De igual forma que en las acciones descritas, advertimos en el discurso de los profesores el compromiso asumido con el proyecto político-pedagógico. Los fragmentos de entrevista subsiguientes lo muestran.

"El otro día [...] me dijo uno de los chicos "[...] voy a dejar la escuela porque tengo que trabajar [...]". Y yo le decía que [...] ellos tienen que venir y estudiar [...] porque estudiar es 
un derecho [...]. Cuando [el alumno] habló conmigo yo le dije que no, que hay que replantear, buscar algún trabajo part-time [...]. "No, voy a seguir [en la escuela]”, me dijo después.”

(Entrevista al profesor de la Asignatura A)

\begin{abstract}
“Vos si en esta escuela "te pusiste la camiseta" [te identificaste con su ideario], [...] no te vas más [...]. Los profes [profesores] que logran querer a los pibes [...] están contribuyendo [...] a cambiar la realidad. [...] Hablás de los pilares que fundan esa escuela [...]: qué "plus" le pones a la tarea. [...] Plus en términos políticos. [...] Son pibes [jóvenes] que merecen doblemente la posibilidad de poder pensar. [...] Entonces el hecho de uno entender y comprometerte con ese proyecto $[. .$.$] , pertenecer a un proyecto que intenta mejorar la vida.”$
\end{abstract}

(Entrevista al profesor de la Asignatura B)

\begin{abstract}
“Hay que ser realistas, yo me tengo que poner en la piel del pibe [ser empática con el joven]. ¿Yo qué le puedo decir a Martín [alumno de quinto año] hoy cuando me tira [dice] "tengo problemas que me agobian”? [...] ¿Qué le puedo decir? “A ver, explícame lo de Seguridad Social”. Bueno,
\end{abstract} hoy no me lo podes explicar, tenemos tiempo, me lo explicas más adelante."

(Entrevista a la profesora de la Asignatura C)

En los extractos de entrevista citados se evidencia el compromiso de los tres docentes por comprender la realidad social de los alumnos e intentar transformarla desde lo educativo. El profesor de la Asignatura A muestra su compromiso por la inclusión educativa al relatar un caso en el que alentó a un alumno a no abandonar la escuela por trabajo, lo cual entrevé su defensa del derecho a la educación. Por su parte, el discurso del docente de la Asignatura B da cuenta de la apropiación del marco teórico en el que se basa el proyecto políticopedagógico: menciona la importancia de añadir un "plus político" y encarar la tarea docente comprendiendo que la escuela puede "mejorar la vida" de estos alumnos. Por último, la docente de la Asignatura $\mathrm{C}$ denota su adhesión al proyecto político-pedagógico cuando permite que un alumno, que comenta tener problemas personales, cumplimente en otro momento las actividades que requiere su asignatura.

Resumiendo, los documentos institucionales recabados y las transcripciones de entrevistas evidencian un ideario común que considera como parte del trabajo docente el asegurar la permanencia escolar de los alumnos contemplando sus necesidades específicas. Esta identificación con los valores de un proyecto político-pedagógico pareciera no solo orientar sino también sostener la labor de los profesores. 


\title{
5.1.2. Encarar un trabajo colectivo para abordar problemáticas
}

El trabajo en equipo en una institución ocupa un lugar destacado, según Acosta (2006), en la bibliografía sobre gestión educativa. En concreto, Redondo (2006a) señala que trabajar en equipo impulsa las acciones institucionales hacia objetivos comunes. En cuanto al objetivo de la retención escolar, los estudios de Dabenigno y otros (2010) y Jacinto y Freytes Frey (2004) coinciden en que las escuelas que obtienen buenos resultados al respecto se caracterizan por tener un grupo de integrantes que motorizan las acciones tendientes a ello.

Observamos, en la escuela en la que indagamos clases, la consolidación de un grupo de trabajo para afrontar las problemáticas emergentes que, a la vez, permite sostener el compromiso asumido con el proyecto político-pedagógico. Los actores que entrevistamos refieren que los sucesos que ponen en jaque la permanencia escolar se analizan y discuten con otros miembros de la institución. Por ejemplo, ante situaciones que dificultan el trabajo áulico, los profesores pueden recurrir a tutores, preceptores, colegas, asesores pedagógicos o directivos para pensar estrategias de abordaje. Asimismo, los directivos pueden acudir al plantel docente cuando consideran que no pueden manejar en forma individual alguna cuestión. Este modo de trabajo en equipo fue descrito detalladamente por el ex rector de la institución en la entrevista, tal como se muestra a continuación:

\begin{abstract}
"[Es importante] el acompañamiento a ese profesor, no dejarlo solo: hay un preceptor que está con él [...]. Yo les decía [a los docentes] siempre "Ustedes no consideren que el problema que tienen con un alumno es un problema de ustedes [...]; [por el contrario,] es un problema de la escuela". Por lo cual un profesor nunca tiene que ir a abordar solo ese problema. [...] Tiene que ser un problema del equipo. [Ante] un problema colectivo, una respuesta colectiva [...], me ha pasado de pibes [alumnos] que no se entendían conmigo [...], no llegaba yo a ellos, entonces alguien se ocupaba [...]. Como trabajamos en equipos, uno permanentemente [tiene] al profesor, al preceptor, al coordinador, al asesor pedagógico."
\end{abstract}

(Entrevista al ex rector)

En este extracto de entrevista, este directivo destaca el acompañamiento institucional que reciben los docentes ante las dificultades con las que puedan toparse. Al respecto, resalta la necesidad de afrontar estas dificultades como un "problema colectivo" y buscar una solución conjunta. Este tipo de abordaje contrasta con un fenómeno descrito por Poggi (2003): el aislamiento profesional impuesto por las culturas profesorales hegemónicas, que impide que los docentes discutan su tarea, aprendan de las dificultades y conviertan los obstáculos en desafíos. En efecto, en esta institución los problemas con los que se enfrentan 
los profesores son abordados en forma grupal, tal como ejemplifican los siguientes extractos de entrevista.

\begin{abstract}
"Veo que [en los alumnos] no hay [...] el código del respeto del adulto [...] las malas palabras [insultos] [...] lo dicen abiertamente y a veces uno no tiene que reaccionar. Eso es lo que el otro día hablábamos con Paulina [rectora actual]. Porque ellos tienen otra realidad, vienen mal, vienen drogados [...]. [En los trabajos prácticos de su materia] a los [alumnos] que les fue bien los felicito. [...] Eso lo aprendí de Mauricio [ex rector], [...] cuando empecé acá [...], que tenía dificultad con un alumno."
\end{abstract}

(Entrevista al profesor de la Asignatura A)

"Hay pibitos [alumnos] que están de fierro [portan armas] todos los días. [Hacer frente a esto] es un abordaje que es común de todo el cuerpo docente. Es un abordaje institucional."

(Entrevista al profesor de la Asignatura B)

\begin{abstract}
“Acá hay un docente tutor, que [...] lleva a la reunión de tutoría los comentarios, conflictos [...] de los distintos docentes [...]. Por otro lado, tenés el asesor pedagógico [...], le podes pedir ayuda a él [...], y si no, con la Dirección se puede hablar tranquilamente un montón de cuestiones [...]. A mi cuando me pasó lo del examen que a todo el mundo le fue mal [se refiere a un parcial que solo aprobaron tres de los catorce alumnos de quinto año], le dije al asesor "Che, me pasó esto, ¿qué hacemos?”. Y después se lo dije a Paulina [rectora actual] [...] y ella me decía "[...] a ver, ¿qué es lo que falló?"
\end{abstract}

(Entrevista a la profesora de la Asignatura C)

En los fragmentos de entrevista previos, los profesores de las Asignaturas A y C relatan situaciones concretas en las que acercaron sus inquietudes a otros integrantes de la escuela. El primero interpeló a los directivos por su incomodidad ante los insultos de los alumnos y por una dificultad específica con uno de ellos; mientras que la segunda lo hizo por las bajas calificaciones que obtuvieron en un examen. Estos ejemplos dan cuenta de una reflexión conjunta con otros actores institucionales acerca de cómo hacer frente a las preocupaciones. A partir de estas consultas, tal como narran, los docentes deciden no reaccionar ante las agresiones verbales de los estudiantes, resaltar lo positivo en el desempeño escolar y cuestionarse el porqué de los resultados de una evaluación administrada. Por su parte, el docente de la Asignatura B, al mencionar la portación de armas como problemática que atraviesan algunos alumnos, refiere también al abordaje institucional que se encara para trabajar con ellos. 
Efectivamente, observamos en el trabajo de campo un tratamiento colectivo de las problemáticas. En el cuaderno de notas registramos una reunión entre docentes y directivos llevada a cabo en la sala de profesores, en la cual se debatió qué decisión institucional tomar tras el descubrimiento de que un grupo de alumnos había fumado marihuana durante el recreo en un aula del primer piso. Aunque no participamos de dicha reunión, tomamos nota de su extensión temporal y de la presencia de diversos actores institucionales.

Las acciones descritas muestran que, desde la institución y en consonancia con el proyecto político-pedagógico inclusivo, se promueve que los profesores desarrollen una actitud tolerante y paciente con los alumnos que, en simultáneo, los conduzca a cuestionarse su propia injerencia en los comportamientos de estos. A sabiendas de las situaciones de vida de algunos alumnos, marcadas por experiencias de marginalidad, delincuencia, trayectorias escolares discontinuas, proximidad con la venta de drogas en "El Barrio" y/o consumo propio, estos profesores resuelven destacar lo positivo y brindar contención, a favor de la permanencia escolar.

\subsection{Acciones de carácter interpersonal}

Distintos estudios en escuelas que atienden a estratos socioeconómicos desfavorecidos señalan que la dimensión vincular es una vía sustancial para lograr objetivos institucionales (Belossi y Palacios de Caprio, 2004; Redondo, 2006a; Ziegler, 2011). En relación con la permanencia escolar, la construcción de un vínculo interpersonal entre docentes y alumnos resulta fundamental. Debido a que gran parte del tiempo escolar se transita frente a un profesor, este vínculo puede motivar a los estudiantes a asistir a clase, propiciando la permanencia.

Hallamos que los docentes entrevistados, en línea con el compromiso políticopedagógico que asumen y el abordaje en equipo de problemáticas, desarrollan tres tipos de acciones de carácter interpersonal: construyen una relación afectiva con los alumnos, manifiestan confianza en su posibilidad de aprender y acompañan en forma personalizada sus trayectorias. A continuación, abordamos estas acciones en detalle.

\subsubsection{Construir un vínculo afectivo con los alumnos}

Involucrarse en forma positiva con la escuela y sus integrantes es uno de los factores que contribuye al sostenimiento de la escolaridad (Fredricks, Blumenfeld y Paris, 2004). De acuerdo con Dabenigno y otros (2010), el lazo afectivo que los estudiantes establecen con sus 
profesores favorece su sentido de pertenencia a la institución y, al mismo tiempo, anima que continúen asistiendo a clases.

En consonancia con estos resultados, desde los documentos institucionales recopilados se acuerda que los educadores han de encarar un proceso de vinculación interpersonal para constituirse en referentes significativos de los alumnos. Basándose en los principios de "pedagogía sin violencia" y "pedagogía de la presencia", estos documentos definen esa relación a través de las características que debe ofrecer el adulto: respeto, buen trato, atención de las demandas, gestos de afecto y diálogo. Algunos de estos aspectos vinculares fueron mencionados por el ex rector como necesarios para el trabajo áulico diario:

“En esta escuela a los chicos se los trata bien, no se los puede tratar mal, no se puede gritar a un chico... aunque él grite [...]. Nosotros somos adultos, somos educadores [...] yo esto no lo pongo en discusión: si vos no querés a los pibes no podés [educarlos]. [A los alumnos] les importa lo que hacés vos en el aula y cómo te vinculás [con ellos] [...]. Se dan cuenta si vos los querés o no los querés, ellos lo perciben. [...] El marco tiene que ser siempre ese, el vínculo de buen trato, buena relación, de diálogo, de poder escuchar [...], entrar a una clase [...] [y decir] “Chicos, buen día, ¿cómo andan? ¿Están bien?” [...], te tomás algunos minutos para ver si hay alguna cuestión [para charlar].”

(Entrevista al ex rector)

Como puede verse en el fragmento de entrevista citado, este directivo resalta la relación afectiva que los docentes de la escuela deben establecer con los estudiantes. Del mismo modo, los profesores de las tres materias que observamos reconocen en las entrevistas el valor de este vínculo, argumentando acerca de la importancia de desarrollar una relación significativa con los alumnos o aportando ejemplos de ésta.

\footnotetext{
"El otro día, entrevisté a un chico de primer año que lo veíamos que estaba mal, y le decíamos “Bueno, pero nosotros te queremos ayudar", "No, no, pero vos me enfermás [me enloquecés]” le decía a la preceptora. [Respondí] "Pero ella te está tratando bien" [...]. Uno siempre tiene que estar [presente], no ponerse al nivel de él y tampoco voy a gritar. Yo no soy de gritar. [En cambio, sí soy] de decirle "Nosotros te estamos tratando bien a vos, te queremos ayudar."
}

(Entrevista al profesor de la Asignatura A)

"Hay un clima de trabajo que es necesario [...] hay mucho de buen trato y de respeto que tenés que permanentemente tener [...], estar atento a las demandas [...]. [Los alumnos de quinto año] están mucho más receptivos [...] se han encontrado con una escuela amigable, con adultos 
Leer y escribir en tres asignaturas de una escuela secundaria a la que asisten sectores socioeconómicos desfavorecidos Natalia Rosli

significativos [...], entran sabiendo quién sos vos. Saben que no sos ortiva [traidor], [...] que no los juzgas."

(Entrevista al profesor de la Asignatura B)

"Este grupo en particular [curso de quinto año] lo conocí en un campamento, así que eso te da un vínculo importante. Para esta escuela es muy importante. Entonces ya cuando arrancás el año [...] ya los conocés y él [alumno] te conoce [...]. No concibo poder explicarle algo a un pibe [joven] y que el pibe me pueda entender si yo no tengo un vínculo establecido con él. [...] Partimos del respeto, eso es básico [...]. Pero es elemental construir un vínculo, y es algo que se va construyendo [...], llegar, darte un beso, [...] preguntar cómo está uno [...]. Una palmadita en la pierna, o en el brazo, [decir] “¿Qué tal? ¿Cómo estás?” [...], yo creo que a ellos les queda que hay un vínculo afectivo con la otra persona."

(Entrevista a la profesora de la Asignatura C)

En los extractos de entrevista precedentes, el profesor de la Asignatura A hace referencia a la importancia del vínculo entre docentes y estudiantes y aporta un ejemplo en el que intervino, junto con la preceptora, asistiendo a un alumno alterado. Por su parte, los docentes de las Asignaturas $\mathrm{B}$ y C conceptualizan la relación que creen necesario establecer con los estudiantes para poder enseñar en las materias. Ambos la refieren como un vínculo que tanto el profesor como el alumno construyen progresivamente. Por ello, estos profesores mencionan la ventaja de que los estudiantes sepan de antemano quién será su docente: "entran sabiendo quién sos vos", "ya los conocés y él te conoce". En conjunto, los tres profesores sostienen que se relacionan con sus alumnos sin gritar ni juzgarlos, tratándolos bien, interesándose por ellos y evidenciando su voluntad de ayudarlos.

Más allá de la importancia que atribuyen el directivo y los docentes a estos vínculos, para evaluar su alcance resulta interesante recabar la opinión de los estudiantes. En relación con ello, distintas investigaciones hallan que en escuelas que atienden a poblaciones de sectores socioeconómicos desfavorecidos, los alumnos asignan gran importancia al involucramiento emocional con sus docentes (Belossi y Palacios de Caprio, 2004; Dabenigno y otros, 2010; Feijoó y Corbetta, 2004; Ziegler, 2011). Similar jerarquía otorgan los estudiantes del curso de quinto año -en el que observamos clases- al vínculo con los docentes. En las entrevistas, caracterizan a sus profesores como una fuente de contención afectiva que, a la vez, brinda distintos tipos de ayuda. Mencionan que los tres docentes participantes de este estudio toman en cuenta sus situaciones de vida, los escuchan y aconsejan; por lo que llegan incluso a sentirlos como familiares o amigos. 
Martín: [los docentes] te incentivan. Ves que te preguntan, “¿Y? ¿Cómo te está yendo?”, te ayudan si pueden...

Denise: [...] aparte de ser profesores como que te ayudan, ¿entendés?

Martín: Te hablan como del lado "de afuera".

Denise: Te hablan como si fuesen tus papás.

Martín: Por eso, yo hablo con Sonia [profesora de Contabilidad y Administración] y me dice " ¿Y Martín? Te tenés que poner las pilas [poner dedicación y empeño], tenés que terminar [la escuela]". [...] Como un amigo te lo dicen.

Entrevistadora: ¿Y a vos te sirve cuando te dice así?

Martín: Sí, porque se preocupa. [...] Bueno, y la profesora de Inglés sabe [que su novia está embarazada] y viene y me pregunta. Pero yo creo que Sonia [...] Es una madre más.

Nadia: La escuela siempre ayuda, ¿entendés? Otra escuela capaz [...] tenés un problema familiar, [pero] no se meten [...]. Acá es distinto, ponéle, yo hace poco cuando mi papá cayó [terminó] preso, nosotros nos dieron [ofrecieron]... por si queríamos ir al psicólogo, estuvieron más atentos, [...] tenemos una confianza con profesores que sí o sí vas a tener que contarle [los problemas], [...] y después mi mamá tuvo un accidente [...]. Me ayudaban, venían, preguntaban si estábamos bien, [insistían] que venga a la escuela, que ellos me miraban al nene [su hijo pequeño]. Yo lo traía, lo dejaba con los profesores. Lo cuidaban, si el nene lloraba, lo subian [al aula].

Lautaro: [...] Ya uno viniendo al colegio ya hacen muchísimo, te ayudan muchísimo [...]. [La profesora de la Asignatura C] es una persona excelente porque podés hablar cualquier cosa con ella.

Nadia: Sonia [profesora de Contabilidad y Administración] también.

Lautaro: Claro, es más mamá Sonia [...], te acaricia, es mimosa.

Guadalupe: Acá en el colegio vos tenés una confianza con los profesores [...], está bueno porque es como una gran familia, ¿entendés? Todos conocen a todos, los profesores todos saben tu vida y si sos de "El Barrio", si no. Está bueno eso [...] porque te dan ganas de venir al colegio [...]. Son todos así. [...] Decís "Uh, bueno, tengo con [nombra a la profesora de la Asignatura C] tres horas pero bueno, no importa, voy igual" [...]. Por eso te digo que es como diferente, por ahí, a otros colegios.

Fabiana: [Los profesores] te tiran chistes ahí. O te tiran un "¿Qué onda? ¿Qué pasó en el curso?". [Nombra al profesor Asignatura $\mathrm{B}]$ te pregunta qué materias seguís [...], o te ayudan en las [materias] previas [...]. Son profesores que te ayudan mucho en todo sentido [...]. Porque si no te llevás bien con el profesor... me cuesta llevarme bien con la materia, [...] tengo que prestarle atención al profesor, o decirle "Profe, no entiendo" y ese "no entiendo" no se lo puedo preguntar si yo estoy enojada. [...] Me costaría más la materia [si no me llevara bien con el profesor]." 
En las citas transcriptas, seis estudiantes destacan aspectos del vínculo afectivo que establecen con sus docentes. Resaltan el interés mostrado a partir de palabras de aliento ("Te tenés que poner las pilas. Tenés que terminar") o preguntas acerca de sus vidas (“¿Cómo te está yendo?", "preguntaban si estábamos bien", "te pregunta qué materias seguís") y puntualizan las ayudas ofrecidas para que permanezcan en la escuela y concluyan la cursada ("Yo lo traía [a su hijo], lo dejaba con los profesores. Lo cuidaban"; "te ayudan en las previas"). Según lo que afirman, el hecho mismo de sostener una relación con tales características promueve la permanencia escolar al motivar la asistencia a clases y facilitar la cursada de las materias ("te dan ganas de venir al colegio", "si no te llevás bien con el profesor [...] me costaría más la materia”). Este vínculo cercano que entablan con sus docentes hace que Nadia y Guadalupe les tengan confianza y que Denise, Lautaro, Guadalupe y Martín asemejen sus intervenciones a las que podrían recibir de familiares o amigos.

De modo más conciso, otros seis alumnos del curso hacen referencia a este vínculo interpersonal, aunque solo mencionan aspectos de personalidad que les agradan de sus docentes.

Marisa: [El profesor de la Asignatura A] Es buen profesor [...] No te grita ni nada.

Claudia: Es buenito, es tranquilo. No como...

E: ¿Qué, hay profesores que no son tranquilos?

Claudia: No, hay [algunos] que te gritan. Y eso no me gusta. Pero él es tranquilo, te habla despacito, todo amor y paz [Risas].

(Entrevista a las alumnas Marisa y Claudia)

E: ¿Y del profesor [de la Asignatura B] qué piensan ustedes? ¿Les gusta cómo enseña?

Carla y Lorena: $S i$.

E: ¿Y todos los profesores son asi?

Carla: La mayoría.

Lorena: Sí. Son macanudos [amigables].

(Entrevista a las alumnas Carla y Lorena)

Ernesto: [Nombra al profesor de la Asignatura B] es piola [simpático].

Ariana: Es un capo [excelente] [...] iAguante! [iViva!].

(Entrevista a los alumnos Ernesto y Ariana) 
Con expresiones como "tranquilo”, “macanudo”, “piola”, “capo” y “¡Aguante!”, estos estudiantes formulan su valoración positiva de los docentes. Estas apreciaciones sobre la personalidad y el carácter, que ponen en primer plano la subjetividad de los docentes, según Kessler (2002), son el modo más común mediante el cual estudiantes del nivel secundario dan indicios acerca de su relación con ellos.

En suma, en las entrevistas a profesores y alumnos se observa una toma de conciencia por parte de los primeros de que cierto tipo de vínculo afectivo con los segundos es condición necesaria para la enseñanza. Estar disponible, ser receptivo, escuchar e interesarse por sus cuestiones personales, respetarlos y entender sus situaciones de vida, son actitudes que vuelven a estos docentes confiables a los ojos de los estudiantes. Este principio podría caber para cualquier contexto educativo pero aparece de relieve con relación a este alumnado, que exhibe historias familiares y sociales atravesadas por la exclusión, la fragmentación, la violencia, la desatención de necesidades básicas y, por ende, la falta de reconocimiento estatal en tanto sujetos de derecho.

\subsubsection{Manifestar confianza en la posibilidad de aprendizaje de los alumnos}

Distintas investigaciones muestran que las representaciones que tienen los profesores de sus alumnos inciden en su desempeño escolar (por ejemplo, Bourdieu y Saint Martin, 1998; Kaplan, 2010; Mercier, Sensevy y Schubauer-Leoni, 2000). Específicamente, concebir a los estudiantes como capaces de aprender puede suscitar su avance al modo de una profecía autocumplida, tal como prueban Rosenthal y Jacobson (1968) mediante un experimento en una escuela primaria estadounidense. Esta apuesta por su aprendizaje resulta determinante para la relación pedagógica (Bain, 2004; Carlino, 2005; Cornú, 1999; Falconi, 2011; Thisted, 2011) y puede generar condiciones para motivar la permanencia escolar.

Dentro del vínculo afectivo entablado, los profesores de esta escuela mantienen confianza en que los alumnos, pese a las problemáticas socioeconómicas que dificultan su tránsito por la escolaridad secundaria, son capaces de aprender los contenidos disciplinares que les enseñan. Adoptando esta postura, los docentes se sitúan en el polo opuesto de los discursos fatalistas, descritos por Baquero (2001), que sospechan sobre la "educabilidad" de los jóvenes de sectores socioeconómicos desfavorecidos. Estos discursos llegan a dictaminar incluso, y tal como cuestionan Belossi y Palacios de Caprio (2004), Frigerio (2004) y Kaplan (2005), que estos estudiantes inevitablemente fracasarán en la escuela.

Esta confianza en el progreso escolar de los alumnos es visualizada por el ex rector de la institución como fundamental para poder trabajar con ellos. De acuerdo con su visión, la 
Leer y escribir en tres asignaturas de una escuela secundaria a la que asisten sectores socioeconómicos desfavorecidos Natalia Rosli

confianza involucra el deseo y la convicción de que a través de la enseñanza se logrará un cambio en sus condiciones de vida:

"Querer a un pibe es decir "Creo en él y quiero un destino diferente al que trae". [...] Yo insisto, si no creés que la educación puede hacer algo por ese pibe... [Se queda en silencio tres segundos]. Yo creo que ahí está el tema [...], para mí la clave es que vos [como docente] entrás a un aula con ganas de lograr algo en esos pibes."

(Entrevista al ex rector)

Este extracto de entrevista muestra que el directivo enfatiza la importancia de que los profesores encaren su tarea creyendo firmemente en las posibilidades de aprender de los estudiantes y en el potencial transformador de la educación. Esta confianza que subraya puede verse reflejada en el discurso de los profesores de las tres asignaturas observadas, tal como se ilustra a continuación.

“[Los alumnos] tienen...es un problema de autoestima [...], a mí me llegaron a decir “A mí no me da la cabeza [no tengo la capacidad] [...]". Y les digo "pero si a ustedes no les da la cabeza, no estarían acá en una escuela”. Esto es una escuela "normal”, más allá de las dificultades del contexto en que se encuentran [...]. Habría que romper esta cuestión de que "Yo no puedo", porque ellos están evidenciando eso. "Yo no puedo", "yo no debo" y sí que pueden. Yo estoy convencido de que pueden."

(Entrevista al profesor de la Asignatura A)

“En todos los grupos humanos hay pibes que tienen más interés en el tema, otros que tienen menos interés [...]. Entonces ahi se dan, se dan las diferencias, pero no por capacidades [...]. Todos tienen las mismas capacidades [...]. No es lo mismo un muchacho que tiene que salir a laburar [trabajar] al que no. Lo que no significa que el que tiene que salir a laburar tenga menos capacidad de... escritura."

(Entrevista al profesor de la Asignatura B)

"Uno sabe qué pibe tiene más capacidad para poder estudiar y qué pibe vos le podés ajustar [exigir más]. Vos a Martu y a Ernes [alumnos de quinto año], los ajustas un poco más y son pibes que te rinden, tranquilamente. [...] Está más estereotipado que Ernes es un tipo que sabe, que entiende y que Lauti no. Y Lauti tiene esa carga encima. [...] Si uno desde afuera hace esta lectura de " $Y$, uno es mejorcito que el otro", por ahi él también tiene esa carga sobre su espalda."

(Entrevista a la profesora de la Asignatura C) 
En las citas transcriptas, el profesor de la Asignatura A enuncia su confianza en los estudiantes y marca la necesidad de explicitarla debido a que ha escuchado comentarios que revelarían su baja autoconfianza académica. Por su parte, el profesor de la Asignatura B hace hincapié en la igualdad de "capacidades" de los alumnos, más allá de los diferentes intereses o situaciones de vida que exhiban. De modo similar, la docente de la Asignatura C destaca los rendimientos de los estudiantes y menciona que los estereotipos de los profesores pueden condicionarlos.

Además del discurso, las observaciones de clase evidencian la confianza que estos profesores sostienen en las posibilidades de aprender de los alumnos. Al explicitarse en el trabajo áulico diario, la confianza "hace acto" (Cornú, 1999, p. 21), siendo capaz de ser percibida por los estudiantes y, además, otorgarles una cuota de seguridad en sí mismos que puede incidir en su motivación por asistir a clases. En este punto, la explicitación de la confianza puede facilitar el logro de otro objetivo formulado en el Proyecto Institucional Inclusivo de esta escuela: "promover en el adolescente en dificultades la necesaria confianza en sí mismo". Los siguientes fragmentos de registros de clase presentan ejemplos de cómo se manifiesta verbalmente esta confianza en las materias observadas.

\section{Fragmento $\mathrm{n}^{\circ} 1$ :}

[Clase 2 en la Asignatura A. El docente pide comenzar la puesta en común del cuestionario sobre un texto del sociólogo Mario Margulis]

Daiana: Yo lo terminé pero necesito que me lo explique porque no entiendo.

Docente Asignatura A (DA): [Se acerca, lee en voz baja una de las respuestas que Daiana escribió en su carpeta y habla a todo el curso] Pero ustedes tienen que leer esto [las respuestas] porque está muy bien [...], hay que animarse a leer lo que producen. Porque cuando ustedes vayan a seguir otra carrera...

Yésica: [Interrumpiendo] ¿Usted piensa que vamos a salir de acá...?

Carla: ¿...y vamos a seguir una carrera?

DA: Yo creo que sí, chicos [...], ya están ustedes en la recta final [se refiere a que cursan el último año del nivel secundario], [...] no hay que bajar los brazos [rendirse]. [...] Tal vez se tengan que esforzar un poco más.

[La clase continúa con intercambios verbales del docente con los estudiantes acerca de las carreras que quieren estudiar al finalizar la escuela secundaria].

\section{Fragmento ${ }^{\circ} 2$ :}

[Clase 4 en la Asignatura A. El profesor habla a todo el curso y resume las respuestas que los estudiantes dieron a un cuestionario planteado la clase anterior. En dicha clase, este docente, preocupado por algunos comentarios negativos de los alumnos acerca de la enseñanza brindada en 
Leer y escribir en tres asignaturas de una escuela secundaria a la que asisten sectores socioeconómicos desfavorecidos Natalia Rosli

la escuela y sobre la posibilidad de realizar estudios superiores, había propuesto contestar por escrito seis consignas: 1) ¿Qué significa esta escuela para ustedes?, 2) ¿Qué representa esta escuela en sus vidas?, 3) Expectativas cuando ingresaron y ahora, 4) ¿Qué les preocupaba en primer año y qué les preocupa ahora?, 5) ¿Qué piensan que es la vida después de la escuela? y 6) ¿Qué quieren que se les brinde desde la escuela en estos últimos meses?]

DA: Yo como había visto tanto escepticismo en esta mirada negativa de lo que era la escuela y el futuro [...] les hago una devolución. Es positivo para mí lo que dicen ustedes [en las respuestas a las consignas]. [...] Miren lo que ustedes ponen: "[La escuela] es donde estoy pasando la adolescencia con amigos", "Es una base más para empezar mi carrera”, "Para mí es todo”. Eso es lo que dicen de la escuela: "Tiene un significado importante, ocupa un gran lugar en mi vida”, "Me trataron bien”, "Es mi segunda casa”, "Recibo mucho afecto de amigos, preceptores y profesores". [Continúa leyendo otras respuestas] Yo creo que es positivo. [...] Ustedes tienen otra visión de la escuela, de agradecimiento y demás. [...] También hay que poner un poco de esfuerzo en lo que viene. [...] Siempre hay que luchar y se puede, yo quiero decirles que se puede.

\section{Fragmento $\mathrm{n}^{\circ}$ :}

[Clase 1 en la Asignatura B. El docente expone oralmente sobre la deuda externa. Luego indica leer un texto de un manual de Historia y contestar un cuestionario. A medida que finalizan la tarea, los estudiantes le entregan sus hojas. Hacia el final de la clase, solo quedan en el aula Claudia y Yésica].

Claudia: [Entrega su hoja] No lo pienso arreglar [corregir] si está mal.

Docente Asignatura B (DB): Bueno [Echa un vistazo a la producción de Claudia] ¿Y por qué tendría que estar mal? Si está bien.

Claudia: Por eso le digo, si estaba mal, no lo iba a arreglar.

DB: ¿Y por qué tenés que pensar que está mal?

Claudia: [No responde. Comienza a guardar sus útiles en la mochila].

\section{Fragmento $\mathrm{n}^{\circ} 4$ :}

[Clase 1 de la Asignatura C. La docente indica a los alumnos dividirse en pequeños grupos para leer apartados sobre paraísos fiscales, provenientes de un módulo escolar, y luego socializar lo entendido con el resto del curso].

Fabiana: [Discute con sus compañeras Carla y Ariana sobre lo leído] Lo legal es la plata que uno gana a través de un trabajo y lo ilegal cuando robas, [...] venta de armas. [Percibe que la docente está atenta a sus conversaciones] iY encima estás escuchando vos! Así que ya estás sabiendo que estamos hablando.

Docente Asignatura C (DC): Quiero saber cuál fue la explicación de [dinero] legal e ilegal porque la de recién fue bastante [...] pobretona [insuficiente]. [...] Yo tengo confianza en este grupete [grupo]. 
[Transcurrido el tiempo destinado para leer, dicho grupo comienza a exponer ante los compañeros].

Carla: Eh... [Se detiene, mira el apartado que leyó] los paraísos fiscales son estados o lugares,

eh... [Hace una larga pausa, relee] que poseen regímenes fiscales...

DC: Tranqui, tranqui, ya va a aflojar, ya va a aflojar [ya va a salir la explicación].

[Las alumnas continúan comentando en voz alta lo que entendieron de lo leído]

Estos cuatro fragmentos de registros de clase ilustran cómo, de diversas formas, los tres docentes explicitan su confianza en las posibilidades de aprender de los alumnos. Lo hacen en momentos donde los estudiantes dudan de sí mismos: "hay que animarse a leer lo que producen” (fragmento ${ }^{\circ} 1$ ); “yo quiero decirles que se puede” (fragmento $n^{\circ} 2$ ); “ ¿y por qué tendría que estar mal? Si está bien" (fragmento $n^{\circ} 3$ ), o cuando entienden que deben alentarlos a seguir trabajando alguna idea conceptual incompleta: "yo tengo confianza en este grupete $[. .$.$] tranqui, ya va a aflojar" (fragmento n^{\circ} 4$ ). Estas expresiones resultan alentadoras para estos jóvenes que desconfían de sus posibilidades de aprender y de su futuro como alumnos de nivel superior, tal como muestran algunas de sus preguntas y comentarios en clase (por ejemplo, en fragmento $n^{\circ} 1$ : Yésica: ¿Usted piensa que vamos a salir de acá...? Carla: ¿...y vamos a seguir una carrera?).

En definitiva, los fragmentos de entrevistas y observaciones de clase presentados en este subapartado muestran que, ante la baja autoconfianza académica, los docentes fomentan un vínculo afectivo y manifiestan confianza en las posibilidades de aprender de los estudiantes. Estas acciones parecen tener resonancia en estos alumnos, cuyo historial escolar se caracteriza por reiterados "fracasos": saben que, en esta institución, cuentan con profesores que creen en ellos, dispuestos a acompañarlos y ayudarlos a aprender y finalizar su escolaridad secundaria.

\subsubsection{Acompañar en forma personalizada la trayectoria escolar de los alumnos}

En las escuelas con perfil inclusivo, el seguimiento del recorrido de aprendizaje de los estudiantes ha sido denominado por Ziegler (2011) como formas tuteladas de acompañamiento. Respecto de esta modalidad de seguimiento, Dabenigno y otros (2010) remarcan que privilegia la interacción "uno a uno" y el "cuerpo a cuerpo".

A lo largo del trabajo de campo registramos que los docentes de las asignaturas observadas ponen atención en las trayectorias escolares de los alumnos a través de un acompañamiento personalizado, similar al descrito. Así, se actualizan del proceso de aprendizaje que desarrolla cada estudiante e intervienen para guiarlo y monitorearlo. Los 
Leer y escribir en tres asignaturas de una escuela secundaria a la que asisten sectores socioeconómicos desfavorecidos Natalia Rosli

siguientes extractos de entrevista muestran el seguimiento que estos profesores declaran hacer.

"Yo hago el seguimiento, a su vez, con los alumnos que tienen dificultades. [...] Yo me acerco mucho a ellos y trato de decir “¿a dónde está [en el texto]?”, “¿qué están leyendo?” [...], “¿leiste esto?”. Reviso un poco cómo lo abordó [el texto], si lo leyó, lo subrayó, la lectura. Y ahí estoy más [...] con el [alumno] que tiene la dificultad.",

(Entrevista al profesor de la Asignatura A)

"[Si] empiezo a trabajar y estos [alumnos] están charlando y tengo cuatro [alumnos] que adelante me dan bola [prestan atención], [y] entonces trabajo con esos cuatro nada más... [Es] peor [...]. Es al revés [lo que hay que hacer], [...]: tenés que estar al lado del [alumno] que se te desenganchó [no presta atención en clase]. [... Vos te sentás con los que más dificultad tienen."

(Entrevista al profesor de la Asignatura B)

“Cuando un pibe falta [...] dos o tres semanas [...], no viene siguiendo una secuencia [de clase], [le] cuesta dos veces más comprender un texto. Porque no sabe ni de qué tema es [...]. Hay una [alumna] que en el primer trimestre no vino nunca [...], me senté con ella, la ubicás [en los temas] y la vas tutoreando [...]. Hay otras chicas [...] que están haciendo, intentando ver el tema de la [materia] previa. Entonces ¿qué hacés?, un laburo [trabajo] de tutorado y, si hay alguna dificultad, te sentás y se la explicás.”

(Entrevista al profesor de la Asignatura B)

En los extractos de entrevista reproducidos, los docentes aluden a las intervenciones que realizan para orientar a quienes tienen dificultades en sus materias (monitorean cómo abordan los textos y trabajan al lado de quienes se "desengancharon" en la clase), se ausentan frecuentemente a clase y/o deben rendir materias previas ("laburo de tutorado"). Tal como se vislumbra en dichos extractos, este acompañamiento personalizado implica que los docentes conserven cierta cercanía con los estudiantes para observar su trabajo en clase y poder estar atentos a los momentos que requieren su intervención. Los siguientes fragmentos refieren este acercamiento "cuerpo a cuerpo":

\footnotetext{
"No es solamente [decir] "Ay chicos, la expansión ultramarina, [pongan] la fecha, por favor", sino que es decir “¿Trajeron esto?”, te sentás un poco. Hay otro trabajo [...]: “Bueno por favor, cumplí. ¿Pero qué te pasa?”. [...] El lunes quiero dar una vuelta por el curso [de quinto año] [...] para decirles que tienen que presentar el trabajo [práctico], recordarles un poco eso, que tienen que leer el texto, que vayan completando [las actividades pedidas], como acercarme [...] a decirle las cosas [que deben hacer]."
} 
“En las lecturas [...] intento [...] estar ahí atento. [...] Si yo estoy caminando y [...] vos no estás leyendo [...], me acerco y te digo, “este..., bueno, a ver, dale”. Entonces [...] vos empezaste a leer [...] y me decís "acá está la primera [respuesta], ¿no?”, y yo te digo "No, ¿Por qué no lees primero [todo] el texto? ". [...] Pero en eso tenés que estar [presente] vos ahí.”

(Entrevista al profesor de la Asignatura B)

Estos profesores comentan en estos extractos de entrevista que monitorean el trabajo diario de los alumnos y que si advierten que estos no realizan las actividades pedidas, intervienen incentivándolos a ello. Para posibilitar ese monitoreo, dicen sostener una atención constante, acercarse a los estudiantes, sentarse a su lado y recordarles las tareas pendientes.

Cabe aclarar que, en diversas situaciones de clase, pudimos observamos en acción este acompañamiento que los docentes afirman ejercer. Efectivamente, tal como los profesores describen en las entrevistas, se trata de momentos donde pasean por el aula, se acercan a los estudiantes y, en la mayoría de las ocasiones, se sientan en el banco próximo para guiarlos en las tareas. Escogimos dos fragmentos de clase para ilustrar este acompañamiento, que reproducimos a continuación.

\section{Fragmento $\mathrm{n}^{\mathrm{o}} 1$ :}

[Clase 2 en la Asignatura A. El profesor comenta que no recibió en su correo electrónico ningún trabajo práctico de los estudiantes].

DA: [Se dirige al curso] Ayer yo controlé el mail, mi casilla, nadie me había, por lo menos de este curso, enviado nada, el trabajo, un borrador... para poder ir haciendo correcciones [...]. El [alumno] que no tiene la posibilidad de hacerlo [en la computadora], lo puede entregar el trabajo en una hoja común [...]. Pero no dejen de cumplir con esa fecha de entrega [...]. Hay que tratar de $[. .$.$] tener una conducta con la lectura. [...] El lunes doy una vuelta y hablo con ustedes$ [...], cierra el trimestre, acuérdense que el tema era hoy la entrega [...], no dejen de hacerlo en esa semana.

[Hacia el final de la clase, el profesor se acerca a Fabiana, quien le pide que revise su trabajo práctico. Durante el lapso del recreo, revisa su producción escrita y le da indicaciones al respecto].

\section{Fragmento ${ }^{\circ} 2$ :}

[Clase 1 de la Asignatura B. El docente ingresa al aula para comenzar la clase. Los alumnos continúan charlando].

DB: [Se acerca al banco de Fabiana] ¿Me trajiste ese trabajito? [Se refiere a un trabajo práctico que le encargó para ir preparando la materia que tiene previa y debe rendir]. 
Leer y escribir en tres asignaturas de una escuela secundaria a la que asisten sectores socioeconómicos desfavorecidos Natalia Rosli

Fabiana: [...] te lo traigo la próxima [clase] [...] sin falta.

DB: [A toda la clase] Bueno, vamos a trabajar chicos. [...] La vez pasaba habiamos empezado a trabajar... [No continúa la frase y mira a Lautaro] Lauti, ¿vos fuiste pidiendo las cosas [las actividades realizadas] de las veces que faltaste?

Lautaro: $E h$, no.

DB: Andá pidiendo las cosas que vamos haciendo. [La clase continúa con una exposición oral del docente. Luego, éste pide a los estudiantes que contesten un cuestionario sobre un texto de un manual de Historia. A continuación, se acerca a Lautaro] ¿Vos también tenés que dar [la materia] previa? [...] Porque tus compañeros me están haciendo trabajos [...], fijáte si te interesa.

Lautaro: Sí, obvio que me interesa, pero no sé cuándo te lo puedo pedir.

DB: [...] Pedíle un libro de Geografía de segundo año a Beatriz [encargada de la biblioteca escolar] el lunes y venís antes de empezar la clase y ya te empiezo a dar un trabajo [...]. La intención es que vayas haciendo [trabajos] como por cuotas [por partes] [...] Y al momento de [rendir] la [materia] previa, charlamos sobre lo que trabajaste.

Lautaro: Dale.

[Los alumnos continúan respondiendo el cuestionario asignado].

Estos dos fragmentos ejemplifican cómo los docentes acompañan las trayectorias escolares de los estudiantes. En el fragmento $n^{\circ} 1$, el profesor de la Asignatura A, al notar que los estudiantes del curso no enviaron el trabajo práctico requerido por correo electrónico, ofrece la posibilidad de hacerlo en formato papel, extiende el plazo de entrega y remarca la necesidad de cumplimentar las tareas en tiempo y forma. Finalizada la clase, este docente se aboca a responder en forma individual las consultas de Fabiana, destinando todo el recreo para ello. El fragmento $\mathrm{n}^{\circ} 2$ muestra intervenciones del docente de la Asignatura $\mathrm{B}$, antes de comenzar la clase y durante la misma, en las que orienta a Fabiana y Lautaro. A la primera le exige un trabajo práctico a modo de preparación para rendir una materia previa mientras que al segundo le propone unirse a esa modalidad, explicitando qué pasos debe seguir para hacerlo, y lo incita a pedir lo realizado en clase cuando estuvo ausente.

En suma, los extractos de entrevista y los fragmentos de registros de clase que reprodujimos revelan que estos profesores entienden que la permanencia también se ve favorecida cuando los estudiantes son acompañados en sus trayectorias escolares. Probablemente, este seguimiento contraste con las anteriores experiencias de repitencia y abandono escolar que vivieron estos alumnos. Es posible que los estudiantes, en otras instituciones, no se hayan topado con docentes que asiduamente los alentaran al trabajo áulico y a rendir sus materias previas, y que los resituaran en tema luego de sus ausencias a clase. A la vez que motivan a los estudiantes a asistir a clase -dado que denotan que allí se 
encuentran profesores dispuestos a guiarlos-, estas intervenciones pueden colaborar con el aprendizaje, ya que facilitan que los docentes monitoreen los avances y/u obstáculos de los alumnos en el proceso de apropiación de contenidos disciplinares.

\subsection{Síntesis}

En este capítulo hemos descrito las diversas acciones de carácter institucional e interpersonal llevadas a cabo por integrantes de esta institución, que se destacan en sus discursos y acciones como favorecedoras de la permanencia escolar de los alumnos, en acuerdo con la bibliografía revisada.

La asunción por parte de directivos y docentes de un compromiso produce un involucramiento con los principios del proyecto político-pedagógico y una correlativa suma de esfuerzos institucionales por el logro de los objetivos allí planteados. Abordar conjuntamente las problemáticas que puedan emerger y poner en riesgo la permanencia escolar de los alumnos forja un núcleo de personas dispuestas a analizar y aportar diversas soluciones. Simultáneamente, la búsqueda de la permanencia se potencia mediante el vínculo afectivo que se construye con los alumnos, porque los motiva a asistir a clases. Los docentes declaran confiar en las posibilidades de aprender de los estudiantes y así lo explicitan en las clases, lo que puede suscitar que estos desarrollen seguridad en sí mismos. Esta confianza también se hace patente mediante el acompañamiento que realizan de las trayectorias escolares de los alumnos, que incluye guía y orientación durante sus procesos de aprendizaje.

El comportamiento de los alumnos de esta escuela no puede tratarse con la misma vara que en otros contextos socioeconómicos. La consideración de las particularidades de estos estudiantes, a través de esta red de acciones descritas, constituye una toma de postura institucional que fundamenta y se extiende a través de toda la práctica educativa. Quienes desarrollan estas acciones lo hacen desde una posición crítica a nivel político, que visualiza las situaciones socioeconómicas de los estudiantes como telón de fondo condicionante de los procesos de enseñanza. Empero, parece necesario que esta comprensión no conlleve actitudes de resignación o impotencia por parte de los actores educativos sino que habilite "lecturas en positivo" (Charlot, 2006, p. 36) acerca de las posibilidades de retener a los alumnos. Es decir, que permita pensar las circunstancias de vida de estos alumnos no como obstáculos insalvables sino como puntos de partida para diseñar intervenciones institucionales efectivas, tal como señalan Dabenigno y otros (2010). La empiria presentada en este capítulo evidencia que dicha "lectura en positivo" es posible y que siembra bases para asegurar el derecho a la educación de los alumnos. 
Aunque las acciones descritas promueven la permanencia de los alumnos de esta escuela, adviértase que no pueden garantizar que todos los jóvenes permanezcan escolarizados. Dado que los factores que intervienen en la permanencia son múltiples y complejos, en ocasiones el desgranamiento igualmente acontece, por lo que éste sigue siendo uno de los mayores problemas durante la escolaridad secundaria (CEPAL, 2014). En efecto, las problemáticas socioeconómicas de los alumnos conducen, a menudo, a la interrupción de sus trayectorias escolares. No puede obviarse que el desafío de generar condiciones para la permanencia trasciende el plano meramente institucional y corresponde a un conjunto de políticas sociales (López, 2006; Terigi, 2009) entre las que se incluyen el financiamiento, la infraestructura y la capacitación de profesores.

En el próximo capítulo dirigimos la mirada hacia la enseñanza impartida en la institución indagada. De acuerdo con el objetivo planteado en esta tesis, abordamos las prácticas de enseñanza en tres materias, para analizar el modo en que éstas abren o cierran oportunidades de apropiación de contenidos a través de la lectura y la escritura. En relación con la temática abordada en este capítulo, puede afirmarse que la apropiación de saberes por parte de los estudiantes incide fuertemente en la permanencia escolar. Tal como sostienen Jacinto y Terigi (2007), las experiencias de aprendizaje fortalecen que los estudiantes concurran a clase. De este modo, al tiempo que analizamos las experiencias de aprendizaje de contenidos se proponen a través del leer y escribir en tres asignaturas también estamos analizando situaciones que podrían promover la permanencia de los estudiantes. 


\section{Prácticas de enseñanza que involucran lectura y escritura de contenidos: intervenciones docentes en la tarea de leer para responder cuestionarios}

En el presente capítulo se analizan las intervenciones docentes en relación con la lectura y la escritura de contenidos disciplinares en las materias indagadas. Este foco de análisis adquiere importancia debido a que, para garantizar la apropiación de saberes disciplinares por parte de los alumnos, es preciso implementar condiciones que propicien su vínculo con los contenidos. Respecto de la apropiación de saberes, conviene observar que los objetivos de permanencia estudiantil, temática abordada en el capítulo precedente, y de aprendizajes relevantes se encuentran relacionados (Jacinto y Terigi, 2007): se pretende retener a los estudiantes para que aprendan y, a la vez, se entiende que las experiencias que logren suscitar aprendizajes serán aquello que concurrentemente fortalecerá la permanencia.

Para abordar entonces las condiciones que se proponen para la apropiación de saberes, es preciso analizar más minuciosamente cómo la enseñanza puede favorecer u obstaculizar aprendizajes en las materias observadas, poniendo en primer plano las intervenciones docentes relacionadas con las tareas de lectura y escritura que se solicitan a los alumnos. Desde nuestros marcos teóricos asumimos que leer y escribir sobre contenidos disciplinares, en ciertas condiciones, son actividades fértiles para la elaboración del conocimientos (ver Capítulo 2). Al respecto, y de acuerdo con nuestro problema de investigación, nos preguntamos qué situaciones se proponen, específicamente, para interpretar y producir textos en estas asignaturas: ¿qué características presentan las tareas propuestas y cómo intervienen los docentes en ellas? ¿Cuál es el uso que hacen los alumnos de la lectura y la escritura en estas materias? ¿Qué puede indicar ese uso respecto del aprendizaje de los contenidos disciplinares?

Para responder tales interrogantes, nos centramos en la tarea de lectura y escritura observada con mayor frecuencia en las tres asignaturas: leer para responder cuestionarios. Escogimos analizarla con profundidad ya que, en la mayoría de las clases en las que registramos actividades de lectura y escritura (32 de 37 clases), encontramos que los alumnos leen y escriben en el marco de esta tarea (ver apartado 3.6 del Capítulo 3). Pese a que encontramos algunas clases donde se propusieron otro tipo de tareas, estas fueron minoritarias (no sucedieron más de una o dos veces durante los siete meses de recolección de 
datos del trabajo de campo). Por ello, y en relación con nuestro objetivo de investigación, las consideramos poco representativas de lo que sucede predominantemente en estas materias. La tarea de leer para responder cuestionarios, dada su recurrencia, nos permite brindar una caracterización general de las prácticas de enseñanza que involucran lectura y escritura de contenidos llevadas a cabo en asignaturas de escuelas secundarias que reciben a población socioeconómicamente desfavorecida, lo cual aporta al área de vacancia delimitada en el Capítulo 1.

El análisis que presentamos a continuación se basa en registros de clases en los que observamos acción conjunta (Sensevy, 2007) entre alumnos y docentes en torno a la tarea de leer para responder cuestionarios. Específicamente, hemos tomado como base empírica del presente análisis 354 intervenciones docentes relativas a dicha tarea, registradas a lo largo de 32 clases correspondientes a tres asignaturas de quinto año. Decidimos agrupar estas intervenciones, en primera instancia, según las funciones docentes que identificamos que los profesores ejercen en forma predominante durante el desarrollo de estas instancias de lectura y escritura. De este modo, las tres funciones docentes predominantes que distinguimos en relación con la tarea mencionada son: a) definición del medio, b) gestión del medio y c) evaluación de la tarea. Al respecto de cada una de estas funciones, también nos ocupamos de definir y caracterizar las siguientes dimensiones del quehacer docente: 1) qué hace el profesor, y 2) las diversas formas en que lo hace, es decir el cómo lo hace. Desde nuestra perspectiva, el cómo materializa el qué y constituye un plano de análisis más particularizado, que permite identificar distintos modos de intervenir de los docentes en la definición del medio de la tarea, su gestión y evaluación. Junto con el análisis de estas intervenciones, incluimos datos de entrevistas a docentes y alumnos, que permiten entender lo observado desde el punto de vista de los participantes. Para un mayor detalle del proceso de análisis de los datos, remitimos al lector al apartado 3.6 del Capítulo 3.

Hemos estructurado el presente capítulo en cuatro apartados. El primero (6.1) presenta las intervenciones en relación con la función docente de definición del medio. La Tabla 9 muestra las categorías y subcategorías identificadas en relación con ello. El segundo apartado (6.2), consigna las intervenciones identificadas en la función docente de gestión del medio. La Tabla 28 exhibe sus categorías y subcategorías. El tercero (6.3) describe intervenciones de los profesores en la función de evaluación de la tarea, cuyas categorías y subcategorías se muestran en la Tabla 46. Cabe aclarar que al final de los apartados, el lector encontrará algunas conclusiones del conjunto de intervenciones analizadas para cada función docente. Por su parte, el cuarto apartado (6.4) presenta semejanzas y diferencias que encontramos 
entre las materias analizadas en cuanto a los elementos de la tarea y las formas de intervenir en ella. El quinto apartado (6.5) distingue tres conjuntos de intervenciones que agrupamos según cómo se ubican en un continuo entre monologicidad y dialogicidad. Por último, el sexto apartado (6.6) reseña las conclusiones del capítulo y discute acerca de las posibilidades que ofrecen las intervenciones identificadas para favorecer que la lectura y la escritura sean herramientas de acceso, participación y apropiación del conocimiento

Tal como mostrará este capítulo, nuestros resultados indican que en la mayoría de las intervenciones que conforman la estructura de la actividad identificada los docentes no proponen explicitar y trabajar con las interpretaciones de los estudiantes.

\subsection{Definición del medio}

En este apartado agrupamos las intervenciones mediante las cuales los profesores construyen una situación que presenta una tarea con un problema a resolver por parte de los alumnos. Si bien Brousseau (2007), en su teoría de las situaciones didácticas, afirma que un medio es un sistema antagonista del sujeto en tanto le ofrece resistencias y retroacciones, siguiendo a Pastré (2008) tomamos dicho término solo como equivalente a una situación-problema que se construye. Definir un medio, entonces, implica proponer una situación-problema y establecer sus parámetros: precisar las tareas de aprendizaje, sus reglas definitorias y los recursos disponibles que orientan la actividad del alumno hacia la construcción de conocimientos (Rickenmann, 2006, 2007; Sensevy, 2007).

Acerca de la antedicha función docente de definición del medio, identificamos 91 intervenciones de los profesores enfocadas a proponer la tarea de leer para responder cuestionarios en términos de situación-problema. El análisis de las mismas nos condujo a construir cuatro categorías que agrupan distintos modos de intervenir para definir el medio: 1) “define la tarea", 2) "define recursos de lectura", 3) "establece significados compartidos" y 4) "propone acciones generales para facilitar la tarea". La Tabla 9 presenta estas categorías, su división en subcategorías y los tipos de intervenciones docentes identificadas, detallando su contabilización. 
Leer y escribir en tres asignaturas de una escuela secundaria a la que asisten sectores socioeconómicos desfavorecidos Natalia Rosli

Tabla 9. Categorías y subcategorías de la función docente "definición del medio"

\begin{tabular}{|c|c|c|c|c|c|}
\hline Categoría & $\begin{array}{c}\text { Total de } \\
\text { intervenciones }\end{array}$ & Subcategoría & $\begin{array}{c}\text { Total de } \\
\text { intervenciones }\end{array}$ & $\begin{array}{c}\text { Intervenciones } \\
\text { docentes }\end{array}$ & $\begin{array}{c}\text { Total de } \\
\text { intervenciones } \\
\end{array}$ \\
\hline \multirow{2}{*}{ Define tarea } & \multirow{2}{*}{$18 / 91$} & \multirow{2}{*}{ Da consignas } & \multirow{2}{*}{$18 / 18$} & $\begin{array}{l}\text { Da consignas para } \\
\text { resolver en clase }\end{array}$ & $10 / 18$ \\
\hline & & & & $\begin{array}{l}\text { Da consignas } \\
\text { domiciliarias }\end{array}$ & $8 / 18$ \\
\hline \multirow{5}{*}{$\begin{array}{l}\text { Define } \\
\text { Recursos de } \\
\text { lectura }\end{array}$} & \multirow{5}{*}{$44 / 91$} & \multirow{2}{*}{$\begin{array}{l}\text { Requiere } \\
\text { material de } \\
\text { lectura }\end{array}$} & \multirow{2}{*}{$24 / 44$} & $\begin{array}{l}\text { Pregunta si han } \\
\text { traído a clase su } \\
\text { propio material }\end{array}$ & $19 / 24$ \\
\hline & & & & $\begin{array}{c}\text { Pide a quienes se } \\
\text { ausenten fotocopiar } \\
\text { material }\end{array}$ & $5 / 24$ \\
\hline & & \multirow{3}{*}{$\begin{array}{c}\text { Brinda material } \\
\text { de lectura }\end{array}$} & \multirow{3}{*}{$20 / 44$} & $\begin{array}{c}\text { Entrega material de } \\
\text { lectura de la } \\
\text { biblioteca o } \\
\text { fotocopias de textos }\end{array}$ & $10 / 20$ \\
\hline & & & & $\begin{array}{c}\text { Escribe } \\
\text { definiciones } \\
\text { teóricas en el } \\
\text { pizarrón para leer y } \\
\text { copiar }\end{array}$ & $6 / 20$ \\
\hline & & & & $\begin{array}{c}\text { Facilita su } \\
\text { bibliografía a los } \\
\text { alumnos que no la } \\
\text { han traído }\end{array}$ & $4 / 20$ \\
\hline \multirow{3}{*}{$\begin{array}{c}\text { Establece } \\
\text { significados } \\
\text { compartidos }\end{array}$} & \multirow{3}{*}{$13 / 91$} & \multirow{2}{*}{$\begin{array}{l}\text { Organiza } \\
\text { memoria } \\
\text { didáctica }\end{array}$} & \multirow{2}{*}{$8 / 13$} & $\begin{array}{l}\text { Retoma oralmente } \\
\text { contenidos } \\
\text { trabajados sin hacer } \\
\text { referencia a textos } \\
\text { o autores leídos }\end{array}$ & $6 / 8$ \\
\hline & & & & $\begin{array}{l}\text { Retoma oralmente } \\
\text { contenidos } \\
\text { trabajados haciendo } \\
\text { referencia a textos } \\
\text { o autores leídos }\end{array}$ & $2 / 8$ \\
\hline & & $\begin{array}{l}\text { Contextualiza } \\
\text { los contenidos }\end{array}$ & $5 / 13$ & $\begin{array}{l}\text { Sitúa oralmente } \\
\text { contenidos en } \\
\text { determinado } \\
\text { contexto socio- } \\
\text { histórico } \\
\end{array}$ & $5 / 13$ \\
\hline \multirow{3}{*}{$\begin{array}{l}\text { Propone } \\
\text { acciones } \\
\text { generales } \\
\text { para } \\
\text { facilitar la } \\
\text { tarea }\end{array}$} & \multirow{3}{*}{$16 / 91$} & \multirow{3}{*}{$\begin{array}{c}\text { Sugiere } \\
\text { consultar } \\
\text { distintas fuentes } \\
\text { ante dudas de } \\
\text { comprensión }\end{array}$} & \multirow{3}{*}{$16 / 16$} & $\begin{array}{c}\text { Recomienda } \\
\text { consultar al docente }\end{array}$ & $9 / 16$ \\
\hline & & & & $\begin{array}{c}\text { Recomienda } \\
\text { consultar línea de } \\
\text { tiempo }\end{array}$ & $5 / 16$ \\
\hline & & & & $\begin{array}{l}\text { Recomienda } \\
\text { consultar } \\
\text { diccionario } \\
\end{array}$ & $2 / 16$ \\
\hline
\end{tabular}

Tal como muestra la Tabla 9, en la definición del medio predominan las intervenciones docentes en las que se definen recursos de lectura (44/91). En relación con ello, notamos mayor cantidad de intervenciones en las que se requieren materiales (24/44) en comparación con las intervenciones en las que estos se brindan (20/44). Para definir la tarea 
(18/91), se dan más consignas para resolver en clase (10/18) que consignas domiciliarias (8/18). Otras 13 intervenciones (13/91) apuntan a establecer un trasfondo de significados comunes con los alumnos a través de organizar una memoria didáctica (8/13) y contextualizar los contenidos disciplinares (5/13). Si bien su número es menor en comparación con las otras intervenciones de definición del medio, cabe resaltar que se trata de intervenciones que involucran varios turnos de habla de los docentes y los estudiantes, por lo que ocupan mayor tiempo de clase. Finalmente, identificamos 16 propuestas de acciones generales para facilitar la tarea (16/91), en las que se sugiere consultar distintas fuentes ante posibles dudas de comprensión de los textos indicados para leer. A continuación describimos y ejemplificamos estas intervenciones docentes.

\subsubsection{Define la tarea}

Las tareas de aprendizaje que plantean los docentes especifican lo que los estudiantes tienen que hacer y, por tanto, condicionan sus comportamientos (Rickenmann, 2006).

En nuestro análisis, identificamos intervenciones docentes en las que se define la tarea de leer para responder cuestionarios a través de precisar qué consignas tienen que contestar los estudiantes y si deben hacerlo en clase o en los hogares. A lo largo de las clases analizadas, contabilizamos 18/91 intervenciones en las que los profesores de las tres asignaturas dan consignas relativas a la tarea (ver Tabla 9). La Tabla 10 muestra de qué modo se define la tarea en cada materia.

Tabla 10. Subcategoría e intervenciones docentes de la categoría "define la tarea"

\begin{tabular}{|c|c|c|c|c|}
\hline Subcategoría & Intervenciones docentes & $\begin{array}{c}\text { Total de } \\
\text { intervenciones }\end{array}$ & Asignatura & $\begin{array}{c}\text { Total de } \\
\text { intervenciones } \\
\text { por } \\
\text { asignatura } \\
\end{array}$ \\
\hline \multirow{3}{*}{ Da consignas } & \multirow{2}{*}{ Da consignas para resolver en clase } & \multirow{2}{*}{$10 / 18$} & $\mathrm{~B}$ & $6 / 10$ \\
\hline & & & $\mathrm{C}$ & $4 / 10$ \\
\hline & Da consignas domiciliarias & $8 / 18$ & A & $8 / 8$ \\
\hline
\end{tabular}

Tal como ilustra la Tabla 10, identificamos que los profesores de las Asignaturas B y $\mathrm{C}$ optan por dar consignas para resolver en clase, mientras que el docente de la Asignatura A da consignas domiciliarias. Procederemos a ilustrar con ejemplos estos dos modos de dar consignas. 
Como se mencionó, los profesores de las Asignaturas B y C solo dan consignas para realizar en el aula a través de escribirlas en el pizarrón, dictarlas o darlas en fotocopias. Así, diez de las 18 intervenciones en las que se define la tarea (10/18) corresponden a indicaciones de consignas para responder en clase. Incluimos en la Tabla 11 un ejemplo de estas intervenciones.

Tabla 11. Da consignas para resolver en clase. Fragmento de clase de la Asignatura $B$

Clase 12. El profesor introduce oralmente el tema del Acuerdo de Libre Comercio de las Américas (ALCA), enmarcándolo como un bloque regional.

Interacciones $^{23}$

1. DB (Docente Asignatura B): $[14 \min 38 \mathrm{~s} / 43 \mathrm{~min} 6 \mathrm{~s}]^{24}$ Vamos a anotar unas cositas, dale [alienta a los estudiantes a copiar dos consignas que comienza a escribir en el pizarrón: "Explicar las características del Mercosur" y "Explicar cómo se formó la Unión Europea". Luego entrega manuales de Geografía que trae de la biblioteca escolar para que los estudiantes respondan].

[Mientras copian en sus carpetas, el docente conversa con los estudiantes. Cuando terminan de copiar, los alumnos abren los manuales y comienzan a leer. El clima del aula es de silencio. Surgen algunas consultas que el profesor responde acercándose a los bancos de los estudiantes].

Como ejemplifica la Tabla 11, registramos que cuando en las Asignaturas B y C se define la tarea con consignas para resolver en clase, los estudiantes se disponen a leer los materiales para contestarlas. En relación con estas consignas, el docente B afirma en la entrevista que las propone debido a que:

DB: Hay una realidad, los chicos por diferentes particularidades, no es que se llevan el libro y

leen. [...]. La lectura por la lectura misma se hace en el aula, vos lo habrás visto.

Este profesor, al igual que su colega de la Asignatura C, decide solo proponer tareas para efectuar en clase basándose en el conocimiento de que ciertas situaciones de vida de los alumnos dificultarían que lo hagan en sus hogares.

Contrapongamos a las consignas para resolver en clase, aquellas que se indican contestar en forma domiciliaria. Este modo de dar consignas fue registrado en ocho intervenciones de definir la tarea (8/18), y solo en clases de la Asignatura A. El docente de esta materia propone a los estudiantes cuestionarios que han de responder en sus hogares, y

\footnotetext{
${ }^{23}$ Entendemos por interacción, siguiendo al sociólogo Erving Goffman (1997, p. 27), "la influencia recíproca de un individuo sobre las acciones del otro cuando se encuentran ambos en presencia física inmediata". Por ello, en las tablas que presentan fragmentos de clase describimos las intervenciones verbales y no verbales de los docentes y los estudiantes, y las numeramos para, de ser necesario, referirnos a ellas en el análisis. Buscamos, de esta manera, ilustrar que la acción didáctica es necesariamente conjunta (Sensevy, 2007).

${ }^{24}$ En las tablas que reproducen fragmentos de clase detallamos entre corchetes la hora de comienzo de la intervención analizada y la hora total del audio grabado de la clase.
} 
traer resueltos de una clase a otra, o entregarse a modo de trabajos prácticos en determinada fecha. La Tabla 12 presenta un fragmento de clase que ilustra estas intervenciones.

Tabla 12. Da consignas domiciliarias. Fragmento de clase de la Asignatura $A$

Clase 1. Hacia el final de la hora, el docente solicita que, para la próxima clase, lean el texto "Los mitos de la historia argentina" del historiador Felipe Pigna, que figura en el cuadernillo de la materia.

\section{Interacciones}

1. DA (Docente Asignatura A): [50 min/60 min] [Habla parado desde el centro del aula] Tienen que leer para la próxima, [el texto de] Felipe Pigna, "Los mitos de la historia argentina".

2. Daiana: ¡Qué calor! [se refiere a la temperatura del ambiente].

3. DA: Sí, hace calor acá [en el aula] Les decía chicos, que la próxima clase traigan leído y hecho [se refiere a responder las preguntas del cuestionario que figura en el cuadernillo] este texto de Felipe Pigna, "Los mitos de la historia argentina".

[Los estudiantes comienzan a conversar sobre temas ajenos a la materia hasta que suena el timbre del recreo. En clases posteriores, el docente otorga tiempo para leer y responder el cuestionario sobre el texto de Felipe Pigna, dado que los estudiantes reconocen no haberlo hecho en sus hogares.]

Las intervenciones de dar consignas domiciliarias, ilustradas en la Tabla 12, no parecen fomentar por sí mismas la lectura extra-clase. De hecho, la mayoría de los estudiantes en las entrevistas, e incluso durante las clases observadas, reconoce no haber leído ni respondido los cuestionarios en sus casas.

Este encargo de lectura en los hogares, pese a no ser cumplido por los estudiantes, tiene para el docente de la Asignatura A un objetivo orientador. Tal como afirma este profesor en la entrevista, la lectura domiciliaria pedida a los alumnos permitiría que tomasen la palabra en la clase siguiente y se expresaran acerca de los temas.

DA: La intención de la materia es leer la bibliografia, me parece. Antes [de venir a clase] darle una leída a la bibliografía y venir [y poder decir]: “Bueno, a ver, ¿qué leyeron?”. Esto es lo que quiero lograr [en los alumnos] [...]. Hay que leer en la casa, traer el texto leído, me parece que es así.

E (Entrevistadora): [...] ¿Y cuáles pensás que son las causas de las dificultades de escritura?

DA: La no lectura, la no socialización de las lecturas, no hablarlos en clase. [...] Lo que pasa es que a veces uno [el docente] tiene que generar como el espacio para que ese alumno pueda expresarse. O sea, escucharlo y no hablar tanto uno, porque a veces uno siempre habla, habla, habla. Ahi [cuando los alumnos se expresan] es donde me parece que se enriquece [el aprendizaje].

Según este extracto de entrevista, el profesor de la Asignatura A busca relevar en clase las interpretaciones producto de esa lectura en los hogares, es decir, que los estudiantes puedan "expresarse" acerca de los temas y poder "escucharlos", para lo cual es necesario "no hablar tanto uno", como docente. 
Esta idea de dar la palabra a los alumnos sobre lo que leen, de permitirles que expresen sus interpretaciones de los textos, ofrece una potencialidad epistémica destacada por la bibliografía. Dar lugar a distintos puntos de vista, en línea con las investigaciones de Dysthe $(1996,2013)$, puede promover intercambios dialógicos en los que las perspectivas se enfrenten y den lugar a nuevos significados. En modo similar, Wells (1993) halla que las discusiones sobre lo leído pueden promover clarificaciones y el desarrollo de la propia comprensión sobre el contenido. No obstante, y tal como se indicó anteriormente, los estudiantes, cuando se les asignan consignas para responder en sus hogares, no llevan a cabo la tarea pedida, por lo que estos intercambios no pueden generarse.

Hasta aquí hemos descrito dos modos de dar consignas para definir la tarea, que identificamos en las 32 clases analizadas y conforman un total de 18 intervenciones: da consignas para resolver en clase y da consignas domiciliarias. Al analizar la respuesta de los alumnos a estos modos de dar consignas encontramos que la mayoría de los estudiantes no responde los cuestionarios de la Asignatura A, única materia en la cual la tarea se pide realizar en las casas. Es probable que, por ese motivo, el docente, en la gestión del medio, modifique el tiempo y espacio previsto para la tarea y proponga leer y responder las preguntas en clase, lo que se mostrará en el apartado 6.2.2. Por el contrario, los profesores de las Asignaturas B y C plantean directamente leer en clase, a través de preguntas copiadas en el pizarrón, fotocopiadas o dictadas. En estos casos, los alumnos sí leen y completan los cuestionarios por escrito en sus carpetas.

Examinemos ahora qué afirman los estudiantes respecto de sus comportamientos ante estos dos modos de definir la tarea. A partir del análisis de las entrevistas, es posible identificar tres razones por las cuales los alumnos prefieren leer y responder cuestionarios en el aula: 1) en sus hogares no tienen tiempo ni espacio apto para llevarlo a cabo, 2) en clase pueden contar con un docente que los oriente y 3) no están acostumbrados a realizar esta tarea en sus casas.

En relación con el primer motivo señalado, cinco de los catorce alumnos que conforman el curso de quinto año afirman que sus condiciones de vida influyen en el hecho de que no lean en sus hogares.

Lorena: Por ahi [el profesor de la Asignatura A] nos manda a leer pero, bueno, en mi caso es un poco más complicado leerlo afuera, en mi casa. [...] Son otros tiempos los que uno tiene [...]. E: ¿Por eso decías que no llegabas con el tiempo, por tu hijo? 
Lorena: Claro, para leer se me complica mucho. [...] Durante el día [...] si leo me duermo [...]. Estoy todo el día [despierta] desde la seis de la mañana [debido a la necesidad de cuidar de su hijo de tres años].

Carla: Cuando tenés un hijo [...], tus tiempos no son los tuyos, digamos. [Su hermano menor] es como mi hijo más o menos. [...] Estás todo el día pendiente de lo que le pasa, [y de lo que] no le pasa.

Martín: Yo estoy parado [frenado con el estudio]. Desde que empecé a trabajar [...] me di vuelta [cambié]. [...] El tiempo que tenemos lo usamos, bah, yo lo uso para descansar.

E: Algunos de sus compañeros me decían que esto de hacerlo en clase [los cuestionarios] como que les viene mejor...

Martín: Sí, porque en casa no... [...]. Yo no tengo tiempo [...].

$\mathbf{E}:$ ¿Ustedes en sus casas estudian?

Lautaro: No. Yo no. [...] Hay veces que no tengo tiempo porque estoy con la nena [su hija] o porque me encargo de la moto [arregla su motocicleta] o voy a trabajar [trabaja ocho horas diarias haciendo servicio de delivery con su moto]. O hay veces que también me tiro [acuesto] a dormir.

Nadia: [...] Sí, yo también [...] mi nene le dio con un destapalatas [abrelatas] a la netbook, me la rompió, explotó la pantalla. [Si los profesores le dijeran] "Ponéte a estudiar", [les diría] "Sí, ponéte vos, [mi hijo] te va a romper todo”. [Ríe].

Estos alumnos coinciden en que no tienen tiempo para leer en sus casas por sus responsabilidades laborales o domésticas, como trabajar u ocuparse de sus hijos o hermanos menores. Afirman que, si poseen algún tiempo disponible, lo destinan a descansar.

Sin embargo, no todos los obstáculos que refieren los estudiantes a la hora de leer en sus hogares se vinculan con la escasez de tiempo y energía que pueden dedicar a la lectura tras haber cumplido con sus obligaciones laborales y/o responsabilidades familiares. Tal como afirman tres de los alumnos del curso (3/14), la ausencia de orientaciones que permitan superar las dificultades de comprensión de los textos y/o de las consignas es otro motivo por el cual no leen en sus casas. En efecto, según manifiestan, les resulta más productivo y preferible leer en clase, ya que es allí donde pueden consultar dudas con el docente y sus compañeros.

Yésica: ¿Viste que [el docente de la Asignatura B] nos hace hacer los trabajos acá [...]? Y está bueno [...] porque lo que no entendemos se lo preguntamos a él, y él nos explica y para mí es mejor hacerlo acá en la escuela. 
Lautaro: Hacerlos en clase es mejor porque si vos tenés alguna duda le preguntas a algún compañero o le preguntas al profe. Cosa que en tu casa no lo podés hacer.

Nadia: ¿A quién le vas a preguntar [las dudas]? ¿A tu mamá? Te va a sacar cagando [te echa]. Lautaro: [...] mi vieja [mamá] hizo hasta segundo año [del nivel secundario], ¿qué me podés ayudar? [Se refiere a su madre].

Nadia: No entiende nada, no, mi vieja tampoco, hizo hasta tercer año. [La otra vez] me faltaba una pregunta que [la respuesta] no la había marcado yo [en el texto] acá en clase. Solamente tenía que copiar y le pregunté a mi mamá y me dijo “Andá a preguntarle a tu tía”. Así que imagínate, pobre, no debe saber nada, nada, cero. [Sonríe].

Los estudiantes cuyos extractos de entrevista citamos sostienen que no tienen referentes de consulta en sus hogares. Nadia y Lautaro lo explican en referencia al nivel de escolaridad de sus madres: debido a sus trayectorias escolares interrumpidas, asumen que sus progenitoras no podrían ayudarlos en relación con temas que ellas mismas no lograron aprender.

Además de sus condiciones de vida y la imposibilidad de consultar dudas con el docente o compañeros, es posible pensar que algunos estudiantes no efectúan la lectura encargada para los hogares en vistas del contrato didáctico establecido en las materias de esta escuela. De acuerdo con lo que describen dos estudiantes en otros fragmentos de entrevista, en el curso de quinto año están acostumbrados solamente a lecturas en clase: "nosotros hacemos las cosas acá en el colegio. En casa no mandan a hacer nada" (Lautaro); "mayormente lo que tenemos que hacer, lo dan para hacer en la escuela" (Yésica). Dentro de este contrato didáctico, el comportamiento que esperan del profesor es que los ayude mientras leen en el aula. En ese sentido, que el docente de la Asignatura A encargue lectura para los hogares representa una ruptura de ese contrato didáctico. Podríamos hipotetizar así que, como afirma Sensevy (2007), "el peso de las costumbres" (p.10) contribuye a que los estudiantes no estén dispuestos a aceptar el nuevo "hábito de acción” (p.17) que propone este docente.

Ciertamente, es interesante advertir que, además del modo en que se propone responder consignas, otro factor condiciona el desarrollo de la tarea: el tipo de consignas indicadas. Aisenberg (2005a, 2010) muestra que las consignas influyen en la lectura que los estudiantes realizan. Tomando en cuenta ello, y a los fines de analizar cómo se define esta tarea en las asignaturas indagadas, interesa ahondar en los dos tipos de consignas que plantean contestar los cuestionarios de estas materias: consignas globales y consignas de localización. A continuación, detallamos sus particularidades y analizamos los argumentos que proporcionan los docentes para su selección. 
En las Asignaturas B y C la mayoría de las preguntas (dictadas, escritas en el pizarrón o facilitadas mediante fotocopias) pide identificar información puntual en los textos al igual que las consignas de descomposición descritas por Basuyau y Guyon (1994). Para contestar estas consignas alcanza con localizar y extraer del texto las partes requeridas (Aisenberg, 2004, 2005a, 2010; Carlino, 2005). La Tabla 13 reproduce ejemplos de estas consignas de localización y resalta con subrayado la igualdad o similitud con párrafos de los textos que los estudiantes tienen que leer en esas materias.

Tabla 13. Ejemplos de consignas de localización en las Asignaturas B y C

\begin{tabular}{ccc}
\hline $\begin{array}{c}\text { Materia y } \\
\text { clase en la que } \\
\text { se propuso }\end{array}$ & $\begin{array}{c}\text { Consigna } \\
\text { de localización }\end{array}$ & Texto fuente \\
& & \\
& & \\
& ¿Qué errores comete & Manual de \\
Asignatura B & el FMI, según este & Historia \\
Clase 1 & Premio Nobel & Mundial \\
& [Joseph Stiglitz]? & Contemporánea
\end{tabular}

\section{Párrafo del texto donde se localiza la respuesta}

"El FMI ha cometido errores en todas las áreas en las que ha incursionado: desarrollo, manejo de crisis y transición del comunismo al capitalismo. Los programas de ajuste estructural no aportaron un crecimiento sostenido ni siquiera a los países que como Bolivia, se plegaron a sus rigores; en muchos países, la austeridad excesiva ahogó el crecimiento, los programas económicos que tienen éxito requieren un cuidado extremo en su secuencia, el orden de las reformas y ritmo."

"La Unión Europea (UE) se ha ido construyendo por etapas, a partir de acuerdos

$\begin{array}{ccc}\text { Asignatura B } & \begin{array}{c}\text { Explicar cómo se } \\ \text { formó la Unión } \\ \text { Clase } 12\end{array} & \begin{array}{c}\text { Manual de } \\ \text { Europea }\end{array}\end{array}$
sectoriales (minería, energía), que luego se fueron unificando al crearse organizaciones supranacionales; esto es, instituciones que se hallan por encima de los Estados y que están integradas por sus representantes."

"No todos los territorios ofrecen las mismas posibilidades, de allí que sus clientes pueden optar según sus necesidades específicas. En función de las diferencias centrales, se pueden establecer tres modalidades básicas entre ellos: los paraísos físcales "clásicos"; los territorios de

¿Cuáles son las

Asignatura C modalidades básicas de los paraísos fiscales?
Módulo de Cultura Fiscal
En el impuesto a las

Asignatura C Clase 11 ganancias ¿qué contempla la ley acerca de los contribuyentes? elevada fiscalidad que ofrecen ventajas fiscales a personas $y$ entidades que ejercen sus actividades en el extranjero; finalmente, territorios que disponen de centros de servicios complejos (en cuanto a las telecomunicaciones, los bufetes para el asesoramiento a inversores, la disponibilidad de bases de datos, de conocimientos muy especializados necesarios para operar en la economía global y en especial, en las finanzas globales, entre muchos otros)."

"Asimismo, la Ley de Impuesto a las Ganancias establece una serie de disposiciones especiales que contemplan la situación personal y familiar de cada trabajador. Las personas que tienen ganancias por debajo de los valores previstos por la ley, no están alcanzados por el Impuesto a las Ganancias." 
A partir del análisis de los textos mayormente propuestos para leer en las Asignaturas B y C (manuales y módulos que se describirán en apartado 6.1.2) hallamos que las respuestas a las consignas de localización pueden ser fácilmente identificables en estos materiales. Se trata de preguntas que, tal como Dysthe (1996) analiza en clases del nivel secundario, se resuelven con la información disponible en los textos. En su formulación, estas consignas casi en su totalidad elaboradas por los docentes de estas materias- contienen las mismas palabras que los textos, lo que facilita el reconocimiento de las respuestas a través de una correspondencia término a término entre las preguntas y los párrafos del material (Aisenberg, 2004). Esto se asemeja a lo hallado por Rockwell (1995) en cuestionarios que plantean profesores de Ciencias Sociales del nivel primario, cuyas preguntas reproducen frases textuales de los libros, facilitando la localización de las respuestas.

Por el contrario, gran parte de las consignas propuestas en la Asignatura A apunta a la comprensión del sentido global del texto y/o su relación con otros materiales leídos (Aisenberg, 2004, 2005a, 2010; Carlino, 2005). Por este motivo, estas consignas demandan operaciones cognitivas más complejas: interpretar el texto, releer otros vistos anteriormente y relacionarlos, y elaborar una respuesta escrita producto de ello. La Tabla 14 ilustra ejemplos de estas consignas globales e indica las acciones que serían necesarias para contestarlas.

Tabla 14. Ejemplos de consignas globales en la Asignatura A

\begin{tabular}{|c|c|c|c|}
\hline $\begin{array}{l}\text { Clase en la } \\
\text { que } \\
\text { propuso }\end{array}$ & Consigna global & Texto fuente & $\begin{array}{c}\text { Acciones necesarias para } \\
\text { responder }\end{array}$ \\
\hline Clase 1 & $\begin{array}{l}\text { ¿Cómo influyen [en las } \\
\text { juventudes] la historia } \\
\text { y la tecnología? }\end{array}$ & $\begin{array}{l}\text { Cuadernillo de la materia } \\
\text { (Artículo periodístico "El difícil } \\
\text { arte de asir a la juventud" del } \\
\text { sociólogo Mario Margulis) }\end{array}$ & $\begin{array}{l}\text { Comprender cómo el autor, a lo } \\
\text { largo de todo el artículo, describe la } \\
\text { influencia de la historia y la } \\
\text { tecnología en las distintas } \\
\text { juventudes. }\end{array}$ \\
\hline Clase 5 & $\begin{array}{l}\text { ¿Qué significa cuando } \\
\text { [el autor] dice que hay } \\
\text { que remitirse a la } \\
\text { ideología, a los } \\
\text { proyectos políticos, al } \\
\text { pasado para } \\
\text { comprender el } \\
\text { presente? }\end{array}$ & $\begin{array}{l}\text { Cuadernillo de la materia } \\
\text { (Recorte de la introducción del } \\
\text { libro "Los mitos de la historia } \\
\text { argentina" del historiador } \\
\text { Felipe Pigna) }\end{array}$ & $\begin{array}{l}\text { Interpretar, a través de todo el } \\
\text { recorte, cómo el autor expone que } \\
\text { los ciudadanos argentinos conciben } \\
\text { la historia nacional, las } \\
\text { consecuencias de esto y la propuesta } \\
\text { que hace ante ello (relacionada con } \\
\text { comprender las distintas ideologías } \\
\text { y distinciones partidarias en la } \\
\text { historia y usar éstas para entender el } \\
\text { presente). }\end{array}$ \\
\hline Clase 7 & $\begin{array}{l}\text { Desde esa postura } \\
\text { ideológica } \\
\text { [darwinismo social], } \\
\text { ¿cómo se justifica la } \\
\text { pobreza? }\end{array}$ & $\begin{array}{c}\text { Cuadernillo de la materia } \\
\text { (Artículo periodístico "Pobres } \\
\text { habrá siempre") }\end{array}$ & $\begin{array}{l}\text { Comprender la postura ideológica } \\
\text { del "darwinismo social", } \\
\text { desarrollada a lo largo del artículo, y } \\
\text { cómo ésta justifica la pobreza. }\end{array}$ \\
\hline Clase 7 & $\begin{array}{l}\text { ¿Por qué motivos esta } \\
\text { propuesta [proyecto }\end{array}$ & $\begin{array}{l}\text { Cuadernillo de la materia } \\
\text { (Fragmentos del capítulo }\end{array}$ & $\begin{array}{l}\text { Comprender el proyecto económico } \\
\text { del ministro Gelbard, descripto en el }\end{array}$ \\
\hline
\end{tabular}




\begin{tabular}{ccc} 
del ministro de & "Proceso de acumulación y \\
economía José Ber & política económica en & texto y relacionarlo con el modelo \\
capitalista "hacia adentro". \\
$\begin{array}{c}\text { Gelbard] es coherente } \\
\text { con un modelo }\end{array}$ & $\begin{array}{c}\text { Argentina" del economista } \\
\text { Pedro Paz) }\end{array}$ \\
$\begin{array}{c}\text { capitalista "hacia } \\
\text { adentro"? }\end{array}$ & & \\
\hline
\end{tabular}

Como puede verse en la Tabla 14, las consignas propuestas en la Asignatura A requieren que los estudiantes entiendan conceptos o ideas centrales que los autores sostienen a través de todo un texto (por ejemplo, la influencia de la historia y la tecnología en las juventudes, la justificación de la pobreza desde una postura ideológica específica y el proyecto económico de Gelbard), y/o que los relacionen con temas anteriormente trabajados en clase (como el modelo capitalista "hacia adentro"). En cuanto a los textos indicados para leer, ningún párrafo contesta en forma directa estas consignas. Responderlas exige leer el texto en su totalidad, activar conocimientos previos, interpretar los argumentos que los autores utilizan para exponer sus ideas $y$, en ocasiones, releer otros materiales que permitan comprender mejor y ponerlos en relación.

En las entrevistas, los docentes brindan razones por las cuales optan por un tipo u otro de consignas en los cuestionarios. Según las afirmaciones del profesor de la Asignatura B, que presentamos subsiguientemente, la tarea de leer para responder preguntas de localización le permite valorar el cumplimiento de las pautas de trabajo por parte de los alumnos y adquiere otros sentidos a lo largo de los trimestres escolares.

\footnotetext{
DB: Uno puede suponer que el pibe [alumno] va a leer pero la intención es [...] yo poder verificarlo [...] a través de un cuestionario [...]. Las preguntas planteadas de ese trabajo del segundo trimestre englobaban a todo lo que habíamos trabajado en clase [...]. Para lo cual tenían que tener la carpeta completa, de manera tal que el hecho de estar [en clase] tuviese algún tipo de valor y el hecho de no venir pero pedir [a los compañeros] lo que se hizo, también [...]. En el tercer trimestre lo que se da es una gran deserción [se ausentan los estudiantes], [...] tenés cinco pibes un día [...]. Es muy dificil pretender una clase expositiva absoluta porque sino [a los alumnos ausentes] le hacés perder el hilo [la progresión de los temas]. [...] Entonces, [doy] trabajos prácticos que tienen que ver con un tema que sí explicamos [...], trabajos pequeños, cortos, con preguntas [...] que son de resolución diaria, [...] te implica la posibilidad de que el pibe tenga herramientas para poder resolverlos.
}

En la cita anterior el docente de la Asignatura B alega distintos motivos por los cuales decide plantear estos cuestionarios de localización a sus estudiantes. En principio, porque estos cuestionarios le permiten corroborar que los estudiantes han leído e intentado responder 
las consignas dadas. De este modo, el cuestionario funcionaría como instrumento de control del cumplimiento de la tarea. Además, el profesor afirma proponer estos cuestionarios en función del ausentismo escolar de estos estudiantes, abordado en el subapartado 4.2.1 del Capítulo 4, que se agravaría con el correr de los trimestres escolares. Según lo que este docente relata, en el segundo trimestre escolar indica consignas que pueden responderse con lo trabajado previamente en la materia. De ese modo, el profesor dice otorgar valor al hecho de asistir a clase y tener completa la carpeta o, en su defecto, pedir a los compañeros lo trabajado cuando se ausentan.

El agravamiento del ausentismo de los alumnos en el tercer trimestre parece ser una variable didáctica que otorga un nuevo sentido a la propuesta de cuestionarios de localización en la Asignatura B. Para no dictar nuevos contenidos en ocasiones en las que gran parte del curso se encuentra ausente, dado que "le hacés perder el hilo [a los alumnos ausentes]", en dicho trimestre el docente plantea actividades concisas sobre temas ya dados, pensadas para resolverse en la misma clase.

Distintos son los argumentos que brinda el profesor de la Asignatura A para proponer cuestionarios con consignas globales. De acuerdo con la entrevista realizada, a través de estos el docente intenta que los alumnos lean, interpreten y reflexionen sobre los contenidos del texto.

E: ¿Qué actividades das por ejemplo? Esto que yo vi [durante las observaciones], ¿preguntas que están en el cuadernillo [de la materia]?

DA: Si, preguntas que están en el cuadernillo [...], las actividades que están armadas. En el texto anterior [se refiere al texto "Los grupos sociales subalternos en la historiografía argentina", no incluido en el cuadernillo] también les hice un par de cuestionarios, [...] cómo aborda el autor el tema, cómo lo plantea [...]. Una lectura más crítica me parece que tenemos que hacer, reflexionar. Lo que quiero lograr es eso [...], intentar que interpreten el texto [...]. Porque a veces lo que pasa es que ellos leen pero [...] por ahí más abajo del texto sigue la explicación. Por eso yo les digo que hagan una lectura general de todo y después... te va a esclarecer un poco la idea [del autor].

En este extracto de entrevista el profesor de la Asignatura A menciona las consignas globales del cuadernillo de la materia y las enmarca dentro de su objetivo de que los estudiantes puedan, no solo dotar de significado al texto, sino también comprender la postura del autor y evaluarla. Para que puedan lograrlo, dice alentar a los alumnos a leer la totalidad del texto y evitar su lectura fragmentada. 
Estas diferencias que identificamos en los cuestionarios que proponen los docentes de las asignaturas son percibidas por cinco alumnos del curso $(5 / 14)$, quienes califican como "sencillo" responder las consignas de localización de las Asignaturas B y C, en oposición a contestar las consignas globales de la Asignatura A. Los siguientes extractos de entrevista lo evidencian:

Lorena: [En Asignatura B] por ejemplo tenemos el libro [se refiere a los manuales] y nos da las preguntas y las buscamos en el libro, ya está. No es una estructura que vos vas armando. Contestás las preguntas y está bien, no las tenés que... [No continúa la frase] o las podés copiar.

E: ¿Qué hacen con [nombra al profesor de la Asignatura B]?

Guadalupe: Y... trabajos, preguntas y entregar en el mismo día siempre.

E: ¿Y cómo son esas preguntas? ¿Te resultan fáciles?

Guadalupe: Más o menos. Depende el día de [nombra al profesor de la Asignatura B].

E: ¿Algunas veces te parecen complicadas las preguntas?

Guadalupe: Sí, pero no mucho, por ahí prestando atención...está como todo en el texto que él dice [indica leer].

E: ¿ $Y$ [qué hacen con] [nombra a la profesora de la Asignatura C]?

Guadalupe: Nos dicta y nos da preguntas.

E: ¿Y ustedes las responden con eso que tienen dictado?

Guadalupe: Claro, o sino con algo de la carpeta completa.

Fabiana: [En la Asignatura B, las respuestas a las consignas] lo tenemos en el libro, lo tenemos en la carpeta [...]. Así nos sale más sencillo hacerlo [el trabajo práctico].

E: Y cuando ustedes leen [en la Asignatura A] y me dicen que a veces no entienden, ¿por qué creen que no entienden?

Marisa: Y....no sé. Yo a veces leo y no entiendo.

Claudia: [...] algunas cosas de las palabras... lo que está en el libro. Te ponen una pregunta o lo buscás, no lo encontrás y no lo entendés. A mí me pone nerviosa.

E: ¿Las preguntas?

Claudia: Sí. Que yo lo busco y no lo encuentro en el libro. $Y$ [el profesor] te dice "Sí, está ahi" y yo lo busco y no lo encuentro.

Las alumnas Lorena, Guadalupe y Fabiana afirman que las respuestas a cuestionarios como los de la Asignatura B y C son fácilmente localizables en los materiales -lo que coincide con los datos mostrados en la Tabla 13- y que las consignas también pueden contestarse recurriendo a la carpeta, tal como asevera el docente de la Asignatura B en el 
extracto de entrevista citado anteriormente. En razón de ello, estas estudiantes sostienen que este tipo de consignas no comporta gran dificultad. Estas apreciaciones de las alumnas pueden relacionarse con el hecho de que las consignas de localización, al solicitar una modalidad de lectura superficial en la que es suficiente identificar y reproducir la información pedida (Aisenberg, 2005a, 2010; Benchimol, Carabajal y Larramendy, 2008; Lerner, Aisenberg y Espinoza, 2009), les resultarían fáciles de responder.

En sentido contrario, Marisa y Claudia dicen no poder identificar en los textos de la Asignatura A las respuestas a las consignas globales. En efecto, y tal como sostienen, para contestar preguntas globales, no es suficiente "buscar" y "encontrar" la respuesta sino que es necesario leer la totalidad del texto, poner en relación distintos materiales y construir una respuesta con base en lo que se ha logrado interpretar. Por estos motivos, estas consignas suelen presentar mayores dificultades para ser comprendidas y resueltas por los estudiantes (Aisenberg, 2010). Conjuntamente, tal como veremos en el apartado 6.1.2, los textos del cuadernillo de esta materia, al ser principalmente materiales de circulación social no destinados a estudiantes, omiten información porque dan por supuesto ciertos conocimientos de los lectores (Lerner, 2001; Lerner y otros, 1997), lo que dificulta que los alumnos comprendan las ideas allí planteadas.

Estas diferencias que los estudiantes divisan también pueden relacionarse con el grado de experiencia que tienen con un tipo de consigna $u$ otro. Tal como muestran fragmentos de entrevista a continuación, los alumnos están acostumbrados a responder consignas de localización como las que se asignan en las Asignaturas B y C. De ahí se infiere que responder estas consignas representa un hábito usual en los contratos didácticos establecidos en gran parte de las asignaturas de esta escuela. En cambio, las consignas globales que se indican contestar en la Asignatura A aparecen como un elemento no conocido (Rickenmann, 2007) en la tarea de leer para responder cuestionarios. Cinco alumnos del curso (5/14) comentan al respecto en las entrevistas:

Carla: En muy pocas [materias] leés.

Lorena: $[\ldots]$ tanto leer $[\ldots]$ o tener que tener que comprender un texto, no lo tenemos [que hacer]. Solamente en esta materia [se refiere a la Asignatura A]. [...] En realidad no estamos acostumbrados $[\ldots]$ a analizar textos.

Yesica: [El docente de la Asignatura A] lo que quiere es como que amplíes mucho [...] las respuestas [...]. Bueno, eso cuesta un poco. Porque nosotros no leemos mucho [...], no estamos acostumbrados a leer [...], me cuesta explicarlo ahí [en el trabajo práctico], así escribiéndolo. 
Denise: Lo que pasa es que tampoco estamos, bah, yo por lo menos, acostumbrados [...] a leer, ¿entendés? [...]. Acá [en la escuela] mucho no... como que no leíamos, ni siquiera en Lengua.

Daiana: [El profesor de la Asignatura A] Él sí, nos da a leer un montón, y nosotros no estamos acostumbrados a leer.

E: Claro, ¿ustedes dicen que es el que más les hace leer?

Daiana: Sí.

[...] E: ¿Y [en las Asignaturas B y C] cómo son los trabajos?

Daiana: Tranqui.

E: ¿Tranquilos?

Daiana: No son difíciles.

E: ¿Qué les preguntan por ejemplo?

Daiana: Cosas sobre la materia o del tema que estamos viendo.

E: Y eso digamos, ¿les resulta fácil hacerlo?

Daiana: Sí.

E: Ajá, ¿y en la escuela siempre les pidieron que escriban estas cosas o les pedian otras cosas distintas?

Daiana: No, siempre.

En los extractos de entrevista precedentes, Daiana comenta que los trabajos prácticos de las Asignaturas B y C "no son difíciles" y que constan de preguntas acerca de "cosas sobre la materia o del tema que estamos viendo". Respecto de la Asignatura A, coincide con sus compañeras en que en el curso no están "acostumbrados" a realizar las actividades que allí se piden. Las alumnas afirman que esa materia requiere leer textos extensos, a diferencia de otras asignaturas que tienen o han tenido en la escuela. Asimismo, las estudiantes mencionan que en dicha materia tienen que abordar los textos de un modo con el cual no están familiarizados: "comprender", "analizar" y "explicarlo" a través de respuestas en las "que amplíes mucho". Esta forma de abordaje de textos, referida como novedosa por los alumnos dentro del contrato didáctico, remite a la exigencia de las consignas globales de leer todo el material, activar conocimientos previos, interpretar los argumentos de los autores y construir una respuesta.

A partir de lo analizado hasta aquí, podemos concluir entonces que, para definir la tarea, los profesores de las asignaturas indagadas dan consignas para resolver en clase y consignas domiciliarias. A su vez, las consignas dadas a través de esas intervenciones son de distinto tipo según la materia. En las Asignaturas B y C se plantean consignas de localización para contestar en clase, que los estudiantes consideran sencillas y a las cuales están 
habituados. Sus respuestas pueden identificarse fácilmente en porciones específicas de los manuales y módulos, a partir de la similitud de términos entre las preguntas y los párrafos. El docente de la Asignatura B sostiene que, a través de estas consignas que suelen formularse respecto a temas ya vistos, controla el cumplimiento de la tarea por parte de los alumnos, otorga importancia el hecho de asistir a clases y tener la carpeta completa, y evita que aquellos estudiantes ausentes se pierdan la presentación de un nuevo tema. Por su parte, el profesor de la Asignatura A, dado que busca que los alumnos interpreten y reflexionen sobre materiales de circulación social incluidos en el cuadernillo de la materia, plantea consignas globales para contestar en las casas, que requieren la construcción de ideas globales, explicaciones o relaciones. Los estudiantes dicen no estar acostumbrados a leer de ese modo y refieren dificultades para realizar la tarea en sus hogares.

En el próximo subapartado presentamos la categoría "define recursos de lectura" en la cual profundizamos cómo, en la definición del medio, se brindan o se requieren materiales de lectura para la tarea de leer para responder cuestionarios.

\subsubsection{Define recursos de lectura}

En esta categoría, se engloban intervenciones en las que los docentes definen los recursos de lectura para llevar a cabo la tarea: a) requieren o b) brindan materiales bibliográficos a los alumnos.

En las clases analizadas, tal como anticipó la Tabla 9, identificamos 44 intervenciones en las que se delimitan recursos de lectura en la definición del medio (44/91). La Tabla 15 muestra dos modos en que los profesores requieren materiales a los estudiantes (preguntan si han traído a clase sus propios materiales y piden a quienes se ausenten fotocopiar textos) y tres modos mediante los cuales brindan materiales (entregan material de lectura de la biblioteca o fotocopias, escriben definiciones teóricas en el pizarrón para que alumnos lean y copien, y facilitan su bibliografía a aquellos que no la han traído).

Tabla 15. Subcategorías e intervenciones docentes de la categoría “define recursos de lectura”

\begin{tabular}{|c|c|c|c|c|c|}
\hline Subcategoría & $\begin{array}{c}\text { Total de } \\
\text { intervenciones }\end{array}$ & $\begin{array}{l}\text { Intervenciones } \\
\text { docentes }\end{array}$ & $\begin{array}{c}\text { Total de } \\
\text { intervenciones }\end{array}$ & Asignatura & $\begin{array}{c}\text { Total de } \\
\text { intervenciones } \\
\text { por asignatura }\end{array}$ \\
\hline \multirow{2}{*}{$\begin{array}{l}\text { Requiere } \\
\text { material de } \\
\text { lectura }\end{array}$} & \multirow[b]{2}{*}{$24 / 44$} & $\begin{array}{l}\text { Pregunta si han } \\
\text { traído a clase su } \\
\text { propio material }\end{array}$ & $19 / 24$ & A & $19 / 19$ \\
\hline & & $\begin{array}{l}\text { Pide a quienes se } \\
\text { ausenten } \\
\text { fotocopiar } \\
\text { material }\end{array}$ & $5 / 24$ & B & $5 / 5$ \\
\hline
\end{tabular}




\begin{tabular}{|c|c|c|c|c|c|}
\hline \multirow{4}{*}{$\begin{array}{l}\text { Brinda material } \\
\text { de lectura }\end{array}$} & \multirow{4}{*}{$20 / 44$} & Entrega material & & B & $8 / 10$ \\
\hline & & $\begin{array}{c}\text { biblioteca o } \\
\text { fotocopias de } \\
\text { textos }\end{array}$ & $10 / 20$ & $\mathrm{C}$ & $2 / 10$ \\
\hline & & $\begin{array}{c}\text { Escribe } \\
\text { definiciones } \\
\text { teóricas en el } \\
\text { pizarrón para leer } \\
\text { y copiar } \\
\end{array}$ & $6 / 20$ & $\mathrm{C}$ & $6 / 6$ \\
\hline & & $\begin{array}{c}\text { Facilita su } \\
\text { bibliografía a los } \\
\text { alumnos que no la } \\
\text { han traído }\end{array}$ & $4 / 20$ & A & $4 / 4$ \\
\hline
\end{tabular}

De acuerdo con lo presentado en la Tabla 15, podemos anticipar que en las clases de las Asignaturas B y C mayoritariamente se brindan materiales de lectura. Solamente se requieren materiales -fotocopiar textos- en algunas clases de la Asignatura B. En oposición a ello, en gran parte de las intervenciones donde se definen recursos de lectura en la Asignatura A, se requiere trabajar con el propio material.

Observamos que, en las ocasiones en que se facilitan materiales de lectura para leer y responder cuestionarios, los estudiantes se disponen a cumplimentar la tarea. En cambio, la mayoría de los alumnos no realiza la tarea cuando se les requieren materiales: no llevan a clase sus cuadernillos ni fotocopian textos pedidos. Los próximos subapartados presentan ejemplos de estas intervenciones y analizan los comportamientos de los estudiantes ante ellas.

\subsubsection{Requiere material de lectura}

En la categoría "define recursos de lectura", identificamos 24 intervenciones en las que los docentes requieren material de lectura $(24 / 44)$ de los siguientes modos: a) preguntan si han traído a clase los propios textos y b) piden a quienes se ausenten fotocopiar material de lectura.

Registramos que la mayoría de las intervenciones en las que se solicita material de lectura son efectuadas por el docente de la Asignatura A (19/24), al preguntar a sus estudiantes si han traído a clase el cuadernillo de la materia que, a comienzos del año lectivo, indica fotocopiar. Gran parte de los estudiantes del curso, ante estas intervenciones, informa que no trajeron a clase el cuadernillo, tal como ejemplifica la Tabla 16. 
Tabla 16. Requiere material de lectura: pregunta si han traído a clase su propio material. Fragmento de clase de la Asignatura $A$

Clase 8. Al comienzo de la clase, el docente consulta si trajeron el cuadernillo a clase para comenzar a leerlo.

\section{Interacciones}

1. DA: [ $8 \mathrm{~s} / 1 \mathrm{~h} 4$ min $45 \mathrm{~s}$ ] [A Claudia] iVos trajiste el material?

2. Claudia: Sí, lo que pasa es que hubo un accidente.

3. DA: ¿Qué pasó?

4. Daiana: Se lo comió el perro, se lo dejó en partes.

5. Claudia: No sé cómo, es chiquito [el perro], subió [a la mesa] y se lo comió.

6. DA: ¿Querés que te traiga [fotocopie] otro [cuadernillo]?

7. Claudia: Sí, profe.

8. DA: [...] Carla, ¿[trajiste] texto, carpeta, [no trajiste] nada?

9. Carla: No.

10. DA: ¿Querés ir a buscarlo [a tu casa]? [ofrece a la alumna, que vive en la escuela con su familia ya que su madre es la portera de la institución, que busque el material de su casa y retorne al aula].

11. Carla: Es que no sé dónde está [el cuadernillo].

12. DA: Pero vos estas [vivís] acá.

13. Carla: Sí, pero no encuentro el cuadernillo.

14. DA: ¿Cómo vas a hacer el trabajo [práctico]? ¿Vas a pedir [prestado el cuadernillo]?

15. Carla: No, lo voy a buscar [se refiere a que seguirá buscándolo cuando vuelva a su casa]. [A continuación, otras alumnas llaman al docente para efectuarle consultas acerca de lo que están leyendo en el cuadernillo].

La Tabla 16 ilustra cómo el docente de la Asignatura A requiere el cuadernillo a Claudia y Carla, que se excusan por no tenerlo en clase. Como se verá en el subapartado 6.1.2.2, estas intervenciones en las que el docente pregunta si trajeron a clase el material, preceden a otras en las que resuelve prestar su propia bibliografía para que quienes no tengan el cuadernillo puedan trabajar en clase.

Las restantes cinco intervenciones en las que se requiere material en las clases analizadas (5/24) corresponden a pedidos del docente de la Asignatura B para que los alumnos que se han ausentado a clase, o sepan que faltarán determinado día, fotocopien el material de lectura que se trabaja en el aula. En la Tabla 17 mostramos un ejemplo de este modo de requerir material de lectura.

Tabla 17. Requiere material de lectura: pide a quienes se ausenten fotocopiar material. Fragmento de clase de la Asignatura $B$

Clase 16. El docente trae a clase fotocopias de un artículo periodístico titulado "De la gesta que enterró el ALCA a la construcción de la UNASUR". Indica a los alumnos que comiencen a leerlo mientras escribe un cuestionario de cuatro preguntas en el pizarrón.

\section{Interacciones}

1. DB: $[22 \mathrm{~s} / 38 \mathrm{~min} 21 \mathrm{~s}]$ Bueno, el trabajito que vamos a hacer hoy...

2. Ernesto: [Interrumpe] Yo no tengo el anterior [se refiere al artículo periodístico trabajado la clase previa, en la que estuvo ausente].

3. DB: A ver, se lo había dejado a Osvaldo [auxiliar docente], le voy a ir dejando a Osvaldo los trabajos que vamos a ir haciendo [se refiere a las fotocopias de los artículos periodísticos que trabajarán en clase], [él] los va a tener en un folio. Si alguno no viene [a clase], se lo pide.

4. Nadia: Bueno, entonces le pido a Osvaldo.

5. Fabiana: Dejáselo a Amalia [preceptora del curso] también.

6. DB: Los voy dejando abajo [en la preceptoría], por si faltan [a clase]. [Luego entrega fotocopias del artículo periodístico para trabajar en clase y copia en el pizarrón las consignas del cuestionario. Tras 
copiarlas en sus carpetas, los estudiantes empiezan a leer el texto].

7. Lautaro: ¿El otro trabajo [dónde está]? [se refiere al trabajo realizado la clase previa, en la que estuvo ausente].

8. DB: Pedíselo mañana a Amalia, yo le aviso a Osvaldo que lo busquen. Tiene la consigna atrás. [Los alumnos continúan trabajando con el cuestionario].

En la Tabla 17, el docente de la Asignatura B pide a los estudiantes que estuvieron ausentes -0 se ausentarán- valerse de los materiales trabajados en clase (en este caso, fotocopias de artículos periodísticos) y, para ello, indica que dejará copias a un auxiliar docente y a la preceptora del curso. En estas intervenciones, el profesor parecer tener conocimiento y prever la problemática del ausentismo a clase, común en los estudiantes del curso (ver subapartado 4.2.1 del Capítulo 4). No obstante, de acuerdo con los datos analizados de los registros de clase, los estudiantes, con excepción de Fabiana y Guadalupe, si bien consultan al respecto, no fotocopian los materiales de lectura indicados por el docente.

\subsubsection{Brinda material de lectura}

Esta subcategoría se diferencia de la anterior debido a que presenta intervenciones en las que los docentes no requieren material de lectura a los alumnos, sino que lo facilitan ellos mismos durante las clases.

Agrupamos bajo la categoría "define recursos de lectura", 20 intervenciones en las que los profesores brindan textos para que los estudiantes lean y respondan cuestionarios (20/44), que distinguimos en los tres siguientes modos: a) entrega material de lectura de la biblioteca o fotocopias, $b$ ) escribe definiciones teóricas en el pizarrón para que alumnos lean y copien, y c) facilita su bibliografía a los estudiantes que no la han traído.

En la mitad de las intervenciones en las que se brinda material de lectura (10/20), los docentes de las Asignaturas B y $\mathrm{C}$ entregan materiales provenientes de la biblioteca u ofrecen fotocopias de textos. La Tabla 18 muestra un ejemplo de cómo se definen recursos de lectura en la tarea de leer para responder cuestionarios a través de la entrega de materiales.

Tabla 18. Brinda material de lectura: entrega material de lectura de la biblioteca o fotocopias de textos. Fragmento de clase de la Asignatura $B$

Clase 7. El profesor copia en el pizarrón consignas de un trabajo práctico sobre globalización. Indica buscar las respuestas en la carpeta de la materia y en manuales de Historia Mundial Contemporánea que trae de la biblioteca escolar.

\section{Interacciones}

1. DB: $[20 \mathrm{~s} / 45 \min 39 \mathrm{~s}]$ Bueno, voy a copiar las consignas del trabajo, mientras ustedes copian la consigna voy a buscar los textos a la biblioteca, con el trabajito este cerramos el segundo trimestre. [Copia en el pizarrón las siguientes consignas: “1) Explicar el proceso de globalización a. características-antecedentes, b. centro-periferia-países beneficiados, c. consecuencias, 2) Explicar qué es la deuda externa, a. Cuáles son los organismos de crédito, b. Cuál es el objetivo de los créditos. c. ¿Qué consecuencias trae a los países de la periferia?, d. En Argentina: cómo y cuándo se amplió la deuda externa”. Luego de copiarlas, 
se dirige a la biblioteca escolar, trae ejemplares de los manuales y entrega uno a cada estudiante, sin indicar qué página leer. Los alumnos comienzan a hojearlos, algunos lo hacen de a pares y otros en forma individual].

Tal como ilustra la Tabla 18, cuando los profesores de las Asignaturas B y C brindan manuales de la biblioteca escolar o fotocopias de textos, los estudiantes del curso comienzan a leerlos para responder las consignas de localización pautadas. Cabe resaltar que, tras estas intervenciones, los materiales tienen diferente lugar de destino: las fotocopias permanecen en las carpetas de los estudiantes mientras que los manuales provenientes de la biblioteca, una vez finalizada la clase, son devueltos allí por el docente que los retiró.

Otro modo que registramos de brindar recursos de lectura para la tarea, únicamente en la Asignatura $\mathrm{C}$, es a través de escribir definiciones teóricas en el pizarrón, para los estudiantes lean y copien en sus carpetas y, posteriormente, las usen para contestar los cuestionarios. En las seis ocasiones en que la profesora de esta materia escribe estas definiciones (6/20), no hace referencia oral ni especifica en el pizarrón los textos fuente a partir de los cuales las transcribe. De acuerdo con nuestras observaciones, las definiciones provienen del mismo módulo escolar del que brinda fotocopias para que los estudiantes lean. Notamos que, ante estas intervenciones, los alumnos copian en silencio y se valen de esas definiciones como material de lectura para contestar cuestionarios, tal como muestra la Tabla 19.

Tabla 19. Brinda material de lectura: escribe definiciones teóricas en el pizarrón para leer y copiar. Fragmento de clase de la Asignatura $C$

Clase 10. Antes de comenzar la clase, los estudiantes piden tiempo a la docente para confeccionar su bandera de egresados. La profesora accede a lo solicitado, con la condición de que, previamente, copien definiciones sobre capacidad contributiva y patrimonio, que escribe en el pizarrón.

\section{Interacciones}

1. DC: [ $5 \min 22 \mathrm{~s} / 53 \min 2 \mathrm{~s}$ ] [Copia en el pizarrón: "Capacidad contributiva. Esta teoría nos dice quienes pagan impuestos y cuanto deben pagar. Cada individuo pagará impuestos en base a= Patrimonio, Renta, Gasto, o Consumo. Parámetro patrimonio: ¿Quién debe pagar? Los que más tienen ¿Cuál es el impuesto? Impuesto a los bienes personales. Este impuesto lo pagan aquellas personas que el conjunto de sus bienes al 31/12 de cada año, supera los $\$ 305.000$. El sujeto deberá tributar por el excedente"].

[Los estudiantes copian en silencio en sus carpetas y luego se disponen a trabajar con la bandera de egresados. En la clase siguiente, utilizan las definiciones copiadas de capacidad contributiva y patrimonio para responder un cuestionario que la profesora entrega en una fotocopia. Vuelven a leer de sus carpetas para contestar las preguntas].

En la Tabla 19 puede verse que la docente de la Asignatura C establece ciertas definiciones teóricas como material de lectura para la tarea de leer para responder cuestionarios. Los estudiantes las copian en sus carpetas y vuelven a leerlas a la clase siguiente para contestar preguntas de localización. 
El tercer y último modo que registramos de brindar recursos de lectura es facilitar la propia bibliografía del docente, lo que sucede solo en clases de la Asignatura A (4/20). Interesa subrayar que se trata de intervenciones ad hoc dado que, a diferencia de las otras dos descritas (entrega material de lectura de la biblioteca o fotocopias de textos y escribe definiciones teóricas en el pizarrón para leer y copiar) que se planifican de antemano, éstas se llevan a cabo para dar solución el hecho de que los estudiantes no llevan a clase su propio material de lectura (ver subapartado 6.1.2.1). Reiteramos al lector que, durante el período de clases observado, gran parte de los estudiantes asiste a la escuela sin su propio cuadernillo de la materia, argumentando haberlo perdido ("Yo sinceramente no sé dónde está"), olvidado ("me olvidé", "no lo traje, salí apurada", "hoy salí rápido de casa) o no haberlo llevado a clase por otras razones ("no tenía lugar [en la mochila]", "no lo traje porque como estaba lloviendo se iba a mojar"). Ante estas situaciones, observamos que el profesor presta su propio cuadernillo e indica a los estudiantes que no lo han traído que, para efectuar la tarea, se agrupen en torno a dicho material. La Tabla 20 ofrece un ejemplo de estas intervenciones.

Tabla 20. Brinda material de lectura: facilita su bibliografia a los alumnos que no la han traído. Fragmento de clase de la Asignatura $A$

Clase 1. Al comenzar la clase, el docente pregunta si respondieron el cuestionario sobre el texto "El difícil arte de asir a la juventud" del sociólogo Mario Margulis, incluido en el cuadernillo de la materia. Contestar ese cuestionario había sido una tarea encomendada para realizar en el hogar. Cuando los alumnos responden negativamente, propone que en dicha clase lo lean y contesten las preguntas.

\section{Interacciones}

1. DA: [ $5 \mathrm{~min} / 60 \mathrm{~min}$ ] [Al iniciar la clase, se encuentra en el aula la mitad de los alumnos que conforma el curso. No se observan textos sobre sus bancos]. Bueno, saquen, ¿dónde van a escribir hoy? Saquen la carpeta, el cuadernillo, todo. [Carla, Daiana, Lorena y Fabiana extraen el cuadernillo de sus mochilas. Marisa y Claudia abren sus netbooks mientras que Ernesto coloca su carpeta sobre el banco]. Chicos [dirige su mirada a Marisa, Claudia y Ernesto], [...] ¿No trajeron el cuadernillo?

2. Marisa: [En voz baja] Yo sinceramente no sé dónde está. [...] No sé dónde lo tengo [Algunos alumnos ríen].

3. DA: ¿Cómo no sabés dónde lo tenés?

4. Claudia: Yo sí lo tengo, pero no tenía lugar [en la mochila, para traerlo].

5. Marisa: Traje la plata igual [para que el docente le fotocopie otro ejemplar] [...] pero lo busqué, lo busqué.

6. DA: [...] Les doy este cuadernillo. A ustedes les doy este cuadernillo [Acerca su propia bibliografía al sector del aula en el que se encuentran Claudia, Marisa y Ernesto].

[Los alumnos que recibieron el cuadernillo comienzan a leer el texto indicado. El resto de los estudiantes lee en voz baja de sus materiales].

Como muestra la Tabla 20, a pesar de concurrir frecuentemente sin el cuadernillo a clase, observamos que cuando los estudiantes reciben la bibliografía del docente, empiezan a leer el texto indicado para responder los cuestionarios.

En relación con las 44 intervenciones docentes agrupadas bajo a la categoría "define recursos de lectura" (ver Tabla 15), podemos concluir que los estudiantes se disponen a leer y 
responder los cuestionarios cuando los profesores brindan textos y no lo hacen cuando estos requieren textos. Respecto a la tenencia de los materiales, podemos efectuar otra observación. Nótese que cuando se prestan a los estudiantes textos de la biblioteca escolar pero se devuelven finalizada la clase -y no se los vuelve a entregar en la siguiente- la posibilidad de releerlos y completar la tarea en el aula se dificulta. Esto no sucede en las ocasiones en que se brindan fotocopias de textos o se escriben definiciones teóricas para copiar del pizarrón, dado que estos materiales permanecen en las carpetas de los estudiantes, por lo que podría recurrirse a ellos en otras clases. Esta posibilidad, que también ofrece el cuadernillo de la Asignatura A que los estudiantes tienen fotocopiado, sin embargo, se obstaculiza debido a que la mayoría de ellos no lo lleva a las clases.

En este punto del análisis, habiendo descrito el modo en que se definen recursos de lectura, nos interesa detenernos en las características de los distintos materiales propuestos para leer y en los motivos de su selección por parte de los profesores. Ahondando en ello, buscamos describir qué textos se dan para leer, por qué se los elige y cómo su materialidad puede influir en las maneras de leerlos.

Advertimos que en las Asignaturas B y C los profesores proponen fundamentalmente la lectura de textos escolares: manuales y módulos, producidos y dirigidos especialmente para alumnos del nivel secundario.

Específicamente en la Asignatura B (Geografía Económica) se trabaja con dos manuales: uno de Historia Mundial Contemporánea ${ }^{25}$ y otro de Geografía ${ }^{26}$. El primero presenta diversos capítulos sobre el estudio de la historia, la consolidación de poder político y económico de la burguesía, la construcción de las naciones, la expansión del capitalismo, las guerras mundiales, el mundo de posguerra y el mundo global. El segundo aborda temas tales como los procesos de integración y bloques económicos, el manejo de los recursos naturales, los problemas ambientales globales y los intercambios comerciales en la economía global. La selección de estos manuales -y los contenidos disciplinares que proponen- pueden dar indicios de la perspectiva epistemológica del profesor. Parece primar en este docente un enfoque de la Geografía que excede la clasificación y descripción de espacios e incluye la acción humana para que los estudiantes entiendan razones y causas de las configuraciones territoriales (Finocchio y García, 1995; Gurevich, 1994, 1998). Al mismo tiempo, la elección de este profesor de trabajar con un contenido como bloques regionales -lo cual fue observado en las clases- indicaría que adopta para la enseñanza de su materia una perspectiva de

\footnotetext{
${ }^{25}$ Eggers-Brass, T. y Gallego, M. (2005). Historia Mundial Contemporánea. Buenos Aires: Maipué.

${ }^{26}$ Barros, C. (Coord.) (2005). Geografía. La organización del espacio mundial. Buenos Aires: Estrada.
} 
integración regional, alejada de los enfoques curriculares predominantes que dan primacía a la noción de Estado (Denkberg y Fernández Caso, 2004).

Aunque mayoritariamente este profesor propone a los estudiantes leer estos dos manuales escolares también ofrece, en otras clases observadas, fotocopias de los siguientes artículos periodísticos: "El mercado es una opción; pero no una necesidad"27, "Pelea por el ALCA: cómo se alineó cada país y qué se puso en juego" 28 y "De la gesta que enterró el ALCA a la construcción de la UNASUR" ${ }^{, 29}$. El primer artículo es una entrevista del diario Miradas al Sur al entonces Secretario de Finanzas, Hernán Lorenzino. El segundo es un análisis del Acuerdo de Libre Comercio de las Américas efectuado en el año 2005 por un periodista económico del diario Clarín. El tercer artículo es una nota del año 2011 que rememora aquel acuerdo, publicada en el diario Miradas al Sur.

Estos artículos conforman materiales de circulación social que, al no ser particularmente escolares, pueden presentar dificultades a los estudiantes para su interpretación. En relación con ello, registramos que en las fotocopias de algunos artículos aparecen marcaciones (subrayados, cruces y numeración de párrafos) hechas por el docente en el texto original, a modo de guía a los alumnos respecto de qué parte leer para hallar las respuestas de los cuestionarios. Estas marcaciones pueden verse en el Anexo 5, que reproduce imágenes de los artículos fotocopiados. A la vez, las consignas de localización pautadas para dichos artículos, que el docente escribe en el pizarrón, indican entre paréntesis el número de párrafo donde encontrar cada respuesta en el texto.

Así como en la Asignatura B se proponen mayormente textos escolares (con excepción de los artículos periodísticos mencionados), en la Asignatura C (Legislación Fiscal) también se plantea la lectura de textos dirigidos a los estudiantes. En particular, se requiere trabajar con fotocopias de un módulo de Cultura Fiscal ${ }^{30}$, producido por la Administración Federal de Ingresos Públicos para alumnos del nivel, tal como informa la docente en la entrevista. Este módulo propone trabajar tres ejes: formación en valores, ciudadanía y cultura fiscal, por lo cual presenta temas como valores ciudadanos, derechos y obligaciones ciudadanas, sistema tributario argentino, evasión, contrabando y trabajo no

\footnotetext{
${ }^{27}$ Laudonia, M. (11 de septiembre de 2011). El mercado es una opción; pero no una necesidad. Entrevista a Hernán Lorenzino, secretario de finanzas. Miradas al Sur, p.5.

${ }^{28}$ Restivo, N. (6 de noviembre de 2005). Pelea por el ALCA: cómo se alineó cada país y qué se puso en juego. Clarín, p.9.

${ }^{29}$ Pérez, G (8 de noviembre de 2011). De la gesta que enterró el ALCA a la construcción de la UNASUR. Miradas al Sur, p.2.

${ }^{30}$ División de Educación Fiscal (2011). Cultura Fiscal. Desde una perspectiva ética y ciudadana. Hacia la construcción del espacio público. Buenos Aires: AFIP.
} 
registrado. También las definiciones teóricas que esta docente copia en el pizarrón, para que los alumnos lean y reproduzcan en sus carpetas, provienen de este módulo escolar.

En este punto, es posible precisar un aspecto epistemológico que parece sustentar la selección de estos contenidos disciplinares. En esta asignatura, los temas propuestos se alejan de los modelos matemáticos impuestos por el paradigma neoclásico predominante en la enseñanza de la Economía (Aronskind, 2011; Cataño, 2001; Corredor, 2005; López Accotto y de Amézola, 2004; Rodas, 2011; Urquiza, Wainer y Martínez, 2011). Por el contrario, los contenidos disciplinares mencionados darían cuenta de un posicionamiento epistemológico que excede los modelos matemáticos y propone un análisis de las relaciones sociales, los intereses económicos y la dominación de clases (Urquiza, Wainer y Martínez, 2011).

En síntesis, los materiales utilizados principalmente en las Asignaturas B y C son manuales y módulos. Estos textos escolares comparten la característica de apelar a recursos gráficos (como imágenes, recuadros y resaltados en negrita) que destacan los temas sobre los cuales requieren contestar las preguntas de localización que plantean estos docentes.

Los criterios por los cuales estos docentes escogen estos manuales y módulos se basan en diagnósticos previos que realizaron respecto de qué materiales necesitan leer los estudiantes para entender los contenidos disciplinares, tal como muestran los siguientes extractos de entrevista.

DB: Lo que hago siempre es como un primer trimestre [...] de repaso general de lo que fue Geografía de primero a tercero [años], porque [...] ellos [los alumnos de quinto año] no venían con una buena base de Geografía, y yo no puedo hablar de lo que hace el Hombre con los recursos naturales si no tienen ni idea de lo que es un recurso natural. [...] Tenemos como tres libros [denomina así a los manuales], [...] un libro de Historia, [...] uno de Geografía Económica y yo saco también partes de Geografía de segundo año, porque [...] tiene [...] una explicación del proceso geopolítico que me cuadra [...]. Yo a veces también traigo fotocopias de artículos de diario [...] el tema del ALCA lo estuvimos trabajando un mes [...] porque estaba en boga, estaba en la tele, salía [en medios de comunicación]. [...] ¿Por qué el tema del ALCA? Porque ves dentro de lo que es la materia, bloques regionales, entonces yo con eso podía ver bloques regionales [...]. El material tiene que ver con el tema que vos tenés que dar. [...] La dificultad es el saber previo que ellos, en términos de...de Sociales [...] lo tienen muy escaso. Porque [...] primero y segundo [año] son más bien heavy [difíciles].

DC: Yo no doy textos súper difíciles, porque son súper básicos [...]. Puede haber una o dos palabras que no entiendas. "Excedente" puede ser que no la entiendas [...]. A principio de año trajimos artículos periodísticos y ahí me di cuenta que costaba muchísimo [...] [porque el 
artículo] te relaciona por ahi varios temas [...]. Entonces costaba mucho que pudiéramos terminar de leer un artículo, que se entendiera algo al menos.

E: $[\ldots]$ Y vi [en las observaciones de clase] que das unas fotocopias de [...] un módulo de AFIP, ¿por qué lo elegiste?

DC: Porque es lo más sencillo, la forma más sencilla que encontré que ellos pudieran leerlo e interpretarlo [...] que puedan sacar [aprender] lo más importante.

Los extractos citados muestran que estos profesores han dedicado tiempo a efectuar diagnósticos para seleccionar los materiales de lectura de sus materias. El profesor de la Asignatura B, tras considerar que los alumnos carecen de contenidos de Ciencias Sociales que entiende como "base" para enseñar aquellos correspondientes a quinto año, elige manuales que le posibilitan realizar un "repaso general" de temas. Moje (2010) denomina como "trabajo de reparación" a estas acciones docentes en las que se abordan contenidos disciplinares pautados por el curriculum escolar para ser trabajados en años anteriores de la escolaridad. Este docente justifica este "trabajo de reparación", en función de lo "heavy [difícil]" que serían los primeros años del nivel. Ello puede relacionarse con las afirmaciones de directivos y docentes, que exhibimos en el subapartado 4.1.3 del Capítulo 4, respecto de que en los primeros años se prioriza el proceso de socialización de los alumnos en las pautas de convivencia, que resultaría arduo, por sobre la enseñanza de contenidos disciplinares propios de esos años.

En paralelo con la propuesta de manuales, este docente comenta haber elegido artículos periodísticos que permiten trabajar temas sociales actuales (como el ALCA) mientras se aprenden contenidos de su materia, tales como bloques regionales.

Por su parte, la profesora de la Asignatura C dice que selecciona el módulo de Cultura Fiscal por su sencillez y porque no incluye vocabulario incomprensible para los estudiantes. Estos aspectos que resalta la docente pueden relacionarse con una particularidad de los textos escolares: la homogeneización que realizan de las formas discursivas y la eliminación de las discusiones teóricas y los problemas no resueltos dentro de la ciencia, tal como muestran investigadores como Carlino (2005) y Tolchinsky (2008). Al mismo tiempo, y a diferencia del docente de la Asignatura B, esta profesora menciona que desestima el uso de artículos periodísticos por la dificultad que ha advertido en su trabajo. Esta decisión da cuenta de que, tras probar su funcionamiento en clase, ha cambiado el material de lectura propuesto de acuerdo con lo que considera que ayuda o no a la comprensión de los alumnos.

En contraste con los manuales y el módulo escolar planteados en esas materias, en la Asignatura A (Estudios Sociales Argentinos) se propone leer un cuadernillo elaborado por un 
equipo de docentes del área de Ciencias Sociales de la escuela. Si bien supone un material curricular, producido para los estudiantes, está compuesto mayoritariamente por textos de circulación social, por ende no dirigidos a estudiantes secundarios, que refieren a temas de sociología e historia ${ }^{31}$. Debajo de cada texto, se incluyen cuestionarios con predominancia de consignas globales. Respecto del ordenamiento y presentación de los textos, el análisis que efectuamos de este material muestra que, aunque no se encuentra explicitado, responde a una periodización de cuatro formas políticas que asume el Estado a través de la historia: construcción del Estado Nacional, Estado liberal, Estado intervencionista y Estado neoliberal. Esta periodización también figura en la planificación anual del docente, en forma de contenidos a ser trabajados durante los trimestres escolares.

En cuanto a la selección de este cuadernillo, el docente de la Asignatura A argumenta en la entrevista motivos disímiles a los esgrimidos por los otros profesores, quienes mencionan haber efectuado un diagnóstico previo respecto de qué textos ofrecer a los estudiantes para que comprendan los contenidos. En cambio, este docente opta por este material ya que supone que los temas a los que aluden los textos pueden promover en los estudiantes interés por su lectura:

E: Y yo vi que tenían un cuadernillo ¿Ese cuadernillo porqué lo elegiste para que lo lean?

DA: [...] el de "Juventudes" [se refiere al artículo periodístico titulado "El difícil arte de asir a la juventud" de Mario Margulis, incluido en el cuadernillo] me pareció un tema que [...] les podía interesar [a los alumnos] como para engancharlos con la lectura [...]. Hay que buscar un texto como que los pueda... [No continúa la frase] ya el de Pigna [se refiere a la introducción del libro "Los mitos de la historia argentina" de Felipe Pigna, incluida en el cuadernillo] es medio complicado [...] Hay muchas palabras que no se entienden, viste.

En el extracto de entrevista citado, el profesor afirma que elige el cuadernillo como material de lectura porque algunos textos que incluye pueden lograr interesar a los alumnos y motivar así su lectura. En línea con esa afirmación, hipotetizamos que este docente considera que el texto nombrado ("El difícil arte de asir a la juventud") 32 podría ser atractivo ya que allí el autor describe la juventud de las clases populares y relata problemáticas que,

\footnotetext{
${ }^{31}$ De los 37 textos que contiene el cuadernillo, identificamos que 16 provienen de libros, diarios (como Página 12 y Clarín) y revistas de divulgación (como El monitor y Caras y Caretas) y nueve proceden de manuales. Algunos de los autores de estos textos son sociólogos, historiadores, economistas, politólogos y periodistas como Mario Margulis, Felipe Pigna, Susana Torrado, Juan Suriano, Fortunato Mallimaci, Juan Villarreal, Pedro Paz, Eduardo Pavlovsky, Julio Godio y Eduardo Galeano. De los 12 textos restantes, no pudimos determinar su procedencia dado que no se encuentra explícita. Sin embargo, por sus características, parecen corresponder a manuales escolares y resúmenes realizados por docentes.

${ }^{32}$ Margulis, M. (2004). El difícil arte de asir a la juventud. N. Revista de Cultura, p. 15.
} 
efectivamente, en las entrevistas los estudiantes del curso refieren atravesar, tales como desempleo o precarización laboral (ver subapartado 4.2.1 del Capítulo 4).

Al mismo tiempo, este docente reconoce que otro de los textos del cuadernillo, la introducción del libro "Los mitos de la historia argentina" de Felipe Pigna, puede ser "medio complicado" para los alumnos y con "muchas palabras que no se entienden". Ello podría deberse a que, a diferencia de los textos escolares, los materiales de circulación social no presuponen a los alumnos como lectores, por lo que no organizan el contenido disciplinar ni modifican su vocabulario en función de ello. Por el contrario, suelen dar por sabidos ciertos conocimientos previos de sus lectores (Lerner, 2001; Lerner y otros, 1997). Sin embargo, este profesor promueve igualmente su lectura, en contraste con la docente de la Asignatura C, quien opta no proponer materiales de circulación social, como artículos periodísticos, por considerar que a los estudiantes se les dificulta comprenderlos, tal como mostramos anteriormente con extractos de entrevista.

Tras estas consideraciones sobre las características de los textos propuestos y los motivos por los cuales los profesores de las materias indagadas los seleccionan, precisaremos ahora qué piensan los estudiantes respecto de estos materiales.

Ciertas características que los docentes mencionan de los textos que proponen leer son retomadas por algunos alumnos en las entrevistas. En relación con los manuales y módulos propuestos en las Asignaturas B y C, Ariana afirma "nosotros lo leemos y es fácil de estudiarlo". Esta facilidad para leerlos y/o estudiarlos puede vincularse con las características de organización y simplicidad de los textos escolares, que en la entrevista valora específicamente la docente de la Asignatura C.

En contraste con esta apreciación de los manuales y módulos, otras dos estudiantes (2/14) consideran difíciles de comprender los textos del cuadernillo de la Asignatura A, como muestran los extractos de entrevista que transcribimos a continuación:

E: ¿Estos textos del cuadernillo por ejemplo? [...] ¿Vos los entendés?

Yésica: [...] cuando los leo a veces hay cosas que faltan. O sea, en el libro no te va a decir todo lo que pasó [...] porque en el libro te explica pero no te explica... hay cosas que no te explica bien también y sí, cuesta a veces entender un poco.

Guadalupe: $[\ldots]$ a veces son textos medios complicados. Muy largos o son cortitos pero mil preguntas y decís “'y esto?”. 
Yésica y Guadalupe concuerdan, al igual que el docente de la Asignatura A en el extracto de entrevista citado anteriormente, en la dificultad que conlleva la lectura de estos textos. Las "cosas que faltan", que el texto "no te explica" serían la información que los materiales de circulación social omiten porque presuponen ciertos conocimientos previos de los destinatarios (Lerner, 2001; Lerner y otros, 1997).

Los datos analizados hasta aquí permiten concluir que los estudiantes se disponen a leer cuando los profesores brindan materiales de lectura. Observamos que leen los manuales (Asignatura B) y las fotocopias de artículos periodísticos (Asignatura B) y del módulo escolar (Asignatura C), leen el cuadernillo que se les presta si no trajeron a clase el propio (Asignatura A), y también leen y copian las definiciones teóricas escritas en el pizarrón (Asignatura C). En cambio, al requerírseles materiales de lectura informan que no los han traído (Asignatura A) o no se encargan de fotocopiarlos cuando se ausentan a clase (Asignatura B).

Empero, respecto a la lectura de estos materiales, los alumnos mencionan diferencias en las entrevistas: se les dificulta interpretar los textos del cuadernillo de la Asignatura A pero consideran fáciles de comprender los manuales y el módulo de las Asignaturas $\mathrm{B}$ y $\mathrm{C}$, respectivamente. También los docentes hacen referencia a ello en las entrevistas. La profesora de la Asignatura C comenta haber elegido un módulo escolar porque lo considera fácil para que los estudiantes lo comprendan, mientras que el docente de la Asignatura A, pese a que admite la dificultad que conlleva para los alumnos leer algunos materiales de circulación social del cuadernillo, insiste en proponerlos por lo interesante que les resultarían sus temas.

En el próximo subapartado presentamos la categoría “establece significados compartidos" en la cual se incluyen intervenciones docentes para determinar un trasfondo común de significados compartidos entre el profesor y los estudiantes en la definición del medio.

\subsubsection{Establece significados compartidos}

Esta categoría, que incluimos en la función docente de definición del medio, engloba intervenciones en las que se define un medio en tanto contexto cognitivo de la acción, es decir, como un marco de concepciones comunes entre el docente y los alumnos (Sensevy, 2007). Este trasfondo, dado que permite la comunicación entre profesores y estudiantes compone, según Sensevy (2012), la estructura básica de las interacciones didácticas junto con 
otros dos elementos: la atención conjunta en los mismos objetos de conocimiento y el reconocimiento de las mismas posibilidades de acción.

Desde la teoría de las situaciones didácticas formulada por Brousseau, este contexto cognitivo es indispensable para resolver el problema planteado por la tarea pero no es en sí mismo suficiente. Es por ello que la resolución de la tarea tiene sentido, ya que el medio también contiene elementos no conocidos por los estudiantes, por lo cual les presenta un desafío que tiene como propósito incitarlos a la construcción de conocimientos.

A partir del análisis de las clases observadas, y tal como anticipó la Tabla 9, identificamos en la definición del medio trece intervenciones docentes en las que se intenta construir una plataforma común de conocimientos compartidos (13/91) mediante dos modos: a) se organiza una memoria didáctica respecto a los contenidos disciplinares trabajados y b) se los contextualiza. Al contextualizar, observamos que se sitúan oralmente contenidos ya trabajados en determinado contexto socio-histórico. Esto se diferencia de las ocasiones en que solo se organiza una memoria didáctica, ya que en este tipo de intervención se fomenta el recuerdo de contenidos trabajados anteriormente para reactivarlos (Brousseau, 1994, 2007; Brousseau y Centeno, 1991) en vistas de la nueva tarea, sin recurrir necesariamente a su contextualización. La Tabla 21 muestra la cantidad de intervenciones que contabilizamos con respecto a cada asignatura.

Tabla 21. Subcategorías e intervenciones docentes de la categoría "establece significados compartidos"

\begin{tabular}{|c|c|c|c|c|}
\hline Subcategoría & $\begin{array}{c}\text { Total de } \\
\text { intervenciones }\end{array}$ & Intervenciones docentes & Asignatura & $\begin{array}{c}\text { Total de } \\
\text { intervenciones } \\
\text { por asignatura } \\
\end{array}$ \\
\hline \multirow{2}{*}{$\begin{array}{c}\text { Organiza memoria } \\
\text { didáctica }\end{array}$} & \multirow{2}{*}{$8 / 13$} & $\begin{array}{c}\text { Retoma oralmente } \\
\text { contenidos trabajados sin } \\
\text { hacer referencia a textos o } \\
\text { autores leídos }\end{array}$ & \multirow{2}{*}{$\mathrm{B}$} & $6 / 8$ \\
\hline & & $\begin{array}{c}\text { Retoma oralmente } \\
\text { contenidos trabajados } \\
\text { haciendo referencia a textos } \\
\text { o autores leídos }\end{array}$ & & $2 / 8$ \\
\hline \multirow{2}{*}{$\begin{array}{l}\text { Contextualiza los } \\
\text { contenidos } \\
\text { disciplinares }\end{array}$} & \multirow{2}{*}{$5 / 13$} & \multirow{2}{*}{$\begin{array}{l}\text { Sitúa oralmente contenidos } \\
\text { en determinado contexto } \\
\text { socio-histórico }\end{array}$} & A & $3 / 5$ \\
\hline & & & $\mathrm{B}$ & $2 / 5$ \\
\hline
\end{tabular}

De acuerdo con lo presentado en la Tabla 21, podemos anticipar que solo se organiza una memoria didáctica en la Asignatura B y se contextualizan contenidos disciplinares en las Asignaturas A y B. Ante estos dos tipos de intervenciones, los estudiantes se involucran participando oralmente, tal como detallan los subapartados siguientes. 


\subsubsection{Organiza memoria didáctica}

En más de la mitad de las intervenciones en las que se establece significados compartidos (8/13), se organiza una memoria didáctica que recupera temas vistos anteriormente. De acuerdo con Brousseau (1994, 2007) y Brousseau y Centeno (1991), la memoria didáctica promueve que se movilicen saberes antiguos en vistas a aprendizajes nuevos.

En nuestro análisis identificamos que solo el docente de la Asignatura B retoma oralmente contenidos trabajados. En la mayoría de las oportunidades lo hace sin hacer referencia a los textos leídos al respecto (6/8), aunque en otras sí los menciona (2/8). Los alumnos escuchan atentos y en silencio y participan respondiendo las preguntas que efectúa este profesor para que recuerden los temas. La Tabla 22 muestra un fragmento de clase para ejemplificar estas intervenciones.

Tabla 22. Establece significados compartidos: organiza una memoria didáctica. Fragmento de clase de la Asignatura B

Clase 3. El docente ingresa al aula y tras conversar con un grupo de alumnos sobre su viaje de egresados, habla a todo el curso.

1. DB: [7 $\min 35 \mathrm{~s} / 37 \min 51 \mathrm{~s}$ ] [Escribe en el pizarrón "Deuda externa"]. La deuda externa decíamos que ¿qué era?

2. Daiana: Una deuda que tenemos con otros países [...]. La deuda que tiene uno, pero con otros países.

3. DB: Bien. Otros países, cuando decimos otros países... ¿o qué en realidad?

4. Ariana: Con el Fondo Monetario Internacional.

5. DB: ¿Qué es el Fondo Monetario Internacional?

6. Ariana: FMI. Ah, re boluda [tonta] [Ríe].

7. DB: Un organismo internacional de crédito. Estaba el Fondo Monetario Internacional, ¿cuál más?

8. Ariana: ¿ONU?

9. DB: No. Las Naciones Unidas, ¿qué es?

10. Fabiana: ¿Banco Mundial?

11. DB: Las Naciones Unidas es una organización de estados pero, en este caso, no son organismos financieros, sino que es cuando los estados se juntan para, entre otras cosas, hablar o intentar resolver los conflictos que puedan tener. [...] En este caso estamos hablando de los organismos financieros de crédito, los que te prestan [dinero]. Uno, el Fondo Monetario Internacional, por allá [señala a Fabiana] dijiste el Banco Mundial, también el Club de París. Todos esos organismos internacionales son los que te prestan dinero [...] ¿Hasta ahí estamos [entendieron]? Cuando nosotros decíamos la importancia de poder acceder a un crédito ¿para qué? [...] para beneficiar ¿a quién?

12. Denise: A la sociedad.

13. Ariana: Al país entero.

14. DB: Al pueblo en general. [...] Ahora, si yo [se refiere a un país] tengo de ingresos 100 pesos por mes, [...] si la cuota es de 150 ¿lo puedo pagar?

15. Ariana: No.

16. DB: No, me compliqué [no puedo pagar esa cuota alta]. [...] Nosotros decíamos que el tema de la deuda externa se generaba como una gran problemática para los países subdesarrollados, para los países más pobres, en el caso de Argentina, como un país latinoamericano. ¿Por qué habría sido un problema la deuda externa? Por esto que les estaba diciendo. Esta cuestión de "me ingresan 100 y tengo que pagar 150", tengo un problema. Porque voy a tener que achicar todo los gastos que yo tenía para pagar esa deuda ¿Hasta ahí estamos?

[Continúan los intercambios respecto a otros temas vistos anteriormente, tales como el aumento de la deuda externa contraída por el gobierno militar, el incremento de la desocupación y el cierre de industrias. La clase siguiente DB propone a los estudiantes ver en clase, y a través de las netbooks, un video de Youtube mientras copia en el pizarrón un cuestionario titulado "La ilegitimidad de la deuda".] 
El fragmento de clase de la Tabla 22 muestra el comienzo de una memoria didáctica que el docente organiza sobre temas relacionados con la deuda externa, que registramos se extiende a lo largo de 19 minutos. Para ello, fomenta la participación de los alumnos, a quienes interpela a través de múltiples preguntas que buscan recordar lo trabajado previamente en clase. Estas preguntas que formula el profesor contienen, tal como conceptualiza Brousseau (1994), referencias a conocimientos "viejos" cuyos recuerdos el docente busca reactivar para articular con los conocimientos "nuevos" que pretende enseñar. Los alumnos contestan sus preguntas recordando temas trabajados anteriormente (interacciones $\left.\mathrm{n}^{\circ} 2,4,10,12,13,17,19\right)$, lo que permite al profesor continuar explicando. Esta memoria didáctica, que no hace referencia a los textos leídos sobre los temas, se establece como plataforma común de conocimientos compartidos frente a la tarea que el docente presenta la siguiente clase: un cuestionario sobre la ilegitimidad de la deuda externa argentina.

Continuemos ahora el análisis de la categoría "establece significados compartidos" con la presentación de otra forma de intervenir que observamos: contextualizar contenidos disciplinares.

\subsubsection{Contextualiza los contenidos}

Además de las intervenciones que organizan una memoria didáctica, registramos otras que, para establecer significados compartidos en la definición del medio, sitúan oralmente contenidos en determinado contexto socio-histórico (5/13). Frente a estas intervenciones observadas en las Asignaturas A y B, los estudiantes se involucran escuchando en silencio y atentamente a los docentes y/o participando con preguntas y comentarios. En la Tabla 23 mostramos un fragmento de clase de la Asignatura A en donde se observa este tipo de intervenciones y el comportamiento de los estudiantes ante ellas.

Tabla 23. Establece significados compartidos: contextualiza los contenidos. Fragmento de clase de la Asignatura $A$

Clase 7. El docente dicta la consigna para el segundo trabajo práctico, que requiere elegir dos textos del cuadernillo y responder las preguntas de los cuestionarios que allí figuran. Al finalizar el dictado, contextualiza los contenidos disciplinares sobre los que tratan algunos de los materiales.

\section{Interacciones}

1. DA: [21 $\min 54 \mathrm{~s} / 59 \min 49 \mathrm{~s}$ ] [Habla a toda la clase]. Hicimos [trabajamos en otras clases sobre] siglo XIX, siglo XX y siglo XXI. ¿De qué tipo de Estado estamos hablando, si estoy hablando del [período del] 80 al 30, de 1880 a 1930 ?

2. Ariana: Estado liberal.

3. DA: Estado liberal, del 80 al 30. ¿Y si digo [pregunto] tipo de economía o cómo se desarrolló la 
economía en este caso? También del [período] 80 al 30.

4. Yesica: Modelo agroexportador.

5. DA: [Asiente] Modelo agroexportador. ¿Y crecimiento...?

6. Yesica: "Hacia afuera".

7. DA: Claro. Entonces si el texto [que eligen para contestar preguntas en el trabajo práctico] es de 1880 a 1930, es [corresponde a un] Estado liberal con un modelo agroexportador con crecimiento "hacia afuera". ¿Por qué era crecimiento "hacia afuera"? ¿Se acuerdan del modelo agroexportador? ¿Acá [en el país] se producía, había producción?

8. Ariana: No.

9. DA: [Asiente]. [Otros países] Se llevaban la materia prima y los productos volvían terminados, no había industrialización. [...] Cuando hablamos de industrialización hay una política de parte del Estado de fomentar la industria.

[A continuación, el docente indica que finalicen un cuestionario que había encomendado como tarea para el hogar. Los estudiantes abren sus cuadernillos y leen].

La Tabla 23 evidencia que este modo de establecer significados compartidos implica una memoria didáctica, pero en función de contextualizar contenidos que abordan los textos indicados para leer en la nueva tarea. En el fragmento de clase presentado, el docente de la Asignatura A retoma temas ya trabajados: las características político-económicas de nuestro país durante el período de 1880-1930. Con la participación de los estudiantes, caracteriza el tipo de Estado (liberal) y el modelo económico (agroexportador y crecimiento "hacia afuera") para dicho período, respecto del cual los estudiantes leerán en los materiales del cuadernillo.

Además de que favorece el establecimiento de un marco de concepciones comunes para la lectura que encararán los alumnos, la acción de contextualizar resulta necesaria para comprender mejor las causas y consecuencias de los sucesos históricos, de acuerdo con Prats y Santacana (2001). No obstante, Wineburg (1991) muestra que en Historia contextualizar los hechos sobre los que relatan los textos es una estrategia que suele presentar dificultades a estudiantes secundarios y universitarios. En intervenciones como la mostrada en la Tabla 23, el docente ejerce esta estrategia junto con los alumnos, quienes se involucran y participan oralmente. De este modo, la contextualización aparece como contenido en acción (Lerner 2001; Lerner y otros, 1996, 1997), esto es, como objeto de enseñanza en la acción.

Resulta interesante precisar el objetivo docente que moviliza estas intervenciones para establecer significados compartidos. En la entrevista, el docente de la Asignatura B afirma utilizar estas intervenciones para constituir una referencia común que facilite la comprensión de los textos por parte de los alumnos.

DB: Yo generalmente explico en el pizarrón, necesito que [los alumnos] estén prestando atención, donde después hacemos una lectura, entonces el pibe [alumno] puede ir hilvanando lo que hablamos con esa lectura.

$\mathbf{E}:[\ldots]$ ¿Qué cosas pensás vos que los ayuda a entender? 
DB: Y eso. [...] Al principio sí tenés que tener un "contexto". Si vos vas con un texto que no está dentro de un “contexto” determinado, es mucho más difícil de entender, porque el pibe no va entendiendo [...] qué es lo que es.

Según este profesor, el "contexto" instaurado previa y oralmente funciona como marco conceptual compartido que hace más accesible para los estudiantes los textos disciplinares, ya que les brinda ciertos conocimientos del tema, de manera que puedan "ir hilvanando lo que hablamos con esa lectura". Así, intenta asegurar cierta aproximación a los contenidos para que estos puedan interpretar los textos que leerán. Este "contexto" referido por el profesor sería equivalente al trasfondo común de significados compartidos entre el docente y los estudiantes, que Sensevy $(2007,2012)$ define como medio en tanto contexto cognitivo de la acción.

Por lo expuesto, cabe pensar que bajo estas intervenciones que contextualizan contenidos y que organizan una memoria didáctica subyace la concepción de que los conocimientos previos de un lector funcionan a modo de esquemas asimiladores en la construcción de significado que se hace sobre un texto (Goodman, 1996; Lerner, 1985; Lerner y otros, 1997). Sostenemos que estas intervenciones para establecer significados compartidos, al incitar el recuerdo de ideas conceptuales ya trabajadas y su interrelación, favorecen a todos los estudiantes pero, especialmente, benefician a aquellos que se ausentan reiteradamente a clases, tal como ocurre con los alumnos del curso de quinto año de esta escuela (ver apartado 4.2.1 del Capítulo 4). Es posible que estos estudiantes, que faltan en forma recurrente y luego se reintegran a las clases, pierdan la progresión de los temas de las materias y desconozcan lo trabajado al respecto. Por ello, podrían verse beneficiados en las ocasiones que se retoman los contenidos trabajados y se los sitúa en determinado contexto socio-histórico.

Aquí conviene detenerse a examinar qué opiniones manifiestan los estudiantes en relación con estas intervenciones. Seis alumnos (6/14) las valoran positivamente y afirman que sin ellas los textos disciplinares les resultan difíciles de comprender.

Nadia: Igual para poder leerlo [un texto] te tienen que explicar un poco también de qué se trata. Antes.

Lautaro: Nah, bueno, hay profesoras que no te explican nada, "Lee esto y mediante eso respondé preguntas".

Nadia: Está bueno ponéle [nombra al profesor de la Asignatura B], te da una charla previa, te explica él con sus palabras, después te da el libro [se refiere al manual]. 
Leer y escribir en tres asignaturas de una escuela secundaria a la que asisten sectores socioeconómicos desfavorecidos Natalia Rosli

Lautaro: Claro, [la charla] es bien completa, ¿entendés?

Nadia: Y después vos hacés el trabajo [se refiere a los cuestionarios]

Guadalupe: [Nombra al profesor de la Asignatura B] no te manda "Bueno, tomá, lee” [...]. No, te dice “bueno, porque esto y esto, lean esto". Es como que te da una introducción, algo así. Está bueno.

Fabiana: [Hay algunos profesores que] te hacen leer y te dicen "Bueno, estas preguntas las tenés que contestar de este texto".

Daiana: Y nosotros lo leemos y no entendemos.

Fabiana: Y hay cosas, palabras, que decís ¿de dónde salió?

E: Pero igual yo noto que [nombra al profesor de la Asignatura B] les hace leer.

Fabiana: Sí pero...

Daiana: Pero porque antes hizo una...

Fabiana: Un resumen...

Daiana: Una previa, digamos, un resumen, un cuadro [...], como que te incentiva a leer.

$\mathbf{E}:[.$.$] Antes de ponerlos a leer ifalta algo, dicen ustedes?$

Daiana: Claro. O sea, no es lo mismo llegar y reirte un rato, explicar un poco, que llegar y decir “saquen el cuadernillo y pónganse a leer”.

Ariana: [Con tono de disgusto] [Otros profesores] más que nada, en realidad [lo que hacen] es “tomen unos textos o tomen estos textos, hagan un trabajo, lo entregan tal día”.

En los extractos de entrevista expuestos, los alumnos sostienen que la aproximación previa a los temas incentiva a que lean los textos propuestos en las materias. Describen esta aproximación con palabras tales como "explicación", "charla", "introducción”, "previa” y "resumen". Probablemente, las intervenciones docentes a través de las cuales se contextualizan contenidos y/o se organiza una memoria didáctica funcionen motivando a los estudiantes a leer por dos razones. Por un lado, en tanto ofrecen claves para jerarquizar y seleccionar la información que luego leerán. Por otro lado, porque establecen cierto propósito lector que da sentido al esfuerzo de abocarse a la tarea (Carlino, 2005; Lerner, 2001; Marucco, 2001): indican que la lectura requerida permite trabajar determinado contenido disciplinar que se encuentra ligado con conocimientos ya construidos en esas asignaturas.

Según lo que refieren, los alumnos valoran que se establezcan significados compartidos, en definitiva, que se instaure un medio en tanto contexto cognitivo de la acción (Sensevy, 2007), que facilite la comprensión de los textos. En concordancia con ello, critican aquellas clases donde estas intervenciones no suceden y solo se indica la tarea que deben 
realizar. En esos casos, sienten que no se los motiva y que se los deja solos, sin ninguna apoyatura introductoria, con el reto de comprender los textos.

Estas afirmaciones se encuentran en línea con el comportamiento que pudimos observar en los estudiantes tras estas intervenciones. En las clases en las que los docentes relacionan los contenidos con otros trabajados con anterioridad, los alumnos, además de participar oralmente, se disponen a leer en clase los textos indicados. Por el contrario, en las clases en las que solo se indica leer, sin establecer significados compartidos que permitan abordar los textos, los alumnos conversan entre ellos o escuchan música de sus netbooks sin iniciar la tarea.

Al llegar aquí, hemos presentado tres categorías correspondientes a la función docente de definición del medio: "define tarea", "define recursos de lectura" y "establece significados compartidos". El próximo subapartado describe la última categoría correspondiente a esta función: "propone acciones generales para facilitar la tarea".

\subsubsection{Propone acciones generales para facilitar la tarea}

En la definición del medio identificamos intervenciones en las que se efectúan recomendaciones generales con el objetivo de facilitar la tarea de leer para responder cuestionarios. Al referirnos a la idea de "generalidad" para caracterizar estas recomendaciones, hemos tenido en cuenta que en tales no se incluye una referencia situada a cierto contenido que se leerá en la bibliografía o cierta consigna de los cuestionarios. En cambio, estas sugerencias se enuncian en forma "universal" o "generalizada" para facilitar la comprensión lectora de cualquier texto y en cualquier materia.

En la definición del medio en las clases analizadas, este tipo de intervenciones solo aparece en la Asignatura A. Al respecto, y tal como anticipó la Tabla 9, identificamos 16 sugerencias del profesor sobre consultar distintas fuentes ante posibles dudas de comprensión (16/91). Las mismas se especifican en la Tabla 24.

Tabla 24. Subcategoría e intervenciones docentes de la categoría "propone acciones generales para facilitar la tarea"

\begin{tabular}{cccc}
\hline Subcategoría & Intervenciones docentes & Asignatura & Total de intervenciones \\
\hline \multirow{2}{*}{$\begin{array}{c}\text { Sugiere consultar } \\
\text { distintas fuentes } \\
\text { ante dudas de } \\
\text { comprensión }\end{array}$} & Recomienda consultar al docente & & $9 / 16$ \\
\cline { 2 - 3 } & Recomienda consultar línea de tiempo & A & $5 / 16$ \\
\end{tabular}


La Tabla 24 muestra las acciones generales que propone el docente de la Asignatura para facilitar la tarea: consultar al profesor (9/16), consultar una línea de tiempo (5/16) y consultar al diccionario $(2 / 16)$.

Registramos que en las clases analizadas los alumnos permanecen en silencio mientras el profesor sugiere estas acciones. Aunque luego consultan al docente por dudas de comprensión, no acuden al diccionario o a la línea de tiempo que poseen en sus carpetas. Conste, pues, que la intervención predominante dentro de esta categoría "propone acciones generales para facilitar la tarea" -consultar al docente (9/16) -, es aquella que los estudiantes finalmente llevan a cabo. En efecto, en las ocasiones en que el docente recomienda que le consulten dudas de comprensión que puedan surgir en la tarea de leer para responder cuestionarios, los estudiantes escuchan en silencio estas sugerencias y luego, tras comenzar a leer, le realizan consultas sobre los textos. La Tabla 25 ilustra un ejemplo de estas intervenciones.

Tabla 25. Sugiere consultar distintas fuentes ante dudas de comprensión: recomienda consultar al docente. Fragmento de clase de la Asignatura $A$

Clase 1. Al comenzar la clase, el docente establece la fecha de entrega del primer trabajo práctico de la materia, cuyas consignas domiciliarias dictó con anterioridad, y la escribe en el pizarrón. Luego, pregunta si completaron el cuestionario sobre el artículo "El difícil arte de asir a la juventud" del sociólogo Mario Margulis, encomendado como tarea para el hogar. Dado que los alumnos responden negativamente, asigna tiempo para que lean y contesten en clase dichas preguntas.

1. Lautaro: [15 min/60 min] [Entra al aula y saluda al docente] Buenas. [Mira el pizarrón] Ah, no hice nada de ese trabajo [se refiere al trabajo práctico de la materia], profe. No hice nada, nada.

2. DA: Tenés que empezar a hacerlo porque mirá que acá están las fechas [se refiere a las fechas de entrega que escribió en el pizarrón] [...] Si hay dudas [sobre el trabajo práctico] me tienen que consultar. ¿Vas a hacerlo solo al trabajo vos?

3. Lautaro: Sí.

4. DA: [Comienza a tomar lista de los alumnos presentes y luego habla a todo el curso] Chicos, yo voy a estar acá [en la escuela], me quedo, como dos o tres horas más, cuando salgo de este curso, así que si quieren consultarme algo, o ahora [sobre el trabajo práctico], no hay problema. Ahora estamos con el texto de "Juventudes" de Margulis, el primer texto del cuadernillo. [Los alumnos continúan leyendo el texto. Lorena y Marisa escriben en sus carpetas. Suena el timbre del recreo. De a poco, los estudiantes se van levantando de sus sillas]. También recuerden que estoy yo lunes y martes acá, abajo [dando clases en las aulas de planta baja].

[En la clase siguiente, algunos estudiantes consultan al docente dudas sobre el trabajo práctico].

En el fragmento de clase reproducido en la Tabla 25, el docente sugiere a los estudiantes consultarle las dudas acerca de un trabajo práctico para el cual tienen que leer en sus hogares textos del cuadernillo de la materia y responder consignas. Para ello, indica en qué momentos se encuentra disponible para contestar las dudas ("ahora", "me quedo, como dos o tres horas más", “estoy yo lunes y martes acá, abajo"). Algunos alumnos, la clase siguiente, le consultan acerca de sus dificultades para interpretar los textos y/o responder las 
preguntas de los cuestionarios. Importa resaltar que sus comportamientos coinciden con la valoración que hacen en las entrevistas sobre la posibilidad de consultar dudas al docente, razón por la cual prefieren realizar la tarea de leer para responder cuestionarios en clase y no en los hogares, tal como suele exigir el profesor de esta materia (ver subapartado 6.1.1).

Detengámonos ahora a analizar las intervenciones en las que el docente de la Asignatura A sugiere consultar una línea de tiempo (5/16), graficada en el pizarrón el primer día de clases (no observado por la investigadora) y copiada por los estudiantes en sus carpetas. Dicho gráfico sitúa las formas políticas que asume el Estado argentino entre el año 1810 y el año 2001 (construcción del Estado Nacional, Estado liberal, Estado intervencionista y Estado neoliberal) junto con los modelos económicos correspondientes (crecimiento "hacia afuera", crecimiento "hacia adentro", crecimiento orientado transnacionalmente y globalización) y acontecimientos históricos relevantes de ese período.

Como ejemplifica la Tabla 26, ante estas recomendaciones, los estudiantes del curso permanecen en silencio y no acuden a la línea de tiempo para responder las consignas de los cuestionarios.

Tabla 26. Sugiere consultar distintas fuentes ante dudas de comprensión: recomienda consultar línea de tiempo. Fragmento de clase de la Asignatura A

Clase 7. El docente dicta las consignas para el segundo trabajo práctico, que requiere elegir dos textos del cuadernillo y responder las preguntas de los cuestionarios que allí figuran. Luego, propone terminar en clase el cuestionario del texto "Normas jurídicas e ideologías políticas relativas a la familia argentina" de la socióloga Susana Torrado", tarea que había sido encargada para el hogar.

\section{Interacciones}

1. DA: [32 $\min 22 \mathrm{~s} / 59 \min 49 \mathrm{~s}$ ] Les dejo tiempo para que terminen [el texto] "Normas Jurídicas" ahora. [Empieza a tomar lista de los alumnos presentes en la clase. Los estudiantes leen el cuadernillo en silencio.] Para el trabajo práctico, cada uno empiece a revisar la línea de tiempo.

[Los alumnos escuchan en silencio y continúan leyendo el cuadernillo].

La Tabla 26 muestra cómo el profesor de la Asignatura A propone que sean los alumnos quienes, para interpretar los textos, sitúen en la línea de tiempo los contenidos disciplinares sobre los que estos tratan. Bajo este tipo de intervenciones parece subyacer la concepción de que tener un gráfico a disposición es suficiente para poder interpretarlo. Así, poseer la línea de tiempo copiada en las carpetas el primer día de clases bastaría para que, al acudir a ella, los estudiantes logren ubicar los acontecimientos históricos que abordan los materiales del cuadernillo y favorecer así su comprensión. Estas intervenciones docentes, entonces, implican el encargo de una práctica (contextualizar contenidos con ayuda de la línea de tiempo) sin mostrar cómo ésta puede ejercerse. 
En oposición a esta concepción, los resultados de una secuencia de enseñanza sobre inmigración que llevaron a cabo Moje y Speyer (2008) en un bachillerato estadounidense con alumnado mayoritariamente latino, muestran que los estudiantes carecían del conocimiento analítico necesario para evaluar por sí mismos tablas estadísticas sobre el país de origen de los inmigrantes. Por ello, estas docentes-investigadoras proponen andamiar la lectura en las materias trabajando junto con los estudiantes en el análisis de imágenes, tablas y gráficos. Un acompañamiento de este tipo, de acuerdo con nuestro análisis, no sucede en las clases observadas de la Asignatura A. Registramos que únicamente en la primera clase de la materia -en la cual copia en el pizarrón la línea de tiempo- este profesor comenta a los estudiantes las formas políticas y modelos económicos que pueden situarse a partir de ese gráfico, aunque sin utilizarlo para contextualizar contenidos de algún texto en particular.

A la complejidad de analizar gráficos como una línea de tiempo, se le suma la dificultad propia para contextualizar acontecimientos en Historia, mencionada anteriormente. Ya hemos mostrado que este docente en la definición del medio busca establecer significados compartidos al contextualizar junto con los estudiantes los contenidos disciplinares que tratan los textos que se leerán del cuadernillo (ver subapartado 6.1.3.2). Más adelante mostraremos que, en la gestión del medio, y para regular la interpretación del texto, también lo hace respecto de temas sobre los cuales los estudiantes se encuentran leyendo en la tarea (ver subapartado 6.2.3.3). Si bien en estos dos tipos de intervenciones el profesor refiere oralmente características político-económicas del Estado argentino, incluidas en la línea de tiempo, al hacerlo no requiere que los estudiantes acudan al gráfico de sus carpetas.

Algunas de las dificultades para contextualizar y analizar gráficos parecen haberse presentado en los estudiantes del curso. Tal como mostraremos en el subapartado 6.3.1.1, en las intervenciones que evalúan aspectos disciplinares de las respuestas escritas, que forman parte de la función docente de evaluación de la tarea, observamos varios señalamientos de este profesor respecto de contextualizaciones erróneas que los estudiantes realizan en los trabajos prácticos encomendados para los hogares. Esto podría indicar que aquellos pocos alumnos que efectúan la tarea en sus casas y entregan los trabajos, no acuden a la línea de tiempo o que, al hacerlo sin ayuda del docente, no saben interpretarla en forma válida.

A la par de las sugerencias sobre consultar al docente y a una línea de tiempo como propuestas de acciones generales para facilitar la tarea, identificamos que en dos oportunidades el docente de la Asignatura A recomienda consultar al diccionario (2/16). La Tabla 27 ilustra un ejemplo de estas intervenciones. 
Tabla 27. Sugiere consultar distintas fuentes ante dudas de comprensión: recomienda consultar al diccionario. Fragmento de clase de la Asignatura $A$

Clase 1. Hacia el final de la hora, el docente solicita que para la próxima clase lean el texto "Los mitos de la historia argentina" del historiador Felipe Pigna, que figura en el cuadernillo.

\section{Interacciones}

1. DA: [50 $\mathrm{min} / 60 \mathrm{~min}$ ] Hay conceptos, palabras, a veces que el texto tiene, que ustedes ven como difícil [de entender]. No tengan miedo, digamos...hay que preguntar, sino voy a un diccionario. [...] Sino uno se queda con la duda [de qué significa la palabra] [...] En el texto [de Felipe Pigna] va a ir apareciendo un vocabulario específico, muy de Historia. Me tienen que consultar a mí, o consultar un diccionario.

[En la clase en la cual se destina tiempo para leer y responder el cuestionario sobre "Los mitos de la historia argentina", los estudiantes consultan al docente sobre términos que no comprenden del texto. No se los observa consultar un diccionario ni referir su uso en los hogares].

En el fragmento de clase que presenta la Tabla 27 el profesor sugiere a los estudiantes que, por su cuenta, consulten con un diccionario las palabras "muy de Historia" que no comprendan de los materiales que indica leer. Aunque no es posible concluir que, por dos ocasiones en las que recomienda este uso, el docente entiende que los problemas para interpretar textos de Historia se reducen a las dificultades para comprender su vocabulario específico, señalamos al lector que esta concepción, identificada por Kaufman y Perelman (1999) en docentes del nivel primario, podría también estar presente aquí.

Aun así, la sugerencia de disipar las dudas de un término con el diccionario corre el riesgo de omitir que, tal como advierte Prats (2000), ciertos conceptos históricos cobran distintas significaciones según los escenarios espacio-temporales a los que un texto remite. Por ende, para comprender un texto no bastaría con hallar en el diccionario los significados de las palabras incomprendidas y considerarlos unívocos.

Según lo observado los estudiantes no consultan el diccionario cuando se topan con palabras que no entienden sino que buscan resolver sus dudas directamente con el profesor. En efecto, esto se mostrará en el subapartado 6.2.3.2, que describe intervenciones que regulan la interpretación del texto en la gestión del medio, en las que los docentes explican siglas y términos disciplinares que aparecen en los textos leídos y por los cuales los alumnos consultan.

Como conclusión de esta categoría, podemos afirmar que estas sugerencias del docente de la Asignatura A imponen de entrada condiciones de lectura independiente que, tal como advierte Carlino (2005), en vez de promover autonomía lectora resultan contraproducentes: los estudiantes, ante la falta de orientación para recurrir solos al diccionario o a la línea de tiempo, no ejercen estas acciones recomendadas. 


\subsubsection{Algunas conclusiones sobre la función definición del medio}

Hasta aquí hemos analizado 91 intervenciones docentes que identificamos corresponden a la función de definición del medio para la tarea de leer para responder cuestionarios. Como se ha visto, distinguimos en cuatro categorías esta función, basándonos en qué hacen los docentes para definir el medio. Así, identificamos que los profesores 1) “definen la tarea”, 2) "definen recursos de lectura", 3) "establecen significados compartidos" y 4) "proponen acciones generales para facilitar la tarea" (ver Tabla 9). Ahora, y tras describir y analizar las distintas intervenciones de los profesores, podemos efectuar algunas conclusiones de acuerdo con cada materia.

En primer término, observamos que la tarea de leer para responder cuestionarios en la Asignatura A presenta elementos cuyo trabajo resulta más difícil para los estudiantes: consignas globales y textos de circulación social. En las materias $\mathrm{B}$ y $\mathrm{C}$, los docentes proponen consignas de localización al respecto de textos de manuales y módulos, que resultan de lectura sencilla para los estudiantes. A diferencia de las consignas de localización, las consignas globales, tal como muestra la investigación de Aisenberg (2010), suelen presentar mayores dificultades para ser comprendidas y resueltas por los alumnos, ya que requieren operaciones complejas como comprender el sentido global del texto y ponerlo en relación con otros materiales leídos (Aisenberg, 2004, 2005a, 2010; Carlino, 2005) y armar una respuesta sobre lo interpretado. Por su parte, los textos de circulación social presuponen ciertos conocimientos previos de los lectores (Lerner, 2001; Lerner y otros, 1997) y no están específicamente dirigidos a lectores-estudiantes de secundaria, por lo que omiten informaciones necesarias para entenderlos, no organizan el contenido disciplinar ni modifican su vocabulario para adaptarlo a estos destinatarios. A estas particularidades que hacen más difícil el trabajo con consignas y textos de este tipo se le suma el hecho de que ambos elementos resultan menos conocidos por los estudiantes dentro del contrato didáctico. Tal como estos afirman en las entrevistas, en las materias de la escuela no suelen leer textos de circulación social ni responder consignas globales. No obstante, el docente de la Asignatura A afirma proponer estos materiales y consignas porque presentan temas que considera pueden motivar que los estudiantes lean y porque busca que, a partir de la lectura total del texto, éstos comprendan la postura del autor y la evalúen.

Respecto a la definición de la tarea, observamos que en la Asignatura A se indica leer esos textos y responder esas consignas en forma domiciliaria con el objetivo de dar lugar en las clases siguientes para que los estudiantes expresen sus puntos de vista sobre lo leído. Esta intencionalidad docente, que apuntaría a generar intercambios dialógicos que potencien la 
construcción de nuevos significados (Dysthe, 1996, 2013), encuentra como primer y principal obstáculo que los alumnos no leen en sus casas. Uno de los motivos que los estudiantes alegan para explicarlo radica en que no están acostumbrados a leer en sus hogares porque no suelen requerírselo en otras asignaturas, lo cual muestra "el peso de las costumbres" dentro del contrato didáctico (Sensevy, 2007; p.10). Además, los entrevistados describen dificultades para leer en sus casas; por un lado, sus situaciones de vida poco propicias para hallar tiempo y espacio para leer y estudiar (alumnos que trabajan además de estudiar, que tienen hijos pequeños y/o están a cargo de hermanos, etcétera), por el otro lado, la falta de orientaciones por parte del docente sobre cómo leer para comprender textos de circulación social y responder las consignas globales que les presenta, sumado al hecho de que en sus hogares no tienen lectores-interpretantes a quienes consultar.

Frente al impedimento de llevar adelante la tarea planificada, esto es, al constatar que los alumnos no leen en sus casas y, por tanto, no es posible trabajar en clase según lo previsto, registramos que el docente interviene reconfigurando la tarea a través de dar tiempo para efectuar en el aula la lectura y escritura que no se realiza por fuera, lo que se mostrará en detalle en el subapartado 6.2.2. No obstante, surge aquí un segundo obstáculo para que los estudiantes lean y luego hablen sobre lo leído, tal como se propone el docente de la Asignatura A: cuando éste requiere a los estudiantes el cuadernillo fotocopiado al principio de la cursada, para leer en clase, los alumnos informan no haberlo llevado a la escuela. Ante esta situación, el profesor interviene brindando su propio material para que trabajen y pidiendo a los estudiantes que se agrupen en torno a los cuadernillos presentes en el aula.

Otro aspecto que caracteriza cómo el docente A define el medio corresponde al modo de "establecer significados compartidos". Hemos descrito que se establece un contexto cognitivo de la acción (Sensevy, 2007) a través de organizar una memoria didáctica y contextualizar los contenidos disciplinares, intervenciones que solo registramos en clases de las materias A y B. Al respecto, identificamos que el docente de la Asignatura B interviene de los dos modos mencionados. En cambio, el profesor de la Asignatura A solo contextualiza los contenidos, con la participación oral de los estudiantes. En otras oportunidades, sin embargo, recomienda que estos lo hagan por su propia cuenta mediante el uso de una línea de tiempo. De esta manera, el docente A pretende ayudar a que los estudiantes sitúen los contenidos en determinado contexto socio-histórico, lo cual es una estrategia que emplean los lectores avanzados en la disciplina (Wineburg, 1991) y que suele presentar dificultades a estudiantes secundarios y universitarios (Carretero, Pozo y Asensio, 1997; Wineburg, 1991). Empero, este profesor, al solicitar que los alumnos consulten solos la línea de tiempo, interviene 
declarativamente enunciando acciones generales que los alumnos deberían llevar a cabo para solventar sus dificultades de comprensión, efectuando así indicaciones propedéuticas y estableciendo condiciones de lectura independiente. En relación con el primer aspecto, Carlino (2013) señala que la enseñanza declarativa de estrategias para aplicar en el futuro corresponde a un enfoque de la lectura y la escritura como habilidades fragmentarias que las desliga del contenido sobre el que se lee y se escribe. En cuanto al segundo aspecto, esta investigadora muestra que la exigencia prematura de lectura independiente fomenta la incertidumbre de los estudiantes (Carlino, 2005). Resultan prematuras en tanto se pide a los estudiantes ejercer acciones que no se han enseñado a desempeñar en forma autónoma. Al respecto, el análisis de las observaciones de clase muestra que, cuando la tarea de leer para responder preguntas globales finalmente se inicia en la Asignatura A, los estudiantes no logran poner en práctica dichas estrategias de contextualización recomendadas por el docente, sino que se limitan a consultarle sobre palabras que no entienden del texto o por partes del texto para copiar en sus carpetas y responder las consignas globales como si éstas fuesen de localización. Así, encontramos que las intervenciones docentes descritas al respecto de la lectura contrastan con lo que distintas investigaciones han mostrado que favorece la comprensión de los contenidos a abordar, esto es, el acompañamiento del docente trabajando junto con los alumnos, por ejemplo, en la interpretación de imágenes, tablas y gráficos (Moje y Speyer, 2008), en vez de su sola indicación declarativa.

A diferencia de los modos en que se define la tarea y los recursos de lectura en esta materia, observamos que en las Asignaturas B y $\mathrm{C}$ se ofrecen materiales para responder cuestionarios durante la clase, ante lo cual los estudiantes responden disponiéndose a leer. En contraste con los elementos pautados en la Asignatura A, estos profesores plantean consignas de localización y proponen textos escolares con los cuales los alumnos, debido al contrato didáctico prevalente en las materias de esta escuela, se encuentran familiarizados. Las razones por las cuales los profesores de estas asignaturas seleccionan estos elementos, según afirman al ser entrevistados, se basan en ciertas características de los estudiantes que tomarían en cuenta: sus conocimientos previos y su alto porcentaje de ausentismo a clase. Ambos docentes escogen manuales y módulos porque han efectuado diagnósticos previos respecto de qué materiales de lectura resultan ajustados para trabajar con los alumnos. La docente de la Asignatura $\mathrm{C}$ elige un módulo escolar porque considera que presenta contenidos disciplinares de un modo "sencillo", que facilita la comprensión de los estudiantes. Esta sencillez a la que alude puede relacionarse con el modo en que los textos escolares organizan los temas de un campo de estudio que, para algunos investigadores como 
Carlino (2005) y Tolchinsky (2008), implica la homogeneización de formas discursivas y la eliminación de discusiones teóricas. Por su parte, el profesor de la Asignatura B propone la lectura de manuales diseñados para el ciclo básico del nivel porque le permiten realizar un "trabajo de reparación” (Moje, 2010) revisando temas que, según comenta, están pautados por el curriculum escolar para tratarse en los primeros años de la escolaridad. En dicho período, tal como mostramos en el subapartado 4.1.3 del Capítulo 4, actores institucionales entrevistados afirman que se prioriza la socialización de los estudiantes en las pautas de convivencia por sobre la enseñanza de contenidos disciplinares. Asimismo, el hecho de que los alumnos se ausenten reiteradamente a clase lleva a que este mismo docente, en vez de avanzar con el dictado de contenidos cuando gran parte del curso no concurre a la institución, opte por actividades con consignas de localización respecto de temas ya trabajados, que pueden resolverse en la misma clase en la que se plantean, con ayuda de la carpeta. Este tipo de consignas, que requiere identificar y reproducir información (Aisenberg, 2005a, 2010; Benchimol, Carabajal y Larramendy, 2008; Lerner, Aisenberg y Espinoza, 2009), resultan fáciles de responder para los estudiantes, de acuerdo con sus dichos en las entrevistas.

En la definición del medio, particularmente el docente de la Asignatura B, antes de indicar a los estudiantes que empiecen a leer, contextualiza los contenidos y organiza una memoria didáctica de temas vistos con anterioridad, dándole prioridad a los conocimientos previos que éstos tienen para poder construir significado a partir de los textos (Goodman, 1996; Lerner, 1985; Lerner y otros, 1997). En concordancia con la valoración positiva que los estudiantes expresan respecto de estas intervenciones, registramos que participan de ellas con preguntas y comentarios y luego comienzan a leer los textos indicados. Esta disposición a leer puede deberse a que las contextualizaciones y la memoria didáctica ofrecen claves para jerarquizar y seleccionar información a través del texto, al tiempo que instauran cierto propósito lector (Carlino, 2005; Lerner, 2001; Marucco, 2001) que sugiere que lo que se leerá está relacionado con contenidos anteriormente vistos en clase. El punto, aquí, es que los alumnos se disponen a leer en una situación que no les resulta ajena, y cuyo propósito les es conocido, a diferencia de lo que ocurre en la Asignatura $\mathrm{C}$ donde, como se ha visto, los estudiantes también se abocan a la lectura del módulo pero sin contextualizaciones de los contenidos ni una memoria didáctica que brinden claves para leer o establezcan un propósito lector. Suponemos que su disposición a leer en dicha materia radica en la necesidad de efectuar la tarea y ser aprobados.

Hemos de realzar que las intervenciones que establecen significados compartidos a través de contextualizaciones (Asignatura A y B) y memorias didácticas (Asignatura B) 
benefician especialmente a un alumnado como el de quinto año, que suele ausentarse frecuentemente a clase. En efecto, al promover que se movilicen saberes antiguos en vistas a aprendizajes nuevos (Brousseau, 2007; Brousseau y Centeno, 1991), los estudiantes podrían, bajo la guía de los docentes, estar al tanto de los temas que se abordan en las materias durante las clases en las que se ausentan y tener una nueva oportunidad de aprenderlos. A través de estas intervenciones, los profesores no solo considerarían una característica de los estudiantes, su ausentismo a clase, sino que también accionarían para atenuar sus efectos sobre los aprendizajes de los alumnos.

Esta síntesis que realizamos permite notar que en las Asignaturas $\mathrm{B}$ y $\mathrm{C}$ el medio se define sobre la base del contrato didáctico prevalente en las materias de la escuela. La tarea de leer para responder cuestionarios se pauta principalmente a partir de elementos conocidos por los estudiantes (consignas de localización y textos escolares). Para contestar esas consignas, y así resolver la tarea, el reto de los alumnos se limita a identificar y reproducir la información de esos materiales. Contrariamente, en la Asignatura A, dado que se busca promover una interpretación de los textos -opuesta a la lectura de localización-e incentivar una escritura que no se reduzca a la reproducción de párrafos, el profesor define un medio diferente al de las otras materias, que desafía el contrato didáctico de las materias de esta escuela al presentar cláusulas novedosas: leer en las casas textos de circulación social para responder consignas globales. No obstante, la definición del medio en la Asignatura A se encuentra con diferentes obstáculos: los estudiantes no leen en sus casas, no traen el cuadernillo para trabajar en clase, no acuden al diccionario ni a la línea de tiempo que tienen en sus carpetas. Resulta paradójico que, pese a sus intenciones, a la hora de solventar estos obstáculos, el profesor de la Asignatura A reconstruya el medio habitual del contrato didáctico prevalente en las materias: propone leer en clase. Para ello, facilita su propio material de lectura y propone acciones para solventar posibles dudas, de las cuales la única que realizan los alumnos, según nuestras observaciones, es consultar al profesor.

Habiendo descrito cómo definen el medio en la tarea de leer para responder cuestionarios los profesores de estas tres asignaturas, el próximo apartado analiza las intervenciones mediante las cuales los docentes gestionan este medio.

\subsection{Gestión del medio}

En este apartado presentamos intervenciones docentes en las que, siguiendo a Sensevy (2012), se orienta y direcciona la acción de los estudiantes dentro del medio. Estas intervenciones no forman parte de la función de definición del medio, dado que suceden 
cuando ya se han dispuesto los recursos y materiales para que los estudiantes trabajen en la tarea indicada; es decir, son intervenciones que se ejercen como modos de gestionar el medio definido.

Respecto de esta función docente, identificamos en las clases observadas un total de 159 intervenciones en las que los profesores de las materias guían a los alumnos en la tarea de leer para responder cuestionarios. Tras su análisis, construimos cuatro categorías que distinguen diversos modos de gestionar el medio: 1) "promueve y monitorea la puesta en tarea", 2) "modifica tiempo y espacio para la tarea", 3) "sostiene tarea" y 4) "cierra parcialmente tarea". La Tabla 28 ilustra estas categorías y sus subcategorías, especificando las intervenciones docentes que les corresponden.

Tabla 28. Categorías y subcategorías en la función docente "gestión del medio"

\begin{tabular}{|c|c|c|c|c|c|}
\hline Categoría & $\begin{array}{c}\text { Total de } \\
\text { intervenciones }\end{array}$ & Subcategoría & $\begin{array}{c}\text { Total de } \\
\text { intervenciones }\end{array}$ & $\begin{array}{c}\text { Intervenciones } \\
\text { docentes }\end{array}$ & $\begin{array}{c}\text { Total de } \\
\text { intervenciones }\end{array}$ \\
\hline \multirow{2}{*}{$\begin{array}{l}\text { Promueve y } \\
\text { monitorea la } \\
\text { puesta en } \\
\text { tarea }\end{array}$} & \multirow[b]{2}{*}{$35 / 159$} & $\begin{array}{c}\text { Incita } \\
\text { oralmente a } \\
\text { ponerse en } \\
\text { tarea } \\
\end{array}$ & $24 / 35$ & $\begin{array}{l}\text { Indica que se } \\
\text { pongan a leer y/o } \\
\text { responder los } \\
\text { cuestionarios }\end{array}$ & $24 / 35$ \\
\hline & & $\begin{array}{l}\text { Consulta por } \\
\text { inicio de tarea }\end{array}$ & $11 / 35$ & $\begin{array}{l}\text { Pregunta si están } \\
\text { leyendo y/o } \\
\text { respondiendo los } \\
\text { cuestionarios } \\
\text { mientras recorre } \\
\text { aula }\end{array}$ & $11 / 35$ \\
\hline $\begin{array}{l}\text { Modifica } \\
\text { tiempo y } \\
\text { espacio para } \\
\text { la tarea }\end{array}$ & $11 / 159$ & $\begin{array}{c}\text { Extiende } \\
\text { tiempo y } \\
\text { cambia espacio }\end{array}$ & $11 / 11$ & $\begin{array}{c}\text { Pregunta si } \\
\text { cumplimentaron la } \\
\text { tarea en los hogares } \\
\text { y ofrece tiempo } \\
\text { para responder en } \\
\text { clase }\end{array}$ & $11 / 11$ \\
\hline \multirow{5}{*}{ Sostiene tarea } & \multirow{5}{*}{$66 / 159$} & Devuelve & & $\begin{array}{c}\text { Incita a volver al } \\
\text { texto }\end{array}$ & $9 / 18$ \\
\hline & & $\begin{array}{l}\text { responsabilidad } \\
\text { por resolución } \\
\text { de tarea }\end{array}$ & $18 / 66$ & $\begin{array}{c}\text { Devuelve la } \\
\text { pregunta que } \\
\text { realizan los } \\
\text { alumnos }\end{array}$ & $9 / 18$ \\
\hline & & \multirow{3}{*}{$\begin{array}{l}\text { Regula la } \\
\text { interpretación } \\
\text { del texto }\end{array}$} & \multirow{3}{*}{$29 / 66$} & $\begin{array}{c}\text { Explica siglas o } \\
\text { términos } \\
\text { disciplinares que } \\
\text { los estudiantes } \\
\text { consultan } \\
\end{array}$ & $16 / 29$ \\
\hline & & & & $\begin{array}{c}\text { Explica oraciones o } \\
\text { párrafos que los } \\
\text { estudiantes } \\
\text { consultan a través } \\
\text { de ejemplos } \\
\text { familiares y } \\
\text { significativos }\end{array}$ & $6 / 29$ \\
\hline & & & & $\begin{array}{l}\text { Sitúa oralmente } \\
\text { contenidos en } \\
\text { determinado }\end{array}$ & $7 / 29$ \\
\hline
\end{tabular}




\begin{tabular}{|c|c|c|c|c|c|}
\hline & & & & $\begin{array}{l}\text { contexto socio- } \\
\text { histórico } \\
\text { ante dudas } \\
\text { formuladas }\end{array}$ & \\
\hline & & & & $\begin{array}{l}\text { Indica partes del } \\
\text { texto donde hallar } \\
\text { la respuesta }\end{array}$ & $13 / 19$ \\
\hline & & $\begin{array}{l}\text { búsqueda de } \\
\text { respuestas en el } \\
\text { texto }\end{array}$ & $19 / 66$ & $\begin{array}{c}\text { Incita a leer partes } \\
\text { del texto que } \\
\text { contienen ideas } \\
\text { clave leyendo su } \\
\text { comienzo en voz } \\
\text { alta }\end{array}$ & $6 / 19$ \\
\hline \multirow{4}{*}{$\begin{array}{c}\text { Cierra } \\
\text { parcialmente } \\
\text { tarea }\end{array}$} & \multirow{4}{*}{$47 / 159$} & \multirow{2}{*}{$\begin{array}{c}\text { Avala } \\
\text { respuesta }\end{array}$} & \multirow[b]{2}{*}{$32 / 47$} & $\begin{array}{c}\text { Avala localización } \\
\text { de párrafos } \mathrm{u} \\
\text { oraciones }\end{array}$ & $22 / 32$ \\
\hline & & & & $\begin{array}{c}\text { Avala } \\
\text { interpretación del } \\
\text { texto enunciada por } \\
\text { los alumnos }\end{array}$ & $10 / 32$ \\
\hline & & \multirow{2}{*}{$\begin{array}{l}\text { Enuncia } \\
\text { respuesta }\end{array}$} & \multirow[t]{2}{*}{$15 / 47$} & $\begin{array}{c}\text { Explicita oralmente } \\
\text { la respuesta } \\
\text { esperada }\end{array}$ & $11 / 15$ \\
\hline & & & & $\begin{array}{l}\text { Lee en voz alta la } \\
\text { respuesta esperada }\end{array}$ & $4 / 15$ \\
\hline
\end{tabular}

Podemos efectuar algunas anticipaciones a partir de los datos presentados en la Tabla 28. Observamos mayor cantidad de intervenciones docentes para sostener (66/159) y cerrar parcialmente la tarea (47/159) que para promover su comienzo (35/159) y modificar el tiempo y el espacio destinados a la misma (11/159). En relación con la gran cantidad de intervenciones que apuntan a sostener la tarea (66/159), identificamos mayor número de regulaciones de la interpretación del texto (29/66) y una cantidad similar de regulaciones de la búsqueda de respuestas en el texto (19/66) y de devoluciones de la responsabilidad por la resolución de la tarea (18/66). En cuanto al cierre parcial de la tarea (47/159), la mayoría de las intervenciones docentes lo hacen a través de avalar las respuestas que los estudiantes localizan en el texto o enuncian (32/47).

Los subapartados siguientes describen cada categoría, ejemplificando las intervenciones docentes y analizando el comportamiento de los estudiantes ante ellas.

\subsubsection{Promueve y monitorea la puesta en tarea}

Esta categoría agrupa las intervenciones en las cuales observamos que los docentes fomentan que se establezca y se mantenga la atención conjunta en la tarea. De acuerdo con Sensevy (2012), la atención conjunta es uno de los conceptos centrales para pensar la estructura básica de las interacciones didácticas porque remite a la focalización de alumnos y profesores en los mismos objetos de conocimiento presentados en la tarea. Particularmente, en nuestro estudio, 
y para la tarea de leer para responder cuestionarios, consideramos que la "puesta en tarea" implica la concentración de los estudiantes en las consignas y materiales de lectura pautados, que conforma su disposición a cumplimentarla.

Tal como anticipó la Tabla 28, en la gestión del medio, identificamos 35 intervenciones (35/159) en las que, para posibilitar la puesta en tarea los profesores o bien incitan oralmente a los estudiantes a que empiecen a leer la bibliografía para responder los cuestionarios, o bien monitorean que el grupo haya efectivamente comenzado a leer y escribir a partir de preguntar si lo están haciendo mientras recorren el aula para constatarlo. La Tabla 29 presenta la cantidad de intervenciones contabilizadas y las desagrega por cada materia indagada.

Tabla 29. Subcategorías e intervenciones docentes de la categoría "promueve y monitorea la puesta en tarea”

\begin{tabular}{|c|c|c|c|c|}
\hline Subcategoría & $\begin{array}{c}\text { Total de } \\
\text { intervenciones }\end{array}$ & Intervenciones docentes & Asignatura & $\begin{array}{c}\text { Total de } \\
\text { intervenciones } \\
\text { por asignatura } \\
\end{array}$ \\
\hline \multirow{3}{*}{$\begin{array}{l}\text { Incita oralmente a } \\
\text { ponerse en tarea }\end{array}$} & \multirow{3}{*}{$24 / 35$} & \multirow{3}{*}{$\begin{array}{c}\text { Indica que se pongan a leer } \\
\text { y/o responder los } \\
\text { cuestionarios }\end{array}$} & A & $1 / 24$ \\
\hline & & & $\mathrm{B}$ & $13 / 24$ \\
\hline & & & $\mathrm{C}$ & $10 / 24$ \\
\hline \multirow{2}{*}{$\begin{array}{c}\text { Consulta por inicio } \\
\text { de tarea }\end{array}$} & \multirow{2}{*}{$11 / 35$} & \multirow{2}{*}{$\begin{array}{c}\text { Pregunta si están leyendo } \\
\text { y/o respondiendo los } \\
\text { cuestionarios mientras } \\
\text { recorre aula }\end{array}$} & $\mathrm{A}$ & $8 / 11$ \\
\hline & & & $\mathrm{B}$ & $3 / 11$ \\
\hline
\end{tabular}

Según lo mostrado en la Tabla 29, en las tres asignaturas los docentes incitan a los estudiantes a ponerse en tarea. Observamos que son los docentes de las Asignaturas B y C quienes mayormente intervienen de este modo (13/24 y 10/24, respectivamente), mientras que el profesor de la Asignatura A suele permanecer a la espera de que sean los estudiantes quienes espontáneamente comiencen la tarea, por lo que solo los incita a ello en una ocasión $(1 / 24)$ e interviene en mayor medida consultando por su inicio (8/11). Por su parte, no registramos intervenciones de la docente de la Asignatura $\mathrm{C}$ en la que ésta pregunte a los alumnos si están leyendo y/o respondiendo los cuestionarios, sino únicamente indicaciones de que lo hagan. A continuación, describimos y analizamos las subcategorías mencionadas.

\subsubsection{Incita oralmente a ponerse en tarea}

En las materias indagadas, se promueve la puesta en tarea a través de 24 intervenciones en las que los docentes indican en forma oral comenzar a leer y/o responder los cuestionarios (24/35). Para posibilitar la atención conjunta (Sensevy, 2012), notamos que estos profesores buscan establecer un encuadre de trabajo: ante distracciones que obstaculizan la puesta en 
tarea, tales como conversar de temas ajenos a la materia, usar teléfonos celulares o netbooks para navegar por redes sociales o escuchar música en volumen alto, piden hacer silencio o apagar estos artefactos, porque ello impide que lean para responder los cuestionarios. Tal como ejemplifica la Tabla 30, notamos que los primeros pedidos de los profesores no provocan el comportamiento buscado, ya que los estudiantes responden con bromas o continúan conversando y/o escuchando música. Sin embargo, luego de la reiteración de estas solicitudes, los alumnos acceden a comenzar la tarea: buscan en los materiales la página correspondiente al texto que deben leer y empiezan a hacerlo.

Tabla 30. Promueve y monitorea la puesta en tarea: incita oralmente a ponerse en tarea. Fragmento de clase de la Asignatura $C$

Clase 3. Para responder veintidós consignas dictadas la clase previa, los estudiantes leen sobre paraísos fiscales a partir de fotocopias del módulo de Cultura Fiscal.

\section{Interacciones}

1. Nadia: [8 min $32 \mathrm{~s} / 1 \mathrm{~h} 41 \mathrm{~min} 1 \mathrm{~s}$ ] No voy a copiar [se refiere a copiar las consignas del cuestionario, dado que estuvo ausente la clase en la cual fueron dictadas], no tengo ganas.

2. DC: ¿Por qué?

3. Nadia: No, mentira. [Al rato, comienza a observa su celular] Tengo frío.

4. DC: Oíme, ponéte a trabajar. [Algunos alumnos conversan, otros leen para responder el cuestionario].

5. Ernesto: ¿Tenés una fotocopia para darme [sobre el módulo que se encuentran trabajando]? La 1levo a casa. Y te la traigo el martes. [Nadia canta en voz alta una canción].

6. DC: Pero vamos a trabajar ahora [en clase].

7. Ernesto: Sí.

8. DC: Bueno [le entrega una copia], pero ponéle ganas ahora [Nadia se encuentra sentada en su silla con los ojos cerrados] Nadi, ¡dale! [...] ¿Sabes que estoy así como a un pelito [cerca] de enojarme [porque no realiza la tarea]? No tengo ganas de enojarme un viernes.

9. Nadia: Estoy por copiar, eh. Para que no digas nada, porque estoy hablando [conversando con los compañeros] también.

10. DC: No, pero hablá y copiá, yo no tengo problema [Nadia comienza a copiar las consignas en su carpeta mientras conversa con Daiana acerca de un campeonato de fútbol que se lleva a cabo en "El Barrio". Lautaro y Ernesto, compañeros de banco, leen el texto].

11. Lautaro: Te informo que no tengo ganas de hacer nada.

12. DC: Te informo que tenés que ponerte a hacer [Lautaro y Ernesto empiezan a charlar sobre temas ajenos a la materia. DA se acerca] [Habla con tono de disgusto] ¿Qué parte [de cumplimentar la tarea] es la que no entienden?

13. Lautaro: Ah, bueno, qué mala esa actitud [Ríe].

14. DC: Pónganse a trabajar.

15. Ernesto: Sí, lo voy a hacer igual. Ya me avisaste que vas a tomar prueba y son 22 preguntas [las consignas del cuestionario] [Retoma la lectura del texto].

En el fragmento de clase que reproduce la Tabla 30, algunos estudiantes no se hallan concentrados en la tarea: Nadia no copia las consignas del cuestionario, canta o conversa con compañeros, mientras que Lautaro y Ernesto no las responden sino que charlan entre sí. Ante ello, la docente de la Asignatura $\mathrm{C}$ interviene indicando que se pongan a copiar las consignas y leer el texto, logrando concentrar la atención de los alumnos en la tarea tras varios intentos. 


\subsubsection{Consulta por inicio de tarea}

Además de promover la puesta en tarea, identificamos que en once intervenciones los docentes de las Asignaturas A y B monitorean si efectivamente los estudiantes se encuentran leyendo y/o respondiendo los cuestionarios (11/35). Para ello, recorren el aula, observando el comportamiento y la actividad de los alumnos y les preguntan si han iniciado la tarea. Tal como muestra el fragmento de clase de la Tabla 31, los estudiantes que han comenzado la tarea responden afirmativamente o mostrando lo escrito mientras que aquellos que no la han iniciado bromean al respecto o permanecen en silencio.

Tabla 31. Promueve y monitorea la puesta en tarea: consulta por inicio de tarea. Fragmento de clase de la Asignatura $A$

Clase 8. El docente propone que comiencen a leer en clase textos del cuadernillo para responder consignas, tal como requiere un trabajo práctico de la materia. Luego, comienza a recorrer el aula observando a los estudiantes.

\section{Interacciones}

1. DA: [24 $\min 3 \mathrm{~s} / 1 \mathrm{~h} 4 \min 45 \mathrm{~s}$ ] [Algunos estudiantes conversan] Daiana, ¿están trabajando?

2. Daiana: Sí, estoy copiando [las consignas del trabajo. La alumna se había ausentado la clase previa, en la cual DA dictó las consignas del trabajo práctico].

3. DA: [Sigue recorriendo el aula. Comienza a escucharse música del celular de Daiana] Daiana, ¿vos estas con el celular?

4. Ernesto: ¡Dale Daiana, Daianaaa! [Ríe]

5. DA: [Contesta dudas de alumnos. Ernesto conversa con sus compañeras] Ernesto ¿qué les pasa hoy que no trabajan?

6. Ernesto: Tenemos prueba hoy [en otra materia] [Ríe] [El docente no responde, permanece en silencio]. [Algunos estudiantes charlan sobre lo que hicieron el fin de semana, otros leen del cuadernillo y consultan con el docente sus dudas].

La Tabla 31 muestra un ejemplo de cómo el docente de la Asignatura A monitorea la puesta en tarea de los estudiantes. Cuando nota que la atención de Daiana y Ernesto no se focaliza en la tarea, consulta qué ocurre que no se encuentran leyendo y/o respondiendo el cuestionario. Ante estas intervenciones, Daiana informa que está copiando las consignas mientras que Ernesto, quien no está leyendo el texto indicado, bromea justificando su distracción de la tarea.

\subsubsection{Modifica tiempo y espacio para la tarea}

La presente categoría refiere a las intervenciones en las que se decide modificar el tiempo y el espacio destinado a la tarea (ver Tabla 28). En nuestro análisis identificamos que solo el docente de la Asignatura A, al tomar conocimiento de que los alumnos no han efectuado la tarea de leer para responder cuestionarios en sus hogares, interviene en la gestión del medio extendiendo el tiempo y cambiando el espacio (11/159). 
Al referirnos a esta forma de intervenir, es preciso recordar que, como mostramos en el subapartado 6.1.1, la misma se presenta como una solución ad hoc al obstáculo que el docente de la Asignatura A encuentra al respecto de su definición inicial del medio. Efectivamente, este profesor observa que cuando solicita que en los hogares lean y respondan por escrito preguntas globales que figuran en el cuadernillo, la mayoría de los alumnos llega a clase sin haber realizado esta tarea e incluso, en algunos casos, sin el material bibliográfico. Así, en todas las ocasiones que obtienen respuestas negativas a su pregunta sobre si los alumnos han efectuado la tarea en sus hogares, este docente decide cambiar el espacio y otorgar tiempo de clase para que la inicien y/o completen. Dicho tiempo, valga aclarar, el profesor informa haberlo planificado originalmente para realizar otra actividad.

Este modo de gestionar el medio implica una redefinición de la tarea, dado que modifica principalmente el contexto espacio-temporal asignado para llevarla a cabo. La Tabla 32 muestra un ejemplo de estas intervenciones, en las que el profesor A decide dar tiempo para leer y responder los cuestionarios en clase.

Tabla 32. Modifica tiempo y espacio para la tarea: extiende tiempo y cambia espacio. Fragmento de clase de la Asignatura $A$

Clase 2. El profesor propone poner en común las respuestas al cuestionario sobre el texto "El difícil arte de asir a la juventud" de Mario Margulis, incluido en el cuadernillo. La clase previa, el docente había indicado comenzar a leerlo para contestar las consignas y finalizar la tarea en los hogares

\section{Interacciones}

1. DA: [7 min $44 \mathrm{~s} / 1 \mathrm{~h} 36 \mathrm{~s}$ ] ¿Cerramos hoy “Juventudes” [se refiere al texto de Margulis]? A mí me hubiera gustado que estén todos [los alumnos] [hace referencia a la cantidad de alumnos ausentes: solo se encuentra presente la mitad de los estudiantes que conforma el curso] [Dirigiéndose a Daiana] ¿Qué pusiste vos, por ejemplo, en la [pregunta] seis? ¿Cómo abordaste la seis?

2. Daiana: Yo hice las dos [respuestas] juntas.

3. DA: ¿La [pregunta] seis y la siete?

4. Daiana: No, la [pregunta] siete la verdad que yo no la entendí. La siete y la ocho no la entendí.

5. DA: Bueno, ahora vamos a llegar a eso [se refiere a que, luego de poner en común la respuesta a la sexta consigna, revisarán las subsiguientes]. Bueno, ¿la [pregunta] seis quién... [la hizo]? ¿Carla?

6. Carla: No, no la hice [respondí] la [consigna] seis.

7. DA: ¿No la hiciste?

8. Fabiana: Yo no tengo hecho ninguna [respuesta].

9. DA: Bueno, ¿por qué no terminan ustedes de analizar esa última parte [se refiere a las últimas preguntas que los estudiantes dicen no haber respondido] y ya hacemos la puesta en común? Les doy unos minutos. Tenemos tiempo todavía [se refiere a la hora de finalización de la clase]. Con que [todavía] no empecemos con el otro texto... [se refiere al material que había planificado comenzar a trabajar dicha clase]. Terminen la seis, la siete y la ocho. Terminen acá [en clase], lo tendrían que haber traído para hoy ya terminado [el cuestionario], [pero] según ustedes, si no terminaron... [No continúa la frase]. [Los alumnos toman sus cuadernillos y comienzan a leer].

La Tabla 32 ejemplifica las intervenciones que modifican en forma espacial y temporal la tarea, provocando una redefinición de ésta. En el fragmento de clase mostrado se propone una extensión del tiempo planificado para leer y responder consignas sobre el texto de Margulis y, a la vez, un cambio de lugar para hacerlo. Como denotan las intervenciones 
verbales de los estudiantes, algunos no han finalizado el cuestionario (Daiana y Carla) mientras que otros no lo han comenzado siquiera (Fabiana). Probablemente, esto se relacione con las dificultades para cumplimentar la tarea en sus casas, tal como mencionan en las entrevistas (ver subapartado 6.1.1). Estas intervenciones, entonces, no solo dan más tiempo para completar la tarea sino que ofrecen un contexto distinto al de sus hogares, con un docente disponible para responder consultas y un clima de silencio favorecedor de la concentración y atención que requiere la lectura e interpretación de textos de estudio. Como respuesta a estas intervenciones, los estudiantes comienzan o retoman la lectura del cuadernillo para contestar los cuestionarios globales.

\subsubsection{Sostiene tarea}

En esta categoría se engloban intervenciones de devolución y regulación a través de las cuales los docentes buscan promover la interacción de los alumnos con la problemática que presenta la tarea. Específicamente, nos referimos aquí a intervenciones en las que los profesores devuelven la responsabilidad que les incumbe a los alumnos en la tarea (Brousseau, 1986, 1994, 2007) y regulan su actividad (Rickenmann, 2006; Sensevy, 2007).

En total, tal como mostró la Tabla 28, hallamos 66 intervenciones en las que los docentes de las materias indagadas sostienen la tarea (66/159) en la gestión del medio, promoviendo que los estudiantes sigan leyendo para contestar los cuestionarios. Para sostener la tarea, a) devuelven a los estudiantes la responsabilidad por su resolución, b) regulan la interpretación del texto o c) regulan la búsqueda de respuestas en los materiales. Basándonos en la caracterización de movimientos docentes que propone Sensevy (2012) mostraremos cómo, a través de estas tres formas de sostener la tarea, los profesores adoptan distintas posiciones transaccionales en las que no utilizan el mismo tipo de reticencia acerca del conocimiento que poseen. La Tabla 33 ilustra las subcategorías que construimos a partir del análisis y las intervenciones docentes que observamos, mediante las cuales los profesores de las tres asignaturas sostienen la tarea.

Tabla 33. Subcategorías e intervenciones docentes de la categoría "sostiene tarea"

\begin{tabular}{cccccc}
\hline Subcategoría & $\begin{array}{c}\text { Total de } \\
\text { intervenciones }\end{array}$ & $\begin{array}{c}\text { Intervenciones } \\
\text { docentes }\end{array}$ & $\begin{array}{c}\text { Total de } \\
\text { intervenciones }\end{array}$ & Asignatura & $\begin{array}{c}\text { Total de } \\
\text { intervenciones }\end{array}$ \\
\hline \multirow{2}{*}{$\begin{array}{c}\text { Devuelve } \\
\text { responsabilidad } \\
\text { por resolución } \\
\text { de tarea }\end{array}$} & $18 / 66$ & $\begin{array}{c}\text { Incita a volver } \\
\text { al texto }\end{array}$ & $9 / 18$ & $\mathrm{~A}$ & $1 / 9$ \\
\cline { 2 - 6 } & & $\begin{array}{c}\text { Devuelve la } \\
\text { pregunta que } \\
\text { realizan los }\end{array}$ & $9 / 18$ & $\mathrm{~B}$ & $7 / 9$ \\
\cline { 3 - 6 } & & & $\mathrm{B}$ & $7 / 9$ \\
\hline
\end{tabular}




\begin{tabular}{|c|c|c|c|c|c|}
\hline & & alumnos & & & \\
\hline \multirow{7}{*}{$\begin{array}{c}\text { Regula la } \\
\text { interpretación } \\
\text { del texto }\end{array}$} & \multirow{7}{*}{$29 / 66$} & Explica siglas & \multirow{3}{*}{$16 / 29$} & A & $2 / 16$ \\
\hline & & disciplinares & & B & $13 / 16$ \\
\hline & & $\begin{array}{l}\text { estudiantes } \\
\text { consultan }\end{array}$ & & $\mathrm{C}$ & $1 / 16$ \\
\hline & & $\begin{array}{c}\text { Explica } \\
\text { oraciones o } \\
\text { párrafos que } \\
\text { los estudiantes } \\
\text { consultan a }\end{array}$ & \multirow[t]{2}{*}{$6 / 29$} & B & $3 / 6$ \\
\hline & & $\begin{array}{l}\text { traves de } \\
\text { ejemplos } \\
\text { familiares y } \\
\text { significativos }\end{array}$ & & $\mathrm{C}$ & $3 / 6$ \\
\hline & & $\begin{array}{c}\text { Sitúa } \\
\text { oralmente } \\
\text { contenidos en }\end{array}$ & \multirow[b]{2}{*}{$7 / 29$} & A & $5 / 7$ \\
\hline & & $\begin{array}{l}\text { determinado } \\
\text { contexto socio- } \\
\text { histórico ante } \\
\text { dudas } \\
\text { formuladas }\end{array}$ & & B & $2 / 7$ \\
\hline \multirow[b]{3}{*}{$\begin{array}{c}\text { Regula la } \\
\text { búsqueda de } \\
\text { respuestas en el } \\
\text { texto }\end{array}$} & \multirow[b]{3}{*}{$19 / 66$} & $\begin{array}{c}\text { Indica partes } \\
\text { del texto donde }\end{array}$ & \multirow{2}{*}{$13 / 19$} & B & $6 / 13$ \\
\hline & & $\begin{array}{c}\text { hallar la } \\
\text { respuesta }\end{array}$ & & $\mathrm{C}$ & $7 / 13$ \\
\hline & & $\begin{array}{c}\text { Incita a leer } \\
\text { partes del texto } \\
\text { que contienen } \\
\text { ideas clave } \\
\text { leyendo su } \\
\text { comienzo en } \\
\text { voz alta }\end{array}$ & $6 / 19$ & A & $6 / 6$ \\
\hline
\end{tabular}

En la Tabla 33 se aprecia que casi la mitad de las intervenciones en las que se sostiene la tarea corresponden a regulaciones de la interpretación del texto (29/66). Dentro de estas regulaciones, notamos mayoría de intervenciones en las que se explican siglas o términos disciplinares (16/29), ejercidas casi en su totalidad por el profesor de la Asignatura B (13/16). Respecto de las otras intervenciones de regulación de la interpretación del texto, cuya cantidad es similar, observamos que los docentes de las Asignaturas B y C explican párrafos u oraciones a través de ejemplos familiares y significativos (6/29) y que los profesores de las Asignaturas A y B, ante dudas formuladas por los estudiantes al leer los textos, sitúan oralmente contenidos en determinado contexto socio-histórico (7/29).

En cuanto a las intervenciones en las que se regula la búsqueda de respuestas en el texto (19/66), en su mayoría son indicaciones de porciones donde hallar las respuestas (13/19), ejercidas por los docentes de las Asignaturas B y C. Sin embargo, el profesor de la Asignatura A también interviene regulando la búsqueda de respuestas, diferenciándose de los 
otros docentes en que incita a leer partes de los materiales donde hallar ideas clave para responder las consignas leyendo su comienzo en voz alta (6/19).

Finalmente, de los datos presentados en la Tabla 33 se desprende que también se sostiene la tarea mediante la devolución de la responsabilidad por resolverla (18/66) a través de una cantidad equivalente de intervenciones en las que se incita a volver al texto (9/18) y se devuelve la pregunta que los estudiantes realizan (9/18). Quién mayormente acciona de ambos modos es el profesor de la Asignatura B mientras que los otros docentes así intervienen solamente en una o dos ocasiones.

Otro análisis puede efectuarse a partir de los datos presentados en la Tabla 33. Si ponemos el énfasis en los modos de sostener la tarea, hallamos que el docente de la Asignatura A interviene una cantidad similar de ocasiones para regular la interpretación del texto y la búsqueda de respuestas (7 y 6 veces, respectivamente), el profesor de la Asignatura B acciona mayormente regulando la interpretación del texto (18 veces) y la profesora de la Asignatura $\mathrm{C}$ regulando la búsqueda de respuestas ( 7 veces). A continuación, detallamos estas intervenciones con ejemplos de cada subcategoría.

\subsubsection{Devuelve responsabilidad por resolución de la tarea}

La teoría de las situaciones didácticas de Brousseau postula que los estudiantes aprenden si construyen conocimientos en forma autónoma, como respuesta al problema planteado por la situación. Para posibilitar esto, los docentes tienen que promover que los estudiantes asuman la responsabilidad por resolver ellos mismos la tarea, gestionando condiciones para devolverles el problema (Brousseau, 1986, 1994, 2007). De ese modo, siguiendo a Sensevy (2007, 2012), se preserva la cláusula proprio motu, dado que se impulsa que los estudiantes produzcan estrategias por su propio movimiento, sin que los docentes les indiquen cómo ganar el juego didáctico. Al respecto, Sadovsky (2005) recalca que no hay actos que garanticen per se que el alumno se hará cargo del problema planteado por la tarea, porque de sus acciones dependen finalmente que ello suceda. No obstante, a través de las intervenciones que describimos a continuación, pueden apreciarse condiciones para su devolución.

Conviene subrayar que en la tarea de leer para responder cuestionarios no se configura un problema, tal como lo concibe Brousseau (2007), a partir de un medio antagonista que plantea contradicciones y desequilibrios como sucede en las situaciones matemáticas que este investigador analiza. No obstante, la tarea de leer y dar respuesta a las consignas de los cuestionarios plantea una situación-problema, cuya responsabilidad por resolverla los profesores deben fomentar que los estudiantes asuman. En relación con dicha tarea, 
identificamos 18 intervenciones en las que los docentes de las tres asignaturas sostienen la tarea mediante la devolución a los estudiantes de la responsabilidad por resolver los cuestionarios (18/66). En estas oportunidades, originadas a partir de consultas de los alumnos sobre cómo responder consignas, los profesores no comunican su saber sino que incitan a que los estudiantes vuelvan al texto para buscar la respuesta, o bien devuelven la pregunta formulada por los estudiantes para que éstos continúen pensando al respecto.

Respecto de la devolución de responsabilidad a los alumnos registramos que, en la mitad de las intervenciones contabilizadas, los profesores de las tres materias indagadas incitan a volver al texto (9/18). Estas intervenciones sostienen la tarea al recordar a los estudiantes que es suya la responsabilidad por contestar las consignas de los cuestionarios y que es posible responderlas a partir de la lectura de los materiales propuestos. Cuando los profesores intervienen promoviendo volver a la bibliografía, y no responden la pregunta efectuada por los estudiantes, estos retornan a los materiales para poder contestarla. En la Tabla 34 puede verse un ejemplo de ello.

Tabla 34. Devuelve responsabilidad por resolución de tarea: incita a volver al texto. Fragmento de clase de la Asignatura $B$

Clase 15. Los estudiantes se encuentran leyendo el artículo periodístico "Pelea por el ALCA: cómo se alineó cada país y qué se puso en juego" para responder un cuestionario que el docente copia en el pizarrón al comenzar la clase.

\section{Interacciones}

1. Lautaro: [32 $\min 31 \mathrm{~s} / 58 \mathrm{~min} 4 \mathrm{~s}$ ] [En voz alta y dirigiéndose a sus compañeros] ¿Encontraron la [respuesta a la consigna] cuatro? [se refiere a la consigna “¿Qué países estaban de acuerdo (con el ALCA) y por qué?].

2. DB: [Se acerca al banco de Lautaro] Si vos te ponés a leer, fijáte a ver cómo yo puedo... [encontrar la respuesta a la pregunta] [No continúa la frase].

3. Lautaro: Chile [Sin volver al texto, efectúa una posible respuesta a la consigna por la cual consulta].

4. DB: Bueno, puede llegar a ser [un país que estaba de acuerdo con el ALCA]. Leé.

5. Claudia: ¿La cuatro? [consulta por la misma consigna que Lautaro]

6. DB: [En voz alta, habla a todo el curso] Bueno, lo que tenemos que hacer en principio es leer todo [el artículo], ¿no? Leer todo esto. Y después [ver si] “¿me responde acá?”.

[Los alumnos lo escuchan en silencio y continúan leyendo la fotocopia del artículo en búsqueda de la respuesta a la consigna].

En el fragmento de clase que reproduce la Tabla 34, el docente de la Asignatura B, ante la consulta de Lautaro y Claudia por una consigna del cuestionario, incita a los estudiantes a volver al artículo periodístico que se encuentran leyendo para poder responderla. Respecto de la rápida respuesta de Lautaro (“Chile”), el profesor no indica si contesta o no la consigna, sino que mantiene en suspenso su saber para que el alumno pueda responderse a sí mismo tras leer el texto. Ante estas intervenciones, los estudiantes vuelven al texto para intentar resolver las consignas por las que consultan. 
Mediante intervenciones como estas, los docentes ceden su lugar como fuentes de saber disciplinar para otorgárselo a los textos, instituyendo la bibliografía como portadora de un conocimiento que precisa ser interpretado y reconstruido. Así, los profesores destacan que en la bibliografía puede hallarse la solución al problema planteado por la tarea $\mathrm{y}$, al mismo tiempo, promueven que los estudiantes adopten el rol de interpretantes de los textos para construir conocimientos dentro de la situación planteada.

Además de las intervenciones que devuelven la responsabilidad por la resolución de la tarea, registramos que en las Asignaturas B y C los profesores devuelven preguntas que los estudiantes realizan acerca de consignas que no logran comprender y/o contestar. De este modo, evitan facilitar las respuestas para fomentar que los alumnos sigan pensando al respecto. En efecto, tras estas intervenciones, los estudiantes continúan leyendo los materiales para responder los cuestionarios, tal como ilustra el fragmento de clase reproducido en la Tabla 35 .

Tabla 35. Devuelve responsabilidad por resolución de tarea: devuelve la pregunta que realizan los alumnos. Fragmento de clase de la Asignatura $B$

Clase 16. Los estudiantes se encuentran leyendo el artículo periodístico "De la gesta que enterró el ALCA a la construcción de la UNASUR", para responder un cuestionario que el docente copia en el pizarrón al comenzar la clase.

\begin{tabular}{l} 
Interacciones \\
\hline 1. Claudia: [35 min $40 \mathrm{~s} / 38 \mathrm{~min} 21 \mathrm{~s}$ ] La [respuesta a la pregunta] cuatro [Se refiere a la consigna “¿Cómo \\
finalizó esa cumbre de países?”], era lo de la Casa Blanca ¿o no? \\
2. DB: La pregunta dice “¿Cómo finalizó esa cumbre de países?” ¿Qué pasó finalmente? \\
[Claudia vuelve a concentrar su mirada en la fotocopia del artículo, buscando la respuesta. Otros \\
estudiantes llaman al docente y éste se acerca a sus bancos].
\end{tabular}

En las interacciones que muestra la Tabla 35, Claudia consulta por la respuesta a una consigna del cuestionario. Ante ello, el docente no responde la pregunta (no contesta cómo finalizó la cumbre de países donde se discutió sobre el ALCA) sino que vuelve a formularla a los estudiantes para que sigan buscando la respuesta en el artículo periodístico. Estas intervenciones, tal como ilustra la Tabla 35, promueven que los alumnos retomen la lectura del texto.

\subsubsection{Regula la interpretación del texto}

Otro tipo de intervenciones que sostienen la tarea, son aquellas en las que el docente regula la interpretación del texto (29/66), brindando algún tipo de ayuda que permita avanzar con la lectura. De acuerdo con nuestro análisis, intervenciones docentes tales como explicar siglas, términos disciplinares, oraciones y/o párrafos que aparecen en la bibliografía y por los cuales 
los estudiantes consultan, o bien situar oralmente contenidos en determinado contexto sociohistórico ante dudas formuladas, contribuyen a que los estudiantes sigan involucrados en la resolución de la tarea, leyendo el texto y escribiendo las respuestas a los cuestionarios. Tal como veremos en el análisis a continuación, estas intervenciones, valoradas por los estudiantes en las entrevistas como ayudas para entender los temas, ofrecen aclaraciones y explicaciones de las dudas comandadas bajo la perspectiva del docente y no requieren que éstos enuncien lo que comprenden de lo que están leyendo.

Identificamos que una forma de regular la interpretación del texto consiste en que los docentes expliquen siglas o términos disciplinares que figuran en los textos indicados para leer y responder cuestionarios (16/29). El docente de la Asignatura B es quien exhibe mayor número de estas regulaciones (13/16). Precisemos un ejemplo de estas intervenciones en la Tabla 36.

Tabla 36. Regula la interpretación del texto: explica siglas o términos disciplinares que los estudiantes consultan. Fragmento de clase de la Asignatura $B$

Clase 7. Los alumnos se encuentran leyendo un manual de Historia Mundial para responder consignas que el profesor copia en el pizarrón.

\section{Interacciones}

1. Daiana: [17 $\min 23 \mathrm{~s} / 45 \min 39 \mathrm{~s}$ ] [Se encuentra con sus compañeros Ernesto y Nadia leyendo el manual] ¿Qué era profe la URSS?

2. DB: La Unión de Repúblicas Socialistas Soviéticas. [Daiana asiente y continúa leyendo el manual].

Como muestra el fragmento de clase de la Tabla 36, la aclaración del docente de la Asignatura B sobre el significado de la sigla "URSS", al zanjar la duda conceptual de Daiana, facilita una comprensión local del texto que le permite avanzar con la lectura.

Estas intervenciones en las que se regula la interpretación del texto no proponen entender las siglas o los términos disciplinares apelando al contexto en el que son utilizados ni a través de imaginar su significado o consultarlo con los compañeros, estrategias que Lerner (2001) y Lerner y otros (1997) han mostrado son propias de los lectores competentes, y cuya enseñanza se observó productiva para la lectura de textos considerados difíciles. La utilidad de estas estrategias radica en que ponerlas en práctica y apropiarse de ellas permite a los estudiantes resolver con relativa autonomía las dudas respecto de siglas o términos disciplinares que aparecen en los textos, sin necesidad de depender de un docente que las clarifique, tal como sucede en las intervenciones ejemplificadas anteriormente.

En comparación con estas intervenciones en las que se explica el significado de siglas o términos disciplinares, hallamos menor cantidad de intervenciones en las que se regula la interpretación del texto a través de explicar, mediante ejemplos familiares y significativos 
para los estudiantes, oraciones o párrafos del texto por los que consultan (6/29). Identificamos estas intervenciones solo en las Asignaturas B y C. La Tabla 37 presenta un fragmento de clase donde se observa este tipo de intervenciones.

Tabla 37. Regula la interpretación del texto: explica oraciones o párrafos que los estudiantes consultan a través de ejemplos familiares y significativos. Fragmento de clase de la Asignatura C

Clase 9. Para responder un cuestionario, los alumnos se encuentran leyendo de sus carpetas la definición del impuesto sobre los bienes personales, que copiaron del pizarrón.

\section{Interacciones}

1. Ernesto: [ $40 \mathrm{~min} 21 \mathrm{~s} / 1 \mathrm{~h} 10 \mathrm{~min} 42 \mathrm{~s}$ ] [Lee en voz alta de su carpeta] ¿"Todos los bienes gananciales que tenga la mujer"? [Se refiere a una parte de la definición del impuesto al patrimonio que refiere a la sociedad conyugal: "Tributará el marido todos los bienes propios y los de la sociedad conyugal con excepción: bienes adquiridos por la mujer en el ejercicio de la profesión, que exista separación de bienes, que la administración de todos los bienes gananciales la tenga la mujer según resolución judicial]

2. DC: Sí, [suponéte que] vos te casas. Una vez que te casaste, todo lo que consigas después de eso es [bien] ganancial.

3. Ernesto: ¿Y lo que tenías antes?

4. DC: Lo que tenías antes, es tuyo.

5. Ernesto: ¿Y cómo saben [los jueces]?

6. DC: Porque vos en la escritura de una casa siempre te salta [aparece] la fecha.

7. Ernesto: ¿Y un televisor? [Suponéte que] Yo me compré un plasma de 42 pulgadas.

8. Yesica: Es tuyo.

9. Ernesto: ¿Pero qué sabe el tipo [juez] si es tuyo?

10. DC: Vos tenés que tener una boleta, la factura, específicamente a tu nombre.

11. Ernesto: Y si no [tenés la factura], fuiste... [no podés acreditar que es tuyo].

12. DC: Si no [tenés la factura], fuiste. Viste que a veces en la factura [de compra] no te ponen a nombre de quién [se expide]. Pero si vos lo pedís te ponen [el nombre], es una pavada [sencillo]. Pero todo lo que vos tenías antes de tu matrimonio es tuyo y lo de ella [la esposa] es de ella, y de ahí en adelante, es de los dos. Excepto que vos declares lo contrario. Que vos mientras estés casado hayas... [Por ejemplo] se murió tu viejo [papá] y heredaste una propiedad, en la costa, entonces eso, como es por herencia, es solo tuyo y ya no pasa a ser [bien] ganancial. Si vos el día de mañana te separas, por más que haya sido [heredada la propiedad] después que te casaste, sigue siendo tuyo.

13. Ariana: ¿Y cuándo tienen que firmar esa cosa? Ese...prenupcial.

14. DC: ¿Un acuerdo prenupcial? Lo hace la gente que tiene mucha guita [plata], nosotros no vale la pena que hagamos eso. ¿Qué voy a declarar? ¿Qué tengo una biblioteca de 500 libros y dos televisores? Yo otra cosa no tengo, o sea...pero la gente que tiene mucha plata, antes de casarse, establece que todo lo que era mío, va a seguir siendo mío, que eso es normal, es por ley. Pero [establecen que], lo que yo gane en el ejercicio de mi profesión va a seguir siendo mío, no va a ser algo conyugal, ¿se entiende? Y lo que vos [como esposo] ganás en el ejercicio de tu profesión, va a ser tuyo. Eso es.

[Los alumnos escuchan en silencio la explicación de la docente. Luego retoman la lectura de la definición].

En la Tabla 37 puede verse cómo la profesora de la Asignatura C regula la interpretación de uno de los materiales de lectura que ofrece en sus clases: definiciones teóricas que copia en el pizarrón para que los estudiantes lean y reproduzcan en sus carpetas y, luego, las utilicen para responder cuestionarios. Concretamente, en el ejemplo mostrado, explica una de las oraciones que forma parte de la definición del impuesto a los bienes personales, por la cual Ernesto consulta. Para explicar el contenido disciplinar en juego en dicha oración, recurre a diversos ejemplos como la escritura de una casa y la herencia de un inmueble en la costa. Ante estas intervenciones, los estudiantes se involucran participando 
oralmente con preguntas (interacciones $\mathrm{n}^{0} 3,5,7,9$ y 13) y comentarios que parecen evidenciar comprensión del tema (interacciones $\mathrm{n}^{\circ} 8 \mathrm{y} \mathrm{n}^{\circ} 11$ ).

En las entrevistas, los profesores de las Asignaturas B y C, que observamos que explican oraciones o párrafos de los textos utilizando ejemplos, mencionan valerse de estos recursos para relacionar los contenidos disciplinares con las experiencias cotidianas de los alumnos.

DB: [Trato de] Bajarlo [adaptarlo] a la forma [...] como ellos [los alumnos] hablan. [...] $Y$ después aplicarlo a una situación de la realidad concreta de ellos. [...] A veces les quedan lejos [los contenidos disciplinares].

DC: [Lo que busco es] poder vincularle [los contenidos] con algo cotidiano de ellos. ¿Yo como le puedo hacer entender a un pibe [los] impuestos sobre los bienes personales? [...] [Que se trata de] gente que gana más de 305 mil pesos al año. [...] A vos se te hace difícil entender lo que no ves, lo que no tocas, lo que no lo sentís cerca [...]. [Cuando se da cuenta que los alumnos no entendieron] tratamos de explicar de nuevo [...] con más ejemplos [...] más bajadito a la realidad. $[. .$.$] Que ellos [\ldots]$ puedan sentirlo como algo cercano.

Según estos docentes, la abstracción y la lejanía de ciertos contenidos disciplinares quedan allanadas al concretizarlos en ejemplos vinculados a los mundos significativos de los estudiantes. Sus afirmaciones coinciden con el registro de clase de la Tabla 37, en donde la docente de la Asignatura $\mathrm{C}$ recurre a ejemplos que verbaliza con términos de uso cotidiano de los alumnos, como "viejo" y "guita" (interacciones n¹2 y 14). Es posible pensar que, a través de estas explicaciones, los docentes buscan activar esquemas asimiladores previos de los alumnos y facilitar así la apropiación de los contenidos. En el mismo sentido, Wells (1993) halla en clases de Ciencias Naturales del nivel primario, que el lenguaje familiar empleado en ejemplos orales brindados por el docente tiende puentes entre las experiencias cotidianas de los alumnos y los significados abstractos que presentan los textos disciplinares.

En coincidencia con la importancia que los docentes otorgan a estas explicaciones, algunos estudiantes entrevistados sostienen que las mismas favorecen su comprensión de los contenidos porque, además de que apelan a ejemplos que les resultan cercanos a su cotidianeidad, también incorporan modos de utilizar el lenguaje que les resultan familiares y en los que pueden reconocerse. 
Yésica: [El profesora de la Asignatura B] me gusta como enseña, me re gusta. Aparte que te explica de una manera como que lo llegás a entender.

Ariana: Lo entendés, claro.

E: ¿Por qué? ¿Cómo hace?

Ariana: Y porque siempre te da un ejemplo.

Fabiana: [El profesor de la Asignatura B] cuando te da explicaciones, te da explicaciones de cosas de acá. Ponéle, el otro día estábamos viendo no sé qué cosa de países y nos tiró [dijo] "un kiosco y otro kiosco" [refiere a la Clase 3 de la materia, en la cual el docente explica la competencia entre industrias a través del ejemplo de dos kioscos instalados en una misma cuadra], entonces nosotros lo entendemos con nuestras palabras. Eso está bueno.

En estos extractos de entrevista, dos alumnas (2/14) vinculan su comprensión de los temas con el hecho de que los ejemplos que brinda el profesor de la Asignatura B les resultan cercanos, cotidianos y sencillos. Esta valoración positiva concuerda con el hecho de que, efectivamente, pudimos observar en las clases que los ejemplos promueven el involucramiento de los estudiantes a través de la participación oral y la escucha atenta y silenciosa de las explicaciones, tal como ilustramos en el fragmento de la Tabla 37.

Otra de las intervenciones docentes observadas para regular la interpretación del texto que se lee en la tarea consiste en situar oralmente contenidos disciplinares en determinado contexto socio-histórico. Estas intervenciones son similares a aquellas donde se contextualizan contenidos en la definición del medio, descritas en el apartado 6.1.3.2. Pero a diferencia de estas últimas, que buscan establecer significados compartidos con anterioridad a que los estudiantes comiencen a leer, las intervenciones docentes que aquí se detallan se producen en la gestión del medio y se suscitan a partir de consultas que los estudiantes efectúan respecto del material que están leyendo.

Identificamos siete intervenciones (7/29) en las cuales los profesores de las Asignaturas A y B regulan la interpretación del texto ubicando en cierto contexto sociohistórico los contenidos disciplinares sobre los que se lee. Tal como detallamos en el apartado 6.1.2, referente a la definición de recursos de lectura, estas dos materias abordan temas correspondientes a disciplinas como historia, sociología y geografía, que pertenecen al área de Ciencias Sociales. En cambio, en la Asignatura C, cuyos contenidos corresponden al área Jurídico-Contable, no registramos intervenciones de contextualización en la definición del medio ni en su gestión, lo que tal vez se deba a que en dicha área no sea tan relevante apelar a un contexto socio-histórico para trabajar los temas. 
Ante estas intervenciones que contextualizan contenidos en la gestión del medio, los estudiantes escuchan atentamente y en silencio a los docentes y participan oralmente con comentarios y preguntas, tras lo cual reemprenden la lectura de los textos. En la Tabla 38 reproducimos un fragmento de clase que ilustra estas intervenciones.

Tabla 38. Regula la interpretación del texto: sitúa oralmente contenidos en determinado contexto sociohistórico ante dudas formuladas. Fragmento de clase de la Asignatura A

Clase 11. Dado que los estudiantes admiten no haber comenzado a realizar el tercer trabajo práctico de la materia, que requiere leer y responder cuestionarios sobre textos del cuadernillo, el docente propone empezar a hacerlo en clase.

Interacciones

1. Yésica: [42 min $59 \mathrm{~s} / 1 \mathrm{~h} 38 \mathrm{~s}$ ] [Se encuentra leyendo el texto "La sociedad salarial está de fiesta"] [Lee en voz alta una consigna del cuestionario] “¿Cuáles son las implicancias en la sociedad en ese contexto?”. Ah, mirá, acá dice [lee en voz alta del texto], “los gobiernos peronistas de 1946-1955..." [No continúa leyendo] [...]. Es difícil [entender las implicancias de la sociedad] porque los otros [textos] te dicen [especifican] "sociedad", "economía".

2. DA: [Habla en voz alta a toda la clase]. Este texto [habla] del Estado intervencionista [...] se les va a hacer un poco más largo [leerlo] [refiere a la extensión del texto, que ocupa cuatro carillas del cuadernillo], [...] ¿cómo hay que pensar acá [en el texto] el Estado intervencionista? [...] En el modelo agroexportador, la Argentina era productor de materias primas. La exportábamos ¿a dónde?

3. Yésica: Estados Unidos.

4. Denise: Japón.

5. Marisa: Europa.

6. DA: Estados Unidos todavía no. Europa, básicamente, Inglaterra y recibíamos de Inglaterra ¿qué?

7. Yésica: Las cosas ya fabricadas.

8. DA: Las cosas ya fabricadas, los productos terminados. Y ese era el modelo agroexportador. Acá, que es el texto que ustedes le va a costar [se refiere al texto "La sociedad salarial está de fiesta"], piensen en eso. [El texto trata de] la industrialización por sustitución de importaciones. En un momento hay un crecimiento "hacia afuera", lo que crecen son los países extranjeros y, a partir de las crisis internacionales, la primera guerra [mundial], la crisis de Wall Street en 1929... [No continúa la frase]. En la ISI [industrialización por sustitución de importaciones], hay un crecimiento "hacia adentro" dicen algunos autores [...] porque [antes] el país no estaba industrializado, no había industrias. [...] El Estado por eso interviene en la economía, se "cierra" y hay una política de parte del Estado. [...] Hay un crecimiento también de la población, de los sectores del conurbano bonaerense, ¿las fabricas donde se instalan? En ciudades, Buenos Aires, Rosario, y el cordón del Gran Buenos Aires también aumenta, y ese aumento de la población también va a tener repercusiones en lo social.

9. Yésica: ¿Por qué [usted] dice [Estado] "intervencionista”?

10. DA: Porque el Estado interviene en la economía.

11. Yésica: Ahhh.

12. DA: Por eso digo también que hay una política, hay una industrialización porque el Estado como política implementa la industrialización, se nacionalizan los ferrocarriles.

[Los alumnos lo observan y escuchan en silencio. Luego, vuelven a dirigir su mirada al cuadernillo de la materia].

La Tabla 38 muestra cómo el profesor de la Asignatura A, a partir de la consulta de Yésica, interviene regulando la interpretación del texto "La sociedad salarial está de fiesta". Para ello, sitúa los contenidos disciplinares que entiende centrales (Estado intervencionista, industrialización por sustitución de importaciones) en el marco de cierto contexto sociohistórico y brinda características de ese período al que refiere la bibliografía (crecimiento "hacia adentro", crecimiento poblacional) y del período anterior (modelo agroexportador, 
crecimiento "hacia afuera", crecimiento de países extranjeros, guerras mundiales, crisis de Wall Street). Los estudiantes responden a estas intervenciones involucrándose a través de la participación oral y la escucha silenciosa y atenta, tras lo cual vuelven al texto para seguir leyendo.

Estas intervenciones en las que se contextualizan contenidos, al dar lugar en clase para hablar sobre períodos históricos, permiten que algunos alumnos efectúen preguntas al respecto que, de otro modo, posiblemente no se hubiesen formulado. Esto puede verse en la interacción $n^{\circ} 9$, cuando Yésica consulta por la denominación de "Estado intervencionista".

En el subapartado siguiente analizamos la tercera y última forma de sostener la tarea que identificamos en nuestro análisis.

\subsubsection{Regula la búsqueda de respuestas en el texto}

En las clases observadas, distinguimos otro modo de sostener la tarea: regular la búsqueda de respuestas en el texto mediante el señalamiento de ciertos apartados o párrafos donde hallar las respuestas o incitar su lectura leyendo su comienzo en voz alta. A diferencia de las intervenciones en las que los docentes regulan la interpretación del texto (ver subapartado 6.2.3.2), en donde los estudiantes aún deben leer todo el material para resolver la tarea, cuando los profesores regulan la búsqueda de respuestas de los modos descritos, limitan el problema a la lectura de determinadas partes. Por ello, en este tipo de regulación, los docentes ejercen una influencia mayor para que los estudiantes resuelvan la tarea: adoptan una "posición más alta" en las interacciones didácticas al intervenir direccionando y focalizando la atención de éstos en "signos relevantes" de la situación (Sensevy, 2012, p. 509) que, en la tarea de leer para responder cuestionarios, serían las partes donde es posible hallar las respuestas a las consignas. Si bien en estas intervenciones se acota la dificultad de la tarea, las mismas no se han incluido en la categoría "cierra parcialmente tarea" (ver apartado 6.2.4) debido a que, tras ellas, el problema de qué y cómo responder aún permanece sin solución: resta que los alumnos lean esas porciones de la bibliografía para identificar la respuesta o las ideas clave para contestar.

En el análisis de la gestión del medio, registramos 19 intervenciones en las que se sostiene la tarea a través de regular la búsqueda de respuestas en el texto (19/66). En relación con estas intervenciones, identificamos que los docentes de las Asignaturas B y C, cuando los estudiantes consultan por los textos y/o por las consignas de localización, indican los párrafos o apartados en los que pueden hallarse las respuestas (13/19), mientras que el profesor de la Asignatura A incita a leer el inicio de algunas partes del texto donde encontrar ideas claves 
para contestar las consignas globales (6/19). Para ilustrar el primero de estos modos de intervenir, seleccionamos un fragmento de clase de la Asignatura C, reproducido en la Tabla 39, donde se muestra cómo la profesora señala partes del material donde identificar respuestas a los cuestionarios.

Tabla 39. Regula la búsqueda de respuestas en el texto: indica partes del texto donde hallar la respuesta. Fragmento de clase de la Asignatura $C$

Clase 3. Los estudiantes se encuentran leyendo fotocopias del módulo de Cultura Fiscal para terminar de responder el cuestionario sobre paraísos fiscales que la docente dictó la clase anterior, que consta de veintidós preguntas.

1. Claudia: [2 min $11 \mathrm{~s} / 1 \mathrm{~h} 41 \mathrm{~min} 1 \mathrm{~s}$ de audio] Me falta [responder las preguntas número] 17 y 18 .

2. DC: [Se acerca a su banco].

3. Claudia: [Leyendo la pregunta número 17 del cuestionario dictado] “¿Cuáles son las dos formas de mover el dinero de manera electrónica?".

4. DC: Esta es una y esta es otra [Señala en las fotocopias dos párrafos que detallan las dos formas de mover el dinero en forma electrónica].

5. Claudia: Y después [leyendo la pregunta número 18] “¿Cuál es la manera de blanquear dinero?”

6. DC: Está en este pedacito [Señala un apartado en la fotocopia].

7. Claudia: [Comienza a leer dicho apartado].

8. Yésica: A mí me falta la última [se refiere a la pregunta número 22: “¿Qué sucede con el Impuesto a las Ganancias en las empresas radicadas en un paraíso fiscal?’].[Comienza a lee la consigna en voz alta.] “Qué sucede con el Impuesto a las Ganancias de las empresas radicadas....?"

9. DC: [Interrumpe] Está del otro lado de la hoja, debajo del título [se refiere al apartado bajo el subtítulo “¿Cómo operan las empresas radicadas en los TBT?”].

10. Yésica: [Voltea la fotocopia que estaba leyendo para dirigirse a la sección indicada y empieza a leerla].

11. Lautaro: [Lee la cuarta pregunta del cuestionario] “¿Cuáles son las modalidades básicas de los paraísos?” Bueno, es un poco larguita, ¿no? [se refiere a la extensión de un apartado bajo el subtítulo “¿Cuáles son las características básicas de un "paraíso fiscal"?”]

12. DC: No, no, no. Porque yo estoy hablando de las modalidades básicas y es otra cosa. [Se acerca a Lautaro, señala un párrafo de la fotocopia del módulo y lee en voz alta] "En función de las diferencias centrales, se pueden establecer tres modalidades básicas". Son esas tres.

13. Lautaro: [Hablándole a Ernesto, su compañero de banco, señala el párrafo indicado por la docente hasta su última oración] Desde "en función" hasta acá. [Ambos comienzan a copiar en sus carpetas el párrafo indicado].

Las interacciones $\mathrm{n}^{\circ}$ 4, 6, 9 y 12 de la Tabla 39 ilustran cómo la docente de la Asignatura $\mathrm{C}$ indica apartados o párrafos específicos donde hallar las respuestas buscadas. Si bien puede pensarse que estas intervenciones son producto de la necesidad de hacer avanzar el tiempo didáctico para iniciar las actividades planificadas para el día -dado que finalizar dicho cuestionario era una tarea pautada para la clase anterior-, vale aclarar que se registraron en numerosas clases observadas.

Ante estas indicaciones, se acota la dificultad del problema: los estudiantes se dirigen a ciertas porciones del material, evitando leer otras. Luego, copian en sus carpetas esas partes como respuesta a las preguntas de localización planteadas en las Asignaturas B y C. En la Tabla 39, Claudia y Yésica lo evidencian cuando retoman la lectura donde lo indica la 
profesora (interacciones $\mathrm{n}^{\mathrm{o}} 7$ y 10 ), mientras que Lautaro lo muestra al informar a su compañero que deben copiar el párrafo que ésta ha señalado (interacción $n^{\circ} 13$ ).

Observamos que en ninguna de las intervenciones en las que se señalan párrafos o apartados donde localizar respuestas, los docentes de las Asignaturas B y C alientan a los estudiantes a enunciar sus interpretaciones acerca de lo que están leyendo. Esto puede verse en las interacciones que muestra la Tabla 39: la docente no indaga las razones por las cuales los estudiantes no han finalizado el cuestionario: si se debe a la cantidad de consignas, a la falta de tiempo para terminarlas en la clase anterior, a la incomprensión de ciertas preguntas de localización y/o a la dificultad para entender el módulo de Cultura Fiscal que leen. Un ejemplo de ello es el caso de Lautaro: su interpretación del material (o una simple correspondencia entre términos de la consigna y el texto) lo lleva a situar la respuesta a la pregunta “¿Cuáles son las modalidades básicas de los paraísos?” en el párrafo bajo el subtítulo “¿Cuáles son las características básicas de un paraíso físcal?” (Interacción n¹1). Sin embargo, la profesora se limita a señalar dónde está el párrafo que responde la pregunta. No le pregunta a Lautaro qué comprende, ni por qué cree que ese párrafo contesta la consigna. Tampoco aclara la posible confusión conceptual entre "modalidades" y “características", en el marco de su disciplina.

Volvamos aquí al análisis de las intervenciones que regulan la búsqueda de respuestas, describiendo otras en las que se incita a leer ciertas partes del texto que contienen ideas clave leyendo su comienzo en voz alta. Hallamos que solo el profesor de la Asignatura A interviene así en seis oportunidades (6/19). Tal como ilustra la Tabla 40, ante estas intervenciones, los alumnos concentran su atención en esas porciones del texto y las leen en voz baja.

Tabla 40. Regula la búsqueda de respuestas en el texto: incita a leer partes del texto que contienen ideas clave leyendo su comienzo en voz alta. Fragmento de clase de la Asignatura $A$

Clase 5. Los estudiantes se encuentran leyendo "Los mitos de la historia argentina" del historiador Felipe Pigna, texto incluido en el cuadernillo, para responder el cuestionario que allí figura.

1. Yésica: [41 $\min 25 \mathrm{~s} / 49 \min 57 \mathrm{~s}$ ] Profe.

2. DA: [Se acerca a su banco]

3. Yésica: La [consigna] tres dice “¿Cuál es la relación entre historia y política?”. [...] Porque acá [en el texto] dice que [lee en voz alta] es "alarmante la efectividad de este mecanismo que despolitiza y reduce, en el imaginario social, prácticamente a la nada nuestra historia".

4. DA: O como esto [lee en voz alta el párrafo siguiente al que leyó Yésica]: "resulta interesante destacar el valor didáctico y formativo que tuvo y tiene inculcar este concepto de la historia y, por ende, de la política. En esta concepción de que la política es para los otros...". [No termina la lectura de la oración]. Esto es lo que dice él [el autor] [Otras alumnas lo llaman y DA se acerca a sus bancos].

5. Yesica: [En voz baja habla a su compañera de banco Daiana] Bueno tenés que leer hasta acá [se refiere al párrafo que DA leyó en voz alta]. Porque esto explica [la relación entre historia y política]. [Ambas alumnas comienzan a leer el párrafo]. 
De modo similar a las intervenciones en las que se señalan partes del texto donde hallar respuestas, aquí el docente de la Asignatura A lee en voz alta algunas partes del texto de Felipe Pigna para que los alumnos continúen leyéndolas. Al hacerlo, da la pauta a los estudiantes de que allí se encuentran ideas clave del autor que permiten, luego de interpretarlas, contestar las consignas globales planteadas en los cuestionarios del cuadernillo. Cabe aclarar que los textos de esta asignatura presentan ideas principales que se encuentran explícitas en el texto así como ideas implícitas que los autores sostienen en ciertos párrafos, sin expresarlas directamente, o a lo largo del material.

$\mathrm{Al}$ igual que las intervenciones en las que los docentes $\mathrm{B}$ y $\mathrm{C}$ indican párrafos $\mathrm{o}$ apartados, en estas intervenciones el profesor de la Asignatura A no requiere a los alumnos que digan lo que han entendido de las oraciones por las cuales lo consultan ni tampoco que enuncien lo que comprenden de las partes cuyo inicio lee en voz alta. En la Tabla 40 puede verse un ejemplo de ello: Yésica lee en voz alta una oración del texto de Pigna que cree responde cierta consigna (“¿Cuál es la relación entre historia y política?”) y luego escucha la lectura de otra oración por parte del docente, pero éste no pide que explicite sus interpretaciones al respecto. De esa forma, permanece velada la comprensión que Yésica ha alcanzado sobre lo qué sostiene Pigna en esas oraciones así como sus dificultades para responder cuál es la relación entre historia y política para el autor. Puede afirmarse entonces que estas intervenciones dejan a los alumnos solos ante el reto de construir las ideas integrales, explicaciones o relaciones que requieren las consignas globales, según Aisenberg (2004, 2005a, 2010) y Carlino (2005).

El comportamiento de los estudiantes ante estas intervenciones es idéntico al descrito para los señalamientos de párrafos o apartados realizados por los profesores de las Asignaturas B y C. En vez de continuar leyendo el texto en su totalidad, o discutir lo que entienden de lo leído y así resolver la tarea, se dirigen a las partes que indica el docente de la Asignatura A, para leerlas y reproducir algunas oraciones a modo de respuesta a las consignas. Por ello, estas intervenciones también acotan la dificultad del problema planteado por la tarea.

\subsubsection{Cierra parcialmente tarea}

Aquí se categorizan dos tipos de intervenciones en las cuales los docentes, antes de que los estudiantes respondan por escrito las consignas, dan cierre parcial a la tarea revelando las respuestas que consideran correctas, alcanzadas, en un caso, por su propia actividad 
(enuncian respuesta) y, en el otro, por la actividad de los alumnos (avalan respuesta). Con cierre "parcial" nos referimos a que, si bien estas intervenciones colaboran con la resolución de la tarea al enunciar o avalar las respuestas esperadas, los alumnos aún deben escribirlas en sus carpetas para concluir la tarea.

En el primer tipo de intervenciones que identificamos, enunciar las respuestas, los profesores abandonan la reticencia mostrando su saber (Sensevy, 2007, 2012) al explicitar oralmente las respuestas esperadas o leerlas en voz alta del texto. En el segundo tipo de intervenciones que distinguimos, los profesores también cierran parcialmente la tarea al avalar las localizaciones o interpretaciones de los textos que efectúan los alumnos. No obstante, en esos casos, son los estudiantes los que han obtenido por sí mismos la respuesta a las consignas.

En la gestión del medio, tal como anticipó la Tabla 28, identificamos un total de 47 intervenciones correspondientes a cerrar parcialmente la tarea de leer para responder cuestionarios (47/159). En la Tabla 41 se muestran las subcategorías construidas a partir del análisis y las intervenciones docentes observadas, junto con su contabilización por cada asignatura.

Tabla 41. Subcategorías e intervenciones docentes de la categoría "cierra parcialmente tarea"

\begin{tabular}{|c|c|c|c|c|c|}
\hline Subcategoría & $\begin{array}{c}\text { Total de } \\
\text { intervenciones }\end{array}$ & $\begin{array}{c}\text { Intervenciones } \\
\text { docentes }\end{array}$ & $\begin{array}{c}\text { Total de } \\
\text { intervenciones }\end{array}$ & Asignatura & $\begin{array}{c}\text { Total de } \\
\text { intervenciones } \\
\text { por } \\
\text { asignatura } \\
\end{array}$ \\
\hline \multirow{5}{*}{$\begin{array}{l}\text { Avala } \\
\text { respuesta }\end{array}$} & \multirow{5}{*}{$32 / 47$} & \multirow{3}{*}{$\begin{array}{c}\text { Avala } \\
\text { localización de } \\
\text { párrafos u } \\
\text { oraciones }\end{array}$} & \multirow{3}{*}{$22 / 32$} & A & $4 / 22$ \\
\hline & & & & B & $12 / 22$ \\
\hline & & & & $\mathrm{C}$ & $6 / 22$ \\
\hline & & \multirow{2}{*}{$\begin{array}{c}\text { Avala } \\
\text { interpretación } \\
\text { del texto } \\
\text { enunciada por } \\
\text { los alumnos }\end{array}$} & \multirow[t]{2}{*}{$10 / 32$} & B & $4 / 10$ \\
\hline & & & & $\mathrm{C}$ & $6 / 10$ \\
\hline \multirow{4}{*}{$\begin{array}{l}\text { Enuncia } \\
\text { respuesta }\end{array}$} & \multirow{4}{*}{$15 / 47$} & \multirow{3}{*}{$\begin{array}{l}\text { Explicita } \\
\text { oralmente la } \\
\text { respuesta } \\
\text { esperada }\end{array}$} & \multirow{3}{*}{$11 / 15$} & A & $1 / 11$ \\
\hline & & & & B & $3 / 11$ \\
\hline & & & & $\mathrm{C}$ & $7 / 11$ \\
\hline & & $\begin{array}{c}\text { Lee en voz alta } \\
\text { la respuesta } \\
\text { esperada }\end{array}$ & $4 / 15$ & A & $4 / 4$ \\
\hline
\end{tabular}


La Tabla 41 muestra que los docentes de las asignaturas indagadas cierran parcialmente la tarea en más ocasiones avalando las respuestas de los estudiantes (32/47) que enunciándolas ellos mismos (15/47). Al respecto, es más frecuente que avalen la localización de párrafos u oraciones (22/32) que lo hagan de las interpretaciones enunciadas por los alumnos (10/32).

Respecto de enunciar las respuestas esperadas (15/47), contabilizamos mayor número de intervenciones en las que éstas se explicitan oralmente (11/15) en comparación con su lectura en voz alta de los textos (4/15). Las primeras corresponden a intervenciones que, en su mayoría, ejerce la docente de la Asignatura C (7/11), mientras que las segundas solo las realiza el profesor de la Asignatura A. Los siguientes subapartados describen y analizan en detalle estos modos de intervenir dando cierre parcial a la tarea.

\subsubsection{Avala respuesta}

En más de la mitad de las intervenciones que distinguimos dan cierre parcial a la tarea, los docentes avalan la localización de párrafos u oraciones o la interpretación del texto que enuncian los alumnos a modo de respuesta a las consignas (32/47), antes de que éstos las escriban en sus carpetas. En este punto, estas intervenciones se distinguen de aquellas que mostraremos en el subapartado 6.3.1.1, mediante las cuales los profesores, en la evaluación de la tarea, brindan avales sobre las respuestas ya escritas.

Concretamente, gran parte de las intervenciones en las que los profesores avalan respuestas y cierran parcialmente la tarea se produce luego de que los estudiantes indican ciertos párrafos u oraciones que localizaron (22/32). Al respecto, notamos que los profesores de Asignaturas B y C intervienen confirmando las respuestas que los alumnos hallan para las consignas de localización mientras que el docente de la Asignatura A aprueba la identificación de ciertos párrafos como necesarios para contestar las consignas globales. Ejemplificamos estas intervenciones con un fragmento de clase reproducido en la Tabla 42.

Tabla 42. Avala respuesta: avala localización de párrafos u oraciones. Fragmento de clase de la Asignatura $\underline{B}$

Clase 1. El docente propone leer un texto de un manual de Historia Mundial Contemporánea y contestar las preguntas del cuestionario que allí figura.

\section{Interacciones}

1. Lautaro: [39 $\min 47 \mathrm{~s} / 56 \min 55 \mathrm{~s}$ ] [Pregunta en voz alta al docente, refiriéndose a la consigna "¿Qué importancia tuvo el proteccionismo para el capitalismo, según Stiglitz?’] ¿[La respuesta] Puede ser [comienza a leer en voz alta una oración del texto] "edificaron...”? Vení un segundo. [Continúa leyendo la oración] “...sus economías mediante la protección sabia y selectiva de alguna de sus industrias".

2. DB: Está bien.

3. Lautaro: Eso [sería la respuesta] ¿no? 
4. DB: Ajá. [Lautaro copia en su hoja la oración que leyó en voz alta].

5. Daiana: Profe.

6. DB: Sí. [Se acerca a su banco]

7. Daiana: La [respuesta de la consigna número] dos, ¿es esto? De acá hasta acá. [Señala un fragmento del texto].

8. DB: Sí, sí. Muy bien. [Daiana copia en su carpeta el fragmento que señaló al docente].

En la Tabla 42 el docente de la Asignatura B avala las localizaciones que Lautaro y Daiana hacen de fragmentos que creen contestan ciertas consignas de un cuestionario. Tras recibir ese aval, los estudiantes transcriben en sus carpetas las partes que señalan al docente.

$\mathrm{Al}$ analizar estas intervenciones en las que se avalan localizaciones, registramos que ninguno de los tres profesores pregunta a los alumnos qué han entendido de esos fragmentos ni por qué piensan que contestarían las consignas, sean de localización o globales. Efectúan, en cambio, una convalidación inmediata de esas partes identificadas por los estudiantes sin antes relevar la comprensión de los estudiantes. Al mismo tiempo, y siguiendo a Brousseau (2007), estas intervenciones impiden que los estudiantes asuman la responsabilidad de juzgar el valor de las respuestas que identifican.

En las restantes 10 intervenciones en las que se avalan respuestas (10/32), los profesores de las Asignaturas B y C ratifican las interpretaciones de los textos que los estudiantes enuncian en forma oral. El hecho de que no sucedan intervenciones de este tipo de la Asignatura A puede relacionarse con que las consignas globales allí propuestas requieren la construcción de ideas globales que, de acuerdo con lo que los estudiantes dicen en las entrevistas, se les dificulta efectuar, por lo que tampoco las enunciarían en forma oral.

La Tabla 43 muestra un ejemplo en el que se avalan las interpretaciones de los estudiantes.

Tabla 43. Avala respuesta: avala interpretación del texto enunciada por los alumnos. Fragmento de clase de la Asignatura $C$

Clase 8. Para responder preguntas de un cuestionario, los alumnos se encuentran leyendo de sus carpetas la definición de impuestos internos que la docente escribió en el pizarrón y estos copiaron.

\section{Interacciones}

1. Ernesto: [59 min 37 s/1 hs 49 min 16 s] Profe, "expendio" sería la transmisión del producto, que lo manden al mercado si son importados.

2. DC: ¿Qué pregunta [querés responder]?

3. Martín: [Compañero de banco de Ernesto] [Lee la consigna cinco del cuestionario] "¿A qué se denomina expendio del producto?"

4. D: Ah, está bien.

[Ernesto y Martín copian en sus carpetas la oración que leyeron en la definición de impuestos internos, que menciona el expendio del producto, y a partir de la cual interpretaron su significado].

En la Tabla 43 la docente de la Asignatura C avala la interpretación de Ernesto sobre lo que se denomina como expendio del producto en los impuestos internos. Tanto Ernesto, 
quien ha consultado por dicha consigna de localización, como su compañero de banco Martín, toman ese aval para copiar en sus carpetas, a modo de respuesta, la oración que leyeron en la que encuentra el término "expendio".

En estas intervenciones, ejemplificadas con la Tabla 43, notamos que los profesores de las Asignaturas B y C no preguntan a los alumnos cómo han llegado a esa interpretación, no ahondan en las dudas de aquellos que no lo logran ni tampoco promueven que las interpretaciones se confronten con las de otros estudiantes.

Como mostraremos más adelante, algunas de las interpretaciones de los estudiantes, aun siendo avaladas por los profesores, no aparecen en las producciones escritas del modo que son enunciadas. En cambio, las respuestas a los cuestionarios son mayoritariamente reproducciones de partes de los textos leídos. Esto indicaría que el hecho de que los alumnos formulen una interpretación, y aparentemente hayan comprendido ciertos contenidos disciplinares del modo que buscan los docentes, no alcanza para que puedan escribir al respecto prescindiendo de la copia de lo leído. Para ello se necesitaría un profesor que ayude a trabajar lo interpretado para que el conocimiento pueda ser apropiado y que acompañe la producción textual para que allí pueda expresarse lo entendido.

\subsubsection{Enuncia respuesta}

Registramos 15 intervenciones en las que los tres docentes de las materias indagadas cierran parcialmente la tarea (15/47) renunciando a la reticencia que el juego didáctico requiere para que los alumnos puedan movilizar sus conocimientos y producir respuestas proprio motu (Sensevy, 2007, 2012). Este abandono que efectúan cuando explicitan oralmente la respuesta esperada o la leen en voz alta de los textos, representa una paradoja del contrato didáctico denominada por Brousseau (1986) como trasmisión de las situaciones: los estudiantes no hallan la solución del problema didáctico por sí mismos sino que son los profesores quienes la revelan. Se trata de una paradoja en la medida en que los docentes terminan dando la solución del problema que esperan resuelvan los alumnos. En vez de "esconder" (Sensevy, 2007, p.12) lo que saben, lo suministran directamente.

Uno de los modos de abandonar esta reticencia, identificado en las tres materias indagadas, y en la mayoría de las intervenciones de enunciar las respuestas (11/15), es explicitarlas oralmente. En algunas ocasiones, esta explicitación está precedida por la corrección por parte de los docentes de una respuesta enunciada por los alumnos que consideran errónea. En la Tabla 44 presentamos un fragmento de clase con un ejemplo de estas intervenciones. 
Tabla 44. Enuncia respuesta: explicita oralmente la respuesta esperada. Fragmento de clase de la Asignatura $C$

Clase 11. La docente reparte una fotocopia del módulo de Cultura Fiscal que versa sobre los parámetros renta y consumo y otra fotocopia con consignas. Luego, indica a los alumnos que respondan las consignas con la información de la fotocopia y con las definiciones copiadas en sus carpetas la clase anterior.

\section{Interacciones}

1. Fabiana: [19 $\min 9 \mathrm{~s} / 55 \min 17 \mathrm{~s}$ ] [Se levanta de su silla y se acerca a la docente]. No entiendo. [Lee una consigna del cuestionario] "En los impuestos a los bienes personales ¿sobre qué paga impuesto el contribuyente?"

2. DC: $[\ldots]$ Por el excedente de 305 mil pesos.

[Fabiana lee la fotocopia del módulo y cuando identifica el párrafo en el que se encuentra dicha cifra, lo copia en su carpeta].

La Tabla 44 muestra cómo, ante la pregunta de Fabiana, la docente interviene explicitando la respuesta que espera en relación con lo que se debe tributar en el impuesto sobre los bienes personales. Observamos que en esta intervención, la profesora no indaga si los motivos por los cuales esta alumna consulta se deben a dificultades para comprender la pregunta en cuestión o para entender los contenidos disciplinares que presenta el texto. Por su parte, Fabiana utiliza esta intervención para identificar el párrafo donde figura lo enunciado por la docente, que sería la respuesta "correcta", y lo copia en su carpeta. Aquí puede verse cómo la profesora da un cierre parcial a la tarea, enunciando cuál es la respuesta que espera, pero para concluir la tarea la alumna aún debe escribir la respuesta a la consigna en su carpeta.

Además de estas intervenciones en las que se explicita oralmente la respuesta esperada, se cierra parcialmente la tarea en otras cuatro intervenciones en las cuales se enuncia la respuesta esperada a través de su lectura en voz alta del texto (4/15). Hallamos que solo el docente de la Asignatura A lo hace de este modo, tal como ejemplifica la Tabla 45.

Tabla 45. Enuncia respuesta: lee en voz alta la respuesta esperada. Fragmento de clase de la Asignatura $A$

Clase 11. Los estudiantes se encuentran leyendo textos del cuadernillo para responder un cuestionario que dicta el docente.

\section{Interacciones}

1. Yésica: [38 min $3 \mathrm{~s} / 1 \mathrm{hs} 38 \mathrm{~s}$ ] [Se encuentra leyendo el texto "La sociedad salarial está de fiesta"] Profe. [Llama al docente y señala en su carpeta la consigna "Características del modelo de Estado y modelo económico"].

2. DA: Empezá a contextualizarlo [el texto], ahí viendo que dice eso, lo económico es esto [lee una oración del segundo párrafo del texto] "modelo de crecimiento 'hacia adentro', mercado interno, sector industrial".

3. Yesica: ¿Eso pongo como característica [del modelo de Estado y modelo económico]?

4. DA: Del estado y la economía.

5. Yésica: Yo pensé que la contextualización era [una respuesta] más...[No termina la frase]

6. DA: Más amplia, sí, por eso, lo de la contextualización abarca eso y [lee una oración del primer párrafo del texto] "[El Estado intervencionista] en sus diversas vertientes, restaurador, burocrática, autoritaria, militar, distributivo, desarrollista". [Yesica copia en su carpeta esas oraciones el docente leyó en voz alta]. 
Al igual que en las intervenciones en las que los docentes explicitan las respuestas en forma oral, cuando el profesor de la Asignatura A lee oraciones en voz alta que responden las consignas de localización que en ocasiones propone, los estudiantes copian en sus carpetas las partes leídas por éste, tal como muestra la Tabla 45. Antes de efectuar esa reproducción, Yésica lo pregunta claramente al docente en la interacción n⿳3: “Eso pongo como característica [del modelo de Estado y modelo económico]?”. Su comentario en la interacción n5 ("Yo pensé que la contextualización era [una respuesta] más...”) sugiere que no le ha quedado claro en qué consiste contextualizar, tal como pide el profesor.

A diferencia de las intervenciones en las que se enuncian las respuestas oralmente, en estas intervenciones el profesor de la Asignatura A, aunque también cierra parcialmente la tarea tomando a su cargo la responsabilidad de identificar la respuesta, lo hace volviendo al texto, lo que resalta la importancia de recurrir a la bibliografía como fuente de saber. Por este motivo, estas intervenciones pueden relacionarse con aquellas en las que este docente incita a leer partes del texto que contienen ideas clave leyendo su comienzo en voz alta (ver subapartado 6.2.3.3). Sin embargo, en estas últimas el profesor regula la búsqueda de respuestas en el texto señalando implícitamente que allí, tras su lectura, se pueden encontrar ideas claves para contestar las consignas globales que mayoritariamente propone. Por este motivo, incluimos esas intervenciones dentro de la categoría "sostiene tarea", dado que éstas promueven que los estudiantes continúen leyendo e interpretando el material para responder la consigna por la que consultan. En cambio, las intervenciones que analizamos aquí forman parte de la categoría "cierra parcialmente tarea" porque enuncian la respuesta esperada y los estudiantes solo deben copiarlas en sus carpetas para concluir la tarea: el profesor directamente lee las oraciones que responden algunas de las consignas de localización que también dicta (aunque en forma minoritaria), tales como la que los alumnos deben responder en el fragmento de clase de la Tabla 45: "[Indicar] Características del modelo de Estado y modelo económico". El análisis que realizamos del texto "La sociedad salarial está de fiesta", incluido en el cuadernillo, muestra que la respuesta a esta consigna puede identificarse en párrafos específicos.

Mediante estos dos tipos de intervenciones de enunciar la respuesta (explicitándola oralmente o leyéndola en voz alta de los textos), los docentes de las tres asignaturas ofrecen a los estudiantes los conocimientos que quieren ver aparecer y les revelan la solución del problema, lo cual fue denominado por Brousseau $(1990,2007)$ como un efecto Topaze en la negociación del contrato didáctico. De acuerdo con Sensevy (2007), esto representa una trampa en la producción de estrategias ganadoras: si bien dentro del contrato didáctico se 
espera que los estudiantes busquen cómo "ganar" el juego de aprendizaje, en el efecto Topaze los docentes toman a su cargo dicho trabajo y dan las respuestas que permiten ganarlo.

Estas intervenciones son mencionadas en las entrevistas por tres alumnos del curso de quinto año (3/14):

E: Y cuando ustedes leen un texto de la materia, ¿entienden lo que están leyendo?

Denise: Yo a veces no, [...] ayer me pasó con [nombra al profesor de la Asignatura B] [...] [el texto] era con palabras, viste, raras [...] me confundía.

E: ¿Y qué hiciste?

Denise: Este...lo releí, lo releí, le pregunté y más o menos como que me dijo y así pude encontrar [la respuesta] y lo hice.

Fabiana: [Nombra al profesor de la Asignatura B] es todo el tiempo [decirle] “¿Venís? ¿Esto está bien?". [Él] Te va tirando un palo [ayuda] para que a vos te salga.

E: Y ponéle que vos tenés una pregunta y no entendés qué está preguntando, ¿qué hacés?

Guadalupe: Y le pregunto al profesor y ahí más o menos explica, y cuando te explica por ahí te tira la respuesta.

En estos extractos de entrevistas tres alumnas comentan que, ante las dificultades de comprensión de las consignas o del texto, los docentes suelen ayudar "tirando un palo", "la respuesta" o "me dijo y así pude encontrar [la respuesta]". Sus dichos corroboran que intervenciones de este tipo proporcionan a los estudiantes las respuestas a las consignas de los cuestionarios. Al producir un efecto Topaze, el riesgo que conllevan estas ayudas es que se dependa de ellas (y por ende, de un docente presente en el aula que las brinde) para resolver la tarea y/o que se las utilice sin haberlas comprendido.

\subsubsection{Algunas conclusiones sobre la función gestión del medio}

Tras describir y analizar las 159 intervenciones docentes identificadas para la función docente de gestión del medio, es posible sostener algunas conclusiones por cada materia.

En las tres asignaturas indagadas los docentes, para asegurar que haya una atención conjunta (Sensevy, 2012) en la tarea, incitan a los estudiantes a ponerse en tarea y monitorean si lo hacen mientras recorren el aula. En la Asignatura A, el docente interviene mayormente consultando por su inicio, a diferencia de las otras materias, en las cuales los profesores alientan explícitamente a hacerlo, en ocasiones, ordenándolo (ver Tabla 29). Los resultados 
muestran que la sola consulta no alcanza para estimular a los alumnos a ponerse en tarea sino que es necesario incitarlos reiteradamente a que comiencen a leer y contestar las consignas.

Ya anteriormente mostramos que la mayoría de los alumnos se dispone a cumplimentar la tarea si ésta se propone en clase. Los profesores de las Asignaturas B y C directamente plantean leer y responder consignas de localización en clase ya que asumen que, en caso de proponer hacerlo en las casas, los estudiantes no lo harán. Adviértase que, en cambio, el docente de la Asignatura A debe dar tiempo para responder en clase como una intervención ad hoc, ya que su propuesta inicial de contestar cuestionarios en las casas no es llevada a cabo por los alumnos. Por este motivo, este docente redefine la tarea a través de modificar el tiempo y el espacio: asigna tiempo de clase para contestar en el aula las consignas globales. Al realizar estos cambios espacio-temporales, postula un contexto favorecedor de la concentración y la atención necesarias para leer e interpretar textos de estudio, en el cual él mismo se haya disponible para responder consultas, lo que solventaría las dificultades enunciadas por los estudiantes para leer en sus casas: la ausencia de un lectorinterpretante que ayude a comprender los textos de circulación social y la falta de un escenario propicio para realizarlo.

Pasemos ahora a considerar las intervenciones en las que se sostiene la tarea promoviendo la interacción de los alumnos con la problemática que presenta la tarea. En nuestro análisis, contabilizamos mayor cantidad de intervenciones en las que se regula la actividad de los estudiantes (Sensevy, 2007) que cantidad de intervenciones en las que se devuelve la responsabilidad que les concierne por resolver la tarea (Brousseau, 1986, 1994, 2007). Al respecto, tal como mostró la Tabla 33, el docente de la Asignatura A interviene una cantidad similar de oportunidades para regular la interpretación del texto y la búsqueda de respuestas, el profesor de la Asignatura $\mathrm{B}$ acciona mayormente regulando la interpretación del texto y la profesora de la Asignatura $\mathrm{C}$ regulando la búsqueda de respuestas.

En gran parte de las intervenciones que regulan la interpretación del texto, el docente de la Asignatura B explica siglas o términos disciplinares que los estudiantes consultan. Estas explicaciones sostienen la tarea al permitir que los estudiantes sigan leyendo tras resolver sus dudas. Sin embargo, según Lerner (2001) y Lerner y otros (1997), para enseñar a leer textos difíciles resulta productivo otro tipo de intervenciones: fomentar que los estudiantes imaginen el significado de las siglas o términos, lo consulten con compañeros o apelen al contexto en el que se usan para entenderlos.

También mostramos que, en una cantidad similar de intervenciones, se regula la interpretación de los textos mediante explicaciones de oraciones o párrafos a través de 
ejemplos significativos para los alumnos (Asignaturas B y C) o contextualizaciones de los contenidos (Asignaturas A y B). En relación con los ejemplos que brindan los docentes, en las entrevistas los estudiantes afirman que les ayudan a entender los temas, lo que coincide con la investigación de Wells (1993), que identifica que ciertos ejemplos orales que dan profesores de Ciencias Naturales establecen puentes entre las experiencias cotidianas de los alumnos y los significados de los textos disciplinares.

En cuanto a la regulación de la búsqueda de respuestas en el texto, los profesores de las Asignaturas B y C intervienen indicando partes para leer mientras que el docente de la Asignatura A incita lectura de las mismas al leer su inicio en voz alta. Estas intervenciones se realizan desde una "posición más alta" en las interacciones didácticas, ya que promueven que los estudiantes focalicen la atención en "signos relevantes" de la situación (Sensevy, 2012, p. 509), limitando el problema a la lectura de ciertas partes de los textos. Lo que resalta, desde luego, es que a través de esta posición los docentes ejercen un quehacer considerado por Aisenberg (2004) como imprescindible en la lectura: localizar información de un texto, que soluciona la dificultad de los estudiantes para identificar qué parte del texto leer para responder consignas, en vez de convertirla en un problema didáctico para trabajar en conjunto en la clase. Por ello, es dable pensar que estas intervenciones de regulación de la búsqueda de respuestas en el texto representan una sobrerregulación que quita responsabilidad a los estudiantes por identificar información en los materiales. En efecto, tal como mostramos, estos docentes no preguntan a los alumnos que presentan dificultades en la resolución de la consigna por qué no pueden hallar en las fuentes las ideas para resolver el cuestionario ni tampoco generan situaciones para discutir lo leído. Nótese que fuera de situaciones escolares, el quehacer de localizar información de un texto prescinde de la facilidad que otorgan los cuestionarios de localización (en los que las preguntas presentan la misma redacción con la cual pueden hallarse sus respuestas en el texto) y los manuales y módulos escolares (que presentan resaltados de ideas clave) usuales en las Asignaturas B y C. En razón de ello, cobraría aun más relevancia el hecho de crear oportunidades de dialogo sobre lo leído para intercambiar interpretaciones, confrontarlas y desarrollar la comprensión.

Todas estas intervenciones de regulación (tanto del texto como de la búsqueda de respuestas) sostienen la tarea, dado que los estudiantes continúan leyendo para contestar los cuestionarios. No obstante, deseamos subrayar al lector que las explicaciones -de siglas, términos disciplinares, oraciones o párrafos del texto- y las contextualizaciones de los contenidos se ofrecen directamente sin requerir que, con anterioridad, los estudiantes analicen el problema de comprensión que les presentan los materiales y expresen sus interpretaciones 
acerca de lo que están leyendo. Por ello, en estas intervenciones lo que los estudiantes interpretan queda en un segundo plano en comparación con la perspectiva del profesor sobre cómo deben entenderse los temas sobre los que tratan los textos.

En paralelo con este análisis respecto de las intervenciones de regulación en la gestión del medio, notamos que si bien se suceden algunos intercambios docente-alumnos en torno a estas explicaciones y contextualizaciones, no se promueven intercambios alumno-alumno en los cuales sus interpretaciones entren en discusión. Según Sadovsky (2005), las interacciones entre pares pueden promover confrontaciones de los puntos de vista (en este caso, sobre lo leído) que funcionen a modo de retroacciones y lleven a modificar las perspectivas o a producir argumentos que refuten los planteos de otros. Cabe señalar en relación con ello que, aunque estas intervenciones fomentan que algunos estudiantes participen de la clase sumando preguntas y comentarios a las explicaciones y contextualizaciones mencionadas-, varios alumnos permanecen en silencio y no dan muestras de cómo entienden lo explicado por los profesores y/o lo comentado por sus compañeros.

Lo mismo sucede en las ocasiones en las que se regula la búsqueda de respuestas en los textos a través de indicar partes donde hallar respuestas, como en las Asignaturas B y C, o incitar la lectura de las mismas leyendo su comienzo en voz alta, como en la Asignatura A. Ambos tipos de intervenciones promueven que los estudiantes continúen en tarea pero dependiendo de un profesor que reduzca la dificultad del problema al identificar en qué lugar específico encontrar información para responder consignas de localización o para reconstruir las ideas y relaciones sobre las que requieren contestar consignas globales. Tal como afirmamos, a través de estas intervenciones los docentes focalizan ciertas partes de los textos, pero no promueven que se discutan interpretaciones sobre aquellas.

Para sostener la tarea, además de la regulación de la interpretación del texto y de la búsqueda de respuestas, identificamos otras intervenciones que gestionan condiciones para devolver a los estudiantes (Brousseau, 1986, 1994, 2007) la responsabilidad por resolver la situación-problema planteada por la tarea. De acuerdo con la contabilización que presentó la Tabla 33, por amplia diferencia es el profesor de la Asignatura B quien mayormente incita a los estudiantes a volver al texto para responder una consigna o devuelve las preguntas formuladas. Cuando así lo hace, los alumnos efectivamente retornan a los materiales para seguir pensando cómo contestar sus propias dudas. A través de este tipo de reticencia de los docentes, se fuerza a los estudiantes a continuar resolviendo la tarea proprio motu (Sensevy, 2007, 2012) adoptando el rol de interpretantes de los textos. Al mismo tiempo, estas intervenciones muestran que es en la bibliografía donde pueden encontrar por sí mismos 
respuesta a sus preguntas. Por este motivo, se trataría de intervenciones que buscan promover autonomía lectora al evitar que, para resolver dudas y poder continuar leyendo, se dependa de un lector experto como el profesor.

Por último, en la gestión del medio identificamos intervenciones docentes que cierran parcialmente la tarea. La mayoría de estas intervenciones avalan localizaciones de respuestas en el texto (en las tres materias) o la enunciación oral de interpretaciones (Asignaturas B y C) por parte de los estudiantes. En el primer caso, los alumnos copian directamente los párrafos que identificaron de los textos y que los docentes de las materias $\mathrm{B}$ y $\mathrm{C}$ avalan para contestar consignas de localización o que el profesor de la Asignatura A aprueba como parte necesaria para responder consignas globales. Los avales que estos tres profesores efectúan no requieren que los estudiantes expresen su interpretación acerca de lo leído ni las razones por las cuales creen que esas partes de los textos contestarían las consignas. Por este motivo, hemos afirmado que estos avales inmediatos impiden que los estudiantes asuman la responsabilidad de juzgar el valor de las respuestas que identificaron (Brousseau, 2007), argumentando en función de lo que entendieron. Recordemos al lector que, tal como se aprecia en la Tabla 41, en la Asignatura B contabilizamos mayor cantidad de avales de las localizaciones de párrafos, a diferencia de las otras dos materias. En cuanto a las intervenciones que avalan las interpretaciones de los estudiantes formuladas en forma oral, solo registramos que ocurren en las Asignaturas B y C. Notamos que tras éstas, los alumnos reproducen en sus carpetas los párrafos a partir de los cuales han forjado las interpretaciones. Es posible que la ausencia de enunciaciones orales sobre lo entendido de los textos de circulación social de la Asignatura A se deba a la dificultad que conlleva la comprensión de éstos, según lo que dicen los estudiantes en las entrevistas.

Tanto la localización de párrafos como la expresión de interpretaciones, alcanzadas por los estudiantes, comportarían una oportunidad para trabajar en clase confrontando perspectivas sobre lo leído. Empero, no observamos en las clases analizadas que los profesores de estas materias promuevan estas discusiones. Existen, por el contrario, investigaciones didácticas en el nivel primario llevadas a cabo por Lerner (2001) y Lerner y otros (1997) que muestran que una condición didáctica para enseñar a leer textos difíciles es que los profesores no aprueben ni contradigan rápidamente las perspectivas de los estudiantes, tal como sucede en las clases observadas, sino que lo hagan una vez suscitada una discusión grupal en la que se confronten interpretaciones con los compañeros y se busquen indicios en los materiales que verifiquen o rechacen las propias. 
También registramos que los docentes, ante algunas consultas surgidas en la gestión del medio, además de cerrar parcialmente la tarea avalando las respuestas, lo hacen enunciándolas directamente. Estas enunciaciones ocurren a través de su explicitación oral (en las tres materias) o su lectura en voz alta del texto (Asignatura A). Como sostuvimos, se trata de un efecto Topaze (Brousseau, 1990, 2007) en el que se quita la responsabilidad a los alumnos por la resolución de la tarea, y en el cual los profesores cometen una trampa al mostrar el saber necesario para ganar, abandonando la reticencia que requiere el juego didáctico (Sensevy, 2007, 2012). Por ello, estos dos tipos de intervenciones se oponen principalmente a aquellas en las que, para sostener la tarea, se intenta devolver la responsabilidad a los estudiantes por su resolución, a través de incitar a volver al texto y devolver las preguntas formuladas. En cambio, cuando se enuncia la respuesta esperada, se provoca que los alumnos solamente lean esos párrafos a los que los docentes aluden, para copiarlos en sus carpetas, ya sea por economía de esfuerzo y/o porque sus dudas de comprensión no han sido saldadas.

Habiendo reseñado conclusiones respecto de los modos en que los docentes de las tres materias indagadas intervienen en la gestión del medio, analizaremos a continuación intervenciones que identificamos en la función de evaluación de la tarea.

\subsection{Evaluación de la tarea}

En este apartado se engloban las intervenciones en las que los profesores de las tres materias efectúan distintas evaluaciones frente a las respuestas a los cuestionarios que los estudiantes escriben en las carpetas o entregan en forma de trabajos prácticos. Reconociendo las distintas funciones que puede cumplir esta práctica, y los múltiples enfoques acerca de lo que significa evaluar, especificamos al lector que, de acuerdo con lo analizado en las clases observadas, circunscribimos el término evaluación a las intervenciones mediante las cuales los profesores valoran y emiten un juicio sobre el trabajo y acciones de los estudiantes en la tarea de leer para responder cuestionarios.

En relación con la evaluación de la tarea de leer para responder cuestionarios, identificamos un total de 104 intervenciones docentes que distinguimos en cuatro categorías: 1) “evalúa las respuestas escritas", 2) “evalúa las interpretaciones”, 3) "evalúa la actividad de los alumnos" y 4) "propone acción general para facilitar futuras tareas". La Tabla 46 presenta estas categorías, las subcategorías e intervenciones docentes que les corresponden, especificando la contabilización de cada una de ellas. 
Tabla 46. Categorías y subcategorías en la función docente "evaluación de la tarea"

\begin{tabular}{|c|c|c|c|c|c|}
\hline Categoría & $\begin{array}{c}\text { Total de } \\
\text { intervenciones }\end{array}$ & Subcategoría & $\begin{array}{c}\text { Total de } \\
\text { intervenciones }\end{array}$ & $\begin{array}{c}\text { Intervenciones } \\
\text { docentes }\end{array}$ & $\begin{array}{c}\text { Total de } \\
\text { intervenciones }\end{array}$ \\
\hline \multirow{6}{*}{$\begin{array}{l}\text { Evalúa las } \\
\text { respuestas } \\
\text { escritas }\end{array}$} & \multirow{6}{*}{$67 / 104$} & \multirow{3}{*}{$\begin{array}{c}\text { Evalúa } \\
\text { aspectos } \\
\text { disciplinares }\end{array}$} & \multirow{3}{*}{$49 / 67$} & $\begin{array}{c}\text { Avala respuesta } \\
\text { escrita }\end{array}$ & $29 / 49$ \\
\hline & & & & $\begin{array}{l}\text { Señala errores } \\
\text { conceptuales o } \\
\text { incompletudes }\end{array}$ & $13 / 49$ \\
\hline & & & & $\begin{array}{c}\text { Requiere lectura } \\
\text { de respuestas de } \\
\text { otros alumnos }\end{array}$ & $7 / 49$ \\
\hline & & \multirow{3}{*}{$\begin{array}{l}\text { Evalúa } \\
\text { aspectos } \\
\text { formales }\end{array}$} & \multirow{3}{*}{$18 / 67$} & $\begin{array}{c}\text { Marca error } \\
\text { ortográfico y/o } \\
\text { gramatical }\end{array}$ & $11 / 18$ \\
\hline & & & & $\begin{array}{l}\text { Valora carátula de } \\
\text { trabajo práctico, } \\
\text { inclusión de } \\
\text { viñetas, gráficos e } \\
\text { imágenes } \\
\end{array}$ & $5 / 18$ \\
\hline & & & & $\begin{array}{c}\text { Marca omisión u } \\
\text { error en carátula y } \\
\text { modo de envío del } \\
\text { trabajo }\end{array}$ & $2 / 18$ \\
\hline \multirow{3}{*}{$\begin{array}{c}\text { Evalúa las } \\
\text { interpretaciones }\end{array}$} & \multirow{3}{*}{$11 / 104$} & \multirow{2}{*}{$\begin{array}{c}\text { Pregunta } \\
\text { sobre los } \\
\text { contenidos } \\
\text { disciplinares a } \\
\text { los que } \\
\text { refieren las } \\
\text { respuestas } \\
\end{array}$} & \multirow[b]{2}{*}{$10 / 11$} & $\begin{array}{l}\text { Formula pregunta } \\
\text { y expone acerca } \\
\text { de los contenidos }\end{array}$ & $6 / 10$ \\
\hline & & & & $\begin{array}{l}\text { Formula pregunta } \\
\text { y la sostiene para } \\
\text { que los alumnos } \\
\text { argumenten }\end{array}$ & $4 / 10$ \\
\hline & & $\begin{array}{c}\text { Formula } \\
\text { pregunta } \\
\text { abierta }\end{array}$ & $1 / 11$ & $\begin{array}{l}\text { Comienza puesta } \\
\text { en común } \\
\text { preguntando al } \\
\text { grupo-clase sobre } \\
\text { qué trata el texto } \\
\text { leído }\end{array}$ & $1 / 1$ \\
\hline $\begin{array}{l}\text { Evalúa la } \\
\text { actividad de los } \\
\text { alumnos }\end{array}$ & $10 / 104$ & $\begin{array}{c}\text { Valora el } \\
\text { cumplimiento } \\
\text { de la tarea }\end{array}$ & $10 / 10$ & $\begin{array}{c}\text { Expresa } \\
\text { apreciación } \\
\text { positiva de la } \\
\text { producción final }\end{array}$ & $10 / 10$ \\
\hline $\begin{array}{l}\text { Propone acción } \\
\text { general para } \\
\text { facilitar futuras } \\
\text { tareas }\end{array}$ & $16 / 104$ & $\begin{array}{c}\text { Sugiere } \\
\text { revisar lo } \\
\text { escrito antes } \\
\text { de entregarlo }\end{array}$ & $16 / 16$ & $\begin{array}{l}\text { Recomienda } \\
\text { revisar aspectos } \\
\text { formales en la } \\
\text { presentación de } \\
\text { trabajos prácticos }\end{array}$ & $16 / 16$ \\
\hline
\end{tabular}

La Tabla 46 evidencia que más de la mitad de las intervenciones de evaluación de la tarea consisten en evaluar las respuestas escritas (67/104). Respecto de estas respuestas escritas, se evalúan mayormente aspectos disciplinares (49/67) por sobre los aspectos formales (18/67). En cuanto a estos aspectos disciplinares, un gran número de intervenciones avala lo escrito en las respuestas (29/49), mientras que menor cantidad de intervenciones 
señala errores conceptuales o incompletudes (13/49), o requiere la lectura de respuestas de otros alumnos (7/49).

En comparación con la gran cantidad de intervenciones que evalúan las respuestas escritas, solo una minoría de intervenciones aborda las interpretaciones de los alumnos (11/104) y su actividad (10/104). Al respecto, cuando se evalúan las interpretaciones, casi en su totalidad se pregunta por los contenidos disciplinares a los que refieren las respuestas escritas (10/11) y solo en una ocasión se formula una pregunta abierta al grupo-clase acerca de qué trata el texto leído (1/11). A pesar de suceder una sola vez, incluimos el análisis de esta intervención ya que, como se verá en el subapartado 6.3.2.2, promueve en los alumnos un comportamiento diferente al de las otras intervenciones, que consideramos significativo para el trabajo en clase con las interpretaciones sobre lo leído.

En cuanto a la evaluación de la actividad de los estudiantes, contabilizamos 10 intervenciones que se abocan a valorar exclusivamente el cumplimiento de la tarea, expresando apreciación positiva sobre la producción final.

Finalmente, otras intervenciones docentes en la evaluación de la tarea proponen acciones generales para facilitar futuras tareas (16/104), específicamente, sugieren la revisión de aspectos formales de lo escrito antes de su entrega al profesor.

Los subapartados siguientes ahondan en las categorías descritas, ejemplificando y analizando intervenciones docentes en cada subcategoría que construimos.

\subsubsection{Evalúa las respuestas escritas}

Esta categoría describe cómo intervienen los profesores ante las respuestas escritas que los estudiantes muestran de sus carpetas, entregan escritas como parte de trabajos prácticos o leen en voz alta de sus carpetas en puestas en común de los cuestionarios.

A partir del análisis de producciones escritas de los alumnos (obtenidas a partir de carpetas fotocopiadas, trabajos prácticos confeccionados por computadora que el docente de la Asignatura A nos reenvió por correo electrónico y registros de clase que transcriben respuestas leídas en voz alta en puestas en común), identificamos que, en las tres asignaturas, la mayoría de los estudiantes contestan los cuestionarios de igual forma: mediante la estrategia de localizar y transcribir información de los textos. Sus producciones resultan un patchwriting (Howard, 1995, 1999) o collage: no reproducen literalmente todos los párrafos sino que combinan oraciones, eliminan algunas palabras, utilizan sinónimos y cambian la gramática y sintaxis. Para ilustrar esta mayoría de respuestas textuales, mostramos algunos ejemplos en el Anexo 6. 
Tal como mostró la Tabla 46, identificamos 67 intervenciones (67/104) en las que los profesores de las tres asignaturas evalúan los aspectos disciplinares y formales de estas respuestas collages: las avalan, señalan errores conceptuales o incompletudes, requieren la lectura de respuestas de otros alumnos, marcan errores ortográficos y/o gramaticales, valoran la carátula de trabajo práctico y la inclusión de viñetas, gráficos e imágenes, y marcan omisiones u errores en la carátula y el modo de envío del trabajo. La Tabla 47 muestra cuántas de estas intervenciones se efectúan en cada materia.

Tabla 47. Subcategorías e intervenciones docentes de la categoría "evalúa las respuestas escritas"

\begin{tabular}{|c|c|c|c|c|c|}
\hline Subcategoría & $\begin{array}{c}\text { Total de } \\
\text { intervenciones }\end{array}$ & $\begin{array}{c}\text { Intervenciones } \\
\text { docentes }\end{array}$ & $\begin{array}{c}\text { Total de } \\
\text { intervenciones }\end{array}$ & Asignatura & $\begin{array}{c}\text { Total de } \\
\text { intervenciones } \\
\text { por asignatura }\end{array}$ \\
\hline \multirow{8}{*}{$\begin{array}{c}\text { Evalúa } \\
\text { aspectos } \\
\text { disciplinares }\end{array}$} & \multirow{8}{*}{$49 / 67$} & \multirow{3}{*}{$\begin{array}{l}\text { Avala respuesta } \\
\text { escrita }\end{array}$} & \multirow{3}{*}{$29 / 49$} & A & $5 / 29$ \\
\hline & & & & B & $7 / 29$ \\
\hline & & & & $\mathrm{C}$ & $17 / 29$ \\
\hline & & \multirow{3}{*}{$\begin{array}{l}\text { Señala errores } \\
\text { conceptuales o } \\
\text { incompletudes }\end{array}$} & \multirow{3}{*}{$13 / 49$} & A & $9 / 13$ \\
\hline & & & & B & $2 / 13$ \\
\hline & & & & $\mathrm{C}$ & $2 / 13$ \\
\hline & & \multirow{2}{*}{$\begin{array}{c}\text { Requiere lectura } \\
\text { de respuestas de } \\
\text { otros alumnos }\end{array}$} & \multirow{2}{*}{$7 / 49$} & B & $1 / 7$ \\
\hline & & & & $\mathrm{C}$ & $6 / 7$ \\
\hline \multirow{3}{*}{$\begin{array}{l}\text { Evalúa } \\
\text { aspectos } \\
\text { formales }\end{array}$} & \multirow{3}{*}{$18 / 67$} & $\begin{array}{c}\text { Marca error } \\
\text { ortográfico y/o } \\
\text { gramatical }\end{array}$ & $11 / 18$ & \multirow{3}{*}{ A } & $11 / 11$ \\
\hline & & $\begin{array}{l}\text { Valora carátula } \\
\text { de trabajo } \\
\text { práctico, } \\
\text { inclusión de } \\
\text { viñetas, gráficos } \\
\text { e imágenes }\end{array}$ & $5 / 18$ & & $5 / 5$ \\
\hline & & $\begin{array}{c}\text { Marca omisión u } \\
\text { error en carátula } \\
\text { y modo de envío } \\
\text { del trabajo }\end{array}$ & $2 / 18$ & & $2 / 2$ \\
\hline
\end{tabular}

En la Tabla 47 se observa que el docente de la Asignatura A es el único que interviene evaluando aspectos formales de las respuestas escritas. Tal como veremos en los subapartados siguientes, esto lo hace en momentos de clase (observados en las Clases 3, 9 y 10) en los que pide a los estudiantes que se acerquen a su banco en forma individual para comentarles las correcciones que ha realizado de los trabajos prácticos entregados. En esos momentos, también interviene para avalar respuestas o señalar los errores o incompletudes que advierte en ellas. 
Por su parte, la profesora de la Asignatura C interviene principalmente avalando las respuestas escritas que los alumnos leen en voz alta en las puestas en común que propone o, en caso de no considerar correcta una respuesta leída, requiriendo que otros estudiantes lean las suyas. Finalmente, el docente de la Asignatura B, en la mayoría de intervenciones en las que evalúa respuestas escritas que los alumnos le muestran de sus carpetas o leen en voz alta en las puestas en común, las avala. Se describen en los subapartados a continuación ejemplos de estas intervenciones docentes.

\subsubsection{Evalúa aspectos disciplinares}

Identificamos que los docentes de las tres materias indagadas intervienen en la evaluación de la tarea para evaluar aspectos disciplinares de las respuestas escritas (49/67) mediante su aval, el señalamiento de errores o incompletudes o el requerimiento de lectura de respuestas de otros alumnos.

La mayor parte de las intervenciones en las que los profesores evalúan aspectos disciplinares de las respuestas escritas corresponden a avales (29/49) que efectúan luego de escuchar su lectura en voz alta en las puestas en común o leerlas de las carpetas o trabajos prácticos de los alumnos. De ese modo, les dan a las respuestas un "reconocimiento "final" (Sensevy, 2007; p.19) dictaminándolas como correctas. Para ilustrar estas intervenciones la Tabla 48 presenta un fragmento de clase de la Asignatura C, cuya docente exhibe mayor número de intervenciones que avalan respuestas, en comparación con sus colegas de las otras dos materias.

Tabla 48. Evalúa aspectos disciplinares: avala respuesta escrita. Fragmento de clase de la Asignatura C Clase 3. La profesora propone poner en común un cuestionario sobre paraísos fiscales.

\section{Interacciones}

1. DC: [31 min $35 \mathrm{~s} / 1 \mathrm{~h} 41 \mathrm{~min} 1 \mathrm{~s}$ ] Empezamos a corregir los que ya las tienen hechas [las respuestas], [...] Vamos, arranquen: pregunta-respuesta, pregunta-respuesta, rapidito, vamos. Cualquiera de ustedes.

2. Daiana: [Lee la consigna número uno del cuestionario] "Definición de paraísos fiscales".

3. DC: Sí.

4. Daiana: [Lee en voz alta su respuesta] "Los paraísos fiscales son estados o lugares que se caracterizan por poseer regímenes fiscales que establecen una nula o una escasa tributación para determinados inversores".

5. DC: Bien, ¿estamos todos de acuerdo?

6. Alumnos: Sí.

7. Daiana: [Lee en voz alta la consigna número dos y luego su respuesta] “QQué es tributar?”. “Tributar es pagar los impuestos al Estado o determinados lugares".

8. Claudia: Yo puse "Pagar impuestos" nada más.

9. DC: Pagar impuestos, está bien. Está bien.

10. Daiana: [Lee la consigna número tres y luego su respuesta] “¿De qué otra manera se denomina a los paraísos fiscales?". "Paraísos fiscales se suelen denominar a los países de baja tributación y como países o territorios de tributación privilegiada".

11. DC: Bien. ¿Están de acuerdo? [Durante cuatro segundos ningún alumno responde]. 
12. Daiana: Sí. [Lee la consigna número cuatro y luego su respuesta] “¿Cuáles son las modalidades básicas de los paraísos fiscales?". "Modalidades básicas, entre ellas, los paraísos 'clásicos', los que ofrecen ventajas fiscales a personas que ejercen sus actividades en el extranjero, finalmente también territorios que disponen de centros de servicios complejos, por ejemplo, las telecomunicaciones".

13. DC: Está bien.

[Continúa la puesta en común de las 22 consignas del cuestionario que la docente dictó]

En este fragmento de clase que reproduce la Tabla 48, la docente de la Asignatura C avala las respuestas escritas que los alumnos leen en voz alta en una puesta en común. Tal como anticipamos al comienzo de este apartado, se trata de respuestas que reproducen casi textualmente el módulo de Cultura Fiscal que los estudiantes deben leer para la tarea.

Registramos que en estas intervenciones en las que se avalan respuestas escritas, los docentes no requieren previamente que los alumnos expresen su interpretación sobre lo escrito o que otros estudiantes lean sus respuestas a la misma consigna para su confrontación. Esto último, en cambio, tal como mostraremos más adelante en este subapartado, sí sucede en otras intervenciones que identificamos en puestas en común en las Asignaturas B y C.

Tras estas intervenciones de evaluar aspectos disciplinares, si bien en las carpetas o trabajos prácticos quedan registradas respuestas avaladas por los docentes, al no preguntarles a los estudiantes qué entienden de lo que escriben, no se recogen indicios respecto de la comprensión de los contenidos a los que éstas refieren. De esa forma, es probable que estas intervenciones produzcan lo que Brousseau $(1990,2007)$ ha denominado como efecto Jourdain: se reconocen de inmediato ciertos comportamientos de los alumnos (en este caso, haber identificado las respuestas "correctas") como estrategias ganadoras, decretándose el final del juego didáctico. Así, se evita el debate de conocimiento con los estudiantes que podría evidenciar las dificultades de comprensión de los temas o un posible "fracaso" (p. 77) en el aprendizaje que se espera que logren, eso es, en la apropiación de ciertos contenidos disciplinares.

Otro modo mediante el cual los docentes intervienen para evaluar aspectos disciplinares de las respuestas escritas es señalando ciertas respuestas como erróneas o incompletas (13/49) en las puestas en común (Asignatura B y C) o en las situaciones en las que se comentan individualmente las correcciones de los trabajos prácticos (Asignatura $\mathrm{A}$ ). En contraposición con las intervenciones de los profesores de las materias $\mathrm{B}$ y $\mathrm{C}$, que señalan errores o incompletudes tras escuchar las respuestas en las puestas en común, el docente de la Asignatura A se toma un tiempo con los alumnos para comentar las correcciones de los trabajos prácticos y justificar el motivo de las calificaciones otorgadas. Al hacerlo, habilita un lugar personalizado en el que muestra reconocimiento hacia cada producción escrita: las 
imprime -dado que pide su entrega por correo electrónico-, las lee y realiza marcas para posteriormente comentar a los estudiantes. No obstante estas diferencias, tanto en las puestas en común como en esos encuentros individuales, son los docentes de estas tres materias los únicos que juzgan las respuestas de los alumnos, dado que no promueven que éstos argumenten al respecto ni fomentan confrontaciones entre respuestas de los pares. Hallamos también otra semejanza entre estas intervenciones: los profesores no piden a los estudiantes que reescriban las respuestas completándolas o subsanando los errores indicados, aunque cabe mencionar que ello tendría sentido solo si esas producciones se utilizaran posteriormente como material de estudio.

En la Tabla 49 mostramos un ejemplo de los espacios en los que el docente de la Asignatura A comenta individualmente con los estudiantes las respuestas escritas e interviene para marcar un error conceptual.

Tabla 49. Evalúa aspectos disciplinares: señala errores conceptuales o incompletudes. Fragmento de clase de la Asignatura $A$

Clase 10. El docente pide que algunos estudiantes se acerquen a su banco para comentarles las correcciones del segundo trabajo práctico.

1. DA: [53 min $26 \mathrm{~s} / 1 \mathrm{~h} 3 \mathrm{~min} 31 \mathrm{~s}$ ] [Se encuentra comentando el trabajo práctico de Daiana] [Lee en voz la respuesta de Daiana a la consigna "Contextualizar los textos y mencionar el tipo de Estado y forma de desarrollar su economía en el periodo"] "Los grupos subalternos: [se refiere al texto "Los grupos subalternos en la historiografía argentina"] El Estado era democrático". Ojo con esto, eh [con identificar como Estado democrático al período al que refiere el texto] [...] tenés que saber bien cuándo es el Estado liberal, el Estado intervencionista, el Estado desarrollista, el Estado neoliberal. Y cómo era el modelo económico.

[Daiana permanece en silencio. El docente continúa comentándole las correcciones de su trabajo práctico].

La Tabla 49 ilustra una de las situaciones en las cuales el docente de la Asignatura A interviene para marcar un error en una respuesta escrita. En concreto, el error que el docente señala a Daiana radica en la inexactitud de identificar un Estado democrático como la organización política del período al que refiere el texto leído. Es probable que dicha bibliografía haya comportado dificultades de comprensión a los estudiantes. Dicho texto es un material incluido en un documento producido por el Ministerio de Educación para docentes de Historia y Educación Cívica. Dado que presupone ciertos conocimientos en los destinatarios (que serían docentes expertos en los temas de su disciplina), resulta un texto complejo de entender para los alumnos. Sin embargo, en esa intervención el docente no pregunta a la alumna qué entiende del texto, no indaga la causa del error (es decir, porqué considera que dicho período histórico corresponde a un Estado democrático) ni aporta pistas 
para que la alumna pueda lograr una interpretación más ajustada e identificar correctamente el tipo de Estado y modelo económico del período.

Respecto de estas intervenciones en las que marca errores o incompletudes de las respuestas escritas, el profesor de la Asignatura A esgrime sus razones para ejercerlas en forma individual con los alumnos, tal como muestra el siguiente fragmento de entrevista.

E: ¿Y por qué hacés esto que me contás de que los llamás [a los alumnos] para ver lo que estuvieron haciendo [en los trabajos prácticos]?

DA: [...] para verlo [al alumno] [...] que me lo explique, que se exprese y explicarle ahí los errores [...] el alumno necesita escuchar el motivo, porqué vos [...] le marcaste [en el trabajo práctico] tal cosa [...]. Aunque me lleva un tiempito [realizarlo], [...] les pongo una silla y le digo [al alumno] "sentáte". Y le digo "[...] te equivocaste acá, este fue tu error [...]". O sea, le marco todo lo que me parece que le va a servir a él, pero lo tienen que ver [el error] y yo lo tengo que mirar. Me tiene que decir "si" [...].

E: ¿Solo a los [alumnos] que les fue mal [en el trabajo práctico] los llamás?

DA: No, no, no. A los que le fue bien los felicito.

En este extracto de entrevista el docente asevera que busca que el alumno "explique" o "se exprese". Sin embargo, observamos que en las intervenciones en las que indica errores conceptuales no pide que los estudiantes comenten lo que entendieron de lo leído o vuelvan a los textos para revisar lo escrito, formular alternativas y/ o reelaborar la respuesta. En relación con ello, el análisis de las observaciones muestra que los alumnos, en estos espacios, permanecen en silencio o solo emiten monosílabos y/o frases escuetas, sin explicar porqué escribieron esas respuestas, expresar dudas y/o responder de alguna otra manera a los señalamientos del docente. Los datos analizados nos interrogan, por tanto, sobre las razones de esta actitud que podría considerarse como pasiva por parte de los estudiantes. ¿Debemos entenderla como una muestra de que los alumnos se sienten intimidados en estos intercambios personalizados con su docente en los que prima su voz autorizada? ¿Sería posible, a la vez, que no comprendan las correcciones o señalamientos recibidos? O aun más ¿el silencio de los estudiantes manifestaría acaso que, dado que ya saben que sus trabajos han sido aprobados, no reviste interés para ellos comprender en qué se han equivocado y cómo subsanarlo?

Cabe resaltar que señalar los errores y justificar así las calificaciones otorgadas a los trabajos prácticos es una acción valorada por estudiantes como Guadalupe: 
E: Esto, por ejemplo, de que [el profesor de la Asignatura A] te diga "vení y vemos lo que estuvo mal del trabajo", ¿qué te parece?

Guadalupe: Está bueno porque [...] te dice lo que está mal [...]. Y sí, te pone la nota, te llama, ¿viste que llama de a uno [en forma individual]? [Te dice] "Bueno, acá mirá, te puse tal nota porque hiciste mal esto”. O sea, te explica porqué [te puso] la nota.

En este fragmento, la alumna destaca el hecho de que el profesor se tome el trabajo y dedique tiempo para hablarle sobre su producción escrita, específicamente acerca de lo que está "mal". Esta valoración positiva que hace la alumna de estas intervenciones no radica en la posibilidad que ofrecerían de comprender mejor el contenido disciplinar a partir del señalamiento y corrección de un error conceptual sino en el hecho de que, de este modo, la calificación estaría justificada y no se aplicaría de modo arbitrario.

Identificamos, en las Asignaturas B y C, una tercera y última forma de intervenir en la evaluación de aspectos disciplinares de las respuestas escritas: pedir a otros estudiantes que lean sus respuestas durante las puestas en común (7/49). Si bien estas intervenciones contienen la posibilidad de abrir confrontaciones entre respuestas, esto no se logra porque, ante este requerimiento, los alumnos afirman haber escrito lo mismo que la primera respuesta leída o bien no se logra porque, tras la lectura de otra respuesta, los profesores intervienen identificando cuál de ellas consideran correcta, avalando ambas, o no se expiden sobre las mismas y directamente explican los contenidos disciplinares. La Tabla 50 ilustra una intervención en la Asignatura $\mathrm{C}$, en la que se requiere la lectura de otras respuestas y se avala una de ellas.

Tabla 50. Evalúa aspectos disciplinares: requiere lectura de respuestas de otros alumnos. Fragmento de clase de la Asignatura $C$

Clase 3. En la clase se desarrolla una puesta en común de las respuestas al cuestionario sobre paraísos fiscales.

1. Daiana: [36 min $12 \mathrm{~s} / 1 \mathrm{~h} 41 \mathrm{~min} 1 \mathrm{~s}$ ] [Lee la consigna y luego su respuesta] "¿Por qué motivo la Organización Mundial del Comercio cuestiona la existencia de paraísos fiscales?". "La Organización Mundial del Comercio cuestiona la existencia de los paraísos fiscales porque ellos reciben dinero de distintos lugares, obtenidos de diversos modos".

2. DC: A ver, ¿alguien dio otra respuesta a eso?

3. Yésica: Sí.

4. DC: A ver, sí, [léela] porque no me terminó de convencer [la respuesta de Daiana]. No está mal, pero no me terminó de convencer.

5. Yésica: "Por el motivo de que el dinero legal y dinero ilegal se combinan en los flujos que llegan a los paraísos, con procedencia dudosa".

6. DC: Bien, me gustó la respuesta de Yesi. Lo cuestionan [la existencia de paraísos fiscales] básicamente porque [allí] entran dinero obtenido legalmente e ilegalmente, ¿se entiende? Eso es lo que se cuestiona, que también meten plata conseguida...no muy sanamente [legalmente]. ¿Bien? Eso. [Continúa la puesta en común]. 
En la Tabla 50 la profesora de la Asignatura C pide que, además de Daiana, otro alumno lea en voz alta la respuesta que ha escrito para la misma consigna (interacción $\mathrm{n}^{\mathrm{o}} 2$ ), y luego justifica ese pedido dando a entender que podrían incluirse otras informaciones más convincentes para contestar la pregunta (interacción $n^{\circ} 4$ ), aunque no explica la razón por la cual no le "convence" la primera respuesta para darle su aval. Cuando Yésica lee en voz alta su respuesta escrita, la avala y la comenta (interacción $n^{\circ} 6$ ). No obstante, las diferencias entre las respuestas de Daiana y Yésica no quedan claras: la docente no las puntualiza, no incita a que las alumnas debatan al respecto y/o retornen al material para leer sobre la postura que la Organización Mundial del Comercio adopta ante los paraísos fiscales. Como ya sostuvimos, para armar las respuestas los estudiantes suelen reproducir sin mayores cambios algunas partes de los textos. Cabe señalar que en esta ocasión, las respuestas parecen indicar un trabajo de interpretación y producción textual, que se aleja de la mera reproducción del material, en el cual puede leerse el siguiente párrafo: "Dinero legal y dinero ilegal se combinan en los flujos que llegan a los paraísos y esto genera conflictos importantes con las intenciones de Organismos nacionales e internacionales de lucha contra actividades delictivas. De alli que, en forma creciente, la existencia de los paraísos fiscales ha sido puesta en cuestión y, desde la Organización Mundial del Comercio, por ejemplo, se proponen estudios y medidas para que las zonas de baja tributación frenen la recepción de flujos de dinero de procedencia dudosa.". Empero, no se requiere que los alumnos se explayen acerca de lo que entendieron al leer y responder las preguntas del cuestionario.

\subsubsection{Evalúa aspectos formales}

Identificamos que solo el docente de la Asignatura A evalúa aspectos formales de las respuestas y la producción escrita general de los estudiantes. En oposición a los aspectos relacionados con el contenido disciplinar, por aspectos formales nos referimos a cuestiones locales y de superficie del texto que no se vinculan con el significado de los temas.

Identificamos que en 18 intervenciones en las que se evalúa las respuestas escritas a los cuestionarios (18/67), este profesor marca errores ortográficos y/o gramaticales, valora la carátula y la inclusión de viñetas, gráficos e imágenes, y marca omisiones u errores en la carátula y la forma de envío del trabajo práctico. Esta cantidad de intervenciones supera el número de intervenciones en las cuales el profesor evalúa aspectos disciplinares de las respuestas escritas (ver Tabla 47). La Tabla 51 ejemplifica estas intervenciones en la Asignatura A. 
Tabla 51. Evalúa aspectos formales: marca error ortográfico y/o gramatical. Fragmento de clase de la Asignatura $A$

Clase 10. El docente pide que algunos estudiantes se acerquen a su banco para comentarles las correcciones del segundo trabajo práctico.

\section{Interacciones}

1. DA: [44 $\min 50 \mathrm{~s} / 1 \mathrm{~h} 3 \mathrm{~min} 31 \mathrm{~s}$ de clase] ¿Marisa? [La alumna se levanta y se acerca al banco del docente, donde se encuentra el trabajo práctico que envió por correo electrónico, impreso y marcado con birome por éste] [...] "Revolución liberatoria" [lee en voz alta del trabajo práctico]. Vos seguramente lo escribiste bien [...] y la máquina [se refiere a la netbook] te lo cambia a esta palabra "liberatoria", y vos te quedás con que escribiste "libertadora". Entonces hay que volver a releer y tener cuidado en la entrega [...]. [Marisa permanece en silencio] "Liberatoria", te lo marco de vuelta, aparece dos veces [escrito así en el trabajo práctico]. [...] Pero bueno, para otra vez.

2. Marisa: [Se levanta y vuelve a su asiento].

3. DA: ¿Daiana? [...] Quiero marcar algunas cosas de acá [extrae de un folio el trabajo práctico de la alumna. Ésta se levanta y se acerca a su banco] [...] Ojo con la máquina [netbook] porque a veces cambia... [las palabras]. Acá...la máquina tiene para [corregir] ortografía, ¿eso lo sabes? [Daiana permanece en silencio] [...]. [Lee el comienzo de una oración del trabajo práctico donde la alumna responde la pregunta “¿Que análisis sostiene Fradkin sobre la población rural subalterna?”]. "Para dar cuenta de las..." [No continúa la frase. En el trabajo de la alumna dice "frmas"].

4. Daiana: [Corrigiendo su error] "Formas" diría ahí [en su trabajo práctico]. Ay, son faltas de ortografía.

5. DA: "No fue..." [Lee el comienzo de otra oración del trabajo práctico de Daiana. En el trabajo práctico de la alumna dice "No fue cinecial"].

6. Daiana: Lineal.

7. DA: Claro y acá dice "cinecial".

8. Daiana: Son faltas de ortografía porque escribo rápido, profe, porque estoy chateando [con otros] en el Facebook.

[DA continúa comentándole las correcciones de su trabajo].

En la Tabla 51 pueden verse intervenciones en las que el profesor de la Asignatura A evalúa aspectos formales de los trabajos prácticos de Marisa y Daiana. Los errores que puntualiza de esas producciones escritas los atribuye al corrector automático del procesador de textos o al tipeo (la escritura de "frmas" y "cinecial" en vez de "formas" y "lineal" y de "Revolución Liberatoria" para la dictadura cívico-militar autodenominada "Revolución Libertadora"). Dado que no consulta a las estudiantes, da por hecho dichas razones y descarta otras, como la posible creencia de Marisa de que la dictadura de 1955 en realidad se denomina tal como la escribe ("revolución liberatoria").

Pareciera que en esta relevancia otorgada a los aspectos formales de las respuestas escritas, el profesor pasa por alto en qué medida éstas responden a las consignas formuladas. Aquí tampoco evalúa el docente qué entienden los alumnos de los contenidos disciplinares sobre los que leyeron y escribieron. Particularmente, el párrafo en el cual Daiana escribe "frmas" conforma un collage a través del cual intenta responder una consigna sobre el texto "Los grupos subalternos en la historiografía argentina". En el trabajo práctico de Daiana, que envió por correo electrónico al profesor de la Asignatura $\mathrm{A}-\mathrm{y}$ éste nos reenvió durante el trabajo de campo en la institución- puede leerse: "Fradkin sostiene sobre la poblacion rural subalterna el proposito de indagar sobre ello obliga a ampliar el campo de analisis para dar 
cuenta de las frmas y contenidos que esta politizacion pudo haber adquirido lo cual invita a leeer la documentacion registrar". Al respecto, el profesor no indaga con la alumna qué entendió del texto y qué dificultades encontró para interpretarlo. De toda esa respuesta escrita, solo remarca la escritura de "frmas".

Observemos aquí que la focalización en lo formal de las respuestas escritas, en desmedro del significado de los temas, y el no trabajar lo que entendieron de lo leído, va en línea con el desinterés manifestado por la alumna, quien en la interacción $n^{\circ} 8$ da a entender que su atención, mientras responde el cuestionario, está puesta en la red social Facebook, cuya actividad tendría más sentido para ella.

\subsubsection{Evalúa las interpretaciones}

En la evaluación de la tarea, a diferencia de la gran cantidad de intervenciones que evalúan de las respuestas escritas (67/104), registramos que una minoría que evalúa las interpretaciones alcanzadas por los estudiantes tras cumplimentar la tarea (11/104), esto es, lo que han comprendido de los contenidos disciplinares sobre los que se escribió (ver Tabla 46). Tal como muestra a continuación la Tabla 52, casi en su totalidad son intervenciones en las que los profesores efectúan preguntas que refieren a los temas acerca de los cuales piden responder las consignas. Además, contabilizamos otra intervención en la que se formula una pregunta abierta para inaugurar una puesta en común.

Tabla 52. Subcategorías e intervenciones docentes de la categoría "evalúa las interpretaciones"

\begin{tabular}{|c|c|c|c|c|c|}
\hline Subcategoría & $\begin{array}{c}\text { Total de } \\
\text { intervenciones }\end{array}$ & $\begin{array}{c}\text { Intervenciones } \\
\text { docentes }\end{array}$ & $\begin{array}{c}\text { Total de } \\
\text { intervenciones }\end{array}$ & Asignatura & $\begin{array}{c}\text { Total de } \\
\text { intervenciones } \\
\text { por asignatura }\end{array}$ \\
\hline \multirow{3}{*}{$\begin{array}{l}\text { Pregunta } \\
\text { sobre los } \\
\text { contenidos } \\
\text { disciplinares } \\
\text { a los que } \\
\text { refieren las } \\
\text { respuestas }\end{array}$} & \multirow{3}{*}{$10 / 11$} & $\begin{array}{c}\text { Formula } \\
\text { pregunta y } \\
\text { expone acerca }\end{array}$ & \multirow{2}{*}{$6 / 10$} & B & $3 / 6$ \\
\hline & & $\begin{array}{l}\text { de los } \\
\text { contenidos }\end{array}$ & & $\mathrm{C}$ & $3 / 6$ \\
\hline & & $\begin{array}{c}\text { Formula } \\
\text { pregunta y la } \\
\text { sostiene para } \\
\text { que los } \\
\text { alumnos } \\
\text { argumenten }\end{array}$ & $4 / 10$ & A & $4 / 4$ \\
\hline $\begin{array}{l}\text { Formula } \\
\text { pregunta } \\
\text { abierta }\end{array}$ & $1 / 11$ & $\begin{array}{l}\text { Comienza } \\
\text { puesta en } \\
\text { común } \\
\text { preguntando al } \\
\text { grupo-clase } \\
\text { sobre qué trata } \\
\text { el texto leído }\end{array}$ & $1 / 1$ & A & $1 / 1$ \\
\hline
\end{tabular}


En la Tabla 52 puede verse que los docentes de las Asignaturas B y C solo evalúan las interpretaciones de los estudiantes preguntando por los contenidos disciplinares a los que refieren las respuestas y exponiendo acerca de los mismos. En contraste con ello, el profesor de la Asignatura A interviene formulando preguntas sobre los temas y sosteniendo dichas preguntas para que los estudiantes argumenten al respecto. También se observa que la única intervención de formular una pregunta abierta al grupo-clase es ejercida por este profesor. A continuación, profundizamos en estas dos subcategorías y las intervenciones docentes que les corresponden.

\subsubsection{Pregunta sobre los contenidos disciplinares a los que refieren las respuestas}

Registramos 10 intervenciones en las que los profesores de las tres materias, para evaluar las interpretaciones de los estudiantes, preguntan por los contenidos disciplinares que aparecen en las respuestas leídas en voz alta en las puestas en común (10/11). Tal como dijimos, la mayoría de las respuestas escritas de los estudiantes constituye collages de los textos (ver Anexo 6). Luego de estas preguntas que realizan, notamos que los profesores de las Asignaturas B y C exponen oralmente y en forma extensa sobre los contenidos disciplinares a los que refieren las respuestas leídas (6/10) mientras que el docente de la Asignatura A, en cambio, sostiene la pregunta para fomentar que los estudiantes enuncien lo que han comprendido (4/10). Detengámonos ahora a analizar estos tipos de intervenciones docentes.

Concretamente, observamos que los profesores de las Asignaturas B y C preguntan sobre los contenidos disciplinares a los que refieren las respuestas escritas y cuando los estudiantes dicen no haberlos entendido, exponen información acerca de esos temas. En estas intervenciones los docentes explican los temas a través de ejemplos y/o cuadros en el pizarrón. A modo de ejemplo, presentamos un fragmento de clase en la Tabla 53 donde se observan estas intervenciones.

Tabla 53. Pregunta sobre los contenidos disciplinares a los que refieren las respuestas: formula pregunta y expone acerca de los contenidos. Fragmento de clase de la Asignatura $B$

Clase 2. El docente plantea poner en común un cuestionario acerca de un texto titulado "El FMI y el fundamentalismo de mercado" del economista Joseph Stiglitz, leído de un manual de Historia Mundial Contemporánea.

\section{Interacciones}

1. Daiana: [11 $\min 7 \mathrm{~s} / 37 \mathrm{~min} 21 \mathrm{~s}$ ] [Lee una pregunta del cuestionario y luego la respuesta que escribió en su carpeta] “¿Qué errores comete el FMI, según este Premio Nobel?”, "No aportaron un crecimiento sostenido, se plegaron a sus rigores, la aus... [detiene la lectura] la austeridad excesiva ahogó el crecimiento, los programas requieren de un cuidado extremo de su secuencia, el orden de las reformas y ritmo."

2. DB: ¿Qué es esta austeridad excesiva?

3. Daiana: Qué se yo. 
4. DB: ¿Qué piensan que es austeridad?

5. Daiana: No sé, tengo los pies helados [Sus compañeros permanecen en silencio].

6. DB: Cuando yo soy austero es que gasto poco, ¿eh? Cuando controlo mis gastos, ¿qué es lo que está planteando [el texto]? [Ninguno de los alumnos responde] [...] El FMI cuando te presta plata, ¿qué pretende si te presta plata? ¿qué quiere cuando presta plata?

7. Nadia: Que la devuelvas.

8. DB: Que la devuelvas, claro. [...] [Escribe "FMI" en el pizarrón] [...] Cuando vos tenés un Estado que tiene dinero, puede distribuir ese dinero de las maneras que entienda que sean necesarias: haciendo un puente $[\ldots]$, entregando computadoras a los estudiantes, haciendo escuelas, en fin, [eso se puede hacer] cuando vos tenés plata. ¿Qué era lo que sucedía, entonces, con un Estado [que no tiene plata] y con esto que estábamos hablando? Lo que sucedía era que el Estado no tenía plata. ¿Por qué no tenía plata el Estado? [...] Vos [se refiere a un Estado] tenías que devolverle [al FMI] esa plata $[\ldots]$. Tenemos que pagar un crédito... el Estado entonces nunca tenía plata. Con lo cual, como no tenía plata, ¿qué sucedía? Sucedía lo que terminó sucediendo en el [año] 2001 en la Argentina, quebró. ¿Por qué quebró? Y... si no tenía plata. Ya no tenía plata para nada. ¿Se entiende chicos, más o menos, lo que estamos hablando?

[Los alumnos asienten, continúa la puesta en común del cuestionario].

La Tabla 53 reproduce un fragmento de clase en la cual el docente de la Asignatura B consulta a Daiana por su comprensión de uno de los temas centrales que aparece en la respuesta escrita que ésta lee en voz alta: la austeridad excesiva adoptada por países endeudados con el FMI. Cuando sus compañeros permanecen en silencio y dicha alumna admite no saberlo, el profesor inicia una exposición oral -de una duración de 7 min 53 sacerca el endeudamiento que provoca en los países los préstamos del Fondo Monetario Internacional y la consiguiente austeridad que éstos deben adoptar.

Tal como evidencia la interacción $\mathrm{n}^{\mathrm{0}} 7$ en la Tabla 53, y como pudimos observar en otras situaciones de clase analizadas, estas exposiciones guiadas bajo la perspectiva del docente consiguen la participación de algunos estudiantes, que dan muestras de haber podido poner en relación dicha explicación con sus propios conocimientos, y de extraer inferencias a partir de ello. Estas participaciones pueden brindarle a los profesores cierta idea de cómo los estudiantes van comprendiendo los temas que explican. No obstante, ese seguimiento solo es viable para aquellos que toman la palabra. Los estudiantes que permanecen en silencio, o los que intervienen escasamente, no ofrecen indicadores a los profesores acerca del modo en que entienden los contenidos.

En contraste con estas intervenciones de los docentes de las Asignaturas B y C en las que formulan a los estudiantes preguntas sobre los contenidos y luego los explican, el profesor de la Asignatura A sostiene preguntas acerca de los temas sobre los cuales los alumnos han leído y respondido consignas, a fin de que argumenten al respecto. Esto origina un extenso intercambio de interpretaciones entre el docente y los estudiantes, que se desarrolla durante la única puesta en común de respuestas que éste propone durante los siete meses en los que observamos clases, tal como ejemplifica la Tabla 54. 
Tabla 54. Pregunta sobre los contenidos disciplinares a los que refieren las respuestas: formula pregunta y la sostiene para que los alumnos argumenten. Fragmento de clase de la Asignatura $A$

Clase 2. En la clase se desarrolla una puesta en común del cuestionario sobre el artículo de Mario Margulis titulado "El difícil arte de asir a la juventud".

\section{Interacciones}

1. Yésica: [15 min $28 \mathrm{~s} / 1 \mathrm{~h} 36 \mathrm{~s}$ ] [Lee en voz alta su respuesta a la consigna "Explica a qué se refiere (el autor) cuando menciona "la juventud dorada"']. "La juventud dorada se refiere a las juventudes poseedoras de cuerpo legítimo, delgados, blancos, rubios, etc. Estos jóvenes son para sí mismos porque sienten la cercanía respecto de la vejez y de la muerte".

2. DA: El autor plantea esto de "juventud dorada" y ¿a qué hace referencia cuando dice "juventud dorada"? ¿Sería “dorada” o qué otro sinónimo le podemos... [no termina la pregunta]? Dice [leyendo la pregunta del cuadernillo] "Explica a qué se refiere cuando menciona la 'juventud dorada"”.

3. Ernesto: Lo mejor.

4. Carla: Que tenés que ser perfecto.

5. DA: ¿Lo mejor...? O lo añorado, ¿no? sería la juventud soñada, dorada. ¿Y tenés que ser... [no termina la pregunta]? [Mira a Carla] Me dijiste vos...

6. Carla: Perfecto.

7. DA: Perfecto.

8. Carla: [En voz baja] [Tenés que ser] otro tipo de persona...

9. DA: ¿Qué quién? ¿Quién acepta? ¿Cómo lo definirían ustedes? ¿Por qué [el autor] explica eso? ¿Cómo tiene que ser la juventud según esta concepción de la juventud?

10. Fabiana: Como los chicos de la propaganda.

11. DA: Claro, ¿por qué habla de juventud dorada? ¿Los chicos de la propaganda?

12. Fabiana: Sí, que son son rubios, ojos claros, todo eso. Como que lo muestran de una manera perfecta pero no se sabe cómo es realmente por dentro.

13. DA: Claro.

14. Fabiana: Porque una persona puede ser muy perfecta por fuera, pero por dentro debe ser tremendamente... [no termina la frase].

15. Carla: Los medios de comunicación dicen que tenés que ser flaca, alta, cheta.

16. DA: Muy bien. Bueno, es eso un poco, los medios de comunicación nos muestran una cosa que legitiman como válido.

17. Yesica: Aparte también, no solo eso, sino el nivel social, de la clase social [...] porque vos la ves re alta [a la persona] y hay muchos lugares pobres y esas cosas que no se ven en la tele.

18. DA: Claro, y eso lo que muestran es como que hay que llegar a ese modelo, ¿no? ¿si uno no llega a ese modelo?

19. Fabiana: Está fuera de...

20. DA: Está fuera. Y ahí entran aquellos sectores excluidos que vamos a llegar ahora, a los sectores populares.

[Continúan poniendo en común las respuestas al cuestionario].

En la Tabla 54 se muestra cómo el docente de la Asignatura A, tras escuchar la respuesta de Yésica, formula una pregunta respecto a la juventud dorada y la sostiene. El análisis del texto de Margulis muestra que la respuesta de esta alumna reproduce algunas oraciones de material, en el que puede leerse: “Aunque se los suele ignorar, en las clases populares también hay jóvenes, los que con frecuencia no se asemejan a los modelos corporales con que se significa a aquellos que aparecen como ejemplos de la juventud dorada de las propagandas, los poseedores del cuerpo legítimo, delgados, blancos, rubios...Son jóvenes para sí mismos porque sienten la cercanía respecto de la vejez y de la muerte, porque lo son para los otros, que los perciben como miembros jóvenes, nuevos, con determinados lugares y roles en la familia y en otras instituciones". Empero, cuando este 
profesor sostiene la pregunta respecto de los contenidos disciplinares que aparecen en la respuesta escrita, logra que algunos estudiantes, como Carla, Fabiana e inclusive Yésica, expresen sus interpretaciones acerca de ese concepto y comenten desde sus universos de significado. Esto permite trabajar sobre dichas interpretaciones para avanzar en la comprensión del desarrollo argumental del autor.

Intervenciones como éstas, en las que se sostienen preguntas en relación con los temas disciplinares, incitan a reflexionar sobre los conceptos de un autor para fomentar la comprensión global del texto, en función del contenido a aprender (en este caso, la construcción socio-histórica de distintas “juventudes”).

\subsubsection{Formula pregunta abierta}

En la evaluación de las interpretaciones de los alumnos, identificamos solo una intervención docente (1/11) en la que se formula una pregunta abierta, hallada en la Asignatura A. Tal como sostuvimos anteriormente, durante el trabajo de campo observamos que el docente de esta materia suele destinar tiempo de clase para señalar a cada estudiante aspectos disciplinares y formales de las respuestas escritas a los cuestionarios entregados en forma de trabajos prácticos. Sin embargo, registramos que en una oportunidad este docente no procede en esta forma habitual, sino que propone realizar una puesta en común de las respuestas a un cuestionario y la inaugura mediante una pregunta al estilo de las consignas abiertas descritas por Aisenberg $(2005,2010)$, que apuntan a explorar una temática en forma amplia. Optamos por describir esta única intervención ya que, a diferencia de las intervenciones docentes analizadas hasta el momento, ésta promueve que los alumnos hablen acerca de lo leído sin circunscribirse necesariamente a la información que debieron identificar para contestar las consignas del cuestionario. La Tabla 55 ilustra un fragmento de clase en la cual sucede esta intervención.

Tabla 55. Evalúa las interpretaciones: formula pregunta abierta. Fragmento de clase de la Asignatura A Clase 2. El docente propone poner en común las respuestas al cuestionario sobre el artículo de Mario Margulis.

\section{Interacciones}

1. DA: $[8 \min 11 \mathrm{~s} / 1 \mathrm{~h} 36 \mathrm{~s}]$ ¿Qué plantea el autor, el sociólogo Mario Margulis? El texto ¿qué plantea en general? ¿Cuál es la idea que ustedes... [no termina la pregunta]?

2. Fabiana: ¿En general? Más que nada lo...

3. Carla: [Interrumpiendo] Los distintos temas que podés tocar de las juventudes.

4. DA: ¿Analiza...?

5. Fabiana: Sí, los distintos temas que podés tocar de la juventud.

6. DA: Analiza las juventudes, bueno, muy bien. [Se levanta de la silla y escribe en el pizarrón "Juventud" y se detiene]. Pero ¿qué analiza?, ¿la juventud?, ¿qué plantea él, como la juventud o las juventudes? 
7. Fabiana: Juventudes, que no piensa que hay una sola juventud, sino varias juventudes.

8. DA: Bueno, muy bien. [Agrega "es" a la palabra "Juventud". En el pizarrón queda escrita la palabra "Juventudes"].

9. Fabiana: Esa es la palabra que usó en realidad él.

10. DA: Bien, entonces ahí ya tenemos que él no plantea que hay una sola juventud sino que plantea que hay...

11. Fabiana: Varias.

12. DA: Varias juventudes, muy bien. [...] Ahí tienen una guía de estudio [se refiere a las consignas del cuestionario] ¿sí? Hay unas preguntas. [Enuncia la primera consigna del cuestionario] “¿Cuáles son los factores que condicionan a la juventud?” ¿Cuáles son en general? Primero dice cuáles son los factores ¿no?

13. Fabiana: Sí. [Lee la pregunta del cuadernillo] “¿Qué factores condicionan a la juventud?”.

14. DA: ¿Carla? [Pregunta a dicha alumna] ¿Qué factores por ejemplo? [Escribe en el pizarrón "Factores"].

15. Yésica: [Leyendo de su carpeta] "Naturales, sociales, el lugar dónde viven, la generación a la que pertenecen".

16. DA: [Copia en el pizarrón lo enunciado por Yésica] Y después él [autor] plantea [enuncia la segunda consigna del cuestionario] “¿Cuáles son las condiciones más notorias?”. Es la pregunta ¿Mabel? [Continua la puesta en común de las respuestas al cuestionario].

En la Tabla 55 puede verse que si bien este profesor requiere contestar consignas globales a partir de la lectura del texto de Margulis, para iniciar la puesta en común formula una pregunta abierta. Mediante el interrogante “¿Qué plantea el autor?”, el docente promueve que los estudiantes expresen sus propias interpretaciones del texto, desligándose por un momento de los recortes y jerarquizaciones requeridas por las consignas del cuestionario. Es decir, invita a los alumnos a decir lo que entienden de lo leído.

En efecto, esta pregunta abierta permite a algunos estudiantes como Carla y Fabiana enunciar sus interpretaciones acerca de lo que comprenden sobre el texto en general (interacciones $\mathrm{n}^{\mathrm{o}} 3,5,7,9$ y 11). No obstante, esta intervención permite que solo dos alumnas hablen acerca de lo leído ya que, tras la participación oral de ambas, el docente focaliza la atención en las respuestas puntuales a las preguntas del cuestionario. Cuando estas estudiantes expresan la interpretación que espera oír (que Mario Margulis sostiene la existencia de diversas juventudes y no de una juventud), el profesor da inicio a una clásica puesta en común de las respuestas escritas (interacción ${ }^{\circ} 12$ ), que se circunscribe a la lectura de lo que cada alumno ha escrito en sus carpetas.

\subsubsection{Evalúa la actividad de los alumnos}

Esta categoría agrupa intervenciones en las cuales lo que se evalúa es la actividad realizada por los alumnos. Identificamos que respecto de esta actividad se valora específicamente el cumplimiento de la tarea. Tal como mostró la Tabla 46, hallamos 10 intervenciones en las que los profesores de las tres materias expresan apreciación positiva de la producción escrita final (10/104). Aquí debemos aclarar que para la contabilización de estas intervenciones nos 
limitamos a aquellas en las que los docentes formulan explícita y verbalmente tales apreciaciones. La Tabla 56 detalla la cantidad de intervenciones registradas en cada materia.

Tabla 56. Subcategoría e intervenciones docentes de la categoría "evalúa la actividad de los alumnos"

\begin{tabular}{cccccc}
\hline Subcategoría & $\begin{array}{c}\text { Total de } \\
\text { intervenciones }\end{array}$ & $\begin{array}{c}\text { Intervenciones } \\
\text { docentes }\end{array}$ & $\begin{array}{c}\text { Total de } \\
\text { intervenciones }\end{array}$ & Asignatura & $\begin{array}{c}\text { Total de } \\
\text { intervenciones } \\
\text { por asignatura }\end{array}$ \\
\hline $\begin{array}{c}\text { Valora el } \\
\text { cumplimiento } \\
\text { de la tarea }\end{array}$ & $10 / 10$ & $\begin{array}{c}\text { Expresa } \\
\text { apreciación } \\
\text { positiva de la } \\
\text { producción } \\
\text { final }\end{array}$ & $10 / 10$ & $\mathrm{~A}$ & $8 / 10$ \\
\cline { 3 - 5 } & & & $\mathrm{B}$ & $1 / 10$ \\
\hline
\end{tabular}

La Tabla 56 evidencia que casi la totalidad de las intervenciones en las que se valora el cumplimiento de la tarea corresponde al docente de la Asignatura A. Es por ello que escogemos presentar en la Tabla 57 un ejemplo de intervenciones en esta materia.

Tabla 57. Evalúa la actividad de los alumnos: valora el cumplimiento de la tarea. Fragmento de clase de la Asignatura $A$

Clase 10. El docente pide que algunos estudiantes se acerquen a su banco para comentarles las correcciones del segundo trabajo práctico, cuya consigna indica escoger dos materiales del cuadernillo, no trabajados en clase, y responder las consignas que allí figuran.

\section{Interacciones}

1. DA: [48 min $50 \mathrm{~s} / 1 \mathrm{~h} 3 \mathrm{~min} 31 \mathrm{~s}$ ] ¿Daiana? [...] Quiero marcar algunas cosas de acá [extrae de un folio el trabajo práctico de la alumna impreso. Ésta se levanta y se acerca a su banco] Bueno, muy bien esto, la verdad que está bueno. [...] Vos tomaste [...] dos textos que ya habíamos analizado [...]. Este trabajo como está, está para un ocho [de calificación] pero no [pondrá esa nota] porque ya fueron trabajados [los textos]. Muy bien Daiana.

[La alumna vuelve a su asiento y el docente se acerca a otra estudiante para preguntarle por sus ausencias a clase].

El fragmento de clase que presenta la Tabla 57 resulta ilustrativo de estas intervenciones en las que se valora la producción escrita resultante de la tarea, ya que allí se muestra cómo el profesor resuelve aprobar un trabajo práctico que no ha respetado la consigna indicada. Daiana, en vez de elegir dos textos del cuadernillo, no leídos en clase, para contestar preguntas - tal como pide la consigna del trabajo práctico-, responde a partir de materiales que ya habían sido trabajados en clase. Pese a ello, el docente de la Asignatura A aprueba el trabajo y emite comentarios positivos sobre la producción escrita de Daiana: "Bueno muy bien esto, la verdad que está bueno" y "Muy bien". Dado que al hacerlo no especifica qué aspectos resalta de la producción, hipotetizamos que estos comentarios hacen referencia al trabajo práctico en su conjunto, esto es, al cumplimiento y la entrega en sí mismas. El hecho de que el docente haya aprobado los seis trabajos prácticos entregados en ese trimestre, a pesar de que observamos -en las situaciones en las que comenta 
individualmente las correcciones que realizó- que algunos presentan lo que considera errores conceptuales en las respuestas, abonaría a esta hipótesis acerca de la importancia que otorga al cumplimiento de la tarea.

En relación con la valoración de logros de los estudiantes, este docente manifiesta en la entrevista la importancia de expresarla, lo que muestra su preocupación por estimular la actividad de los estudiantes desde un área afectivo-motivacional, enfatizando aspectos positivos para fortalecer su autoestima.

DA: [A los estudiantes les digo] “me parece que vos tenés que entregar más prolijo” [...]. Porque me parece que los pibes [alumnos] necesitan eso. Que le digas "che, que linda letra, que bueno”. [...] Marcar lo que tiene que mejorar, y marcarle lo otro, porque con lo otro lo incentiva a que logre lo que está fallando."

De este extracto de entrevista se desprende que los aspectos que este docente destaca como logros en una producción escrita son principalmente características formales como la presentación general del escrito y la prolijidad de la letra. La gran cantidad de intervenciones en las que este profesor evalúa las respuestas escritas señalando sus aspectos formales (18/67) aportaría evidencia en esa dirección (ver subapartado 6.3.1.2). Es posible que el énfasis en estos aspectos se relacione con cierta intencionalidad del profesor de destacarlos para que los estudiantes los tomen en cuenta, de cara a las demandas sociales que los esperan cuando finalicen la escolaridad. Esta intencionalidad sería coincidente con aquella que subyacería bajo las actividades que, según Wells (1987), se proponen frecuentemente en clases con alumnado proveniente de sectores socioeconómicos desfavorecidos, las cuales recrean usos del lenguaje escrito en la vida cotidiana (como escribir una solicitud de empleo y completar un formulario).

Asimismo, la valoración de este profesor de los logros de las producciones escritas probablemente tenga origen en los distintos comentarios de los estudiantes, que pudimos registrar en las clases de esta asignatura, que evidenciarían su baja autoconfianza académica (ver subapartado 5.2.2 del Capítulo 5). Tratándose de estudiantes con historiales de "fracaso" escolar, caracterizados por repitencias y abandonos reiterados (ver subapartado 4.2.1 del Capítulo 4), intervenciones que remarcan positivamente la actividad de los alumnos cobrarían relevancia dado que valoran su empeño y/o progreso académico.

Tal como dijimos al comienzo de este subapartado, también los docentes de las Asignaturas B y C valoran el cumplimiento de la tarea, aunque lo explicitan en menor 
cantidad de ocasiones. El siguiente extracto de entrevista a una alumna, que rememora una anécdota de clase en la Asignatura B, evidencia esta valoración.

Fabiana: La otra vez, no sé qué teníamos que buscar de globalización, encontramos todos lo mismo [...] y ella [se refiere a Daiana, compañera del curso con quien realizó la entrevista] [...] dictó [la información encontrada]. Le entregamos y [nombra al docente de la Asignatura B] dice “Chicos, esto es el mismo”. [Le respondimos] "Sí, vas a leer en todos [los trabajos] lo mismo porque [...] no encontramos nada más”. [Nos dijo] “bueno, está bien, por lo menos lo tienen todos ahora”. Y después nos explicó igual lo que él quería decir, con sus palabras, para que nosotros lo entendamos.

En la situación relatada, pese a que todos los alumnos reproducen en sus carpetas la misma información acerca de un tema, presumiblemente sin comprenderlo, el profesor valora que hayan cumplido la tarea. No indaga lo que han entendido sobre globalización y/o las razones por las cuales no han encontrado otra información distinta al respecto, sino que se aboca a exponer oralmente el tema, tal como mostramos que también interviene cuando pregunta por los contenidos disciplinares a los que refieren las respuestas y los alumnos admiten no haber entendido los temas (ver subapartado 6.3.2.1).

\subsubsection{Propone acción general para facilitar futuras tareas}

Identificamos un último tipo de intervenciones en la evaluación de la tarea: proponer una acción general para facilitar otras tareas futuras. Concretamente, estas intervenciones sugieren revisar lo escrito antes de entregarlo al profesor. Esta revisión se recomienda específicamente en relación con aspectos formales como la carátula, la numeración de páginas, la inclusión de imágenes y cuadros, la ortografía, el uso de pie de página, el tamaño de la letra, la presentación, la prolijidad y la forma de entrega.

Tal como mostró la Tabla 46, únicamente el docente de la Asignatura A interviene de ese modo en 16 oportunidades (16/104), durante las situaciones en los que propone comentar individualmente las correcciones de los trabajos prácticos. La Tabla 58 ejemplifica estas intervenciones. 
Tabla 58. Propone acción general para facilitar futuras tareas: sugiere revisar lo escrito antes de entregarlo. Fragmento de clase de la Asignatura $A$

Clase 9. El docente pide que algunos estudiantes se acerquen a su banco para comentarles las correcciones del segundo trabajo práctico.

\section{Interacciones}

1. DA: [9 $\min 20 \mathrm{~s} / 59 \mathrm{~min}$ ] [A su lado se encuentra Yésica, a quien le comenta su trabajo práctico] Esto [la carátula] está bien, esto es una opción, podes ponerlo más abajo [se refiere a la inscripción "Ciclo lectivo 2011”, situada en el centro de la carátula], quedaría bien acá, esto [se refiere a datos como nombre y apellido de la alumna, materia y nombre del profesor] un poco más separado [hace referencia al interlineado entre los datos].

2. Yésica: Es que ya me mareé haciendo los "cositos" [se refiere a los efectos especiales que usó de WordArt, una función del procesador de textos que crea textos con texturas y contornos], más [cambios] no podía [hacer].

3. DA: [...] a lo que hay que darle importancia siempre es a la institución donde lo vas a entregar, siempre va como rótulo [del trabajo práctico] el ciclo lectivo, [...] vos hacés dos o tres modelos de éstos [se refiere a los diseños en ordArt y los próximos trabajos copiás la carátula y le cambias.

4. Yésica: Sí, sí. En otro [trabajo] yo tenía caratula [armada] y quise hacerlo distinto [para este trabajo] porque no me gustaba.

5. DA: Lo único que hay que cambiar es el tema [se refiere al tema del cual trata el trabajo, que se explicita en la carátula], después hacés [copiás] todo lo mismo, "Trabajo Práctico № 3", esto es todo lo mismo y cambio [el resto de los datos], y ganás tiempo en la producción. [...] Acá [en el trabajo práctico] falta la numeración [de páginas], te falta, como para enriquecer, una vez que terminas el trabajo, vas numerando las páginas. [Tenés que poner la función en el procesador de textos] "Numerar a todas" [...] [Así] si [el trabajo] quedó sin abrochar, el profe no se pierde [con las hojas sueltas]. [...] Siempre la presentación [del trabajo] vale muchísimo, [los profesores] se fijan mucho en eso, en la ortografía. Si yo trabajo en la máquina [computadora] que tiene corrector ortográfico, [...] tengo que fijarme muy bien, leer el trabajo muchas veces, [tener en cuenta] el tema de la prolijidad, la ortografía y la entrega, [porque] el profe ya lo mira de otra manera [al trabajo, si se tuvieron en cuenta esos aspectos]. [Hay que comprar] Una carpetita, lo entrego ahí, un folio, algo, bien entregadito, eso plantea otra cosa con respecto a la presentación, es parte también de la producción. [Continúa comentando el trabajo práctico de Yésica].

En la intervención que reproduce la Tabla 58, el profesor de la Asignatura A, tras leer la producción escrita de Yésica, recomienda acciones generales para el próximo trabajo práctico que la alumna tenga que entregar. Específicamente, le sugiere realizar cambios en la carátula, guardar en la computadora un modelo de la misma, numerar las páginas del documento, cuidar la prolijidad, revisar la ortografía con el corrector del procesador de textos y entregar la producción en carpeta o folio. La alumna escucha estas recomendaciones y comenta con el docente las dificultades encontradas en el proceso de diagramar la carátula en el procesador Word.

Estas recomendaciones del profesor de la Asignatura A, que enfatizan la revisión de aspectos formales de las producciones escritas, van en línea con otras intervenciones que mostramos este docente realiza en la evaluación de la tarea, en las que también evalúa estos aspectos. Precisamente en el apartado 6.3.1.2 analizamos la evaluación de aspectos formales de las respuestas escritas y ejemplificamos con un fragmento de clase en el que, tras comentar ciertos errores ortográficos, este docente propone la revisión de estas cuestiones en próximos 
trabajos: "hay que volver a releer y tener cuidado en la entrega" (interacción nº 1 de la Tabla $51)$.

\subsubsection{Algunas conclusiones sobre la función evaluación de la tarea}

Las cuatro categorías descritas en este apartado ("evalúa respuestas escritas", "evalúa las interpretaciones", "evalúa la actividad de los alumnos" y "propone acción general para facilitar futuras tareas") agrupan 104 intervenciones identificadas en la función docente de evaluación de la tarea de leer para responder cuestionarios.

El análisis de los datos presentados en la Tabla 46 muestra que los docentes de las tres materias privilegian la evaluación de las respuestas escritas (67/104) por sobre la evaluación de las interpretaciones alcanzadas por los estudiantes (11/104) o la evaluación de la actividad a través de valorar positivamente el cumplimiento de la tarea (10/104). Es decir, buscan preponderantemente estimar qué han escrito los alumnos en las respuestas y emitir un juicio acerca de sus aspectos disciplinares y formales.

En la mayor parte de las intervenciones que evalúan aspectos disciplinares de las respuestas escritas, los docentes las avalan. Tengamos presente que en la gestión del medio, identificamos intervenciones en las que los profesores, para sostener la tarea, regulan la búsqueda de respuestas a los cuestionarios, indicando partes donde hallarlas en los textos o incitando la lectura de ciertas partes que contienen ideas clave a través de leer su inicio en voz alta (ver subapartado 6.2.3.3). En paralelo, hallamos que los docentes cierran parcialmente la tarea cuando enuncian las respuestas que consideran correctas o bien avalan como respuestas las interpretaciones que los estudiantes expresan o la información que localizan en el texto (ver subapartado 6.2.4). Probablemente estas intervenciones mencionadas hayan colaborado en la producción de respuestas juzgadas como correctas por los docentes.

Habiendo presentado este panorama general de intervenciones docentes en la evaluación de la tarea, es posible elaborar algunas conclusiones respecto de cómo se interviene en cada materia para evaluar la tarea.

Anteriormente mostramos que el docente de la Asignatura A interviene evaluando aspectos disciplinares de las respuestas escritas en los espacios en los que comenta individualmente las correcciones de los trabajos prácticos: señala errores e incompletudes o avala las que considera correctas. Además, y a diferencia de los profesores de las otras dos materias, evalúa los aspectos formales de las respuestas escritas (ver subapartado 6.3.1.2). En concordancia con ello, sugiere a los estudiantes una acción general para facilitar tareas 
futuras: revisar estos aspectos antes de entregar los trabajos prácticos al profesor. De lo expuesto se desprende que estas recomendaciones del docente incitan a volver al texto no para retornar a las ideas y retrabajarlas (Olson, 1997, Teberosky, 1997, 2001; Wells, 1990a, 1990b) sino exclusivamente para revisar aspectos formales.

En cuanto a la evaluación de las interpretaciones de los estudiantes, se ha mostrado que el profesor de la Asignatura A, en contraposición con los docentes de las otras dos materias, pregunta por los contenidos disciplinares a los que refieren las respuestas y sostiene dichas preguntas en cuatro oportunidades, logrando que los estudiantes argumenten acerca de lo que han entendido (ver subapartado 6.3.2.1). Además de intervenir de ese modo, este docente, a diferencia de sus colegas y en una sola oportunidad, formula una pregunta abierta al grupo-clase acerca de lo que comprenden de lo leído, promoviendo así que los alumnos comenten, de acuerdo con sus perspectivas, los temas centrales que aborda el texto (ver subapartado 6.3.2.2). Es interesante señalar que investigaciones didácticas en el nivel primario llevadas a cabo por Aisenberg $(2005,2010)$ identifican que este tipo de preguntas abiertas originan situaciones propicias para enseñar a leer en Ciencias Sociales, ya que permiten evidenciar logros y problemas de comprensión de los alumnos y dan pie para un trabajo de interpretación colectiva en el cual el profesor puede ayudar a avanzar en el entendimiento del texto.

Específicamente en la Asignatura A, hablar sobre lo leído ofrecería la posibilidad de trabajar con características propias de los textos históricos. Estudios en didáctica de la Historia remarcan la importancia de que los profesores de nivel primario intervengan ayudando a identificar las visiones de los hechos históricos que sostienen los autores de los textos (Aisenberg, 2010; Aisenberg y otros, 2009; Lerner, Aisenberg y Espinoza, 2009, 2012; Torres, 2008). Sin embargo, no observamos intervenciones del profesor de la Asignatura A en las que haga hincapié en la importancia de relacionar, en Historia, las ideas de un texto con un autor en particular, resaltando que se trata de una perspectiva sobre los acontecimientos históricos, y evitando así que sea considerada por los estudiantes como "lo que de verdad pasó" (Lerner, Aisenberg y Espinoza, 2012, p.533). En relación con ello, se ha estudiado que una de las estrategias que emplean los lectores avanzados en Historia es identificar y evaluar al autor (Wineburg, 1991). No obstante, en la Asignatura A, el docente no da muestras de haberse propuesto discutir con los alumnos las líneas historiográficas que representan a los autores leídos. En el caso de las materias B y C tampoco identificamos este tipo de discusiones, aunque probablemente ello se deba a que los textos trabajados 
principalmente en estas materias -manuales y módulos- presentan los temas sin explicitar autores.

Cabe oponer a las intervenciones en las que se sostienen preguntas sobre los contenidos o se formulan preguntas abiertas, aquellas en las que los profesores de las Asignaturas B y C, para evaluar las interpretaciones de los alumnos en puestas en común, inquieren por los temas a los que refieren las respuestas y los explican en el marco de exposiciones dialogadas y mediante ejemplos orales y cuadros en el pizarrón (ver subapartado 6.3.2.1). En estas intervenciones prepondera la voz del saber que encarnan los docentes, quienes conducen las exposiciones desde sus perspectivas, y los estudiantes participan con preguntas y comentarios al respecto. Según lo observado, las exposiciones docentes de estas puestas en común serían monológicas (Dysthe, 1996, 2013) porque no animan a que las interpretaciones de los estudiantes se expliciten y/o entren en discusión para impulsar que las ideas individualmente producidas puedan repensarse y reelaborarse. En suma, estas exposiciones de contenidos producen que los estudiantes se involucren, pero no les exigen que expliciten sus puntos de vista ni los contrasten con sus compañeros.

En cuanto a la evaluación de aspectos disciplinares de las respuestas escritas, los profesores de las Asignaturas B y C intervienen mayormente avalándolas. Particularmente, la docente de la Asignatura $\mathrm{C}$ se destaca por su gran cantidad de avales, que duplica la de su colega de la Asignatura B (ver Tabla 47). En las puestas en común de los cuestionarios, si las respuestas no satisfacen sus expectativas, esta profesora también requiere la lectura de otras hasta avalar una de ellas. Hemos visto en los registros de sus clases, que los comentarios evaluativos del tipo "bien" que la docente emite para avalarlas, cierran anticipadamente las discusiones posibles. Estos comentarios que no alientan el diálogo en el aula también fueron identificados por Dysthe (1996) en clases de Ciencias Sociales en el nivel secundario. De acuerdo con Rickenmann (2006), estos avales inmediatos conforman un gesto cronogenético usual en los procesos didácticos, que buscan hacer avanzar el tiempo didáctico: cuando un estudiante da la respuesta esperada, los profesores no siguen preguntando a otros estudiantes sino que la avalan.

Por último, hemos de realzar que los tres docentes evalúan la actividad de los estudiantes a través de valorar positivamente el cumplimiento de la tarea (ver subapartado 6.3.3). Empero, es el profesor de la Asignatura A quien interviene en más oportunidades explicitando esta apreciación a los estudiantes durante los espacios en los que comenta en forma individual los trabajos prácticos entregados (ver Tabla 56). 
En el conjunto de intervenciones que evalúan aspectos disciplinares y formales de las respuestas escritas a través de avalarlas, señalar si son erróneas o incompletas, pedir la lectura de otras o marcar cuestiones ortográficas, gramaticales y de presentación general de los trabajos prácticos, los docentes de estas asignaturas no proponen trabajar la comprensión que los estudiantes han alcanzado de los contenidos disciplinares. Más aun teniendo en cuenta que las respuestas conforman collages de los textos leídos, nos preguntamos ¿qué han entendido los alumnos de los temas?

Enfatizamos anteriormente que, respecto de lo que los estudiantes han entendido tras leer y responder los cuestionarios, los docentes relevan pocos datos. Tal como mostró la Tabla 46, en la evaluación de la tarea, solo once intervenciones corresponden a evaluaciones de lo interpretado (11/104). Si de la tarea de leer para responder cuestionarios se espera que los estudiantes logren comprender los contenidos disciplinares sobre los que leen y contestan, ¿cómo dictaminar que lo logran por el solo hecho de haber localizado y reproducido cierta información de los textos? Siguiendo a Sensevy (2007), decidir que en las respuestas escritas que incluyen información considerada correcta los estudiantes se han apropiado de cierto contenido disciplinar, es una "interpretación abusiva" (p.13) efectuada en el momento de la evaluación de la producción de los alumnos.

En vistas de lo expuesto, podemos concluir afirmando que en las 32 clases analizadas en este capítulo se habla poco sobre los textos leídos (debido las escasas intervenciones que evalúan las interpretaciones alcanzadas por los alumnos) a la vez que se habla poco sobre los textos producidos (más concretamente, los estudiantes hablan poco acerca de sus respuestas escritas y son los docentes los que toman la palabra para avalarlas, marcar errores o incompletudes y/o comentar sus aspectos formales). En definitiva, en estas clases los alumnos del curso de quinto año hablan poco acerca de lo que entienden de los temas, con lo cual queda mayormente velado el vínculo de conocimiento que han podido establecer con los contenidos disciplinares que presentan los textos.

\subsection{Semejanzas y diferencias entre los casos de las asignaturas}

De acuerdo con los datos expuestos en los apartados precedentes, que abordaron intervenciones correspondientes a las funciones docentes de definición del medio, gestión del medio y evaluación de la tarea de leer para responder cuestionarios, es posible puntualizar algunas semejanzas y diferencias que identificamos entre las asignaturas indagadas. Si bien a lo largo del capítulo pormenorizamos el análisis de las intervenciones que observamos en cada una de las materias, hallamos que los elementos que componen la tarea (consignas y 
materiales de lectura) y los modos de intervenir pueden considerarse bastante similares en las Asignaturas B y C, en oposición a la Asignatura A.

Respecto de los elementos que componen la tarea, los datos en el subapartado 6.1 muestran que en las materias $\mathrm{B}$ y $\mathrm{C}$ se indicó responder consignas de localización en clase mientras que en la materia A se asignó, en su mayoría, consignas globales para contestar en forma domiciliaria. En cuanto a los materiales de lectura, los profesores de las Asignaturas B y C propusieron principalmente leer textos escolares, a diferencia del profesor de la Asignatura A, quien planteó mayoritariamente el trabajo con un cuadernillo que incluye textos de circulación social. Registramos que los docentes $\mathrm{B}$ y C entregaron materiales de lectura o fotocopias en cada clase observada, para que los estudiantes trabajasen, mientras que el profesor de la Asignatura A pidió leer el cuadernillo que había pedido fotocopiar a los alumnos a principios del ciclo lectivo.

De acuerdo con los datos analizados, la mayoría de los estudiantes cumplimentó la tarea en las materias B y C pero no lo hizo en la Asignatura A. Al respecto, los alumnos afirmaron en las entrevistas que tuvieron dificultades para realizar la tarea en los hogares, tal como se exigió en la materia A, porque no contaron con tiempo y espacio para leer, por la falta de orientaciones del docente sobre cómo hacerlo y porque en sus hogares no tienen lectores-interpretantes a quienes consultar. A estos motivos se le suma el hecho de que, tal como comentaron, les resulta más difícil el trabajo con textos de circulación social y consignas globales que propone esta asignatura, en comparación con los textos escolares y las consignas de localización que presentan las otras dos materias.

A lo largo de la tarea de leer para responder cuestionarios, también identificamos semejanza entre los modos de intervenir en las Asignaturas B y C, a diferencia de la Asignatura A. En esta última, el profesor propuso acciones generales para facilitar la tarea (consultar distintas fuentes ante dudas de comprensión) y una acción para facilitar tareas futuras (revisar aspectos formales de lo escrito antes de entregarlo). Analizamos dichas intervenciones en los subapartados 6.1 .4 y 6.3.4, respectivamente. Este docente también modificó el tiempo y espacio para la tarea, otorgando tiempo de clase para leer y responder las consignas que inicialmente había encomendado contestar en los hogares (ver subapartado 6.2.2). A diferencia de estas intervenciones, los docentes de las materias B y C no intervinieron recomendando acciones generales ni modificaron el tiempo y espacio para la tarea, dado que los estudiantes la cumplimentaron cuando les fue pedido. Según lo analizado, en la materia A los estudiantes comenzaron la tarea cuando se otorgó tiempo de clase para 
hacerlo pero no ejercieron las acciones recomendadas, a excepción de aquella que sugería consultar dudas al docente.

En la gestión del medio, hallamos que los profesores de las Asignaturas B y C regularon la interpretación del texto explicando oraciones o párrafos que los estudiantes consultaron, a través de ejemplos familiares y significativos (ver subapartado 6.2.3.2). No observamos intervenciones de este tipo en la materia A. De acuerdo con el análisis de los registros de clase, los alumnos participaron de las explicaciones mediante comentarios y preguntas, y en las entrevistas valoraron estas intervenciones postulando que los ejemplos les permitieron comprender mejor los contenidos.

Finalmente, en la evaluación de la tarea identificamos que los profesores de las materias B y C principalmente propusieron puestas en común de las respuestas a los cuestionarios, en las cuales preguntaron por los contenidos disciplinares a los que referían las respuestas escritas y expusieron al respecto (ver subapartado 6.3.2.1). En cambio, el docente de la Asignatura A organizó situaciones en la que comentó individualmente a los alumnos las correcciones de los trabajos prácticos. En esas situaciones, evaluó aspectos disciplinares y, a diferencia de sus colegas, evaluó aspectos formales de las respuestas escritas (ver subapartado 6.3.1.2). Si bien registramos que en esta materia el docente mayoritariamente propuso comentar las respuestas escritas en estos espacios, hallamos que en algunas ocasiones organizó puestas en común de las mismas. Estas puestas en común presentaron características diferentes a las observadas en las otras dos materias: en ellas el profesor de la Asignatura A sostuvo preguntas respecto de los contenidos para que los alumnos argumenten sobre lo leído (ver subapartado 6.3.2.1) o formuló una pregunta abierta para indagar con el grupo-clase sobre qué trataba el texto leído (ver subapartado 6.3.2.2). De acuerdo con lo analizado, registramos que en las puestas en común de las materias B y C los estudiantes participaron oralmente con comentarios y preguntas de las exposiciones docentes. En cambio, en la Asignatura A permanecieron en silencio ante las situaciones de corrección de respuestas escritas pero expusieron sus interpretaciones sobre lo leído en las puestas en común.

No obstante esta similitud establecida entre los elementos de la tarea y las intervenciones que analizamos en las Asignaturas $\mathrm{B}$ y C, en contraposición con los elementos e intervenciones que observamos en la Asignatura A, los resultados muestran que en las tres materias los estudiantes respondieron a los cuestionarios adoptando roles de patchwriters, reproduciendo fragmentos de los materiales que leyeron e incorporando algunos cambios en ellos. El hecho de que en la mayoría de las intervenciones en las tres asignaturas no se propuso explicitar y trabajar con las interpretaciones de los estudiantes, de modo de 
comprender mejor el contenido, posiblemente haya provocado que éstos recurriesen a la literalidad para escribir sobre lo leído y poder completar los cuestionarios. En el subapartado 6.6 de este capítulo profundizaremos respecto de esta hipótesis.

\subsection{Conjuntos de intervenciones en un continuo entre monologicidad y dialogicidad}

Según Dysthe (1996) y Wells (2006), para considerar los usos del lenguaje en la educación resulta productivo situarlos en un continuo entre monologicidad y dialogicidad. Tomando esta idea, nos propusimos mirar el conjunto de los datos de este capítulo y reagrupamos las diversas intervenciones identificadas en la estructura de la actividad en tres conjuntos que ubicamos en distintas posiciones de ese continuo. Pasaremos ahora a presentar estos conjuntos de intervenciones de acuerdo con un orden creciente de menor dialogicidad-mayor monologicidad a mayor dialogicidad-menor monologicidad.

El primer conjunto de intervenciones que situamos en un extremo monológico se asienta sobre monólogos docentes, en los que la perspectiva del profesor no solo es predominante sino exclusiva. Las intervenciones que componen este conjunto son: enunciar las respuestas (ver subapartado 6.2.4.2) y evaluar aspectos disciplinares y aspectos formales de las respuestas escritas (ver subapartado 6.3.1). En nuestro análisis observamos que, ante las intervenciones mencionadas, los estudiantes se situaron como receptores de esos saberes porque no se cedió lugar a sus voces. Fueron los profesores quienes dictaminaron lo "correcto" o "incorrecto" de las respuestas a los cuestionarios.

En segundo lugar, encontramos otro grupo de intervenciones - predominante en la estructura de la actividad- que ejerce fuerte influencia para que los alumnos participen oralmente en clase. Situamos estas intervenciones en un punto medio del continuo entre monologicidad y dialogicidad porque no promueven situaciones totalmente monológicas ni totalmente dialógicas. Las intervenciones agrupadas en este conjunto son: organizar una memoria didáctica y contextualizar contenidos (ver subapartado 6.1.3), regular la interpretación del texto a través de explicar oraciones o párrafos con ejemplos familiares y significativos o a través de situar oralmente contenidos en determinado contexto sociohistórico (ver subapartado 6.2.3.2), y preguntar sobre los contenidos disciplinares a los que hacen referencia las respuestas escritas y exponer al respecto (ver subapartado 6.3.2.1). Cuando los docentes ejercieron estas intervenciones pudimos observar que los estudiantes participaron oralmente sumándose con comentarios y preguntas a las explicaciones y contextualizaciones guiadas bajo la perspectiva de éstos. 
Finalmente, distinguimos un tercer conjunto de intervenciones que en el continuo entre monologicidad y dialogicidad ubicamos cercanas al polo dialógico. Estas intervenciones, que ocurrieron en forma minoritaria en las clases observadas (ver Tabla 46), son: sostener preguntas sobre los contenidos disciplinares (ver subapartado 6.3.2.1) y formular preguntas abiertas respecto de qué trata el texto leído (ver subapartado 6.3.2.2). De acuerdo con lo observado, estas intervenciones lograron que los estudiantes expresaran sus interpretaciones acerca de lo que leyeron y escribieron en la tarea. En efecto, notamos que los alumnos participaron oralmente incorporando apreciaciones propias, vivencias de sus mundos significativos y comentarios personales relativos al contenido disciplinar.

\subsection{Conclusiones}

En este capítulo pusimos el foco en las prácticas de enseñanza que involucran lectura y escritura de contenidos en tres materias de una escuela secundaria a la que asisten alumnos de sectores socioeconómicos desfavorecidos. Las materias que seleccionamos para nuestro estudio fueron Estudios Sociales Argentinos (Asignatura A), Geografía Económica (Asignatura B) y Legislación Fiscal (Asignatura C).

El objetivo que nos propusimos fue identificar y comprender las prácticas de enseñanza que en esas asignaturas favorecen u obstaculizan que leer y escribir se conviertan en herramientas de acceso, participación y apropiación del conocimiento. Para tal fin, escogimos centrar el análisis de datos en la tarea mayormente propuesta por los docentes de esas materias: leer para responder cuestionarios. Hallamos que esta tarea se efectuó en 32 de las 37 clases en las que se realizaron actividades de lectura y escritura. Para analizar los datos combinamos una estrategia categorizadora y una estrategia contextualizadora que, de acuerdo con Maxwell y Miller (2008), examinan relaciones de similitud y contigüidad, respectivamente. Así, efectuamos un análisis de la acción conjunta (Sensevy, 2007) de docentes y estudiantes en relación con la lectura y la escritura de contenidos disciplinares, que condujo a identificar modos de intervenir de los profesores y patrones de comportamiento en los estudiantes ante éstos.

El análisis efectuado permitió distinguir tres funciones docentes, definición del medio, gestión del medio y evaluación de la tarea, que conforman la estructura de la actividad, y agrupan distintos modos de intervenir en la tarea. Particularmente, en la definición del medio, distinguimos las siguientes intervenciones docentes: "define la tarea", "define recursos de lectura", "establece significados compartidos" y "propone acciones generales para facilitar la tarea" (ver Tabla 9). También identificamos cuatro formas de intervenir en la gestión de 
medio: "promueve y monitorea la puesta en tarea", "modifica tiempo y espacio para la tarea", "sostiene tarea" y "cierra parcialmente tarea" (ver Tabla 28). Por último, en la evaluación de la tarea identificamos otros cuatro modos de intervenir: "evalúa las respuestas escritas", "evalúa las interpretaciones", "evalúa la actividad de los alumnos” y "propone acción general para facilitar futuras tareas" (ver Tabla 46).

Respecto de los elementos que componen la tarea (consignas y materiales de lectura) y los modos de intervenir en ella, es posible establecer semejanzas y diferencias entre las materias indagadas. De acuerdo con lo expuesto en el subapartado 6.4, es posible establecer una semejanza entre los elementos e intervenciones observadas en las Asignaturas B y $\mathrm{C}$, en oposición a la Asignatura A. Tal como mostraron los subapartados 6.1.1 y 6.1.2, observamos que los profesores B y C propusieron mayoritariamente leer textos escolares, que entregaron en cada clase, para responder consignas de localización. En cambio, el profesor de la Asignatura A planteó en forma predominante el trabajo con un cuadernillo con textos de circulación social -que indicó a los alumnos fotocopiar a principios del ciclo lectivo- para contestar consignas globales en forma domiciliaria. Dado que los estudiantes no efectuaron la tarea en el hogar ni llevaron a clase dicho material, debió dar tiempo para que respondan las consignas en clase (ver subapartado 6.2.2) y facilitar su propio cuadernillo para ello.

Los modos en que los profesores de las Asignaturas B y C intervinieron en la tarea de leer para responder cuestionarios se asemejan entre sí, a diferencia de cómo intervino el docente de la Asignatura A. Solo en la Asignatura A el docente propuso a los estudiantes acciones generales para facilitar la tarea (consultar distintas fuentes ante dudas de comprensión) y una acción para facilitar tareas futuras (revisar aspectos formales de lo escrito antes de entregarlo), que analizamos en los subapartados 6.1 .4 y 6.3.4, respectivamente. Por su parte, solo en las Asignaturas B y C identificamos intervenciones que regularon la interpretación del texto explicando oraciones o párrafos de los textos con ejemplos familiares y significativos para los alumnos (ver subapartado 6.2.3.2).

También hallamos distintas situaciones propuestas por los profesores de estas materias para evaluar la tarea. En las materias B y C, los profesores plantearon puestas en común de los cuestionarios, en las cuales preguntaron por los contenidos disciplinares a los que referían las respuestas escritas y expusieron al respecto (ver subapartado 6.3.2.1). En cambio, el docente de la Asignatura A organizó situaciones en la que comentó individualmente a los alumnos las correcciones de los trabajos prácticos, para evaluar aspectos disciplinares y, a diferencia de los otros profesores, aspectos formales de las respuestas escritas (ver subapartado 6.3.1.2). Vale resaltar que también hallamos una minoría de intervenciones en 
las que este profesor planteó puestas en común y sostuvo preguntas respecto de los contenidos para que los alumnos argumenten sobre lo leído (ver subapartado 6.3.2.1) o formuló una pregunta abierta sobre qué trataba el texto (ver subapartado 6.3.2.2).

Pese a estas semejanzas identificadas en relación con los elementos de la tarea y las formas de intervenir entre las Asignaturas B y C y la Asignatura A, los resultados muestran que en las tres materias los estudiantes adoptaron roles de patchwriters, reproduciendo fragmentos de los textos que leyeron e incorporando pocos cambios en ellos.

Para conjeturar hipótesis respecto a estas producciones collage, retomemos los conjuntos de intervenciones docentes que describimos en el apartado 6.5. En dicho apartado, reagrupamos las intervenciones categorizadas en este capítulo para conformar tres conjuntos, que situamos en diferentes posiciones de un continuo entre monologicidad y dialogicidad, tomando la sugerencia de Dysthe (1996) y Wells (2006) de considerar los usos del lenguaje en la educación a partir de éste. Ubicamos un primer grupo de intervenciones en un extremo monológico, dado que en ellas la perspectiva de profesor fue predominante y exclusiva: enunciar las respuestas (ver subapartado 6.2.4.1) y evaluar aspectos disciplinares y aspectos formales de las respuestas escritas (ver subapartado 6.3.1). Observamos que ante estas intervenciones los alumnos se situaron como receptores de esos monólogos docentes que dictaminaron lo "correcto" o "incorrecto". El segundo grupo de intervenciones se localiza en un punto medio del continuo entre monologicidad y dialogicidad porque promovió que los estudiantes participen con comentarios y preguntas de las explicaciones y contextualizaciones guiadas bajo la perspectiva de los docentes. Las intervenciones que componen este segundo grupo son: organizar una memoria didáctica y contextualizar contenidos (ver subapartado 6.1.3), regular la interpretación del texto a través de explicar oraciones o párrafos con ejemplos familiares y significativos o a través de situar oralmente contenidos en determinado contexto socio-histórico (ver subapartados 6.2.3.2) y formular preguntas sobre los contenidos disciplinares a los que hacen referencia las respuestas escritas y exponer al respecto (ver subapartado 6.3.2.1). Por último, el tercer conjunto de intervenciones, halladas en forma minoritaria en las clases observadas (ver Tabla 46), se sitúa en el polo dialógico del continuo entre monologicidad y dialogicidad, dado que éstas favorecieron que los estudiantes expresaran apreciaciones propias y comentasen vivencias de sus mundos significativos en relación con el contenido disciplinar. Las intervenciones que forman parte de este tercer grupo son: sostener preguntas sobre los contenidos disciplinares para que los alumnos argumenten (ver subapartado 6.3.2.1) y formular una pregunta abierta respecto de qué trata el texto leído (ver subapartado 6.3.2.2). 
Por lo expuesto en relación con los comportamientos de los alumnos, las intervenciones del extremo monológico obstaculizan que leer y escribir se conviertan en herramientas para participar y apropiarse del conocimiento, dado que no otorgan lugar a sus voces. En cambio, aquellas intervenciones que situamos en un extremo dialógico ofrecen posibilidades para un trabajo epistémico ya que fomentan que los estudiantes expresen sus interpretaciones sobre lo leído, lo que puede dar lugar a un trabajo de confrontación y discusión al respecto. Aunque las intervenciones que ubicamos en ese extremo promovieron que los estudiantes hablen acerca de lo que entendieron, no observamos que hayan propuesto contraponerlas entre sí y/o considerar interpretaciones alternativas (ver subapartados 6.3.2.1 y $6.3 .2 .2)$.

Habiendo reseñado las conclusiones de los subapartados 6.4 y 6.5, podemos efectuar algunas conclusiones respecto a los datos analizados a lo largo de todo el capítulo.

De acuerdo con nuestros resultados respecto a la acción conjunta, en la función docente de definición del medio, ciertas intervenciones de los docentes lograron instalar a los estudiantes en la tarea: brindar material de lectura, dar consignas para responder en clase, incitar a ponerse en tarea y extender los tiempos destinados a la misma. Por el contrario, otras intervenciones como requerir materiales de lectura, pedir lectura en los hogares y recomendar acciones para facilitar la tarea, fomentaron que los estudiantes permanecieran en silencio y no llevaran a cabo lo pedido. Es probable que en este contexto, el hecho de que los estudiantes del curso sean trabajadores/as y padres o madres adolescentes y no cuenten con orientación sobre los contenidos disciplinares fuera de la escuela -tal como comentaron en las entrevistas-, haya incidido en las dificultades para ejercer esta lectura a solas. A ello se le suma que, tal como mostramos en el subapartado 6.1.1, leer en los hogares no es una cláusula del contrato didáctico al que están habituados en las materias. Estos resultados indicarían que, en poblaciones con estas características socioeconómicas, se hace necesario establecer un medio en el que los docentes ofrezcan materiales de lectura con los que los estudiantes interactúen, consideren tiempos flexibles, alienten la puesta en tarea y ofrezcan ayuda y guía presencial tanto en acciones que faciliten desarrollar la tarea como en las dificultades de comprensión que emerjan.

Otras conclusiones pueden efectuarse respecto al lugar que ocuparon las interpretaciones de los estudiantes en la estructura de la actividad identificada. Ya mencionamos que representan una minoría aquellas intervenciones que piden a los estudiantes explicitar sus interpretaciones respecto de lo leído. Esto nos conduce a formular algunos interrogantes respecto a las razones por las cuales la actividad, tal como está 
estructurada, no otorga preponderancia a dichas interpretaciones. Es posible conjeturar que la noción de compresión lectora que la sostiene sea aquella que concibe a la lectura como una actividad extractiva del significado dado en lo impreso, en oposición al enfoque interactivo que la entiende como un proceso interpretativo que requiere operar sobre un texto para poner en relación sus pistas informativas con los conocimientos del lector (Lerner, 1985; Smith, 1988, citado en Carlino, 2005). Por concebir que la lectura es una actividad extractiva y, por ende, que no necesitaría enseñarse, la estructura de la actividad no plantearía intervenciones que postulen como objeto de enseñanza el leer para responder interrogantes ni consideraría los cuestionarios como guías para empezar a desentrañar las interpretaciones posibles de un texto.

El hecho de que los docentes, en la mayoría de las intervenciones analizadas, no den lugar al trabajo con las interpretaciones de los estudiantes conduce a formular otras dos presunciones. Primero, que es posible que los profesores no trabajen respecto de lo interpretado por considerar que si las respuestas escritas de los estudiantes son "correctas", ello probaría la adquisición de conocimientos. Esto representaría, en términos de Brousseau (1990, 2007), un efecto Jourdain, en el que se reconocen de inmediato ciertos comportamientos de los alumnos (en este caso, haber identificado las respuestas "correctas") como estrategias ganadoras. Al mismo tiempo, esto podría indicar una concepción respecto de la escritura como representación fiel del proceso cognoscitivo; idea cuestionada por distintos estudios, entre los que podemos citar las investigaciones de Perelman (2008) sobre la construcción de resúmenes escritos en el nivel primario. La segunda presunción supone que estos profesores no indagan las interpretaciones de los estudiantes porque valorarían el cumplimiento de la tarea -tal como observamos que sucede en intervenciones analizadas en el subapartado 6.3.3- por sobre el tipo de vínculo que los estudiantes lograron establecer con el contenido disciplinar. Esto podría indicar que la actividad, tal como se plantea, otorga relevancia al hecho de que los estudiantes se hayan enfrentado a textos de diversa índole para los cuales afirmaron en las entrevistas no contar con experiencia previa-, sostengan una atención conjunta sobre ellos y tengan que esforzarse para producir un escrito. Empero, de confirmarse esa presunción de que los docentes privilegian el cumplimiento de la tarea, es posible advertir un riesgo de que los alumnos, al descifrar estas expectativas del contrato didáctico que recaen sobre ellos, respondan los cuestionarios no como un modo de comprometerse con el problema planteado por la tarea (Brousseau, 1986, 1994, 2007) sino para realizar la tarea de algún modo, aunque éste sea copiar fragmentos sin entenderlos. De esa forma, las respuestas escritas serían producto del conocimiento por parte de los alumnos 
de ciertos hábitos y expectativas propias del contrato didáctico establecido para la tarea: que aun copiando y pegando información serán igualmente aprobados por los docentes. Cabe recalcar que así, la tarea de leer para responder cuestionarios no sería asumida por éstos como un problema al que le atribuyen sentido.

Recapitulemos brevemente. Nuestros datos muestran que la estructura de la actividad no está organizada preponderantemente para indagar la comprensión de los contenidos disciplinares en la gestión del medio ni en la evaluación de la tarea. Nos preguntamos, entonces ¿qué lograron entender los estudiantes sobre lo leído? ¿De qué modo se puso en juego dicha comprensión en las respuestas a los cuestionarios?

En relación con las respuestas collage, producidas por los estudiantes del curso de quinto año, conviene explicitar un debate teórico. Aunque algunas investigaciones sostienen que copiar oraciones de un texto evidencia incomprensión de lo leído y/o ausencia de reelaboración por parte de quien lo realiza, otros estudios que relevamos cuestionan esta afirmación. De acuerdo con estos últimos, las respuestas textuales de los estudiantes respecto de preguntas sobre lo leído no permiten afirmar que, en todos los casos, éstos ejercieron un uso reproductivo de la lectura y la escritura para cumplimentar la tarea. Es posible que algunas respuestas representen un intento por parte de los alumnos de comprender los textos y producir una elaboración personal que dé cuenta de sus interpretaciones. Al respecto, distintos investigadores que analizan clases en el nivel primario muestran que recurrir a la literalidad representa un paso necesario en la apropiación del lenguaje disciplinar (Kaufman y Perelman, 1999; Perelman, 2008; Perelman y Castorina, 2005; Teberosky, 1990). En niveles superiores, reproducir fragmentos de otros autores también es considerado parte de distintos procesos interrelacionados: aprender acerca del uso de fuentes, apropiarse de aspectos del lenguaje académico, construir una identidad de autor y formar parte de una comunidad discursiva disciplinar (Abasi, Akbari y Graves, 2006; Guerin, 2008; Pecorari, 2003; Villalva, 2006). Otros autores como Hull y Rose (1989) identifican que estudiantes universitarios realizan collages para mostrarles a los docentes cierto conocimiento de lo leído sin recurrir a la copia exacta.

A estos estudios que indican que los collages evidencian un proceso de apropiación del lenguaje disciplinar, cabe contraponer otros estudios que examinan producciones de alumnos con transcripciones textuales y descubren que, en ocasiones, éstas indican incomprensión sobre lo leído (Aisenberg y Lerner, 2008; Benchimol, Carabajal y Larramendy, 2008; Howard, 1995, 2001). 
En línea con los hallazgos de estos estudios reseñados, nos preguntamos: ¿los alumnos de quinto año se encontraban en el proceso de apropiarse de las ideas de los autores y para ello utilizaron sus palabras? ¿O tuvieron dificultades en la comprensión de los materiales y copiaron textualmente? En tanto la forma en que está estructurada la actividad no tiende a favorecer la explicitación y el trabajo con las interpretaciones de los estudiantes, las preguntas formuladas permanecen sin respuesta. No obstante, pensamos que estas preguntas podrían ser respondidas por los propios docentes si hicieran lugar a trabajar en clase con lo que los estudiantes entienden.

Para finalizar este capítulo, sinteticemos los resultados que hallamos en relación con la estructura de la actividad. El análisis presentado mostró que en las clases observadas de estas tres asignaturas se logró concentrar la atención conjunta de los estudiantes en textos de diversa índole y promover que, a través de intervenciones que identificamos predominantes, éstos preguntasen y comentasen sobre los temas a partir de las explicaciones y contextualizaciones orales que dirigen los profesores. En cambio, representan una minoría aquellas intervenciones que fomentaron que los estudiantes dieran sus perspectivas respecto de lo leído. Según lo analizado, y en la medida en que las intervenciones predominantes ocasionaron que quedara velada la comprensión de los estudiantes, la estructura de la actividad precisa redefiniciones si se quiere lograr la producción y/o apropiación del conocimiento mediante prácticas de lectura y escritura. Para promover que leer y escribir sean herramientas no solo de acceso sino también de participación y apropiación del conocimiento, es necesario que esta estructura incluya intervenciones que potencien usos epistémicos, tales como las que se describen en nuestro marco conceptual: alentar a los estudiantes a enunciar sus interpretaciones, regular el desarrollo de discusiones en las que se pongan en juego distintas ideas, proponer el retorno a la bibliografía para buscar argumentos que ratifiquen o refuten las interpretaciones, etcétera. Todas estas intervenciones, que se sitúan en el extremo dialógico del continuo entre monologicidad y dialogicidad, permitirían sacar provecho de la potencialidad epistémica de leer, escribir y dialogar. 


\section{Conclusiones generales}

En esta tesis nos propusimos como objetivo principal identificar y comprender las prácticas de enseñanza que favorecen u obstaculizan que leer y escribir se conviertan en herramientas de acceso, participación y apropiación del conocimiento en asignaturas de escuelas secundarias que reciben alumnado de sectores socioeconómicos desfavorecidos. Focalizamos en la lectura y la escritura de contenidos dado que asumimos, en línea con nuestros marcos teóricos, que en ciertas condiciones estas herramientas colaboran con la elaboración del conocimiento.

Nuestro interés por alcanzar el objetivo enunciado se basa en una problemática educativa para la cual hallamos cierta área de vacancia temática. Específicamente en poblaciones de sectores socioeconómicos desfavorecidos, la CEPAL (2014) advierte que solo un 33\% logra finalizar el nivel secundario. Aunque la inclusión educativa de estos jóvenes se encuentra en riesgo, identificamos en nuestra revisión bibliográfica sobre lectura y escritura en el nivel, que existen pocos estudios que aborden la enseñanza que se les brinda. Tal como mostramos en el Capítulo 1, la mayoría de los antecedentes relevados sobre leer y escribir contenidos disciplinares focalizan otros niveles u otras poblaciones. En cuanto a los trabajos anglosajones, éstos estudian cómo en el nivel universitario se enseñan contenidos mediante la lectura y la escritura, o cómo leen y escriben estudiantes de sectores socioeconómicos desfavorecidos. En relación con el nivel secundario, los antecedentes anglosajones indagan en alumnado inmigrante o refugiado. Por su parte, los trabajos nacionales relevados que se concentran en alumnos secundarios que provienen de sectores socioeconómicos desfavorecidos indagan las condiciones institucionales que favorecen la permanencia escolar. Por el contrario, hallamos que son incipientes los estudios que se ocupan de cómo se entrelaza la enseñanza de contenidos disciplinares con la lectura y la escritura en el nivel secundario, y no encontramos investigaciones que aborden dicha cuestión específicamente en alumnado de sectores socioeconómicos desfavorecidos. Por lo expuesto, los resultados de este trabajo doctoral contribuyen con un análisis de condiciones de enseñanza que se ofrecen a estos estudiantes para leer y escribir contenidos en asignaturas de una escuela secundaria pública de la Ciudad de Buenos Aires.

Para dar respuesta a nuestro interrogante principal -cómo se incluyen las prácticas de enseñanza mediadas por lectura y escritura en materias de escuelas secundarias a las que 
asisten alumnos provenientes de sectores socioeconómicos desfavorecidos- diseñamos un estudio de casos. Este abordaje metodológico y los instrumentos de recolección de datos que usamos (entrevistas, observación de clases y recolección de documentos institucionales, materiales de lectura y producciones de los alumnos) se detallan en el Capítulo 3. Al optar por indagar tres asignaturas en un curso de quinto año pudimos analizar distintas prácticas de enseñanza para un mismo grupo de alumnos. Por ello, mantener esa característica constante posibilitó un contraste analítico (Rockwell, 1995) que condujo a identificar qué intervenciones docentes favorecieron $u$ obstaculizaron que, en dicho curso, leer y escribir se conviertan en herramientas para acceder y apropiarse del conocimiento.

Antes de puntualizar los resultados que obtuvimos en relación con la lectura y la escritura de contenidos disciplinares, diremos algunas conclusiones respecto de la permanencia escolar, fenómeno que decidimos abordar frente a las recurrentes alusiones al respecto que identificamos en el discurso de los entrevistados, en los documentos institucionales y en las transcripciones de situaciones extra-áulicas observadas.

A lo largo del Capítulo 5 mostramos que la escuela indagada, que recibe mayoritariamente población de sectores socioeconómicos desfavorecidos, alcanza con claros esfuerzos la retención de gran parte de sus estudiantes. Anteriormente mencionamos que uno de los documentos institucionales que recogimos, denominado Proyecto Escuela, indica que el porcentaje de retención de esta institución a la fecha del estudio era del 90\%, levemente superior al promedio del conjunto de escuelas estatales de la Ciudad de Buenos Aires (GCBA, 2011), que incluye a sectores con mayores recursos socioeconómicos. Esta tasa de retención probablemente se relacione con ciertas estrategias institucionales y estrategias interpersonales que identificamos llevan a cabo directivos y docentes que, de acuerdo con lo que sostienen estos actores en las entrevistas (y la bibliografía relevada en el Capítulo 1), favorecen la permanencia escolar. Estas estrategias desarrolladas por el equipo directivo y docente son: involucrarse en un proyecto educativo inclusivo, abordar conjuntamente las problemáticas que desafían la permanencia escolar, establecer un vínculo afectivo con los estudiantes, manifestar confianza en que éstos lograrán los aprendizajes deseados y acompañar en forma personalizada estos procesos. Siguiendo a Charlot (2006), consideramos que estas estrategias implican "lecturas en positivo" (p. 36) dado que no desconocen las circunstancias de vida de los estudiantes sino que las toman en cuenta para diseñar intervenciones que promuevan su permanencia escolar. En cuanto a esas circunstancias de vida, registramos en las entrevistas que estos actores institucionales adoptan una postura 
ético-política que critica la realidad socioeconómica desigual que las ocasionaría y pretende que la educación postule un cambio al respecto.

De acuerdo con lo expuesto identificamos que, como sostén de dicha permanencia, la institución apunta a que los jóvenes que allí asisten se constituyan en sujetos didácticos (Chevallard, 1988). Este concepto remite a la entrada de individuos en una institución determinada (en este caso, la escuela) y su sujeción al orden que ésta impone. Tal como expresan en las entrevistas, el directivo y los profesores buscan que estos jóvenes acepten las pautas de convivencia institucional y se comprometan con las propuestas didácticas al disponerse a la resolución de las tareas. Esta constitución en sujetos didácticos no es un logro menor considerando su necesidad para impulsar los aprendizajes disciplinares deseados. Nuestras observaciones de clase en materias de segundo y tercer año del nivel, que formaron parte del estudio piloto de esta investigación (ver subapartado 3.4 del Capítulo 3), evidencian esfuerzos de los docentes para favorecer ese proceso.

Tras describir y caracterizar estas acciones que docentes y directivos desarrollan para promover la permanencia escolar, analizamos las prácticas de enseñanza que involucran leer y escribir contenidos en las asignaturas cuyas clases observamos: Estudios Sociales Argentinos (Asignatura A), Geografía Económica (Asignatura B), Legislación Fiscal (Asignatura C). Así, en el Capítulo 6 presentamos un análisis de la tarea mayormente propuesta en 32 de las 37 clases en las que se realizaron actividades de lectura y escritura: leer para responder cuestionarios. Identificamos que la estructura de la actividad está conformada por distintos modos de intervenir de los profesores, que agrupamos en tres funciones: definición del medio, gestión del medio y evaluación de la tarea. Particularmente, en la definición del medio, los docentes intervinieron a través de los siguientes modos: "define la tarea", "define recursos de lectura", "establece significados compartidos" y "propone acciones generales para facilitar la tarea". En la gestión del medio las formas de intervenir que distinguimos corresponden a: "promueve y monitorea la puesta en tarea", "modifica tiempo y espacio para la tarea", "sostiene tarea" y "cierra parcialmente tarea". Por último, en la evaluación de la tarea identificamos como intervenciones típicas: "evalúa las respuestas escritas", "evalúa las interpretaciones", "evalúa la actividad de los alumnos" y "propone acción general para facilitar futuras tareas".

Hallamos que los elementos que componen la tarea (consignas y materiales de lectura) y los modos de intervenir pueden considerarse bastante similares en las Asignaturas B y C, en oposición a la Asignatura A. En el primer caso (Asignaturas B y C) los docentes indicaron responder consignas de localización en clase, ofrecieron textos escolares, regularon la 
interpretación del texto explicando oraciones o párrafos a través de ejemplos familiares y significativos y propusieron puestas en común de las respuestas a los cuestionarios, en las que terminaron exponiendo los temas. En cambio, en el segundo caso (Asignatura A), el docente asignó consignas globales para contestar en forma domiciliaria, a partir de la lectura de textos de circulación social -incluidos en un cuadernillo que los estudiantes habían fotocopiado a principios del ciclo lectivo-, propuso consultar distintas fuentes ante dudas de comprensión y revisar aspectos formales de lo escrito antes de entregarlo, organizó situaciones para comentar en forma individual aspectos disciplinares y aspectos formales de las respuestas escritas a los cuestionarios y desarrolló algunas puestas en común en las que preguntó a los estudiantes qué entendieron de los temas.

De acuerdo con los datos analizados, la mayoría de los estudiantes cumplimentó la tarea en las materias B y C pero no lo hizo en la Asignatura A. Las puestas en común de las Asignaturas B y C promovieron que los alumnos participaran oralmente con comentarios y preguntas de las exposiciones docentes mientras que en la materia A las pocas puestas en común realizadas permitieron que los alumnos expresen sus interpretaciones. No obstante estas diferencias, los resultados muestran que en las tres materias los estudiantes contestaron los cuestionarios reproduciendo fragmentos de los materiales que leyeron. Ello puede deberse a que en la mayoría de las intervenciones que conforman la estructura de la actividad no se propone explicitar y trabajar con las interpretaciones de los estudiantes, de modo de comprender mejor el contenido para luego poder expresar por escrito lo comprendido, sin necesidad de recurrir a la literalidad. Tal como analizamos en el apartado 6.6, podemos conjeturar que la noción de compresión lectora que sostiene la estructura de esta actividad es aquella que concibe a la lectura como una actividad extractiva del significado dado en lo impreso, en oposición al enfoque interactivo, que la considera como un proceso interpretativo que requiere operar sobre un texto para poner en relación sus pistas informativas con los conocimientos del lector (Lerner, 1985; Smith, 1988, citado en Carlino, 2005). Al concebir que la lectura es una actividad extractiva, por ende, no se visualizaría la necesidad de incluir intervenciones que apunten a indagar, a discutir y a retrabajar la comprensión de los estudiantes.

Es posible que el abordaje de la lectura y la escritura de contenidos disciplinares observado en estas aulas no sea privativo de ellas sino común a la enseñanza desarrollada en otras aulas e instituciones. El valor de esta tesis reside en haberlo descrito y caracterizado, haciendo foco en una escuela que, según los datos analizados en los Capítulos 5 y 6, logra promover que estudiantes de sectores socioeconómicos desfavorecidos asistan a clases a 
través de acciones institucionales y acciones interpersonales que favorecen la permanencia escolar, pero en la cual la mayoría de las prácticas de enseñanza en tres asignaturas indagadas no potencian usos epistémicos de la lectura y la escritura.

En este punto, podemos efectuar una hipótesis respecto de la relación entre permanencia escolar y enseñanza de contenidos. En las clases analizadas los profesores aprobaron casi todas las producciones escritas resultantes de la tarea de leer para responder cuestionarios, aunque algunos trabajos prácticos no respetaron las consignas, presentaron errores conceptuales o respuestas incompletas (tal como mostramos en el subapartado 6.3.3 del Capítulo 6). Esta aprobación sucedió pese a que la mayoría de las intervenciones identificadas en la estructura de la actividad no indagó qué fueron entendiendo los estudiantes sobre lo que leyeron y escribieron (ver Tablas 9, 28 y 46). Ante estas producciones escritas, de acuerdo con lo observado, los docentes explicaron los temas en exposiciones dialogadas (ver subapartado 6.3.2.1) y en situaciones de corrección de trabajos prácticos marcaron individualmente los errores e incompletudes (ver subapartado 6.3.1.1).

Esta aprobación de las producciones escritas podría deberse a la necesidad de que los estudiantes permanezcan escolarizados y no sean excluidos de la escuela por desaprobar materias, situación que los docentes podrían considerar como perpetuar las desigualdades socioeconómicas existentes. No obstante, esta postura de "aprobar para evitar la exclusión”, que podría subyacer a estas intervenciones docentes que identificamos, elude otros modos mediante los cuales se puede favorecer la permanencia escolar. Si se fomentaran usos epistémicos de leer y escribir tales como los que describe el marco conceptual de esta tesis en el Capítulo 2 (explicitar y confrontar las interpretaciones, volver a los materiales para corroborar o refutar argumentos, ayudar a desarrollar autonomía como lector y escritor, etcétera), que dieran lugar a experiencias de aprendizaje relevantes, éstas fortalecerían la permanencia escolar de los estudiantes. Al respecto, Jacinto y Terigi (2007) sostiene que las experiencias de aprendizaje fortalecen que los estudiantes concurran a clase. Aun más, creemos que si se propusiera en las clases utilizar la lectura y la escritura en forma epistémica podría favorecerse la inclusión dado que se ofrecería a los estudiantes posibilidades de acceder, comunicar y reflexionar sobre el conocimiento. Esto podría impulsar que paulatinamente éstos comprendan y cuestionen sus situaciones de vida y la realidad social y promuevan cambios al respecto.

Aquí vale la pena considerar que profesores como los indagados en esta institución probablemente no hayan recibido formación acerca de qué aportan la lectura y la escritura a la adquisición de conocimiento ni sobre cómo intervenir para enseñar a interpretar y producir 
textos en sus asignaturas, de modo que estas prácticas funcionen para los alumnos como herramientas de aprendizaje de contenidos, a la vez que incrementen sus posibilidades de participar como ciudadanos activos en el mundo letrado. A pesar de su visible compromiso por incluir a estos alumnos, seguramente no han tenido ocasión de reflexionar sobre el hecho de que la lectura y escritura necesarias para aprender sus materias pueden abordarse de modos más fructíferos que los que plantea la tarea de leer para responder cuestionarios, tal como mostramos que está estructurada. Esos modos más fructíferos también serían inclusivos.

Habiendo reseñado los resultados de esta tesis, nos interesa puntualizar su alcance, efectuando algunas consideraciones metodológicas y teóricas. En cuanto a las consideraciones metodológicas, advertimos que al desarrollar un estudio de casos los resultados no pueden generalizarse a todo el universo. Sin embargo, estos resultados podrían iluminar casos similares, en asignaturas de escuelas secundarias que reciban a poblaciones de estos sectores socioeconómicos. Otros estudios de casos podrán ayudar a conformar un panorama que confirme, matice, restringa, enriquezca, cuestione o extienda los resultados de este estudio. Otra consideración cabe realizar respecto a estudios que pueden enriquecer el trabajo en torno a la temática que indagamos. Focalizar como objeto de estudio las respuestas escritas a los cuestionarios, recogiendo mayor cantidad de carpetas de estudiantes, ampliaría el análisis en relación con lo que logran escribir los estudiantes como producción final de la tarea analizada. En el subapartado 3.5.3 del capítulo metodológico de esta tesis indicamos que solo tres alumnas nos dieron acceso a sus carpetas. Por último, recordamos al lector que en esta tesis nos concentramos en la tarea de lectura y escritura propuesta con mayor frecuencia en las asignaturas estudiadas, por lo que aquellas tareas planteadas en forma minoritaria fueron excluidas del análisis. Analizar estas otras tareas podría aportar un panorama más amplio respecto de las prácticas de enseñanza de contenidos mediadas por la lectura y la escritura. En relación con ello, informamos que dichas tareas serán analizadas durante la beca posdoctoral de la autora de esta tesis.

Además de las consideraciones metodológicas expuestas, podemos realizar otras de orden teórico. Para el análisis de los resultados didácticos de esta tesis, utilizamos diversas aportaciones teóricas: perspectivas didácticas, como la teoría de las situaciones didácticas y la teoría de la acción conjunta, y perspectivas socioculturales que analizan la relación entre leer, escribir y dialogar en clase. Empero, no podemos desconocer que, tal como advierte Sadovsky (2005), las teorías son recortes para pensar sobre algunos aspectos de la realidad, seleccionados intencionalmente. En esta tesis nos valimos de teorías didácticas porque nos 
enfocamos en la acción conjunta de docentes y alumnos en torno a saberes disciplinares que se trabajan mediante la lectura y la escritura. Un análisis didáctico de este tipo, de acuerdo con lo que advierte Edelstein (2011) necesariamente opaca otras dimensiones referidas a los sujetos y al plano institucional. Dado que representa un abordaje que complementaría y enriquecería investigaciones didácticas como la nuestra, vale la pena mencionar una dimensión posible: la ideología pedagógica de los docentes. Tal como describe Dysthe (1996), esta ideología concierne a la visión acerca de qué es aprender, cómo sucede, qué conocimientos son importantes y cuáles son los roles de los estudiantes y los profesores en el proceso de aprendizaje. Analizar esta dimensión resulta importante porque al producir interpretaciones acerca de las necesidades de los estudiantes, influye en las prácticas de enseñanza y el modo de concebir las actividades en las clases. Cierto aspecto de esta ideología pedagógica estaría en juego en el hecho de que los docentes, en la mayoría de las intervenciones identificadas en las clases observadas, no propongan explicitar y trabajar con las interpretaciones de los estudiantes. Conjeturamos al respecto, que ello podría deberse a una concepción de la lectura como actividad extractiva.

Para concluir esta tesis diremos que el desafío de universalizar la educación secundaria consiste en más y mejor educación para todos; asegurando la permanencia escolar a la vez que aprendizajes relevantes para los estudiantes. Con los resultados de esta tesis pretendemos aportar conocimiento respecto de una vía posible para promover aprendizajes disciplinares -enseñar a leer y escribir contenidos disciplinares-, que puede no solo fortalecer la permanencia escolar sino representar posibilidades de que la escuela, siguiendo el acápite que citamos de Ferreiro (1992) en la introducción de esta tesis, "abra horizontes" para aquellos alumnos que "tienen muy poco o casi nada". De esa manera, se fomentaría la inclusión educativa, entendiéndola como "condición para el pleno cumplimiento del derecho a la educación" (Terigi, 2009, p.10). Por los motivos expuestos, estos resultados podrán ser de utilidad para el campo de la formación docente, para la elaboración y evaluación de documentos curriculares del nivel y para ser tenidas en cuenta en el diseño de políticas educativas que consideren incluir a los estudiantes a través de fomentar su permanencia escolar y ofrecerles oportunidades de aprendizajes relevantes. 



\section{Referencias bibliográficas}

Abasi, A. R., Akbari, N., y Graves, B. (2006). Discourse appropriation, construction of identities, and the complex issue of plagiarism: ESL students writing in graduate school. Journal of Second Language Writing, 15, 102-117.

Acosta, F. (2006). Escuelas medias y sectores populares: entre la eficacia y la ley, la moral y la cultura. Revista Electrónica Iberoamericana sobre Calidad, Eficacia y Cambio en Educación, 4(3), 16-29. Recuperado de http://www.rinace.net/arts/vol4num3/art2.pdf

Acosta, F. (2009). Re-configuración de la escuela secundaria frente al ingreso masivo de jóvenes populares. Revista de Pedagogía, 30(87), 217-246. Recuperado de http://www.redalyc.org/articulo.oa?id=65914495002

Afflerbach, P. y VanSledright, B. (2001). Hath! Doth! What? Middle graders reading innovative history text. Journal of Adolescent \& Adult Literacy, 44(8), 696-707.

Aguilar, L. y Zanelli, M. (2008). Prácticas de lectura y escritura en escuelas de nivel medio. En L. Aguilar, R. Austral, A. Corrado, V. Dabenigno, Y. Goldenstein Jalif, M. P. Otero, A. Padawer, M. Rodríguez, y M. Zanelli, La escuela media en foco: indagaciones sobre convivencia y politica, lectura y escritura, y formación para el trabajo. Buenos

Aires: Ministerio de Recuperado de http://www.buenosaires.gob.ar/areas/educacion/dirinv/pdf/escuela_media_parte_1.pdf

Aisenberg, B. (1998). Didáctica de las ciencias sociales: ¿desde qué teorías estudiamos la enseñanza? Revista de Teoría y Didáctica de las Ciencias Sociales, 3, 136-163. Recuperado de http://www.saber.ula.ve/bitstream/123456789/23916/1/bol3_beatriz_aisenberg.pdf

Aisenberg, B. (2004). Entrar al mundo de un texto. La educación en nuestras manos, 72, 27-29.

Aisenberg, B. (2005a). La lectura en la enseñanza de la historia: las consignas del docente y el trabajo intelectual de los alumnos. Lectura y Vida, 26(3), 22-31.

Aisenberg, B. (2005b). Una aproximación a la relación entre la lectura y el aprendizaje de la historia. Revista Íber, 43, 94104.

Aisenberg, B. (2008). Los textos, los alumnos y la enseñanza de la Historia en la escuela primaria: la comprensión de los vaivenes temporales. Enseñanza de las Ciencias Sociales, 7, 37-45. Recuperado de http://www.raco.cat/index.php/EnsenanzaCS/article/view/126352/237111

Aisenberg, B. (2010). Enseñar Historia en la lectura compartida. Relaciones entre consignas, contenidos y aprendizaje. En I. Siede (Coord.), Ciencias Sociales en la escuela. Criterios y propuestas para la enseñanza (pp. 63-98). Buenos Aires: Aique.

Aisenberg, B. y Lerner, D. (2008). Escribir para aprender Historia. Lectura y Vida, 29(3), 24-43.

Aisenberg, B., Lerner, D., Bavaresco, P., Benchimol, K., Larramendy, A., y Olguín, A. (2009). Diferentes explicaciones para un hecho histórico. La enseñanza a través de la lectura. Reseñas de Enseñanza de la Historia, 7, 93-129.

Alexandre, F. (2009). Epistemological awareness and geographical education in Portugal: the practice of newly qualified teachers. International Research in Geographical and Environmental Education, 18(4), 253-259.

Almandoz, M. R. (2000). Descentralización y gobierno de la educación. Sistema educativo argentino. Escenarios y políticas. Buenos Aires: Santillana.

Almer, E. D., Jones, K., y Moeckel, C. L. (1998). The impact of one-minute papers on learning in an introductory accounting course. Issues in Accounting Education, 13(3), 485-497.

Alonso Padilla, C. (2014). Caminos de lectura y lectura de caminos. Hacia nuevos enfoques en torno a las prácticas. El toldo de Astier. Propuestas y estudios sobre enseñanza de la lengua y la literatura, 5(8), 2-14.

Aronskind, R. (2011). Enseñanza de la economía: el deber de superar el estigma de la "ciencia triste". En V. S. Wainer (Comp.), Enseñar economía hoy: desafios y alternativas al paradigma neoclásico (pp. 14-17). Los Polvorines: Universidad Nacional de General Sarmiento. 
Leer y escribir en tres asignaturas de una escuela secundaria a la que asisten sectores socioeconómicos desfavorecidos Natalia Rosli

Arroyo, M. y Poliak, N. (2011). Discusiones en torno a fragmentación, identidades y compromiso. Enseñar en las escuelas de reingreso. En G. Tiramonti (Dir.), Variaciones sobre la forma escolar. Límites y posibilidades de la escuela media (pp. 89-124). Buenos Aires: Homo Sapiens.

Bain, K. (2004). How do they treat their students? What the best college teachers do. Cambridge, MA: Harvard University Press.

Bain, R. B. (2006). Rounding up unusual suspects: facing the authority hidden in the history classroom. Teachers College Record, 108(10), 2080-2114.

Bajtín, M. M. (1981). Discourse in the novel. En M. Holquist (Ed.), The dialogic imagination: four essays by M. M. Bakhtin (pp. 259-422). Austin, TX: University of Texas Press.

Baquero, R. (2001). La educabilidad bajo sospecha. Cuadernos de Pedagogía, 4(9), 71-85.

Baquero, R., Terigi, F., Toscano, A., Briscioli, B., y Sburlatti, S. (2009). Variaciones del régimen académico en escuelas medias con población vulnerable. Un estudio de casos en el área metropolitana de Buenos Aires. Revista Iberoamericana sobre Calidad, Eficacia y Cambio en Educación, 7(4), 293-319.

Barton, D. y Hamilton, M. (2004). La literacidad entendida como práctica social. En V. Zavala, M. Niño-Murcia, y P. Ames (Eds.), Escritura y Sociedad. Nuevas perspectivas teóricas y etnográficas (pp. 109-139). Lima: Red para el Desarrollo de las Ciencias Sociales en el Perú.

Barton, K. C. y Levstik, L. S. (2004). Teaching history for the common good. Mahwah, NJ: Erlbaum.

Basuyau, C. y Guyon, S. (1994). Consignes de travail en histoire-géographie: contraintes et libertés. Revue française de pédagogie, 106, 39-46.

Bazerman, C., Little, J. Bethel, L., Chavkin, T., Fouquette, D., y Garufis, J. (2005). Reference guide to writing across the curriculum. West Lafayette: Parlor Press.

Bazerman, C., Simon, K., y Pieng, P. (2014). Writing about reading to advance thinking: A study in situated cognitive development. En P. D. Klein, P. Boscolo, L. C. Kirkpatrick, y C. Gelati (Eds.), Writing as a learning activity (pp. 249-276). Leiden/Boston: Brill.

Becker, W. E. y M. Watts (2001). Teaching methods in U.S. undergraduate economic courses. The Journal of Economic Education, 32(3), 269-279.

Belossi, M. A. y Palacios de Caprio, M. A. (2004). La escuela media y los jóvenes socialmente desfavorecidos. Buenos Aires: Lugar Editorial.

Benchimol, K., Carabajal, A., y Larramendy, A. (2008). La lectura de textos históricos en la escuela. Lectura y Vida, 29(1), $22-31$.

Benejam, P. y Quinquer, D. (2000). La construcción del conocimiento social y las habilidades cognitivolingüísticas. En J. Jorba, I. Gómez y A. Prat (Eds.), Hablar y escribir para aprender. Uso de la lengua en situación de enseñanzaaprendizaje desde las áreas curriculares (pp. 201-218). Madrid: Síntesis.

Borches, E. y Roni, C. (2012). Escribir cartas de lectores para aprender Biología. Participación ciudadana y debate sobre Determinismo Biológico. Boletín Biológica, 23(6), 17-26.

Bourdieu, P. y Chartier, R. (2010). La lectura: una práctica cultural. En P. Bourdieu, El sentido social del gusto. Elementos para una sociología de la cultura (pp. 253-273). México: Siglo XXI.

Bourdieu, P. y Saint Martin, M. (1998). Las categorías del discurso profesoral. Propuesta Educativa, 9(19), 4-18.

Bravo, H. F. (1994). La descentralización educacional: sobre la transferencia de establecimientos. Buenos Aires: Centro Editor de América Latina.

Brito, A. (2010). Los profesores y la escuela secundaria, hoy. Notas sobre una identidad en repliegue. Buenos Aires: Libros Libres.

Brousseau, G. (1986). Fundamentos y métodos de la didáctica de las matemáticas. Córdoba: Facultad de Matemática, Astronomía y Física de la Universidad de Córdoba. 
Brousseau, G. (1990). ¿Qué pueden aportar a los enseñantes los diferentes enfoques de la didáctica de las matemáticas? (Primera parte) (L. Puig. Trad.). Enseñanza de las Ciencias, 8(3), 259-267. Recuperado de http://www.raco.cat/index.php/Ensenanza/article/view/51335/93083

Brousseau, G. (1991). ¿Qué pueden aportar a los enseñantes los diferentes enfoques de la didáctica de las matemáticas? (Segunda parte) (L. Puig. Trad.). Enseñanza de las Ciencias, 9(1), 10-21. Recuperado de http://www.raco.cat/index.php/ensenanza/article/viewFile/51351/93100

Brousseau, G. (1994). Los diferentes roles de maestro. En C. Parra y I. Saiz (Comp.), Didáctica de matemáticas. Aportes y reflexiones (pp. 65-94). Buenos Aires: Paidós.

Brousseau, G. (2007). Iniciación al estudio de la teoría de las situaciones didácticas. Buenos Aires: Libros del Zorzal.

Brousseau, G. y Centeno, J. (1991). Rôle de la mémoire didactique de l'enseignant. Recherches en didactique des mathématiques, 11(2/3), 167-210.

Brown, J., Miller, J., y Mitchell, J. (2006). Interrupted schooling and the acquisition of literacy: Experiences of sudanese refugees in victorian secondary schools australian. Journal of Language and Literacy, 29(2), 150-162.

Cabado, G., Falcone, J., Greco, M., Krichesky, M., Quintero, S., Saguier, V., y Zanelli, V. (2010). Políticas de inclusión y gestión educativa en escuelas medias en contextos de alta vulnerabilidad. Relación entre políticas y prácticas. Buenos Aires: Dirección de Investigación y Estadística, Ministerio de Educación. Recuperado de http://www.buenosaires.gob.ar/areas/educacion/dirinv/pdf/polinclusiongestioneducativa2010.pdf

Cantero, G. (1999). La gestión escolar en condiciones adversas. Síntesis de una investigación. Revista IRICE, 13, 31-54.

Carbone, G. (2003). Libros escolares. Una introducción a su análisis y evaluación. Buenos Aires: Fondo de Cultura Económica.

Cardoso, C. (1985). Introducción al trabajo de la investigación histórica. Conocimiento, método e historia. Barcelona: Editorial Crítica.

Carlino, P. (2005). Escribir, leer y aprender en la universidad. Una introducción a la alfabetización académica. Buenos Aires: Fondo de Cultura Económica.

Carlino, P. (2008). Leer y escribir en la universidad, una nueva cultura. ¿Por qué es necesaria la alfabetización académica? En S. Cádena y E. Narváez (Comp.), Los desafios de la lectura y la escritura en la educación superior: caminos posibles (pp. 155-190). Cali: Editorial de la Universidad Autónoma de Occidente.

Carr, E. H. (1964). What is history? London: Penguin Books.

Carretero, M., Pozo, J. I., y Asensio, M. (1997). Problemas y perspectivas en la enseñanza de las Ciencias Sociales: una concepción cognitiva. La enseñanza de las Ciencias Sociales. España: Visor.

Cartolari, M. (2014). Leer y escribir en asignaturas disciplinares de la formación docente en Historia: usos y sentidos de la lectura y la escritura desde el punto de vista de los alumnos y los profesores (Tesis de Educación no publicada). Buenos Aires: Universidad Nacional de Tres de Febrero, Universidad Nacional de Lanús y Universidad Nacional de San Martín.

Cartolari, M. y Carlino, P. (2011). Leer y tomar apuntes para aprender en la formación docente: un estudio exploratorio. Magis, 4(7), 67-86.

Castedo, M., Laxalt, I., y Usandizaga, M. R. (2010). La lectura y la escritura en la escuela. Módulo de la Diplomatura de Posgrado en Bibliotecas Escolares, Cultura escrita y Sociedades en Red. Madrid: Centro de Altos Estudios Universitarios de la OEI.

Cataño, J. F. (2001) ¿Porqué el predominio de la teoría neoclásica? Cuadernos de Economía, 20(34), 281-291.

Charlot, B. (2006). ¿La reproducción, el origen social y los hándicaps son "la causa del fracaso escolar”? La relación con el saber. Elementos para una teoría. Montevideo: Trilce.

Chartier, R. (2005). El presente del pasado: escritura de la historia, historia de lo escrito. México: Universidad Iberoamericana. 
Leer y escribir en tres asignaturas de una escuela secundaria a la que asisten sectores socioeconómicos desfavorecidos Natalia Rosli

Chartier, R. (2010). Aprender a leer, leer para aprender. Nuevo Mundo Mundos Nuevos [En línea]. Recuperado de http://nuevomundo.revues.org/58621

Chevallard, Y. (1988). Médiations et individuation didactiques. Interactions didactiques, 8, 23-34.

Chevallard, Y. (1991). La transposición didáctica. Del saber sabio al saber enseñado. Buenos Aires: Aique.

Chizmar, J. F. y Ostrosky, A. L (1998). The one-minute paper: some empirical findings. Journal of Economic Education, 29(1), 3-10.

Coler, M., Con, M., Lacal, D., Lara, L., y Susini, S. (2011). La educación secundaria en la Ciudad de Buenos Aires. Dinámica de la matrícula y desafios institucionales para la inclusión. Buenos Aires: Dirección de Investigación y Estadística. Recuperado http://www.buenosaires.gob.ar/areas/educacion/dirinv/pdf/educacionsecundaria2011.pdf

Comisión Económica para América Latina (CEPAL) (2014). Juventud: áreas críticas de la agenda para el desarrollo con igualdad. Panorama social de América Latina (pp. 127-168). Santiago de Chile: Publicación de Naciones Unidas. Recuperado de http://repositorio.cepal.org/bitstream/handle/11362/37626/S1420729_es.pdf?sequence=4

Converse, C. W. (2012). It's not just the facts, ma'am: writing for success in Career Education. Across the Disciplines, 9(3). Recuperado de http://wac.colostate.edu/atd/second_educ/converse.cfm

Cook, G. (1994). Repetition and learning by heart: an aspect of intimate discourse, and its implications. ELT Journal, 48(2), $133-141$

Cornú, L. (1999). La confianza en las relaciones pedagógicas. En G. Frigerio, M. Poggi, y D. Korinfeld (Comp.), Construyendo un saber sobre el interior de la escuela (pp. 19-26). Buenos Aires: Novedades Educativas.

Corredor, C. (2005). Economía, Sociedad y Matemática: Una discusión sobre la enseñanza de una ciencia social en el contexto de América Latina. Revista Electrónica de la Red de Investigación Educativa, 1(2). Recuperado de http://revista.iered.org/v1n2/pdf/cecorredor.pdf

Creswell, J. W. (2007). Writing a qualitative study. Qualitative inquiry y research design. Choosing among five approaches. London: Sage.

Dabenigno, V., Larripa, S., Austral, R., Tissera, S., y Goldenstein Jalif, Y. (2010). Permanencia e involucramiento escolar de los estudiantes secundarios. Perspectivas y acciones en cuatro escuelas estatales de la Ciudad de Buenos Aires. Buenos Aires: Dirección de Investigación y Estadística, Ministerio de Educación. Recuperado de http://www.buenosaires.gob.ar/areas/educacion/dirinv/pdf/permanenciainvolucramientosecundarios2010.pdf

Dahl, J. (2014). Las consignas de escritura como práctica de apropiación estética y cultural de la literatura. El toldo de Astier. Propuestas y estudios sobre enseñanza de la lengua y la literatura, 5(8), 15-29.

De Ketele, J. M. (1984). Educar, evaluar, observar: el marco de la problemática. Observar para educar. Madrid: Visor.

De La Paz, S. (2005). Effects of historical reasoning instruction and writing strategy mastery in culturally and academically diverse middle school classrooms. Journal of Educational Psychology, 97(2), 139-156.

De la Piedra, M. T. (2010). Adolescent worlds and literacy practices on the United States-Mexico border. Journal of Adolescent \& Adult Literacy, 53(7), 575-584.

Denkberg, A. y Fernández Caso, M. V. (2004). Aportes para pensar la enseñanza de la historia y la geografía en la perspectiva de la integración regional. Enseñanza de las Ciencias Sociales, 3, 49-57.

Denzin, N. K. (1970). Sociological methods: a source book. Chicago: Aldine Publishing Company.

Denzin, N. K. y Lincoln, Y. S. (2005). The sage handbook of qualitative research ( $3^{\text {rd }}$ Ed.). Thousand Oaks, CA: Sage.

Di Benedetto, S. (2012). Corrección de exámenes en la universidad. Significado de esta práctica para alumnos y docentes. Tesis de maestría no publicada. Buenos Aires: Facultad de Psicología de la Universidad de Buenos Aires.

Dubrovsky, J. (2011). Comprender el mundo que nos rodea para aprender economía. En V. S. Wainer (Comp.), Enseñar economía hoy: desafios y alternativas al paradigma neoclásico (pp. 130-137). Los Polvorines: Universidad Nacional de General Sarmiento. 
Duschatzky, S. (2005). Escuelas por dentro. La escuela como frontera. Reflexiones sobre la experiencia escolar de jóvenes de sectores populares. Buenos Aires: Paidós.

Duschatzky, S. (2010). Maestros errantes. Experimentaciones sociales en la intemperie. Buenos Aires: Paidós.

Duschatzky, S. y Corea, C. (2008). Chicos en banda. Los caminos de la subjetividad en el declive de las instituciones. Buenos Aires: Paidós.

Dussel, I., Brito, A., y Núñez, P. (2007). Los profesores y la escuela secundaria: ideales, realidades y esperanzas. Más allá de la crisis. Visión de alumnos y profesores de la escuela secundaria argentina. Buenos Aires: Santillana.

Dysthe, O. (1996). The multivoiced classroom: interactions of writing and classroom discourse. Written Communication, 13(3), 385-425.

Dysthe, O. (2013). Perspectivas teóricas sobre el diálogo y la enseñanza basada en el diálogo. En O. Dysthe, N. Bernhardt, y L. Esbjørn, Enseñanza basada en el diálogo. El museo de arte como espacio de aprendizaje (pp. 45-80). Copenhague: Skoletjenesten.

Dysthe, O., Bernhardt, N., y Esbjørn, L. (2013). Discusión de temas centrales en el marco de la teoría y la práctica. Enseñanza basada en el diálogo. El museo de arte como espacio de aprendizaje. Copenhague: Skoletjenesten.

Edelstein, G. (2011). Formar y formarse en la enseñanza. Buenos Aires: Paidós.

Ek, L. D. (2009). Language and literacy in the pentecostal church and the public high school: a case study of a Mexican ESL Student. High School Journal, 92(2), 1-13.

Evans, J. y Pate, G. (2007). Does scaffolding make them fall? Reflecting on strategies for developing causal argument in years 8 and 11. Teaching History, 128, 18-29.

Falconi, O. (2011). La experiencia escolar de alumnas y alumnos de sectores pauperizados en instituciones públicas. El Monitor de la educación, 28, 24-37.

Farrell-Childers, P., Gere, A. R., y Young, A. (1994). Programs and practices. Writing across the secondary school curriculum. Portsmouth, NH: Boynton/Cook.

Feijoó, M. C. y Corbetta, S. (2004). Escuelas y pobreza. Desafios educativos en dos escenarios del Gran Buenos Aires. Buenos Aires: IIPE-UNESCO. Recuperado de http://unesdoc.unesco.org/images/0014/001423/142343s.pdf

Feres, J. C. y Mancedo, X. (2001). El método de las necesidades básicas insatisfechas (NBI) y sus aplicaciones en América Latina. Chile: CEPAL.

Fernández Enguita, M. (1985). Cualquier día a cualquier hora: invitación a una etnografía de la escuela. Arbor, 121(477), 5787.

Fernández, L. M. (1994). Instituciones educativas. Dinámicas institucionales en situaciones críticas. Buenos Aires: Paidós.

Ferreiro, E. (1992). Presentación. En E. Ferreiro, A. Pellicer, B. Rodríguez, A. Silva y S. Vernón, Haceres y deshaceres con la lengua escrita en la escuela rural (pp. 5-7). Buenos Aires: Libros de Quirquincho.

Ferreiro, E. (2001). Pasado y presente de los verbos leer y escribir. Buenos Aires: Fondo de Cultura Económica.

Ferreiro, E., Pontecorvo, C., Ribeiro Moreira, N., y García Hidalgo, I. (1996). Lengua escrita e investigación comparativa. Caperucita Roja aprende a escribir. Estudios psicolingüísticos comparativos en tres lenguas. Barcelona: Gedisa.

Ferretti, R. P., MacArthur, C. D., y Okolo, C. M. (2001). Teaching for historical understanding in inclusive classrooms. Learning Disability Quarterly, 24(1), 59-71.

Finocchio, S. y García, P. (1995). Construyendo un paradigma para la enseñanza de las Ciencias Sociales. En S. Finocchio (Coord.), Enseñar Ciencias Sociales (pp. 53-136). Buenos Aires: Troquel.

Flower, L. (1979). Writer-based prose: a cognitive basis for problems in writing. College English, 41, 19-37.

Flower, L. y Hayes, J. R. (1980). The cognition of discovery: defining a rhetorical problem. College Composition and Communication, 31(1), 21-32.

Flower, L. y Hayes, J. R. (1981). A cognitive process theory of writing. College Composition and Communication, 32(4), 365-387.

Flyvbjerg, B. (2006). Five misunderstandings about case-study research. Qualitive Inquiry, 12(2), 219-245. 
Leer y escribir en tres asignaturas de una escuela secundaria a la que asisten sectores socioeconómicos desfavorecidos Natalia Rosli

Foglino, A. M., Falconi, O., y López Molina, E. (2008). Una aproximación a la construcción de la experiencia escolar de adolescentes y jóvenes de grupos sociales urbanos en condiciones de pobreza en Córdoba. Cuadernos de Educación, 6(6), 227-243.

Fouberg, E. H. (2000). Concept learning through writing for learning: using journals in an introductory geography course. Journal of Geography, 99(5), 196-206.

Fredricks, J. A., Blumenfeld, P. C., y Paris, A. H. (2004). School engagement: potential of the concept, state of evidence. Review of Educational Research, 74(1), 59-109.

Fregona, D. (2007). Prólogo. En G. Brousseau, Iniciación al estudio de la teoría de las situaciones didácticas (pp. 7-10). Buenos Aires: Libros del Zorzal.

Frigerio, G. (2004). La (no) inexorable desigualdad. Ciudadanos, 4(7/8), 35-41.

Gabbai, M. I. (2013). La construcción social de la experiencia estudiantil: vinculaciones entre las trayectorias sociales y escolares desde una perspectiva socioeducativa. En C. Kaplan y C. C. Bracchi (Comp.), Imágenes y discursos sobre los jóvenes (pp. 165-171). La Plata: Universidad Nacional de La Plata.

Gay, G. (2010). Culturally responsive teaching. Theory, research, and practice. New York: Teachers College Press.

Gerbaudo, A. (2006). El trabajo de lectura y escritura a partir de textos literarios. Propuestas derivadas del análisis de prácticas docentes en Polimodal y en ciclos básicos universitarios. En A. Gerbaudo, D. Riestra, H. Manni, C. Palachi, M. Götte y E. Torti, Lecturas y escrituras. Fundamentos y propuestas de enseñanza (pp.103-118). Santa Fe: Universidad Nacional del Litoral.

Gere, A. R., Buehler, J., Dallavis, C., y Haviland, V. S. (2009). A visibility project: learning to see how preservice teachers take up culturally responsive pedagogy. American Educational Research Journal, 46(3), 816-852.

Gobierno de la Ciudad de Buenos Aires (GCBA) (2001). Total y porcentaje de población con Necesidades Básicas Insatisfechas (NBI) según Distrito Escolar. Buenos Aires: Dirección General de Estadística y Censos. Recuperado de http://www.buenosaires.gov.ar/areas/educacion/lua/sis_indicadores/indicadores/cuadrosFile/IS/018.pdf

Gobierno de la Ciudad de Buenos Aires (GCBA) (2009). Informe de vulnerabilidad social (IVS). Documento metodológico. Buenos Aires: Dirección de Investigación y Estadística. Recuperado de http://www.buenosaires.gob.ar/areas/educacion/dirinv/pdf/indice_vulnerabilidad_social.pdf

Gobierno de la Ciudad de Buenos Aires (GCBA) (2011). Principales Indicadores Nivel Secundario Serie 1998-2011. Buenos Aires: Dirección General de Evaluación de la Calidad Educativa. Recuperado de https:/equidadycalidadeducativa.buenosaires.gob.ar/archivos/estadistica/indicadores//PrincipalesIndicadoresNivel Secundario\%20Serie\%201998_2011.xlsx

Goffman, E. (1997). La presentación de la persona en la vida cotidiana. Buenos Aires: Amorrortu.

Gojman, S. (1994). La historia: una reflexión sobre el pasado. Un compromiso con el futuro. En B. Aisenberg y S. Alderoqui (Comp.), Didáctica de las ciencias sociales. Aportes y reflexiones (pp. 42-61). Buenos Aires: Paidós.

Gómez, E (2011). Cuando la experiencia educativa no fue ni exitosa, ni sencilla, ni agradable: una propuesta de articulación entre la escuela y el trabajo. El toldo de Astier. Propuestas y estudios sobre enseñanza de la lengua y la literatura, 2(3), $2-13$.

Goodman, K. (1996). La lectura, la escritura y los textos escritos: una perspectiva transaccional sociolingüística. Textos en Contextos 2. Los procesos de lectura y escritura (pp. 9-68). Buenos Aires: Lectura y Vida/Asociación Internacional de Lectura.

Guber, R. (2001). La observación participante. La etnografía. Método, campo y reflexividad. Bogotá: Norma.

Guerin, C. (2008). Connecting with the academic community through appropriate appropriation of sources: Avoiding the mistake of plagiarism. Conference presentation, ACTA, Darwin. Recuperado de http://www.adelaide.edu.au/red/tools/svr/Guerin_2008_AvoidingPlagiarism.pdf

Gurevich, R. (1994). Un desafío para la geografía: explicar el mundo real. En B. Aisenberg y S. Alderoqui (Comp.), Didáctica de las ciencias sociales. Aportes y reflexiones (pp. 63-84). Buenos Aires: Paidós. 
Gurevich, R. (1998). Conceptos y problemas en Geografía. Herramientas básicas para una propuesta educativa. En B. Aisenberg y S. Alderoqui (Comp.), Didáctica de las ciencias sociales II. Teorías con prácticas (pp. 159-182). Buenos Aires: Paidós.

Haneda, M. (2006). Becoming literate in a second language: connecting home, community, and school literacy practices. Theory into practice, 45(4), 337-345.

Hansen, J. (2009). Multiple literacies in the content classroom: high school students' connections to U.S. History. Journal of Adolescent \& Adult Literacy, 52(7), 597-608.

Hinde, E. R., Osborn Popp, S. E., Dom, R. I., Ekiss, G. O., Mater, M., Smith, C. B., y Libbee, M. (2007).The Integration of literacy and geography; the Arizona GeoLiteracy Program's effect on reading comprehension. Theory and Research in Social Education, 35(3), 343-365.

Hollman, V. (2005). Cartografía de las representaciones de la globalización en textos de Geografía de Enseñanza Media. Revista de Teoría y Didáctica de las Ciencias Sociales, 10, 7-33.

Howard, R. M. (1995). Plagiarisms, authorships, and the academic death penalty. College English, 57(7), 788-806.

Howard, R. M. (1999). Standing in the shadow of giants: Plagiarists, authors, collaborators. Stamford, CT: Ablex.

Howard, R. M. (2001). Plagiarism: What should a teacher do? Conference on College Composition and Communication. Denver, CO.

Hudson, L. (1996). Contrary imaginations: A psychological study of the english schoolboy. London: Methuen.

Hugonie, G. (2004). Los aprendizajes en geografía propuestos a los alumnos de entre 11 y 16 años: actividades básicas. Enseñanza de las Ciencias Sociales, 3, 69-73.

Hull, G. y Rose, M. (1989). Rethinking remediation: toward a social-cognitive understanding of problematic reading and writing. Written Communication, 6(2), 139-154.

Hynd-Shanahan, C., Holschuh, J. P., y Hubbard, B. P. (2004). Thinking like a historian: college students' reading of multiple historical documents. Journal of Literacy Research, 36(2), 141-176.

Ivanič, R. (1998). Writing and identity: The discoursal construction of identity in academic writing. Amsterdam and Philadelphia: John Benjamins.

Jacinto, C. y Freytes Frey, A. (2004). Políticas y estrategias para el mejoramiento de las oportunidades de los jóvenes: estudio sobre la educación secundaria en la Ciudad de Buenos Aires. París: UNESCO-IIPE. Recuperado de http://unesdoc.unesco.org/images/0013/001360/136065s.pdf

Jacinto, C. y Terigi, F. (2007). ¿Qué hacer ante las desigualdades en la educación secundaria? Aportes de la experiencia latinoamericana. Buenos Aires: Santillana.

Jenkins, K. (2003). Re-thinking History ( $2^{\text {nd }}$ Ed.). London: Routledge.

Juarros, F. y Cappellacci, I. (2009). El proceso de democratización del nivel medio en el sistema educativo argentino. Espacios de crítica y producción, 40, 88-95. Recuperado de http://www.filo.uba.ar/contenidos/secretarias/seube/revistaespacios/PDF/40/40.13.pdf

Kalman, J. (2003). El acceso a la cultura escrita: la participación social y la apropiación de conocimientos en eventos cotidianos de lectura y escritura. Revista Mexicana de Investigación Educativa, 8(17), 37-66. Recuperado de https://www.uam.es/otros/fmee/documentos/kalman_fmee.pdf

Kaplan, C. (2005). Subjetividad y educación ¿Quiénes son los adolescentes y jóvenes, hoy? En M. Krichesky (Comp.), Adolescentes e inclusión educativa. Un derecho en cuestión (pp. 97-112). Buenos Aires: Noveduc.

Kaplan, C. (2010). La confianza hacia las posibilidades de aprender de los alumnos: un umbral necesario para abordar la diversidad sociocultural en la escuela. En M. Vergara Fragoso y J. A. Ríos Gil (Coord.), Diversidad cultural: un reto para las instituciones educativas (pp. 81-100). México: Universidad de Guadalajara.

Kaufman, A. M. y Perelman, F. (1999). El resumen en el ámbito escolar. Lectura y Vida, 20(4), 6-18.

Kessler, G. (2002). La experiencia escolar fragmentada. Estudiantes y docentes en la escuela media en Buenos Aires. Buenos Aires: IIPE-UNESCO. 
Leer y escribir en tres asignaturas de una escuela secundaria a la que asisten sectores socioeconómicos desfavorecidos Natalia Rosli

Krichesky, G. y Duque, J. (2008). Las prácticas inclusivas en la escuela media: la perspectiva de los jóvenes. Buenos Aires: Cimientos- Fundación para la Igualdad de Oportunidades Educativas.

Krichesky, G. y Duque, J. (2011a). Prácticas de enseñanza en escuelas secundarias y procesos de inclusión/exclusión escolar. Buenos Aires: Cimientos- Fundación para la Igualdad de Oportunidades Educativas.

Krichesky, G. y Duque, J. (2011b). Prácticas institucionales y pedagógicas en escuelas públicas a las que asiste población vulnerable: una contribución para la creación de escuelas inclusivas. IX Jornadas de Sociología, Facultad de Sociales de la Universidad de Buenos Aires.

Krichesky, G., Cortelezzi, D., Cura, D., y Morrone, A. (2010). La escuela desde las representaciones de sus estudiantes. Jóvenes que miran la escuela. Una investigación acerca de los procesos de inclusión/exclusión en la escuela secundaria. Buenos Aires: Fundación Cimientos.

Krichesky, M., Migliavacca, A., Alcántara, A., Glass, A., Cabado, G., Greco, M., y Medela, P. (2008). Escuelas medias en contextos de vulnerabilidad social. Perspectivas sobre gestión institucional y políticas de inclusión educativa en la Ciudad de Buenos Aires. Buenos Aires: Dirección de Investigación y Estadística. Recuperado de http://estatico.buenosaires.gov.ar/areas/educacion/dirinv/pdf/esc_medias_vulnerabilidad_social_08.pdf

Kurlat, M. (2010). La construcción de demandas individuales y sociales en la alfabetización de jóvenes y adultos. En J. A. Castorina y V. Orce (Coord.), Diálogos y reflexiones en investigación: contribuciones al campo educativo (pp. 5766). Buenos Aires: Editorial de la Facultad de Filosofía y Letras de la Universidad de Buenos Aires.

Kurlat, M. y Perelman, F. (2013). Procesos de alfabetización inicial en personas jóvenes y adultas: ¿hacia una historia de inclusión? Revista del Instituto de Investigaciones en Ciencias de la Educación, 32, 55-72.

Langer, J. y Applebee, A. (1987). How writing shapes thinking: a study of teaching and learning. Urbana, Illinois, National Council of Teachers of English.

Lea, M. R. y Street, B. V. (1998). Student writing in higher education: An academic literacies approach. Studies in Higher Education, 23(2), 157-172.

Leinhardt, G. y Stainton, C. (1994). A sense of history. Educational Psychologist, 29(2), 79

Lenski, S. D. (1998). Intertextual intentions: Making connections across texts. Clearing House, 72(2), 74-80.

Lenzi, A. M. y Castorina, J. A. (2000). Investigaciones de nociones políticas: psicogénesis "natural” y psicogénesis “artificial”. Una comparación metodológica. En J. A. Castorina y A. M. Lenzi (Comp.), La formación de los conocimientos sociales en los niños. Investigaciones psicológicas y perspectivas educativas (pp. 253-273). Barcelona: Gedisa.

Lerner, D. (1985). La relatividad de la enseñanza y la relatividad de la comprensión. Lectura y Vida, 6(4), 10-13.

Lerner, D. (2001). Leer y escribir en la escuela: lo real, lo posible y lo necesario. México: Fondo de Cultura Económica

Lerner, D., Aisenberg, B., y Espinoza, A. (2009). La lectura en Ciencias Sociales y en Ciencias Naturales: objeto de enseñanza y herramienta de aprendizaje. En J. A. Castorina y V. Orce (Coord.), Anuario del Instituto de Investigaciones en Ciencias de la Educación 2008. Buenos Aires: Editorial de la Facultad de Filosofía y Letras de la Universidad de Buenos Aires. Recuperado de http://www.filo.uba.ar/contenidos/investigacion/institutos/Lice/ANUARIO_2008/textos/36_Delia_Lerner.pdf

Lerner, D., Aisenberg, B., y Espinoza, A. (2012). La lectura y la escritura en la enseñanza de Ciencias Naturales y de Ciencias Sociales. Una investigación en didácticas específicas. En J. A. Castorina y V. Orce (Coord.), Anuario del Instituto de Investigaciones en Ciencias de la Educación 2010-2011 (pp. 529-541). Buenos Aires: Editorial de la Facultad de Filosofía y Letras de la Universidad de Buenos Aires. Recuperado de http://www.filo.uba.ar/contenidos/investigacion/institutos/Iice/ANUARIO_2011/textos/39.Lerner_y_otros.pdf

Lerner, D., Levy, H., Lotito, S., Lobello, S., Llorente, E., y Natali, N. (1996). Documento de trabajo Nó2. Actualización curricular en Lengua. Ciudad de Buenos Aires: Dirección de Curriculum, Secretaría de Educación. Recuperado de http://www.buenosaires.gob.ar/areas/educacion/curricula/docum/areas/prleng/doc2.pdf 
Lerner, D., Levy, H., Lotito, S., Lobello, S., Llorente, E., y Natali, N. (1997). Leer textos difíciles. Documento de trabajo $N^{\circ}$ 4. Actualización curricular en Lengua. Ciudad de Buenos Aires: Dirección de Curriculum, Secretaría de Educación. Recuperado de http://www.buenosaires.gob.ar/areas/educacion/curricula/docum/areas/prleng/doc4.pdf

Libbee, M. y Young, D. (1983). Teaching writing in Geography classes. Journal of Geography, 82(1), 23-26.

Lillis, T. (1999). Whose "common sense"? Essayist literacy and the institutional practice of mystery. En C. Jones, J. Turner, y B. Street (Eds.), Students writing in the university. Cultural and epistemological issues (pp. 127-147). Amsterdam: John Benjamins.

Lillis, T. (2001). Student writing. Access, regulation, desire. London: Routledge.

Litichever, L. y Núñez, P. (2009). Cultura política en la escuela media: diferentes anclajes de la experiencia escolar juveniles. En G. Tiramonti y N. Montes (Comp.), La escuela media en debate. Problemas actuales y perspectivas desde la investigación (pp. 193-210). Buenos Aires: Manantial- FLACSO.

López Accotto, A. y de Amézola, G. (2004). Situación y perspectivas de la Enseñanza de la Economía. Buenos Aires: Dirección de Educación Superior.

López, N. (2006). Educación y desigualdad social. Buenos Aires: Ministerio de Educación, Ciencia y Tecnología de la Nación. Recuperado de http://portal.oas.org/LinkClick.aspx?fileticket=WquM7MNrx/I\%3D

Lorenzatti, M. C. (2006). Reconstruyendo la experiencia áulica desarrollada por los docentes. En M. C. Lorenzatti (Comp.), Saberes y conocimiento acerca de la cultura escrita: un trabajo con maestros de jóvenes y adultos (pp. 61-82). Córdoba: Ferreyra Editor.

Lorenzatti, M. C. (2008). Conocimientos cotidianos y acceso a la cultura escrita en adultos no escolarizados. Buenos Aires: Fundación Santillana - Universidad Nacional de San Martín. Recuperado de http://www.alfabetizacion.fundacionsantillana.org/archivos/observatorio/Articulo\%20Lorenzatti[1].pdf

Marucco, M. (2001). La enseñanza de la lectura y la escritura en el aula universitaria. I Jornadas sobre La lectura y la escritura como prácticas académicas universitarias. Departamento de Educación de la Universidad Nacional de Luján.

Maxwell, J. A. (1992). Understanding and validity in qualitative research. Educational Review, 62, 279-300

Maxwell, J. A. (2005). Qualitative research design: An interactive approach. Thousand Oaks, CA: Sage.

Maxwell, J. A. (2006). Literature reviews of, and for, Educational Research: a commentary on Boote and Beile's "Scholars before researchers". Educational Researcher, 35(9), 28-31.

Maxwell, J. A. y Miller, B. A. (2008). Categorizing and connecting strategies in qualitative data analysis. En S. N. HesseBiber y P. Leavy (Eds.), Handbook of emergent methods (pp. 461-477). New York: Guilford Press.

McElroy, B. W. y Coman, C. L. (2002). Writing to learn in managerial accounting classrooms: further evidence about student performance and perception. Business Quest [En línea] Recuperado de http://www.westga.edu/ bquest/2002/writing.htm

Mendizábal, N. (2006). Los componentes del diseño flexible en la investigación cualitativa. En I. Vasilachis de Gialdino (Coord.), Estrategias de Investigación Cualitativa (pp. 65-105). Barcelona: Gedisa.

Mercier, A., Sensevy, G., y Schubauer-Leoni, M. L. (2000). How social interactions within a class depend on the teachers's assessment of the pupils various mathematical capabilities: a case study. En I. Schwank (Ed.), European Research in Mathematics Education I (pp. 342-353). Osnabrueck: Forschungsinstitut fuer Mathematikdidaktik.

Miles, M. B. y Huberman, A. M. (1994). Qualitative data analysis: And expanded sourcebook (2 ${ }^{\text {nd }}$ Ed.). Thousand Oaks, CA: Sage.

Miras, M. (2000). La escritura reflexiva. Aprender a escribir y aprender acerca de lo que se escribe. Infancia y Aprendizaje, $89,65-80$.

Mitchell, J. C. (1984). Case studies. En R. Ellen (Eds.), Ethnographic research: A guide to general conduct (pp. 237-241). Orlando, FL: Academic Press. 
Leer y escribir en tres asignaturas de una escuela secundaria a la que asisten sectores socioeconómicos desfavorecidos Natalia Rosli

Moje, E. B. (2008). Foregrounding the disciplines in secondary literacy teaching and learning: a call for change. Journal of Adolescent \& Adult Literacy, 52(2), 96-107.

Moje, E. B. (2010). Developing disciplinary discourses and identities: What's knowledge got to do with it? En G. L. Bonilla y K. Englander (Eds.), Discourses and identities in contexts of educational change. New York: Peter Lang.

Moje, E. B. y Dillon, D. R. (2006). Adolescent identities as demanded by science classroom discourse communities. En D. E. Alvermann, K. A. Hinchman, D. W. Moore, S. F. Phelps, y D. R. Waff (Eds.), Reconceptualizing the literacies in adolescent's lives (pp. 85-106). Mahwah, NJ: Erlbaum.

Moje, E. B., Stockdill, D., Kim, K., y Kim, H. (2011). The role of text in disciplinary learning. En M. L. Kamil, P. D. Pearson, E. B. Moje, y P. P. Afflerbach (Eds.), Handbook of reading research (Vol. IV, pp. 453-486). Mahwah, NJ: Erlbaum/Taylor \& Francis.

Moje, E. B. y Speyer, J. (2008). The reality of challenging texts in high school science and social studies: How teachers can mediate comprehension. En K. Hinchman y H. Sheridan-Thomas (Eds.), Best practices in adolescent literacy instruction (pp. 185-211). New York: Guilford.

Molin, L. y Grubbström, A. (2013). Are teachers and students ready for the new middle school geography syllabus in Sweden? Traditions in geography teaching, current teacher practices, and student achievement. Norwegian Journal of Geography, 67(3), 142-147.

Neiman, G. y Quaranta, G. (2006). Los estudios de caso en la investigación sociológica. En I. Vasilachis de Gialdino (Coord.), Estrategias de Investigación Cualitativa (pp. 213-237). Barcelona: Gedisa.

Nobile, M. (2011). Redefiniciones de la relación docente-alumno: una estrategia de personalización de los vínculos. En G. Tiramonti (Dir.), Variaciones sobre la forma escolar. Límites y posibilidades de la escuela media (pp. 179-204) Rosario: Homo Sapiens.

Olson, D. (1997). La escritura y la mente. En J. V. Wertsch, P. Del Rio, y A. Álvarez (Eds.), La mente sociocultural. Aproximaciones teóricas y aplicadas (pp. 77-97). Madrid: Fundación Infancia y Aprendizaje.

Pastré, P. (2008). Apprentissage et activité. En Y. Lenoir y P. Pastré (Eds.), Didactique professionnelle et didactiques disciplinaires en débat: un enjeu pour la professionnalisation des enseignants (pp. 53-79). Toulouse: Octarès Éditions [Traducción de Elisabeth Muños de Corrales].

Pastré, P. (2011). La didactique professionnelle. Un point de vue sur la formation et la professionnalisation. Educational Sciences \& Society, 2(1), 83-95 [Traducción de Patricia Moscato].

Patton, M. (1990). Purposeful sampling. Qualitative evaluation and research methods. Beverly Hills, CA: Sage.

Paviglianiti, N. (1988). Diagnóstico de la administración central de la educación. Buenos Aires: Ministerio de Educación y Justicia.

Pecorari, D. (2003). Good and original: Plagiarism and patchwriting in academic second-language writing. Journal of Second Language Writing, 12, 317-345.

Pecorari, D. (2008). Academic writing and plagiarism. A linguistic analysis. London: Continuum.

Pecorari, D. y Petrić, B. (2014). Plagiarism in second-language writing. Language Teaching, 47, 269-302.

Perelman, F. (2008). El resumen sobre el papel. Condiciones didácticas y construcción de conocimientos. Buenos Aires: Miño y Dávila.

Perelman, F. y Castorina, J. A. (2005). La situación didáctica y la producción del resumen escrito. Restricciones y construcción de conocimiento. Quaderns Digitals [En línea]. Recuperado de http://www.quadernsdigitals.net/index.php?accionMenu=hemeroteca.DescargaArticuloIU.descarga\&tipo=PDF\&ar ticulo_id=8636

Poggi, M. (1995). La observación: elemento clave en la gestión curricular. En M. Poggi (Comp.), Apuntes y aportes para la gestión curricular (pp. 61-78). Buenos Aires: Kapelusz. 
Poggi, M. (2003). La problemática del conocimiento en la escuela secundaria: algunas perspectivas sobre el abordaje de los aspectos curriculares. En E. Tenti Fanfani (Comp.), Educación media para todos. Los desafios de la democratización del acceso (pp. 105-137). Buenos Aires: UNESCO-IIPE.

Prat, A. e Izquierdo, M. (2000). Función del texto escrito en la construcción de conocimientos y en el desarrollo de habilidades. En J. Jorba, I. Gómez, y A. Prat (Eds.), Hablar y escribir para aprender. Uso de la lengua en situación de enseñanza-aprendizaje desde las áreas curriculares (pp. 73-112). Madrid: Síntesis.

Prats, J. (2000). Dificultades para la enseñanza de la Historia en la educación secundaria: reflexiones ante la situación española. Revista de Teoría y Didáctica de las Ciencias Sociales, 5, 71-98.

Prats, J. y Santacana, J. (2001). Principios para la enseñanza de la Historia. En J. Prats, Enseñar Historia: notas para una didáctica renovadora (pp. 13-34). Mérida: Consejería de Educación, Ciencia y Tecnología.

Quintero, S. (2001). La visión de Argentina y de los países vecinos en los manuales de geografía. II Seminario bienal. Enseñanza de la Historia y Geografía en el contexto del Mercosur (pp. 83-88). Chile: Oficina Regional de Educación de la UNESCO para América Latina y el Caribe.

Redondo, P. (2006a). Entre el desasosiego y la obstinación: ser docente en los territorios de la pobreza. Escuelas y pobreza. Entre el desasosiego y la obstinación. Buenos Aires: Paidós.

Redondo, P. (2006b). Interrupciones en los territorios de la desigualdad. En P. Martinis y P. Redondo (Comp.), Igualdad y educación. Escritura entre (dos) orillas (pp. 103-121). Buenos Aires: Del Estante.

Reichelt, M. (2005). WAC practices at the secondary level in Germany. The WAC Journal, 16, 89-100.

Richards, H. V., Brown, A. F., y Forde, T. B. (2006). Addressing diversity in schools: culturally responsive pedagogy. Tempe, AZ: National Center for Culturally Responsive Educational Systems.

Rickenmann, R. (2006). Metodologías clínicas de investigación en didácticas y formación del profesorado: un estudio de los dispositivos de formación en alternancia. Actas del Congreso Internacional de Investigación, Educación y Formación docente, Universidad de Antioquia, Medellín, Colombia. Recuperado de http://www.unige.ch/fapse/clidi/textos/Clinica-did\%E1ctica-RR.pdf

Rickenmann, R. (2007). Investigación y formación docente: dispositivos de formación y elementos para la construcción de una identidad profesional. EccoS, 9(2), 435-463. Recuperado de http://www.uninove.br/PDFs/Publicacoes/eccos/eccos_v9n2/eccosv9n2_2i14.pdf

Rockwell, E. (1982). Los usos escolares de la lengua escrita. En E. Ferreiro y M. Gómez Palacio (Coord.), Nuevas perspectivas sobre los procesos de lectura y escritura (pp. 296-320). México: Siglo XXI Editores.

Rockwell, E. (1987). Reflexiones sobre el proceso etnográfico (1982-1985). México: Departamento de Investigaciones Educativas, Centro de Investigación y Estudios Avanzados.

Rockwell, E. (1995). En torno al texto: tradiciones docentes y prácticas cotidianas. La escuela cotidiana. México: Fondo de Cultura Económica.

Rockwell, E. (2001). La lectura como práctica cultural: conceptos para el estudio de los libros escolares. Educação e Pesquisa, 27(1), 11-26. Recuperado de http://www.revistas.usp.br/ep/article/view/27851/29623

Rodas, E. (2011). La enseñanza de problemáticas socio-económicas: una propuesta para el abordaje de la distribución de la riqueza. En V. S. Wainer (Comp.), Enseñar economía hoy: desafios y alternativas al paradigma neoclásico (pp. 159-174). Los Polvorines: Universidad Nacional de General Sarmiento.

Roni, C., Alfie, L., y Borches, E. (2013). ¡¿Leer, escribir y...YouTube?! Una secuencia didáctica sobre Síntesis de Proteínas. Revista de Educación en Biología, 16(1), 15-27.

Rosenthal, R. y Jacobson, L. (1968). Pygmalion in the classroom: teacher expectation and pupil's intellectual development. New York: Holt, Rinehart y Winston.

Roxas, K. y Roy, L. (2012). "That's how we roll”: a case study of a recently arrived refugee student in an urban high school. Urban Review, 44(4), 468-486. 
Leer y escribir en tres asignaturas de una escuela secundaria a la que asisten sectores socioeconómicos desfavorecidos Natalia Rosli

Ruiz, G. (2009). La nueva reforma educativa argentina según sus bases legales. Revista de Educación, 348, $283-307$. Recuperado de http://www.revistaeducacion.mec.es/re348/re348_12.pdf

Ruiz, G. (2010). La ley de educación reformada. Cuestiones problemáticas en torno a la recurrencia de reformas educativas. Revista Derecho y Ciencias Sociales, 2, 106-131.

Ruiz, G., Marzoa, K., Maucer, M. L., Molinari, A., Muiños, C, Ruiz, M., Schmidt, M., y Schoo, S. (2007). La estructura académica del sistema educativo como canalizadora de la distribución de saberes: un análisis histórico desde la perspectiva de la política educacional. La evolución de los niveles educativos durante el período fundacional. Anuario de Investigaciones, 14, 237-246.

Russell, D., Lea, M., Parker, J., Street, B., y Donahue, T. (2009). Exploring notions of genre in "academic literacies" and "writing across the curriculum": approaches across countries and contexts. En C. Bazerman, A. Bonini, y D. Figueiredo (Eds.), Genre in a Changing World. Perspectives on Writing (pp. 459-491). Colorado: WAC Clearinghouse/Parlor Press.

Sabarots, H. R. (2007). Emergentes de inseguridades en Saavedra-Barrio Mitre: conflictos, organización vecinal y Estado. Cuestiones de Sociología, 4, 160-176. Recuperado de http://www.memoria.fahce.unlp.edu.ar/art_revistas/pr.3682/pr.3682.pdf

Sadovsky, P. (2005). La Teoría de Situaciones Didácticas: un marco para pensar y actuar la enseñanza de la matemática. En H. Alagia, A. Bressan y P. Sadovsky, Reflexiones teóricas para la Educación Matemática (pp. 13-68). Buenos Aires: Libros del Zorzal.

Sadovsky, P. y Lerner, D. (2006). Procesos de cambio en la enseñanza en escuelas primarias de la Ciudad de Buenos Aires: transformaciones, conservaciones, relaciones con la gestión directiva. Recuperado de http://estatico.buenosaires.gov.ar/areas/educacion/dirinv/inv_conluidas/cambio_esc_primaria.pdf

Salemi, M., Siegfried, J., Sosin, K., Walstad, W., y Watts, M. (2001). Research in economic education: Five new initiatives. The American Economic Review, 91(2), 440- 446.

Salinas, C., Fránquiz, M. E., y Reidel, M. (2008). Teaching world geography to late-arrival immigrant students: highlighting practice and content. The social studies, 99(2), 71-76.

Sardoy, M. C. y Lorenzatti, M. C. (2006). Los textos con los que interactuaron los alumnos. En M. C. Lorenzatti (Comp.), Saberes y conocimiento acerca de la cultura escrita: un trabajo con maestros de jóvenes y adultos (pp. 83-102). Córdoba: Ferreyra Editor.

Sarroub, L. K. (2007). Seeking refuge in literacy from a scorpion bite. Etnography and Education, 2(3), 365-380.

Sarroub, L. K., Pernicek, T., y Sweeney, T. (2007). "I was bitten by a scorpion”: Reading in and out of school in a refugee's life. Journal of Adolescent \& Adult Literacy, 50(8), 668-679.

Scardamalia, M. y Bereiter, C. (1992). Dos modelos explicativos de los procesos de composición escrita. Infancia y Aprendizaje, 58, 43-64.

Seixas, P. (2006). Benchmarks of historical thinking: a framework for assessment in Canada. The Center for the Study of Historical Consciousness. Recuperado de http://www.histori.ca/benchmarks/documents/Benchmarks\%20of\%20Historical\%20Thinking\%20A\%20Framewor k\%20for\%20Assessment\%20in\%20Canada.pdf

Seixas, P. y Peck, C. (2004). Teaching historical thinking. En A. Sears y I. Wright (Eds.), Challenges and Prospects for Canadian Social Studies (pp. 109-117). Vancouver: Pacific Educational Press.

Sensevy, G. (2007). Categorías para describir y comprender la acción didáctica. En G. Sensevy y A. Mercier, Agir ensemble: l'action didactique conjointe du professeur et des élèves (pp. 5-34). Rennes: PUR. (Traducción de Juan Duque y revisión de René Rickenmann).

Sensevy, G. (2012). About the joint action theory in didactics. Z Erziehungswiss, 15, 503-516.

Shemilt, D. (1980). History 13-16 Evaluation Study. Edinburgh: Holmes McDougall. 
Shepherd, I. D. H. y Bleasdale, S. (1993). Student reading and course readers in geography. Journal of Geography in Higher Education, 17(2), 103-121.

Siede, I. A. (2010). Ciencias Sociales en la escuela: sentidos de la enseñanza. En I. A. Siede (Coord.), Ciencias Sociales en la escuela. Criterios y propuestas para la enseñanza (pp. 17-48). Buenos Aires: Aique.

Stake, R. E. (2000). Case studies. En N. K. Denzin y Y. S. Lincoln (Eds.), Handbook of qualitative research (2 ${ }^{\text {nd }}$ Ed.) (pp. 435-454). Thousand Oaks, CA: Sage.

Stake, R. E. (2010). Investigación con estudio de casos [5ª edición] Madrid: Morata.

Stead, D. R. (2005). A review of the one-minute paper. Active Learning in Higher Education, 6(2), 118-131.

Stowers, R. H. y Barker, R. T. (2003). Improved student writing in business communication classes: strategies for teaching and evaluation. Journal of Technical Writing and Communication, 33(4), 337-348.

Street, B. (1984). Literacy in theory and practice. Cambridge: Cambridge University Press.

Street, B. (2004). Los Nuevos Estudios de Literacidad. En V. Zavala, M. Niño-Murcia, y P. Ames (Eds.), Escritura y Sociedad. Nuevas perspectivas teóricas y etnográficas (pp. 81-107). Lima: Red para el Desarrollo de las Ciencias Sociales en el Perú.

Tapia, S. M. y Riestra, D. (2014). El momento de la reflexión sobre la lengua en el aula: ¿explicación gramatical azarosa o sistematización de contenidos específicos? Saga, 1(1), 178-206.

Taylor, S. V. y Sobel, D. M. (2011). Culturally responsive pedagogy: teaching like our students' lives matter. London, UK: Emerald Group Publishing.

Taylor, T. y Young, C. (2003). Making History: a guide for the teaching and learning of History in Australian schools. Canberra: Department of Education, Science and Training. Recuperado de http://www.hyperhistory.org/images/assets/pdf/complete.pdf

Teberosky, A. (1990). El lenguaje escrito y la alfabetización. Lectura y Vida, 11(3), 2-15.

Teberosky, A. (1997). El conocimiento cotidiano, escolar y científico en el dominio del lenguaje escrito. En M. J. Rodrigo y J. Arnay (Comp.), La construcción del conocimiento escolar (pp. 243-264). Barcelona: Paidós.

Teberosky, A. (2001). Las prácticas de escritura desde un enfoque constructivista. En J. A. Castorina (Comp.), Desarrollos y problemas en psicología genética (pp. 313-324). Buenos Aires: Eudeba.

Terigi, F. (2009). Las trayectorias escolares. Del problema individual al desafio de política educativa. Buenos Aires: Ministerio de educación-OEI.

Terigi, F., Briscioli, B., Scavino, C., Morrone, A., y Toscano, A. G. (2013). La educación secundaria obligatoria en la Argentina: entre la expansión del modelo tradicional y las alternativas de baja escala. Revista del Instituto de Investigaciones en Ciencias de la Educación, 33, 27-46.

Thisted, S. (2011). Escuelas en la trama de las desigualdades y las diferencias culturales. Debates y aportes para pensar la educación intercultural. En N. Elichiry (Comp.), Politicas y prácticas frente a la desigualdad educativa. Tensiones entre focalización y universalización (pp. 43-58). Buenos Aires: Noveduc.

Tiramonti, G. (2009). Una aproximación a la dinámica de la fragmentación del sistema educativo argentino. Especificaciones teóricas y empíricas. En G. Tiramonti y N. Montes (Comp.), La escuela media en debate. Problemas actuales y perspectivas desde la investigación (pp. 25-38). Buenos Aires: Manantial.

Tiramonti, G., Arroyo, M., Montes, N., Nobile, M., Poliak, N., Sendón, M. A., y Ziegler, S. (2007). Nuevos formatos escolares para promover la inclusión educativa. Un estudio de caso: la experiencia argentina. Informe final. Buenos Aires: FLACSO. Recuperado de http://www.redetis.org.ar/media/document/tiramontireingreso.pdf

Tobío, O. (2011). Acerca del discurso neoclásico: algunas resonancias entre la enseñanza de la economía y la de la geografía social. En V. S. Wainer (Comp.), Enseñar economia hoy: desafios y alternativas al paradigma neoclásico (pp. 138-146). Los Polvorines: Universidad Nacional de General Sarmiento.

Tolchinsky, L. (2008). Usar la lengua en la escuela. Revista Iberoamericana de Educación, 46, 37-54. Recuperado de http://www.rieoei.org/rie46a02.htm 
Leer y escribir en tres asignaturas de una escuela secundaria a la que asisten sectores socioeconómicos desfavorecidos Natalia Rosli

Torres, M. (2008). Leer para aprender historia: el lugar del texto en la reconstrucción de un contenido. Lectura y Vida, 29(4), 20-29.

Travé, G. (1999). Ciencias Sociales y enseñanza de las nociones económicas. Historia de un desencuentro. En M. T. García Santa María (Coord.), Un curriculum de Ciencias Sociales para el siglo XXI: qué contenido y para qué (pp. 7782). Sevilla: Díada.

Travé, G. y Estepa, J. (1997). La investigación sobre la enseñanza de nociones económicas: perspectivas desde la didáctica de las ciencias sociales. En A. Santisteban (Coord.), La formación del profesorado y la Didáctica de las Ciencias Sociales (pp. 27-36). Sevilla: Díada.

Travé, G. y Pozuelos, F. J. (2008). Enseñar economía mediante estrategias de investigación escolar. Estudio de caso sobre las concepciones y prácticas del profesorado. Enseñanza de las Ciencias Sociales, 7, 109-120.

Urquiza, C., Wainer, V. y Martínez, M. (2011). Reflexiones sobre el diseño curricular de economía en la escuela: una mirada a nivel nacional, provincial e institucional. En V. S. Wainer (Comp.), Enseñar economía hoy: desafios y alternativas al paradigma neoclásico (pp. 35-65). Los Polvorines: Universidad Nacional de General Sarmiento.

Villalva, K. E. (2006). Hidden literacies and inquiry approaches of bilingual high school writers. Written Communication, 23(1), 91-129.

Wells, G. (1987). Apprenticeship in literacy. Interchange, 18(1/2), 109-123.

Wells, G. (1990a). Creating the conditions to encourage literate thinking. Educational Leadership, 47(6), 13-17.

Wells, G. (1990b). Talk about text: where literacy is learned and taught. Curriculum Inquiry, 20(4), 369-405.

Wells, G. (1993). Text, talk and inquiry: schooling as semiotic apprenticeship. International Conference on Language and Content, Hong Kong.

Wells, G. (2006). Monologic and Dialogic Discourses as Mediators of Education. Research in the Teaching of English, $41(2), 168-175$.

Wineburg, S. S. (1991). Historical problem solving: A study of the cognitive processes used in the evaluation of documentary and pictorial evidence. Journal of Educational Psychology, 83(1), 73-87.

Wineburg, S. S. (1998). Reading Abraham Lincoln: an expert/expert study in the interpretation of historical texts. Cognitive Science, 22(3), 319-346.

Wineburg, S. S. (2007). Unnatural and essential: the nature of historical thinking. Teaching History, 129, 6-11.

Wineburg, S. S., Reisman, A., y Fogo, B. (2007). Historical evidence and evidence of learning. International Journal of Social Education, 22(1), 146-156.

Wolsey, T. D. y Kelsey, L. (2009). How can we help adolescents think about content through writing? En J. Lewis (Ed.), Essential questions in adolescent literacy. Teachers and researchers describe what works in classrooms (pp. 215236). New York: Guilford Press.

Yi, Y. (2010). Adolescent multilingual writers' transitions across in- and out-of-school writing contexts. Journal of Second Language Writing, 19(1), 17-32.

Yin, R. K. (2003). Case study research. Design and methods ( $3^{\text {rd }}$ Ed). Thousand Oaks, CA: Sage.

Young, K. M. y Leinhardt, G. (1998). Writing from primary documents: a way of knowing in History. Written Communication, 15(1), 25-68.

Zavala, V., Niño-Murcia, M., y Ames, P. (2004). Introducción. En V. Zavala, M. Niño-Murcia, y P. Ames (Eds.), Escritura y Sociedad. Nuevas perspectivas teóricas y etnográficas (pp. 7-18). Lima: Red para el Desarrollo de las Ciencias Sociales en el Perú.

Ziegler, S. (2011). Entre la desregulación y el tutelaje: ¿hacia dónde van los cambios en los formatos escolares? En G. Tiramonti (Dir.), Variaciones sobre la forma escolar. Límites y posibilidades de la escuela media (pp. 71-88). Buenos Aires: Homo Sapiens. 


\section{Anexos}

\section{Anexo 1. Guía de entrevista a docentes}

\section{INFORMACIÓN SOBRE LA ENTREVISTA}

\begin{tabular}{|l|l|}
\hline Número de entrevista & \\
\hline Lugar & \\
\hline Fecha & \\
\hline Duración & \\
\hline Correo electrónico de contacto & \\
\hline
\end{tabular}

SECCIÓN 1: Datos personales y de formación

\begin{tabular}{|l|l|}
\hline Nombre & \\
\hline Edad & \\
\hline Título de base & \\
\hline Otros títulos y/o estudios & \\
\hline Antigüedad en docencia & \\
\hline Antigüedad en esta institución & \\
\hline Materias que dicta en esta escuela & \\
\hline Materia por la que se lo entrevista & \\
\hline Cargos en esta institución & \\
\hline Participación en proyectos institucionales & \\
\hline Otras instituciones donde trabaja & \\
\hline $\begin{array}{l}\text { Hs semanales que trabaja como docente en esta } \\
\text { materia }\end{array}$ & \\
\hline Hs semanales que trabaja en total como docente & \\
\hline
\end{tabular}

\section{SECCIÓN 2: Presentación de la investigadora}

Breve presentación y recordatorio del propósito de investigación: comprender cómo se incluye la lectura y la escritura en la enseñanza de materias de la escuela secundaria.

Pedido de autorización para grabar la entrevista.

\section{SECCIÓN 3: Preguntas de apertura}

¿Qué tienen que hacer los alumnos para aprender en esta materia?

¿Y ellos lo hacen?

¿Y por qué crees que eso les ayuda a aprender?

¿Querés contarme algo de esta materia o de este grupo de alumnos? 
Leer y escribir en tres asignaturas de una escuela secundaria a la que asisten sectores socioeconómicos desfavorecidos Natalia Rosli

\section{SECCIÓN 4: Preguntas sobre tareas y perspectivas de la lectura}

\begin{tabular}{|c|c|}
\hline ¿En qué circunstancias hay que leer en esta materia? ¿Para qué? & \multirow{8}{*}{ Demandas y expectativas } \\
\hline ¿Qué tienen que leer los alumnos? & \\
\hline ¿Hacés alguna actividad o propuesta puntual para leer los materiales? & \\
\hline ¿Por qué elegiste esos materiales? & \\
\hline ¿Qué hacen ellos con lo que leyeron? & \\
\hline ¿Cómo esperás que lean? & \\
\hline ¿Qué esperás que hagan con lo que leyeron? & \\
\hline ¿Los alumnos saben que esperás eso? & \\
\hline ¿Cómo sabes que leyeron lo pedido? & \multirow{9}{*}{$\begin{array}{l}\text { Intervenciones docentes y } \\
\text { desafíos que perciben en los } \\
\text { alumnos }\end{array}$} \\
\hline ¿Les cuesta entender cuando leen? ¿Cómo te das cuenta? & \\
\hline $\begin{array}{l}\text { ¿Qué tipo de dificultades de lectura ves que son más frecuentes en estos } \\
\text { alumnos? }\end{array}$ & \\
\hline ¿Hacés algo cuando no entienden lo que leyeron? & \\
\hline ¿Qué pensás que podría ayudarlos a comprender? & \\
\hline $\begin{array}{l}\text { Desde tu experiencia como docente, ¿en qué sentido crees que las explicaciones } \\
\text { que el docente da en la clase ayudan a que los alumnos comprendan el texto? } \\
\text { ¿Cómo? }\end{array}$ & \\
\hline ¿Crees que estos alumnos leen todos de la misma manera o hay diferencias? & \\
\hline (Si nota diferencias) ¿Por qué pensás que ocurren? & \\
\hline $\begin{array}{l}\text { ¿Encontrás diferencias entre cómo leen los alumnos de esta escuela y los } \\
\text { alumnos de otra? }\end{array}$ & \\
\hline $\begin{array}{l}\text { Muchas veces los estudiantes del nivel medio no entienden cuando leen, } \\
\text { ¿cuáles crees que son las causas? }\end{array}$ & \multirow{5}{*}{$\begin{array}{l}\text { Perspectivas sobre la lectura, } \\
\text { su enseñanza y aprendizaje, y } \\
\text { su relación con contenidos } \\
\text { disciplinares }\end{array}$} \\
\hline $\begin{array}{l}\text { Algunos piensan que cuando se aprende a leer, se aprende para toda la vida } \\
\text { ¿qué pensás de esto? }\end{array}$ & \\
\hline $\begin{array}{l}\text { ¿Creés que se lee de la misma forma en el nivel primario, medio y superior? } \\
\text { ¿Por qué? }\end{array}$ & \\
\hline $\begin{array}{l}\text { ¿Creés que se lee de la misma manera textos de tu área disciplinar que textos de } \\
\text { otras áreas? }\end{array}$ & \\
\hline $\begin{array}{l}\text { ( Si la respuesta es negativa) ¿Dónde creés que se aprende o debería aprenderse } \\
\text { a leer los textos de tu materia? ¿Y los textos de las otras áreas? }\end{array}$ & \\
\hline
\end{tabular}

\section{SECCIÓN 5: Preguntas sobre tareas y perspectivas de la escritura}

\begin{tabular}{|l|}
\hline ¿En qué circunstancias hay que escribir en esta materia? ¿Para qué? \\
\hline ¿Qué tienen que escribir los alumnos? \\
\hline ¿Hacés alguna actividad o propuesta puntual para escribir lo que pedís? \\
\hline ¿Por qué elegiste que escriban eso? \\
\hline ¿Qué hacen ellos con lo que escribieron?
\end{tabular}




\begin{tabular}{|c|c|}
\hline ¿Cómo esperás que escriban? & \\
\hline ¿Qué esperás que hagan con lo que escribieron? & \\
\hline ¿Los alumnos saben que esperás eso? & \\
\hline ¿Les cuesta escribir? ¿Cómo te das cuenta? & \\
\hline $\begin{array}{l}\text { ¿Qué tipo de dificultades de escritura ves que son más frecuentes en estos } \\
\text { alumnos? }\end{array}$ & \\
\hline ¿Hacés algo cuando se les dificulta escribir lo pedido? & \\
\hline ¿Qué pensás que podría ayudarlos a avanzar la escritura? & \\
\hline ¿Qué hacés cuando vos no entendés lo que escribieron? & Intervenciones docentes y \\
\hline $\begin{array}{l}\text { Desde tu experiencia como docente, ¿en qué sentido crees que las explicaciones } \\
\text { que el docente da en la clase ayudan a que los alumnos escriban? ¿Cómo? }\end{array}$ & $\begin{array}{l}\text { desafíos que perciben en los } \\
\text { alumnos }\end{array}$ \\
\hline $\begin{array}{l}\text { ¿Crees que estos alumnos escriben todos de la misma manera o hay } \\
\text { diferencias? }\end{array}$ & \\
\hline (Si nota diferencias) ¿Por qué pensás que ocurren? & \\
\hline $\begin{array}{l}\text { ¿Encontrás diferencias entre cómo escriben los alumnos de esta escuela y los } \\
\text { alumnos de otra? }\end{array}$ & \\
\hline $\begin{array}{l}\text { Muchas veces a los estudiantes del nivel medio se les dificulta escribir, ¿cuáles } \\
\text { crees que son las causas? }\end{array}$ & \\
\hline $\begin{array}{l}\text { Algunos piensan que cuando se aprende a escribir, se aprende para toda la vida } \\
\text { ¿qué pensás de esto? }\end{array}$ & Perspectivas sobre la \\
\hline $\begin{array}{l}\text { ¿Creés que se escribe de la misma forma en el nivel primario, medio y } \\
\text { superior? ¿Por qué? }\end{array}$ & $\begin{array}{l}\text { escritura, su enseñanza y } \\
\text { aprendizaje, y su relación con }\end{array}$ \\
\hline $\begin{array}{l}\text { ¿Creés que se escribe de la misma manera textos en tu área disciplinar que } \\
\text { textos de otras áreas? }\end{array}$ & contenidos disciplinares \\
\hline $\begin{array}{l}\text { ( Si la respuesta es negativa) ¿Dónde creés que se aprende o debería aprenderse } \\
\text { a escribir textos de tu materia? ¿Y los textos de las otras áreas? }\end{array}$ & \\
\hline
\end{tabular}

\section{SECCIÓN 6: Apoyo institucional}

¿Hay alguna instancia institucional en donde se trabaje esto que vos hacés con la lectura y escritura? ¿Con qué canales de comunicación institucional contás para hacer frente a alguna problemática que surja?

\section{SECCIÓN 7: Agradecimiento y final de la entrevista}

Agradecimiento por el tiempo concedido. Se recuerda la importancia que conlleva la entrevista para la investigación. Se ofrece enviar la desgrabación por correo electrónico para su revisión.

Espacio para comentarios adicionales y preguntas del docente a la entrevistadora. 


\section{Anexo 2. Guía de entrevista a alumnos}

\section{INFORMACIÓN SOBRE LA ENTREVISTA}

\begin{tabular}{|l|l|}
\hline Número de entrevista & \\
\hline Lugar & \\
\hline Fecha & \\
\hline Duración & \\
\hline
\end{tabular}

SECCIÓN 1: Datos personales y de formación

\begin{tabular}{|l|l|l|}
\hline & Alumno 1 & Alumno 2 \\
\hline Nombre & & \\
\hline Edad & & \\
\hline Barrio donde vive & & \\
\hline Trayectoria escolar & & \\
\hline Composición familiar & & \\
\hline Nivel educativo alcanzado por el padre & & \\
\hline Nivel educativo alcanzado por la madre & & \\
\hline Nivel educativo alcanzado por hermanos/as & & \\
\hline Situación laboral & & \\
\hline
\end{tabular}

\section{SECCIÓN 2: Presentación de la investigadora}

Breve presentación y recordatorio del propósito de investigación: comprender cómo se incluye la lectura y la escritura en la enseñanza de materias de la escuela secundaria.

Pedido de autorización para grabar la entrevista.

\section{SECCIÓN 3: Preguntas de apertura}

¿Qué tienen que hacer para aprender en estas materias que observo?

¿Y ustedes lo hacen?

¿Y por qué creen que eso les ayuda a aprender?

¿Quieren contarme algo de estas materias que observo?

SECCIÓN 4: Preguntas sobre tareas y perspectivas de la lectura

\begin{tabular}{|l|l|}
\hline ¿Cuándo tienen que leer en estas materias? ¿Para qué? & \\
\hline ¿Qué tienen que leer? & Demandas y expectativas de \\
\hline ¿Qué actividades les proponen los profesores para leer los materiales? & los docentes \\
\hline ¿Por qué creen que eligieron esos materiales y esas actividades? & \\
\hline ¿Ustedes creen que les sirven para aprender? & \\
\hline ¿Qué hacen ustedes con lo que leyeron? & \\
\hline Los docentes, ¿cómo esperan que ustedes lean? & \\
\hline
\end{tabular}




\begin{tabular}{|c|c|}
\hline ¿En todas las materias tienen que leer así? ¿Qué diferencias ven? & \\
\hline ¿En todos los años de la escuela les pidieron leer así? & \\
\hline ¿Les cuesta entender cuando leen? ¿Qué hacen cuando no entienden? & \multirow{7}{*}{$\begin{array}{l}\text { Desafíos que enfrentan a la } \\
\text { hora de leer, intervenciones } \\
\text { docentes y ayudas valoradas }\end{array}$} \\
\hline ¿Por qué creen que no entendieron? & \\
\hline $\begin{array}{l}\text { ¿Qué tipo de dificultades de lectura ven que son más frecuentes en sus } \\
\text { compañeros? }\end{array}$ & \\
\hline Los profesores, ¿qué hacen cuando ustedes no entienden lo que leyeron? & \\
\hline ¿Qué piensan que deberían hacer los profesores en esos casos? & \\
\hline ¿Creen que sus compañeros leen todos de la misma manera o hay diferencias? & \\
\hline (Si notan diferencias) ¿Por qué piensan que ocurren? & \\
\hline $\begin{array}{l}\text { Algunos alumnos piensan que cuando se aprende a leer, se aprende para toda la } \\
\text { vida ¿qué piensan de esto? }\end{array}$ & \multirow{4}{*}{$\begin{array}{l}\text { Perspectivas sobre la lectura, } \\
\text { su enseñanza y aprendizaje, y } \\
\text { su relación con contenidos } \\
\text { disciplinares }\end{array}$} \\
\hline $\begin{array}{l}\text { ¿Creen que se lee de la misma forma en el nivel primario, medio y superior? } \\
\text { ¿Por qué? }\end{array}$ & \\
\hline $\begin{array}{l}\text { ¿Creen que se lee de la misma manera textos de esas materias que textos de } \\
\text { otras asignaturas? }\end{array}$ & \\
\hline $\begin{array}{l}\text { ( Si la respuesta es negativa) ¿Dónde creen que se aprende o debería aprenderse } \\
\text { a leer los textos de las materias que estamos observando para este estudio? }\end{array}$ & \\
\hline
\end{tabular}

\section{SECCIÓN 5: Preguntas sobre tareas y perspectivas de la escritura}

\begin{tabular}{|c|c|}
\hline ¿Cuándo tienen que escribir en estas materias? ¿Para qué? & \multirow{10}{*}{$\begin{array}{l}\text { Demandas y expectativas de } \\
\text { los docentes }\end{array}$} \\
\hline ¿Qué tienen que escribir? & \\
\hline ¿Qué actividades les proponen los profesores para escribir? & \\
\hline ¿Por qué creen que eligieron esas actividades? & \\
\hline ¿Ustedes creen que les sirven para aprender? & \\
\hline ¿Qué hacen ustedes con lo que escribieron? & \\
\hline ¿Lo revisan en algún momento? ¿Cómo? & \\
\hline Los docentes, ¿cómo esperan que ustedes escriban? & \\
\hline ¿En todas las materias tienen que escribir así? ¿Qué diferencias ven? & \\
\hline ¿En todos los años de la escuela les pidieron escribir así? & \\
\hline ¿Les cuesta escribir? ¿Qué hacen en esas situaciones? & \multirow{6}{*}{$\begin{array}{c}\text { Desafíos que enfrentan a la } \\
\text { hora de escribir, } \\
\text { intervenciones docentes y } \\
\text { ayudas valoradas }\end{array}$} \\
\hline ¿Por qué creen que les cuesta? & \\
\hline $\begin{array}{l}\text { ¿Qué tipo de dificultades de escritura ven que son más frecuentes en sus } \\
\text { compañeros? }\end{array}$ & \\
\hline Los profesores, ¿qué hacen cuando a ustedes les cuesta escribir? & \\
\hline ¿Qué piensan que deberían hacer los profesores en esos casos? & \\
\hline $\begin{array}{l}\text { ¿Crees que sus compañeros escriben todos de la misma manera o hay } \\
\text { diferencias? }\end{array}$ & \\
\hline
\end{tabular}


Leer y escribir en tres asignaturas de una escuela secundaria a la que asisten sectores socioeconómicos desfavorecidos Natalia Rosli

\begin{tabular}{|c|c|}
\hline \multicolumn{2}{|l|}{ (Si notan diferencias) ¿Por qué piensan que ocurren? } \\
\hline $\begin{array}{l}\text { Algunos alumnos piensan que cuando se aprende a escribir, se aprende para } \\
\text { toda la vida ¿qué piensan de esto? }\end{array}$ & \multirow{4}{*}{$\begin{array}{c}\text { Perspectivas sobre la } \\
\text { escritura, su enseñanza y } \\
\text { aprendizaje, y su relación con } \\
\text { contenidos disciplinares }\end{array}$} \\
\hline $\begin{array}{l}\text { ¿Creen que se escribe de la misma forma en el nivel primario, medio y } \\
\text { superior? ¿Por qué? }\end{array}$ & \\
\hline $\begin{array}{l}\text { ¿Creen que se escribe de la misma manera textos de esas materias que textos de } \\
\text { otras asignaturas? }\end{array}$ & \\
\hline $\begin{array}{l}\text { ( Si la respuesta es negativa) ¿Dónde creen que se aprende o debería aprenderse } \\
\text { a escribir textos de las materias que estamos observando para este estudio? }\end{array}$ & \\
\hline
\end{tabular}

\section{SECCIÓN 6: Preguntas generales sobre enseñanza y aprendizaje}

¿Qué piensan de estos profesores?

¿Les gustan sus maneras de enseñar?

¿Todos los profesores de la escuela son así?

¿Alguien les enseñó a estudiar? ¿Cómo y dónde?

\section{SECCIÓN 7: Agradecimiento y final de la entrevista}

Agradecimiento por el tiempo concedido. Se recuerda la importancia que conlleva la entrevista para la investigación.

Espacio para comentarios adicionales y preguntas de los alumnos a la entrevistadora. 


\section{Anexo 3. Guía de entrevista a directivo}

\section{INFORMACIÓN SOBRE LA ENTREVISTA}

\begin{tabular}{|l|l|}
\hline Número de entrevista & \\
\hline Lugar & \\
\hline Fecha & \\
\hline Duración & \\
\hline Correo electrónico de contacto & \\
\hline
\end{tabular}

SECCIÓN 1: Datos personales y de formación

\begin{tabular}{|l|l|}
\hline Nombre & \\
\hline Edad & \\
\hline Título de base & \\
\hline Otros títulos y/o estudios & \\
\hline Antigüedad en docencia & \\
\hline Antigüedad en esta institución & \\
\hline Ocupación actual & \\
\hline
\end{tabular}

\section{SECCIÓN 2: Presentación de la investigadora}

Breve presentación y recordatorio del propósito de investigación: comprender cómo se incluye la lectura y la escritura en la enseñanza de materias de la escuela secundaria.

Pedido de autorización para grabar la entrevista.

\section{SECCIÓN 3: Trayectoria directiva en la escuela}

¿Cómo llegaste a la escuela

¿Cómo fue tu experiencia ahí?

¿Por qué decidiste irte?

En todos estos años que estuviste en la escuela, ¿qué te llevaste y qué dejaste?

¿Qué pretendías lograr? ¿Se logró?

SECCIÓN 4: Perspectivas sobre la enseñanza, el aprendizaje y el rol institucional

¿Qué es lo más importante que pueden hacer los docentes por los alumnos?

¿Qué es lo que debe privilegiarse en las aulas?

¿Qué seguimiento hacen del trabajo docente? ¿Y de los programas curriculares?

¿Con qué canales de comunicación institucional cuentan los docentes para hacer frente a alguna problemática que surja?

En cuanto al trabajo con los contenidos, ¿cuál es el rol de la institución?

¿Qué tienen que hacer los alumnos para aprender en la escuela?

¿Qué aprendizajes crees que tiene que llevarse un alumno cuando egresa de esta escuela? 
Leer y escribir en tres asignaturas de una escuela secundaria a la que asisten sectores socioeconómicos desfavorecidos Natalia Rosli

\section{SECCIÓN 5: Preguntas específicas sobre leer y escribir}

¿Qué lugar crees que ocupa la lectura y la escritura para aprender en las materias?

Suele escucharse que a los alumnos les cuesta comprender y producir textos en las materias, basado en tu experiencia ¿qué pensás de esto?

\section{SECCIÓN 6: Agradecimiento y final de la entrevista}

Agradecimiento por el tiempo concedido. Se recuerda la importancia que conlleva la entrevista para la investigación. Se ofrece enviar la desgrabación por correo electrónico para su revisión.

Espacio para comentarios adicionales y preguntas del directivo a la entrevistadora. 


\section{Anexo 4. Viñetas de las clases observadas en las asignaturas}

\begin{tabular}{|c|}
\hline \multicolumn{2}{|c|}{ VINETAS ASIGNATURA A } \\
\hline Clase 1 \\
\hline Fecha: 26/05/11 \\
\hline Al comenzar la clase, el docente establece la fecha de entrega del primer trabajo práctico, cuyas consignas \\
dictó con anterioridad. Al preguntar si completaron el cuestionario encomendado como tarea para el hogar, los \\
alumnos responden negativamente. Entonces, asigna tiempo para que lean y contesten en clase dichas \\
preguntas. Se trata del artículo "El difícil arte de asir a la juventud" del sociólogo Mario Margulis, incluido en \\
el cuadernillo de la materia. Durante ese tiempo, el profesor pasa por los bancos para responder las consultas \\
de los estudiantes. Hacia el final, solicita que para la próxima clase lean la introducción de "Los mitos de la \\
historia argentina" del historiador Felipe Pigna, que figura en el mismo material.
\end{tabular}

Clase 2

Fecha: 02/06/11

Primer trimestre escolar

El docente propone poner en común el artículo de Margulis, trabajado en la clase anterior. A medida que los alumnos enuncian sus respuestas, el profesor realiza anotaciones en el pizarrón. Sin embargo, esta actividad se ve dificultada porque algunos estudiantes no quieren leer en voz alta las respuestas. Ante el comentario negativo de una alumna sobre la enseñada recibida en la escuela, se deriva una conversación acerca de los estudios superiores. El profesor alienta al curso a continuar estudiando y relata su experiencia personal. Posteriormente, retoma la puesta en común del artículo. Minutos antes de finalizar la clase, algunos alumnos consultan sobre cómo hacer la carátula para el trabajo práctico. A través de un gráfico en el pizarrón, el docente explica el formato y las pautas de presentación.

\section{Clase 3 \\ Fecha: 09/06/11 \\ Primer trimestre escolar}

El docente copia en el pizarrón preguntas que apuntan a la valoración que los alumnos tienen de la escuela y remiten a la conversación suscitada la clase anterior. Mientras responden en sus carpetas y en forma anónima, pide que vayan acercándose algunos estudiantes para comentar en forma individual las correcciones del primer trabajo práctico.

Clase $4 \quad$ Fecha: 16/06/11 Segundo trimestre escolar

El docente empieza la clase comentando una serie de dificultades que comparten los trabajos prácticos entregados. Continúa con un resumen de las respuestas de los alumnos a las preguntas formuladas la clase anterior. Luego, indica trabajar con la introducción de "Los mitos de la historia argentina" del historiador Felipe Pigna. Dado que muchos estudiantes mencionan haber olvidado el cuadernillo de la materia, propone leer el texto en conjunto y en voz alta. La mayoría de los alumnos se rehúsa a hacerlo, son pocos los que acceden. Al finalizar la lectura grupal, recuerda que la clase siguiente deben entregar las respuestas y leer “Aquel granero del mundo", del mismo autor. Dibuja en el pizarrón una línea de tiempo en la que sitúa los períodos históricos a los que refiere el texto leído.

\section{Clase 5}

Fecha: 23/06/11

Segundo trimestre escolar

Los alumnos comentan que olvidaron el cuadernillo y, no terminaron el cuestionario sobre "Los mitos de la historia argentina". El profesor otorga tiempo de clase para finalizar la tarea mientras dibuja una línea de

\footnotetext{
${ }^{33}$ Los trimestres escolares se especifican de acuerdo con la Agenda Educativa correspondiente al 2011, año en el que se realizaron las observaciones de clase en la institución escolar.
} 
tiempo en el pizarrón. Marca con una cruz en el período 1976-1983, que remite al texto en análisis, y contesta consultas de los alumnos. Por último, indica que la próxima clase pondrán en común las respuestas sobre "Los mitos de la historia argentina" y pide, nuevamente, que lean “Aquel granero del mundo" de Felipe Pigna.

\begin{tabular}{|ccc|}
\hline & \multicolumn{2}{c|}{ Clase suspendida por motivos no informados } \\
\hline Clase 6 & Fecha: 07/07/11 & Segundo trimestre escolar
\end{tabular}

Para trabajar el modelo nacional agroexportador, el docente realiza una breve introducción oral y proyecta el video "Historia de un país. Argentina Siglo XX" producido por el Canal Encuentro. Entrega a los alumnos una fotocopia con un cuestionario de seis preguntas, que leen y responden oralmente entre todos.

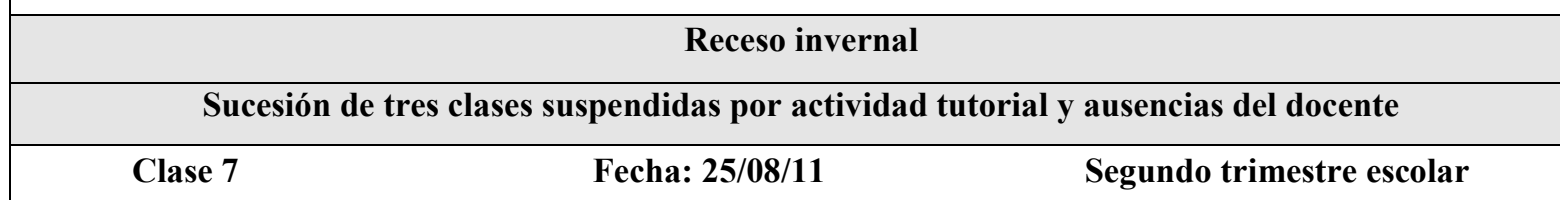

El docente dicta las consignas del segundo trabajo práctico, que requiere elegir dos textos del cuadernillo, contextualizarlos, responder las preguntas de los cuestionarios que allí figuran y elaborar una síntesis de cada uno. Se detiene explicando sus expectativas al respecto y hace hincapié en su presentación y organización. Propone responder en clase las preguntas sobre el texto "Normas jurídicas e ideologías políticas relativas a la familia argentina" de la socióloga Susana Torrado. La mayoría de los alumnos comienza a conversar sobre temas ajenos a la materia.

Clase $8 \quad$ Fecha: 01/09/11 Segundo trimestre escolar

Aparecen dudas de los estudiantes acerca del trabajo práctico pedido. Ante una consulta particular de una alumna, revisa su carpeta y le corrige un error en la línea de tiempo copiada. Dibuja nuevamente este gráfico en el pizarrón y propone que los estudiantes examinen lo que copiaron. Brevemente, explica los períodos históricos que incluye dicha línea de tiempo y responde consultas sobre el trabajo práctico.

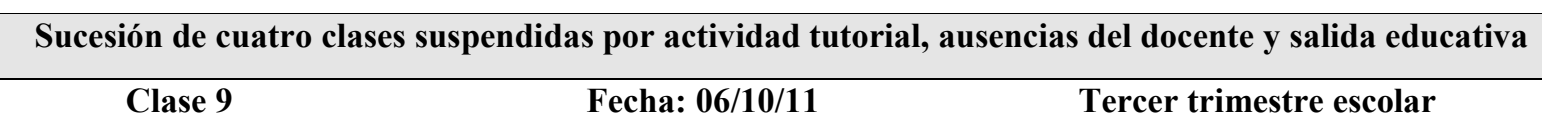

El docente destina tiempo de clase para comentar en forma individual las correcciones del segundo trabajo práctico. Indica que la próxima clase pautará el tercer trabajo práctico del año.

\begin{tabular}{|c|}
\hline Tercer trimestre escolar \\
\hline $\begin{array}{l}\text { Luego de dictar las consignas del tercer trabajo práctico -escoger cuatro textos del cuadernillo, } \\
\text { contextualizarlos y detallar las características políticas, económicas, sociales y educativas del momento- el } \\
\text { profesor grafica en el pizarrón una línea de tiempo donde señala períodos históricos y sus correspondientes } \\
\text { formas políticas. Posteriormente, comenta con estudiantes las correcciones del segundo trabajo práctico. }\end{array}$ \\
\hline Clase suspendida por salida educativa \\
\hline Fecha: $27 / 10 / 11$ \\
\hline $\begin{array}{l}\text { El profesor comenta brevemente la salida educativa a la Expo-Universidad. Propone confeccionar un afiche } \\
\text { alusivo con folletos allí recolectados. Pregunta si tienen dudas sobre el tercer trabajo práctico, pero los } \\
\text { alumnos responden que todavía no lo empezaron. Entonces, el docente anima a comiencen a hacerlo en grupo. } \\
\text { En el pizarrón, dibuja una línea de tiempo y escribe los temas que trabajarán las últimas semanas de clase. } \\
\text { Responde dudas de los alumnos. }\end{array}$ \\
\hline Sucesión de dos clases suspendidas por au \\
\hline
\end{tabular}




\section{VIÑETAS ASIGNATURA B}

Clase 1

Fecha: 23/06/11

Segundo trimestre escolar

El docente comienza la clase repartiendo a los alumnos trabajos prácticos que corrigió. Luego, realiza una introducción oral acerca de la deuda externa. A través de preguntas, incentiva a los alumnos a participar aportando lo que recuerden de lo trabajado en clases anteriores. Finalizada la introducción, les propone leer un texto de un manual de Historia y contestar el cuestionario que allí figura. Guía a los estudiantes cuando lo consultan sobre cómo responder las preguntas. Antes de retirarse del aula, los alumnos entregan lo realizado hasta el momento.

Clase 2

Fecha: 27/06/11

Segundo trimestre escolar

Tras el pedido del profesor, se realiza una puesta en común de las respuestas de la actividad anterior. El docente retoma algunos conceptos, da ejemplos al respecto y repregunta a los alumnos. A continuación, grafica en el pizarrón un cuadro sinóptico sobre la deuda externa, que todos los alumnos copian en sus carpetas. También anota como tarea para el hogar ver un video de Youtube con imágenes del film "Memorias del Saqueo", del político y cineasta Pino Solanas, musicalizado con la canción "Dientes de Cordero" de la banda de rock Los Piojos. Para cerrar la clase, recapitula oralmente los conceptos vistos.

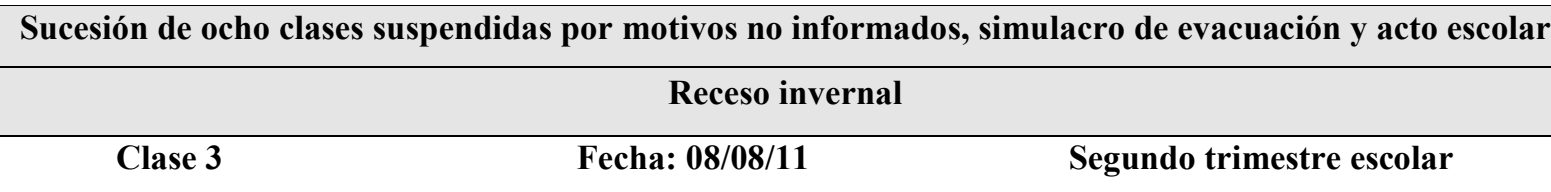

Al entrar a clase, el profesor encuentra a los estudiantes discutiendo sobre estrategias para recaudar dinero para su viaje de egresados. Propone que llamen a la rectora y le consulten sobre la organización de un bingo en la escuela. Una alumna se dirige a Rectoría pero al volver anuncia que la rectora no se encontraba presente en la institución. Entonces, el profesor comienza una exposición oral sobre la deuda externa. Luego, plantea poner en común un cuestionario titulado "La deuda latinoamericana". Ante la primera respuesta leída en voz alta por una alumna, el profesor formula preguntas al curso en relación con algunos conceptos y los explica. Cuando nota que está por finalizar la hora, da por terminada la clase.

\section{Sucesión de cuatro clases suspendidas por ausencias docentes y tareas de limpieza y desinfección}

Clase 4

Fecha: 25/08/11

Segundo trimestre escolar

El docente propone a los estudiantes ver en clase, y a través de las netbooks, el video de Youtube con fragmentos del film "Memorias del Saqueo", mientras copia en el pizarrón un cuestionario titulado "La ilegitimidad de la deuda". Cuando finaliza la reproducción del video, el profesor introduce oralmente el tema de la deuda externa del país e indica copiar y responder las preguntas en las carpetas.

Clase 5

Fecha: 29/08/11

Segundo trimestre escolar

Los estudiantes siguen trabajando con el cuestionario sobre la deuda externa de la clase anterior. Para ello, vuelven a reproducir el video de Youtube en sus netbooks y consultan al profesor. Cuando terminan, le entregan sus hojas.

\section{Clase 6}

Fecha: 01/09/11

Segundo trimestre escolar

El docente anticipa que la próxima clase realizarán un trabajo práctico a carpeta abierta. Luego, copia en el pizarrón un cuadro sinóptico sobre países desarrollados, países subdesarrollados y organismos 
internacionales. Cuando los alumnos terminan de copiar el cuadro en sus carpetas, introduce oralmente el tema de la globalización.

Clase $7 \quad$ Fecha: 05/09/11 Segundo trimestre escolar

El profesor copia en el pizarrón las consignas del trabajo práctico que anticipó la clase anterior, que versa sobre la globalización. Indica buscar las respuestas en las carpetas y en manuales de Historia que trae de la biblioteca escolar. Los alumnos leen y consultan sus dudas. Antes de que termine la clase, el docente pide que entreguen las hojas con lo trabajado hasta el momento.

\begin{tabular}{|ccc|}
\hline & \multicolumn{2}{c}{ Clase suspendida por actividad tutorial } \\
\hline Clase 8 & Fecha: $12 / 09 / 11$ & Segundo trimestre escolar
\end{tabular}

El profesor reparte las hojas de los alumnos que recogió la clase anterior y distribuye nuevamente los manuales para que continúen con el trabajo práctico de globalización. Mientras los estudiantes leen, circula por los bancos y responde las consultas. Al finalizar la clase, los alumnos vuelven a entregar sus producciones.

Clase $9 \quad$ Fecha: 15/09/11 Segundo trimestre escolar

Al comienzo de la clase, el docente copia en el pizarrón otra consigna del trabajo práctico sobre globalización: responder cuatro preguntas acerca de un artículo periodístico titulado "El mercado es una opción, pero no una necesidad". Se trata de una entrevista al entonces Secretario de Finanzas del gobierno nacional, Hernán Lorenzino, publicada en el diario Miradas al Sur. A pesar de que reparte las fotocopias para comenzar esta actividad, la mayoría de los alumnos aun se encuentra resolviendo las consignas anteriores. Solo unos pocos estudiantes empiezan a leer el artículo periodístico.

\section{Clase 10 \\ Fecha: 19/09/11 \\ Tercer trimestre escolar}

La clase se adelanta unas horas para ocupar el horario de una profesora ausente. El profesor autoriza a retirarse a aquellos alumnos que terminaron el trabajo práctico de globalización. Permanecen en el aula tres alumnos que continúan la actividad. A medida que entregan, se retiran de la clase.

\section{Clase 11 \\ Fecha: 22/09/11 \\ Tercer trimestre escolar}

El docente anuncia las calificaciones que los estudiantes obtuvieron en el trabajo práctico sobre globalización. A continuación, introduce el tema de bloques regionales y copia en el pizarrón un cuadro sinóptico al respecto. También anota como tarea para la próxima clase buscar información sobre el Área de Libre Comercio de las Américas (ALCA). Informa a los alumnos que no avanzarán en dicha clase con un tema nuevo por la gran cantidad de alumnos ausentes.

\section{Clase 12}

Fecha: 26/09/11

\section{Tercer trimestre escolar}

El profesor comienza la clase preguntando a los estudiantes qué datos hallaron sobre el ALCA. Cuando una alumna no quiere leer en voz alta la información que extrajo de un sitio web, el docente toma la hoja, lee para el resto de la clase y explica. Luego, copia en el pizarrón un cuestionario con dos preguntas acerca del Mercosur y la Unión Europea, y entrega manuales de Geografía para responderlas.

\section{Clase suspendida por salida educativa}

\section{Clase 13}

Fecha: 03/10/11

\section{Tercer trimestre escolar}

Antes de entrar al curso, el docente informa a la investigadora que desde Rectoría le pidieron que dicte una clase sobre orientación vocacional. Al ingresar al aula, los alumnos se encuentran charlando sobre la 
credibilidad o no del juego de la copa (popular juego que se prepara colocando una copa boca abajo rodeada de las letras del alfabeto. Los participantes sitúan el dedo índice sobre la base de la copa y convocan a espíritus para efectuar en voz alta preguntas sobre el futuro que, supuestamente, serán contestadas a través del movimiento de este objeto alrededor de las letras, formando las respuestas). El profesor retoma esa conversación e introduce la idea del destino. Expone su experiencia personal, pregunta a los estudiantes por su proyección al terminar la escuela y alienta que estudien o trabajen en lo que realmente les guste.

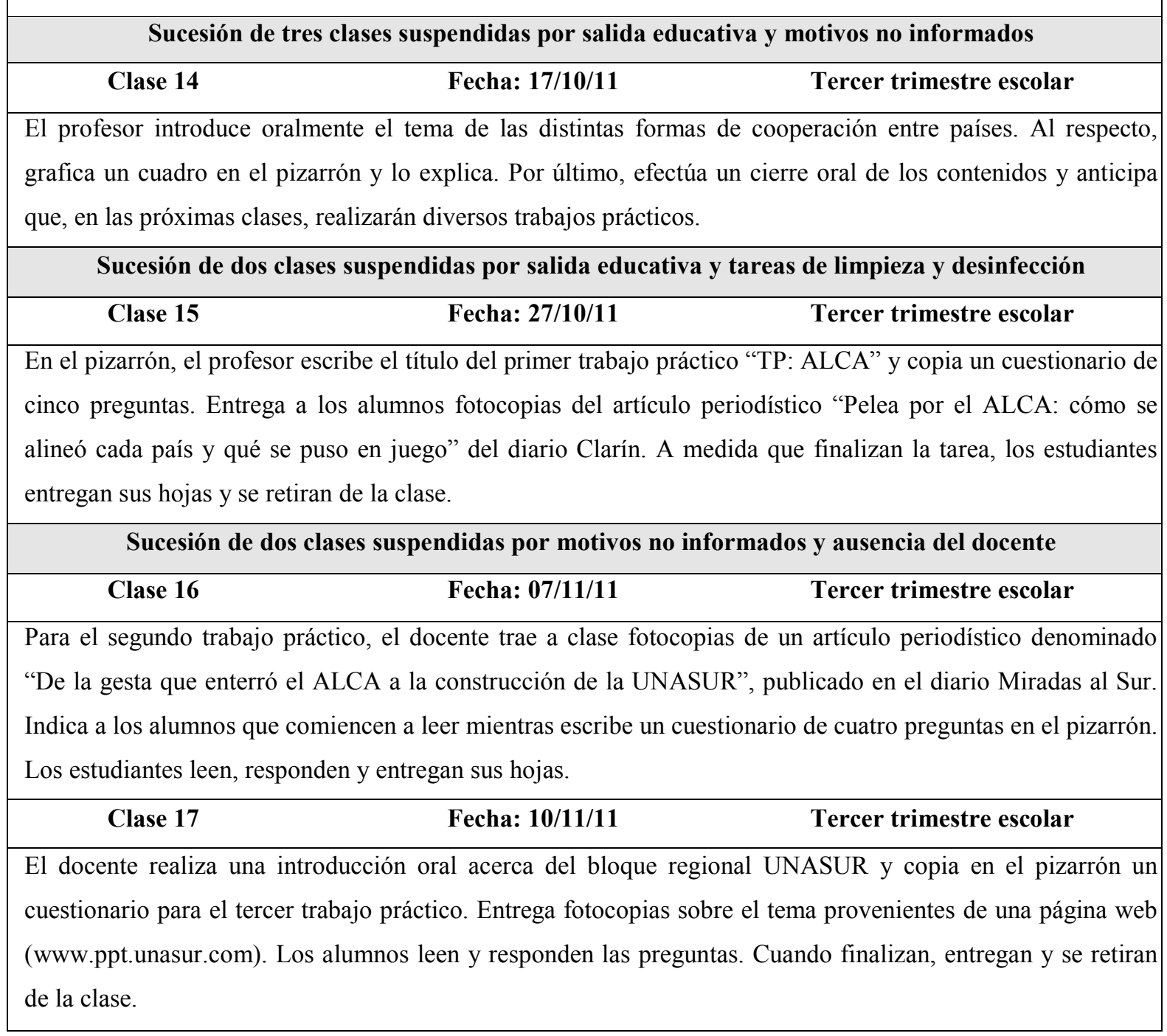




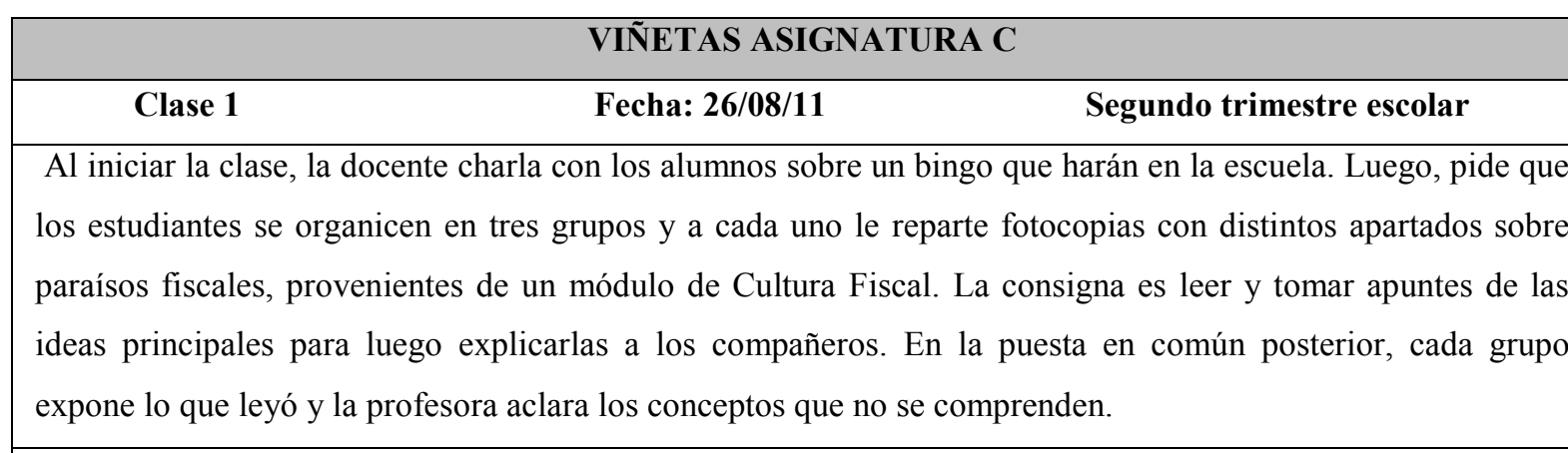

Clase 2

Fecha: 30/08/11

Segundo trimestre escolar

La clase comienza con la docente exponiendo a los alumnos su preocupación por la escasa predisposición al trabajo en clase. Los estudiantes la escuchan en silencio. A continuación, dicta un cuestionario de veintidós preguntas sobre paraísos fiscales y anuncia que tomará una evaluación escrita basándose en ellas. Entrega nuevamente las fotocopias de la clase anterior para que respondan las preguntas y contesta dudas de los estudiantes.

Clase $3 \quad$ Fecha: 02/09/11 Segundo trimestre escolar

La profesora otorga tiempo de clase para que los alumnos terminen las preguntas sobre paraísos fiscales de la clase anterior. Luego, comienza la puesta en común, en la que responde dudas e introduce ejemplos sobre los conceptos. Al terminar, grafica en el pizarrón un cuadro sinóptico sobre las distintas Direcciones Generales de la AFIP. Mientras los alumnos copian en sus carpetas, pasea por el aula y charla con ellos. Antes de finalizar la clase, realiza otro cuadro acerca del tema de seguridad social.

\section{Clase 4}

Fecha: 06/09/11

Segundo trimestre escolar

La docente toma evaluación escrita y presencial sobre paraísos fiscales.

Clase 5 Fecha: 09/09/11 Segundo trimestre escolar

La docente toma recuperatorio a los alumnos que no aprobaron la evaluación.

Clase 6

Fecha: 13/09/11

Segundo trimestre escolar

Durante la clase, la profesora hace una devolución oral de las notas del trimestre. Conversa individualmente con los alumnos y expresa su apreciación personal sobre el desempeño en la asignatura. A los estudiantes que tienen bajas calificaciones les pregunta cómo creen que podrían mejorarlas.

\begin{tabular}{|ccc|}
\hline \multicolumn{3}{|c|}{ Sucesión de cuatro clases suspendidas por acto escolar y ausencia del docente } \\
\hline Clase 7 & Fecha: $30 / 09 / 11$ & Tercer trimestre escolar \\
\hline
\end{tabular}

La docente escribe en el pizarrón siete preguntas que conforman un trabajo práctico sobre seguridad social. A la par que los alumnos comienzan a responder las preguntas revisando sus carpetas, copia en el pizarrón definiciones teóricas sobre trabajo registrado y búsqueda del primer empleo. En relación con estas definiciones, dicta otras tres preguntas. Los estudiantes que terminan la tarea, entregan sus hojas.

\begin{tabular}{|c|c|c|}
\hline \multicolumn{3}{|c|}{ Sucesión de siete clases suspendidas por paro y ausencia del docente y otros motivos no informados } \\
\hline Clase 8 & Fecha: 28/10/11 & Tercer trimestre escolar \\
\hline
\end{tabular}


siete preguntas de un cuestionario. Al rato, copia la definición del impuesto a los bienes personales. Cuando terminan de responder el cuestionario, los estudiantes entregan sus hojas.

Clase 9 Fecha: 01/11/11 Tercer trimestre escolar

Al inicio de la clase, los estudiantes intercambian opiniones con la docente acerca de la historia institucional de la escuela y el cambio producido a partir de la nueva rectora. Tras esa extensa charla, cerca de la mitad de la hora, la profesora comienza a escribir en el pizarrón definiciones sobre la sociedad conyugal y los bienes alcanzados por el impuesto a los bienes personales, que los alumnos copian en sus carpetas.

Sucesión de tres clases suspendidas por paro docente y otros motivos no informados

Clase $10 \quad$ Fecha: 15/11/11 Tercer trimestre escolar

Antes de comenzar la clase, los estudiantes piden tiempo a la docente para confeccionar su bandera de egresados. La profesora accede a lo solicitado, con la condición de que previamente copien en sus carpetas la definición de capacidad contributiva y patrimonio, que escribe en el pizarrón. Luego, cuando nota que algunos estudiantes no colaboran en la realización de la bandera, interviene advirtiendo que todos deben hacerlo.

Clase $11 \quad$ Fecha: 18/11/11 Tercer trimestre escolar

La docente reparte una fotocopia del módulo de Cultura Fiscal que versa sobre los parámetros renta y consumo y otra fotocopia con consignas. Luego, indica a los alumnos que respondan las consignas con la fotocopia entregada y con las definiciones copiadas en sus carpetas la clase anterior. Responde algunas consultas y, ante la confusión de una estudiante, grafica en el pizarrón un ejemplo del parámetro patrimonio. 


\title{
Anexo 5. Imágenes de los materiales de lectura
}

\author{
Felipe Pigna \\ Los mitos \\ de la historia argentina \\ La construcción de un pasado \\ como justificación del presente \\ "Quien controla el pasado controla el futuro, \\ quien controla el presente controla el pasado",
}

\section{Introducción}

GEORGE ORWELL

La sociedad argentina ha vivido los últimos 30 años acosada por las vicisirudes del cotidiano sobrevivir, con escaso nes y las causas remotas de para la reflexión sobre los orígcde exclusión socialy polís males cotidianos. El proceso la mayorí de lacial y polític2 al que vienc siendo sometida cos muy negativos gue obstantina desde 1976 provoca efecformación de una lue obstaculizan decididamente la conderechos con marcos legales y referencialonsciente de sus len sus demandas y hagan posibles sus deseos dos que avapersonal y social.

En este contexto, el poder hi logra ciente o lejana no forme parte logrado que la historia remayoría de la población, parte del menú de intereses de la materia de estudio escolar que visualiza la historia como una para comprender mejor pero no como un instrumento útil

Más allá de la evolucio presente y planificar su futuro. nuestros historiadores y docences gica y metodológica de sistema ha a la escuela primaria que la gente remita la historia argentina cemo un acontecimes decir, la Revolución de Mayo aparece vinculado a la escuela primaria.

Nuestro elemento fundacional como país, históricamente liablando, es un tema de acto escolar. Los sucesos de Mayo son difíciles de pensar -para la mayoría de los argentinosdespojados de betún, corcho quemado y pastelitos.

Es alarmante la efectividad de este y pastelitos.

politiza y reduce, en el imaginario este mecanismo que despolitiza y reduce, en el imaginario social, prácticamente a la nada a nuestra historia. Y, por otra parte, rotula como históricos, con ese pobre concepto de historia, a los hechos remotos vinculados al calendario escolar y les niega historicidada los sucesos más recientes, determinantes de nuestro presente. Asi, para muchos argentinos hablar de la dictadura o cl menemismo no es hacer historia sino política, como si ambas diseiplinas pudieran separarse y prescindir una de la otra.

Resulea interesante destacar el valor didáctico y formativo que tuvo y tiene el inculcar este concepto de la historia y, por cnde, de la política. En esta concepción de que la pocomún" para los otros, que la hacen los otros y que la "gente común", por carecer de coraje, aptitudes y -ultimamenteaudacia, debe abstenerse, podemos encontrar-en parte-las raices dol "algo habrán hecho". En un país que ha vivido gran parte de su historia bajo dictaduras o democracias fraudulentas, restringidas o vigiladas, el compromiso político dificilmente puede ser visto como un hecho positivo.

Es notable cómo uno de los temas más cratados en las 90 or ciento de la poles o de historia-por las que más del 90 por ciento de la población del país ha pasado alguna vez-, la Revolución de Mayo, no llega a ser comptendido nómica y sobre la gente en toda su dimensión social, cco-

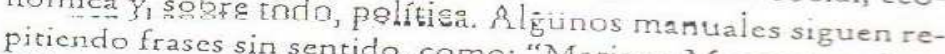
cible y Cornclio Santido, como: "Mariano Moreno era iraspodria invertirsc el orden de los calmental". Como es lógico, Los calificativos personales ocupan eivos y nada cambiaría.

Páginas del cuadernillo de la Asignatura A: introducción de libro 


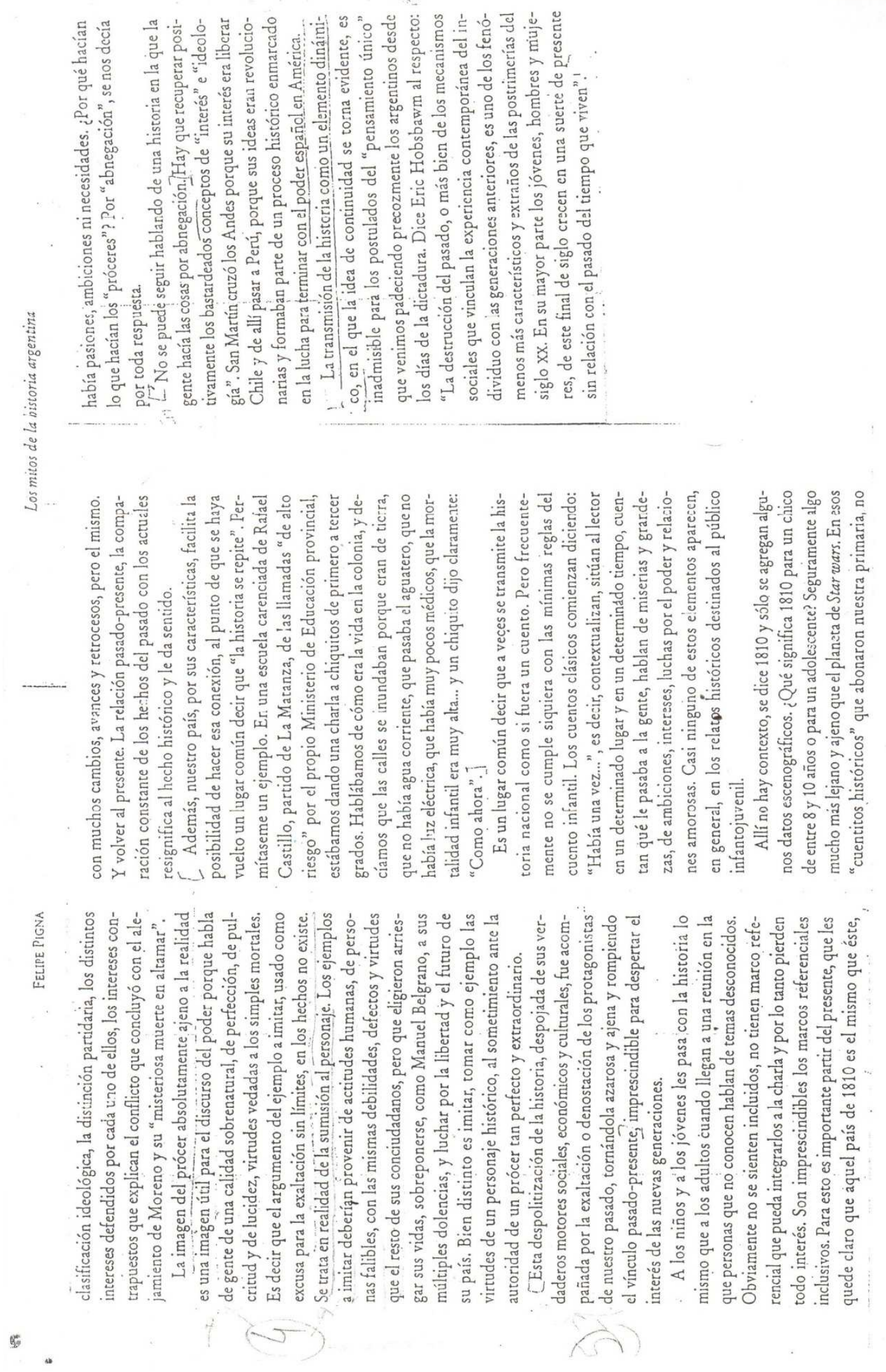

Páginas del cuadernillo de la Asignatura A: introducción de libro 


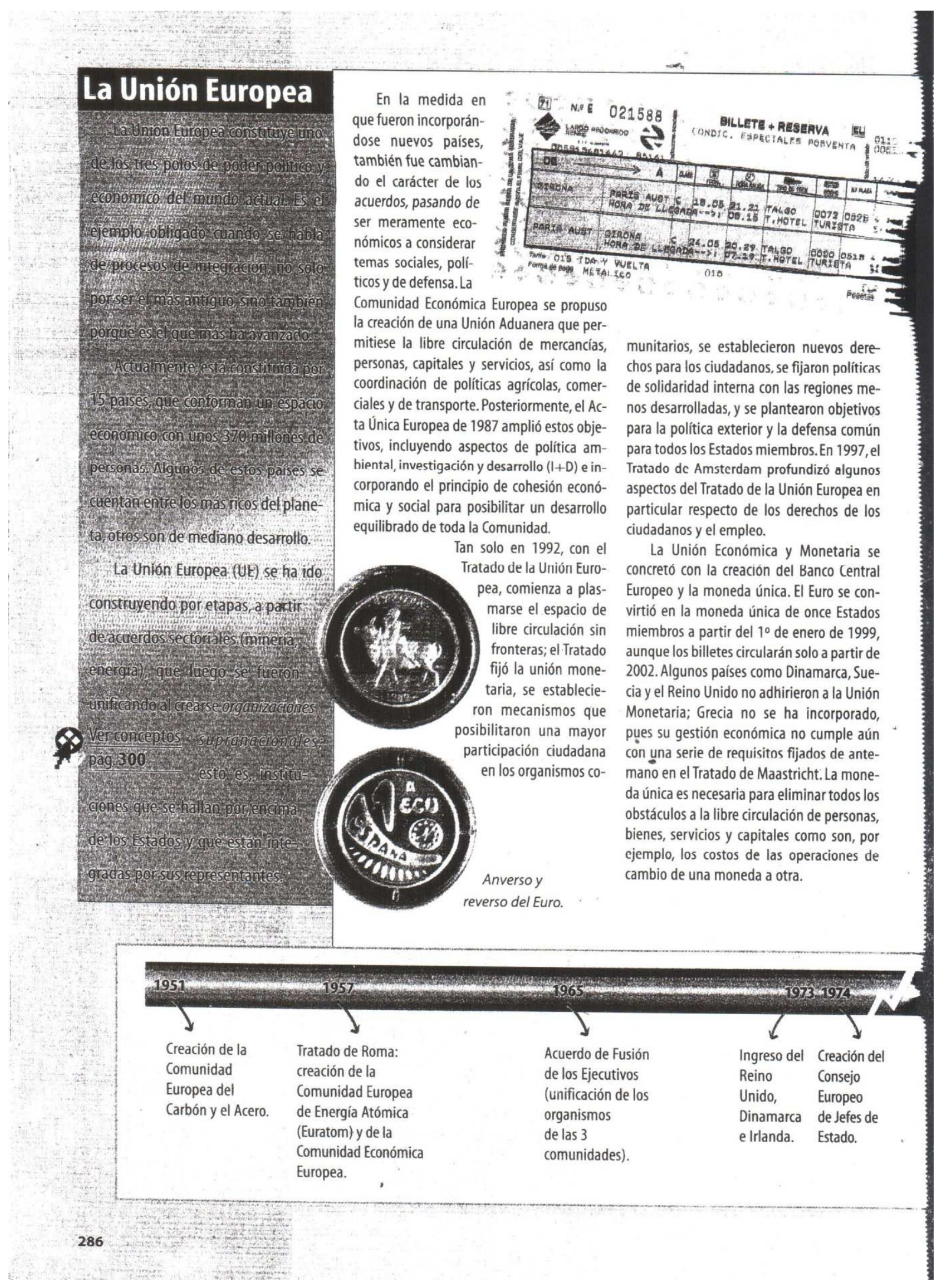

Página del manual de Geografía utilizado en la Asignatura B 


\section{II - La globalización: un nuevo orden mundial}

\section{El mundo se transforma}

Para algunos la globalización se presenta como una nueva etapa de desarrollo del capitalismo o como un nuevo orden internacional inevitable e irreversible.

Para otros, la idea misma de globalización -término utilizado para definir a nuestra época como tendiente hacia una sociedad mundial capitalista, uniforme y armónicadebe relativizarse.

Cuando se habla de globalización económica, se refiere a que el capitalismo llega a ser mundialmente dominante y universal (desaparecida la alternativa socialista). Las corporaciones (las multinacionales), el Banco Mundial y el FMI difunden la "globalización del libre mercado" y extienden su poder sobre todo el planeta. Y unos pocos países ricos toman las decisiones en la economía global (la implantación de nuevas tecnologías, el control de los recursos energéticos como el petróleo y los acuerdos de comercio). Estos Estados constituyeron en principio el G7, o Grupo de los Siete, integrado por EE.UU., Alemania, Japón, Inglaterra, Italia, Francia y Canadá. En 1997, cuando se incorporó la Federación Rusa, este conjunto de países adoptó entonces la denominación de G8 (Grupo de los Ocho).

La creciente integración de las economías provoca movimientos virtuales de capital sin que el dinero real varíe de sitio. Esta globalización financiera amenaza la estabilidad política y económica, de los Estados: cuando estos capitales se retiran bruscamente de algunos países, producen efectos críticos. Por ejemplo, la crisis financiera mexicana de 1994, denominada "el efecto tequila" y la crisis del sudeste asiático en 1998.

La globalización politica hace referencia al fin de la guerra fría y del mundo bipolar. Ha quedado una sola superpotencia global: Estados Unidos, y un único sistema de alianzas militares: la OTAN. También alude a la debilidad de los Estados nacionales frente al poder de un "gobierno mundial" representado por el Consejo de Seguri-

\section{¿Un gobierno Global?
\& "Al Grupo de los Siete comespomero 으 la tarea de coordinar la poifítica ecer $\mp$ nómica de las potencias industriàies: $\bar{\rho}$ EE.UU, Alemania, Japón, Inglazere. Italia, Francia y Canadá (...) Ios micmbros de este ilustie cluil sux,} sin excepción, presidentes o cancilleres ce las democracias occidentales ( ) que en ia práctica excluyen el $96 \%$ de los 185 Escados nacionales registrados en las Naciones Unidas -versus $>0$ en 1945- de todas las decisiones importantes para la economía mundial.

Semejante es la situación en los demás órganos de conducción mundiales. Los procedimientos de participación y decisión no se rigen por principios de la democracia formal, sino al igual que en el G-7, por el poder real. Por ejemplo, la Asamblea General de las Naciones Unidas constituye la única representación política universal de la especie, y en efecto, muestra una estructura formal-democrática en el sentido de que cąda nación dispone de un voto. Sin embargo, tal hecho no reviste mayor importan cià práctica, dado que la Asamblea Genera: es simplemente un foro de debate público. que produce y ratifica resoluciones y naci más. (...)

La política real se hace en el Consejo de Seguridad. Y en esta junta de notanit is democracia no tiene lugar. Ios cir.. miembros permanentes del Conseto st guridad: Gran Bretana, Estacos Zujo Francia, la Unión Soviética y $\mathrm{C} i=\mathrm{in}$ nen de un derecho de veto. cora 200 de bloquear cualquier iniciatira $=20 x$

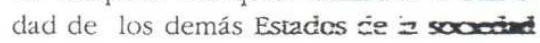
mundial. (...) La presencis ie ies Exalu privilegiados en el Consex. rescin de in correlación de fuerzas erste la tan aliados victoriosos de I. n. cista a fin de la Segunda Grom andie

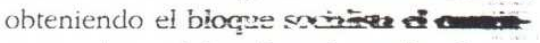

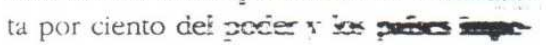
rialistas el sesenta go:

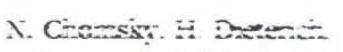
La scriediai givialis ist

Página del manual de Historia Mundial Contemporánea utilizado en la Asignatura B 
: POLITICA

UTREVISTA. HERNÁN LORENZINO. SECRETARIO-DE FINANZAS

"El mercado es una opción;
pero no una necesidad"

a diálogo con Miradas al Sur, el funcionaŕio destacó la autonomía que confiere al Estado nacional la política ə desendeudamiento, subrayó la importancia del Banco del Sur y descartó cambios en las relaciones con el FMI.

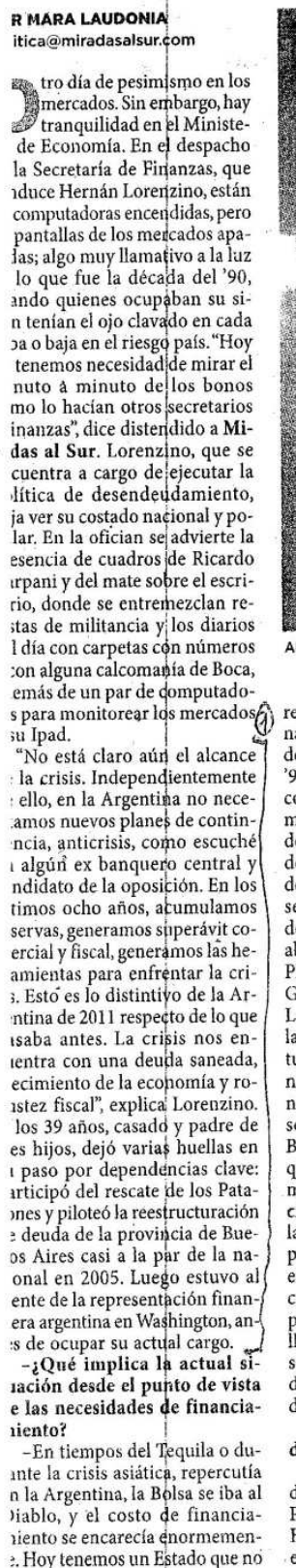

itica@miradasalsur.com

so tro día de pesimismo en los tranquilidad en el Ministede Economia. En el despacho ducretaria de Finanzas, que computadoras encendidas, per pantallas de los metcados apalo que fue la década del ' 90 ndo quienes ocupaban su sitenian el ojo clavado en cada a o baja en el riesgo pals. Hoy nuto à minuto de los bonos inanzas" dice disterdido a Midas al Sur. Jorenzino que se cuentra a cargo de ejecutar la litica de desende lar. En la ofician se advierte esencia de cuadros de Ricardo rpani y del mate sobre el escriitas de militancia y' los diarios I día con carpetas con números emás de un par de domputados para monitorear los mercado
iu Ipad. "No está claro aúr el alcance ello, en la Argentina no neceamos nuevos planes de continalgún ex banquero central didato de la oposicion. En los servas, generamos superávit coarcialy fiscal, generamos las heEsto es lo distintiyo de la Arntina de 2011 respecto de lo que entra con una deuda saneada ecimiento de la economía y rolos 39 años, casadd y padre de es hijos, dejo valas huellas en rticipó del rescate de los Patanes y piloteó la reestructuración os Aires casi a la par de la naonal en 2005. Luego estuvo $s$ de ocupar su actual cargo. sación desde el punto de vista

nte la crisis asiática, repercut iablo, $y$ el costo de financiaHoy tenemos

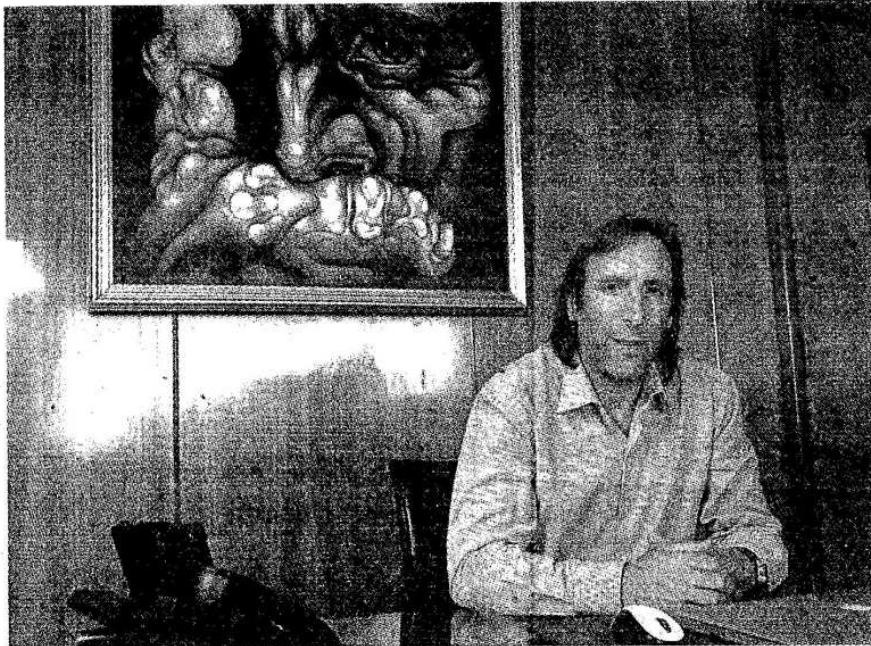

ARGENTINA EN EL MUNDO "EL PAIS ES ESCUCHADO Y ESTUDIADO COMO UN EJEMEPLO A SEGUIR" DICE LORENZINO

requiere de los mercados para fide larse, no estamos pendientes '90, con déficit fiscal $y$ es. En los corren $y 90 \%$ de louda

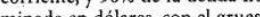
de vencimientos al sector privade der ses - señala Lorenzino Oriund de Puerto Madryn, se recibió de a Plaza y cursó dos másters: unoen Gestión Pública y Finanzas La Plata- y otro en Economía Ia Universidad Di Tella- A suactual función llegó bajo la administración del ex ministro de Economí Carlos Fernández. Lue se ganó la confianza de Amado Boudou, quien lo confirmó y quien acompañó en varios momentos difíciles, como la operción de canje de deuđa de 2010 y la creación del fondo de reservas para pagar deuda. Hoy, devenic en mano derecha del titular de artera, suena como uno de los osibles candidatos a ocupar el sin de ministro de Economia si confirma en las presidenciales del $\mathrm{FpV}$ en las primarias.

Que es la política de desendeudamiento?

- Haber pasado de una relación de deuda del 170 por ciento del BI a menos del 50 por ciento. Hoy, casi la mitad de esa deuda está en el sector público; eve tualmente, sólo un tercio de la deuse en los mercados sin posidide seenlos mercados sin posibilid te refinanciarse. 2002 , necesición de nuestra conomin para re pagar la deuda. Hoy con menos de medio año ta repagamos. desendeudamiento implica repa go de deuda. Es no aumentar deuda pública con el sector privado, que no puedo refinanciar invado, que no

$-\mathrm{i} E \mathrm{E}$ año que viene queda el pago del Boden 2012, es el último bono del corralón del 2002 ? -Sí. Queda el último vestigi mportante de lo que fue la crisis financiera terminal del 2002. Es título que se entregó a los ahorristas que tenían los depósitos acorralados. Se pagará la última cuota de lo que fue la solución interna al default. En 2013, habrá un alivio importante, porque el $\mathrm{Bo}-$ den 2012 tuvo gran peso en el pago de deuda. Y al haberse reducido el endeudamiento con el sector privado, tenemos un margen de maniobra importante.

- Contempla el uso de reservas para pagar deuda o buscar deuda en el Presupuesto 2012? cho las cosas bien es que salir hoy al mercado es una decision y no ina necesidad como era en los 90 . Los analistas coinciden en que vamos a vivir con un tiempo prox da, es decir un 17 por ciento e -La gran ventaja de haber he- longado de crisis en los paises en las opciones bueno dejar todas mento se tomán la mej ción como se hizo siempre y hay tiempo aún para definir la cuestión de las reservas.

Cómo evalúa ia reciente opinión de Moody's sobre los bancos locales?

-Me parece un mamarracho, una falta de profesionalismo. Y creo que siguen una tendencia peligrosa. Lô planteó la Presidenta en noviembre de 2008 en la primera cumbre del G-20. Desde alli o venimos planteando en cada reunión del foro. Me refiero al peigroso rol politico que asumen este tipo de instituciones, y sin legitimidad para hacerlo. Hoy, el peso de variables subjetivas que san para poner una nota pesa más que las objetivas. Si bien con otro escenario, fue aleccionador o que pasó con las rebaja de la nota de los Estados Unidos. Puso n el tapete la discusión de las souciones que venimos reclaman do ante el G-20.

- Respecto del Banco de Sur qué importancia tiene para el

-Es importante pensarlo en tểminos regionales. Es un paso más en la reafirmación de la Unasur como un bloque regional, que busca montar un escudo de defensa contra las crisis que pudieran ve-

Unasur tiene como objetivo la in tegración política, económica comercial. Con esos objetivos, esa unión de países busca tener un es un banco pensado desde la re gión y para la región.

- ¿Cómo está posicionada Argentina? ¿Algunos dicen que sta aislada del mundo?

- Todo lo contrario. La Argentina está muy bien posicionara. El pais tuvo una posicion clara en el G-20 y la vino manteriendo: un modelo sustentado en el trabajo de ir contra los paraisos fiscales, fepenir la fincion man la necesidad de que sea el Estado el que sostenga el creciniento más dé lo que ya dijimos de las calificlo G-20 puso el eje en el crecimiento con empleo, invitando a la OIT como miembro participativo. Esa posición la llevó la Presidenta y fue levantada por Obama cuando asumió. Además, la Argentina preside el foro G-77. Hoy, muchos paside el foro G-77. Hoy, muchos paanalizar como un país que enrentó una crisis terminal salió y estructurósu deuda y que además creció a tasas de 8 por ciento. Todo esto nos posiciona y nos da la justificación para plantear stos temas y ser escuchados. - ¿Y en el tema de las materias rimas?

-Hubo una iniciativa de reguar el precio de los commodities, prosil lidgentina en conjunto con raria. El ministro Boudou será el expositor principal en la proxima reunión sobre el tema en Estamul, programada para el proximo miércoles. Para nosotros, no es un. tema de precios, sino de oferta, y sabemos cómo ampliarla. Lo que no quiere decir que no estemos a favor de la regulación de los mercados de derivados. Una cosa es cuánto vale la tonelada de soja y otra es que pidamos que se transparente el mercado financiero en el cual alguien especula sobre el precio futuro de la soja. Ahí sí es. taremos en la misma vereda. -¿Qué relación piensan que debe mantener el país con el FMI en un ventual próximo mandato? ta que se vino manteniendo de indole deuda tecnica. No tenemos unscrib los. La relación se cirintro aspectos tecnicos, nuestra participacion ectorio. No creo que cambie nada de eso:

Fotocopia de artículo periodístico utilizado en la Asignatura B 
$\ldots$

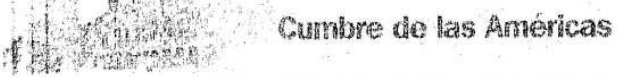

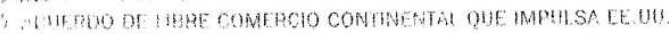

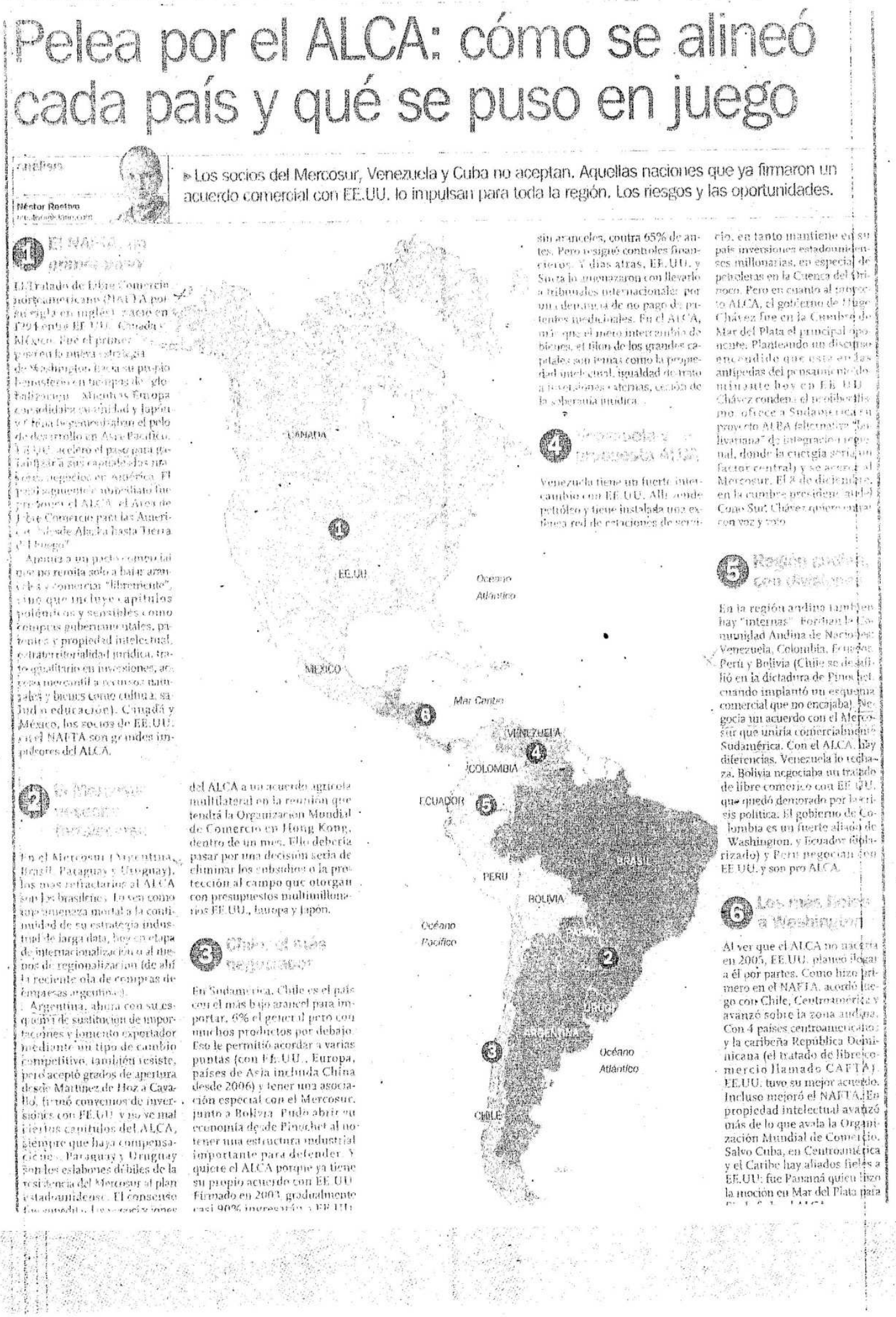

Fotocopia de artículo periodístico utilizado en la Asignatura B 


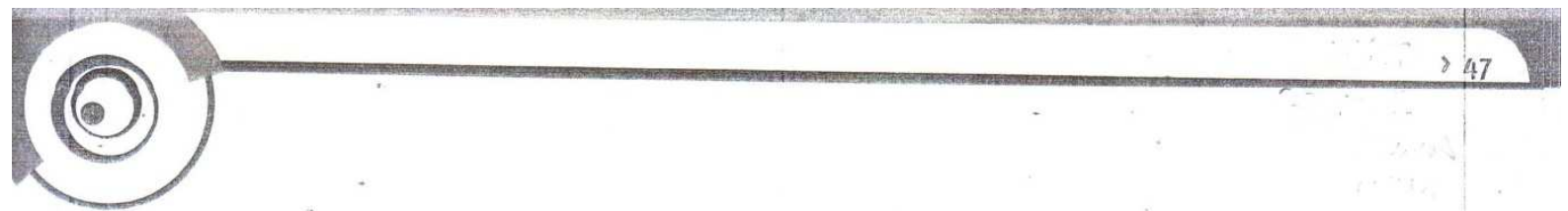

Veamos cómo es el circuito del dinero:

Etapa 1: Ingreso del dinero lavado al Sistema Financiero

El origen del capital que llega a un TBT (paraiso fiscal) puede ser:

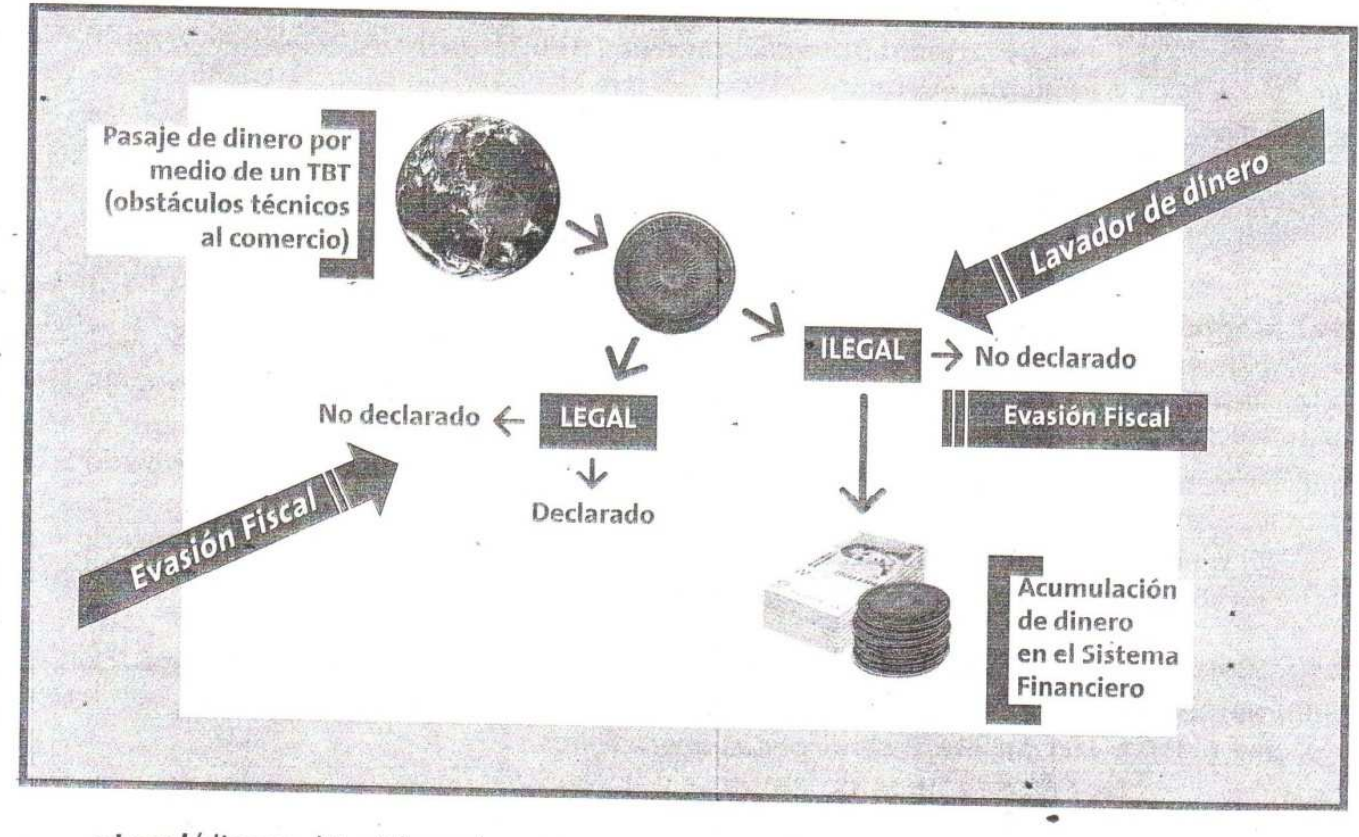

- Legal (dinero obtenido por una persona o grupos de personas en el marco de las leyes de los diferentes países: Por ejemplo, a partir del trabajo en la economía productiva, de inversiones financieras, de la venta de objetos, de propiedades de mucho valor, de herencias).

- llegal (capital reunido a partir de actividades consideradas ilegales, por ejemplo el comercio de armas, de drogas, la actuación de los grupos mafiosos, las "coimas" de funcionarios corruptos). 


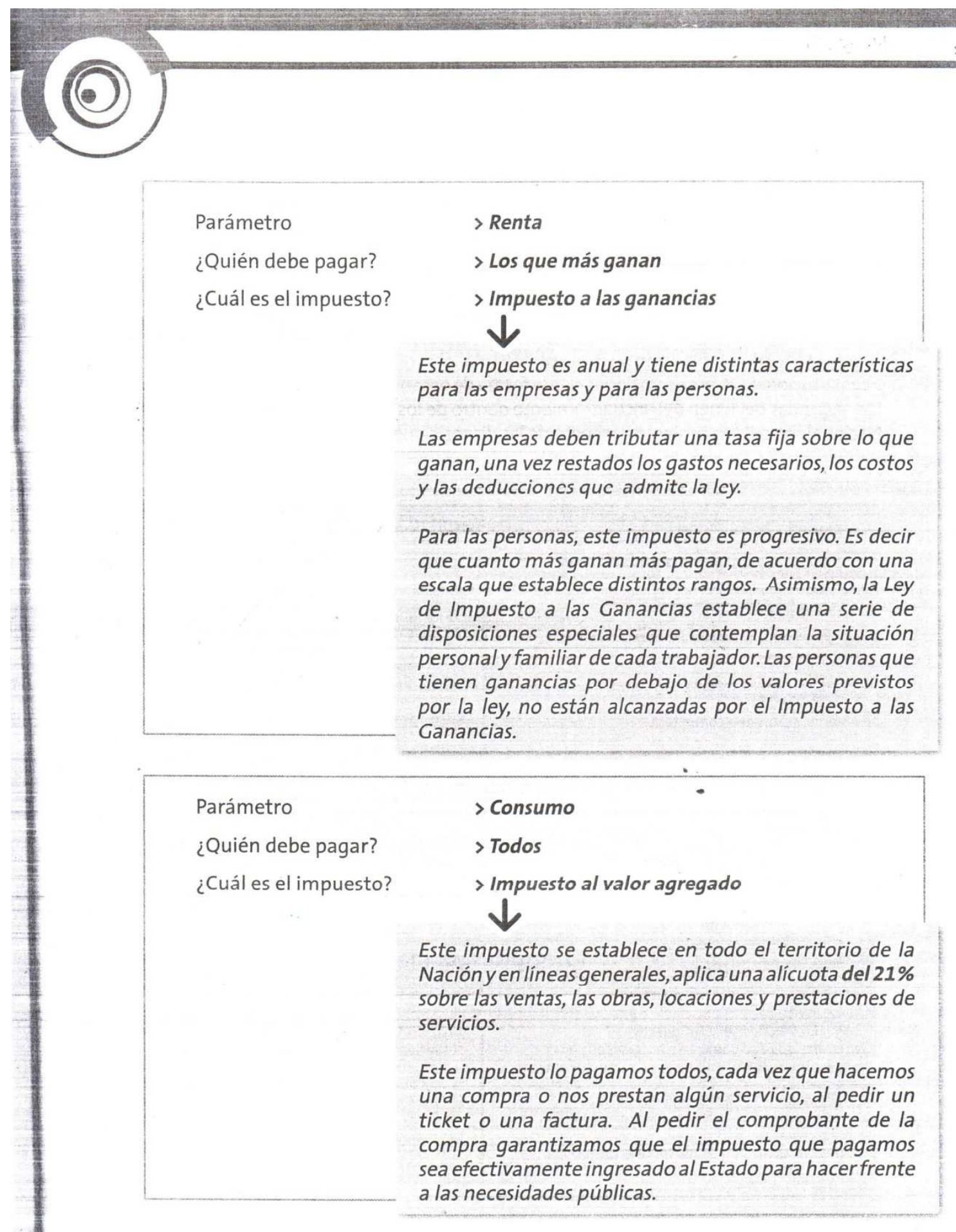




\section{Anexo 6. Ejemplos de respuestas escritas de los alumnos a los cuestionarios}

\begin{tabular}{cl} 
ASIGNATURA A & \multicolumn{1}{c}{ Respuestas de las alumnas } \\
\hline Consigna global & \\
\hline & \\
& Le aseguran un rango constitucional: \\
& el derecho a la igualdad, a la \\
participación y al desarrollo y el \\
¿Qué le aseguran \\
las leyes a las & $\begin{array}{l}\text { perfeccionamiento personal } \\
\text { personas? }\end{array}$ \\
& $\begin{array}{l}\text { conjugado necesariamente con la } \\
\text { solidaridad y unidad familiar. } \\
\text { (Yésica) }\end{array}$
\end{tabular}

(Yésica)
Son notorios los cambios que inciden de modo muy importante en la situación, derechos posibilidades y libertad de las mujeres en las sociedades contemporáneas. Durante la segunda mitad del S. XX, se acrecentó notablemente la inserción de la mujer en los procesos laborales y aparecieron nuevos métodos anticonceptivos que le brindaron un inédito control sobre su cuerpo junto con esos cambios técnicos y sociales.

(Marisa)

\section{Fragmentos de los textos fuente \\ "Progresos aún más trascendentales fueron efectivizados a partir de la reforma de la Constitución Nacional en 1994. En efecto, esta Carta incorpora diversos Tratados} internacionales relacionados con los derechos humanos que, entre otras áreas de la vida social, afectan directamente el derecho de familia. Tienen desde entonces rango constitucional: el derecho a la igualdad, a la participación y al desarrollo y perfeccionamiento personal conjugado necesariamente con la solidaridad y unidad familiar; la protección de la intimidad de la familia; la prescripción del consenso como forma ideal para resolver los conflictos, rechazándose la imposición y la violencia en el manejo de las relaciones familiares; etc."

"También es importante desarrollar el plano histórico, ya que estos procesos han variado en relación con generaciones anteriores. Son notorios los cambios que inciden de modo muy importante en la situación, derechos posibilidades y libertad de las mujeres en las sociedades contemporáneas. Durante la segunda mitad del s.xx, se acrecentó notablemente la inserción de la mujer en los procesos laborales y aparecieron nuevos métodos anticonceptivos que le brindaron un inédito control sobre su cuerpo. Junto con esos cambios técnicos y sociales, la transformación de los códigos que regulaban las conductas sexuales impactó fuertemente en la cultura y a ello se sumó el avance en las luchas emancipatorias que tienen su eje en los géneros y en los derechos de la mujer."

"Así, para muchos argentinos hablar de la dictadura o el menemismo no es hacer historia sino política, como si ambas disciplinas pudieran separarse y prescindir una de la otra.

Ambas disiplinas pudieran separarse y

¿Cuál es la relación entre historia y política? presendir una de la otra se destaca el valor didacto y formativo que tubo y tiene el inculcar este concepto de la historia y por ende de la politica.

(Daiana)
Resulta interesante destacar el valor didáctico $\mathrm{y}$ formativo que tuvo y tiene el inculcar este concepto de la historia y, por ende, de la política. En esta concepción de que la política es para los otros, que la hacen los otros y que la "gente común", por carecer de coraje, aptitudes y -últimamente- audacia, debe abstenerse, podemos encontrar -en parte- las raíces del "algo habrán hecho."

Nota: En la última columna se remarca con subrayado la similitud o igualdad de oraciones entre las respuestas escritas de las alumnas y los fragmentos de textos incluidos en el cuadernillo: "Historia de la familia en la Argentina moderna (18702000)" de la socióloga Susana Torrado, "El difícil arte de asir a la juventud" del sociólogo Mario Margulis y "Los mitos de la historia argentina" del historiador Felipe Pigna. 
ASIGNATURA B

\begin{tabular}{|c|c|c|}
\hline Consigna de localización & Respuestas de las alumnas & Fragmentos del texto fuente \\
\hline \multirow{2}{*}{$\begin{array}{l}\text { ¿Qué consecuencias tiene la } \\
\text { apertura de mercado para } \\
\text { los países en vías de } \\
\text { desarrollo? }\end{array}$} & $\begin{array}{l}\text { Por el hecho de que forzar a un país } \\
\text { en desarrollo a abrirse a los } \\
\text { productos importados que compiten } \\
\text { con los elaborados por alguna de sus } \\
\text { industrias, pueder tener } \\
\text { consecuencias desastrosas, sociales } \\
\text { y económicas. } \\
\text { (Yésica) }\end{array}$ & $\begin{array}{l}\text { "Es verdad que el proteccionismo } \\
\text { generalizado a menudo no ha } \\
\text { funcionado en los países que lo } \\
\text { aplicaron, pero tampoco lo ha hecho una } \\
\text { rápida liberalización comercial. Forzar a } \\
\text { un país en desarrollo a abrirse a los } \\
\text { productos importados que compiten con } \\
\text { los elaborados por alguna de sus }\end{array}$ \\
\hline & $\begin{array}{l}\text { Si por ejemplo, los mercados se } \\
\text { abren a la competencia demasiado } \\
\text { rápidamente, antes del } \\
\text { establecimiento de instituciones } \\
\text { financieras fuertes entonces los } \\
\text { empleos serán destruidos. } \\
\text { (Marisa) }\end{array}$ & $\begin{array}{l}\text { la competencia de buena parte de } \\
\text { industrias más vigorosas en otros países, } \\
\text { puede tener consecuencias desastrosas, } \\
\text { sociales y económicas (...)." } \\
\text { "El FMI ha cometido errores en todas } \\
\text { las áreas en las que ha incursionado: } \\
\text { desarrollo, manejo de crisis y transición }\end{array}$ \\
\hline \multirow{3}{*}{$\begin{array}{l}\text { ¿Qué errores comete el } \\
\text { FMI, según este Premio } \\
\text { Nobel [Joseph Stiglitz]? }\end{array}$} & $\begin{array}{l}\text { El FMI ha cometido errores en todas } \\
\text { las áreas en las que ha incursionado: } \\
\text { desarrollo, manejo de crisis y } \\
\text { transición del comunismo al } \\
\text { capitalismo. } \\
\text { (Yésica) }\end{array}$ & $\begin{array}{l}\text { programas de ajuste estructural no } \\
\text { aportaron un crecimiento sostenido ni } \\
\text { siquiera a los países que como Bolivia, } \\
\text { se plegaron a sus rigores; en muchos } \\
\text { países, la austeridad excesiva ahogó el } \\
\text { crecimiento, los programas económicos } \\
\text { que tienen éxito requieren un cuidado } \\
\text { extremo en su secuencia, el orden de las }\end{array}$ \\
\hline & $\begin{array}{l}\text { El FMI ha cometido errores en todas } \\
\text { las áreas en las que ha incursionado: } \\
\text { desarrollo, manejo de crisis y }\end{array}$ & $\begin{array}{l}\text { mercados se abren a la competencia } \\
\text { demasiado rápidamente, antes del } \\
\text { establecimiento de instituciones }\end{array}$ \\
\hline & $\begin{array}{ll}\text { transición del comunismo al } \\
\text { capitalismo. } \\
\\
\text { (Marisa) }\end{array}$ & $\begin{array}{l}\text { financieras fuertes, entonces los } \\
\text { empleos serán destruidos a más } \\
\text { velocidad que la creación de nuevos } \\
\text { puestos de trabajo." }\end{array}$ \\
\hline
\end{tabular}

Nota: En la última columna se remarca con subrayado la similitud o igualdad de oraciones entre las respuestas escritas de las alumnas y los fragmentos del manual de Historia Mundial Contemporánea. 


\section{ASIGNATURA C}

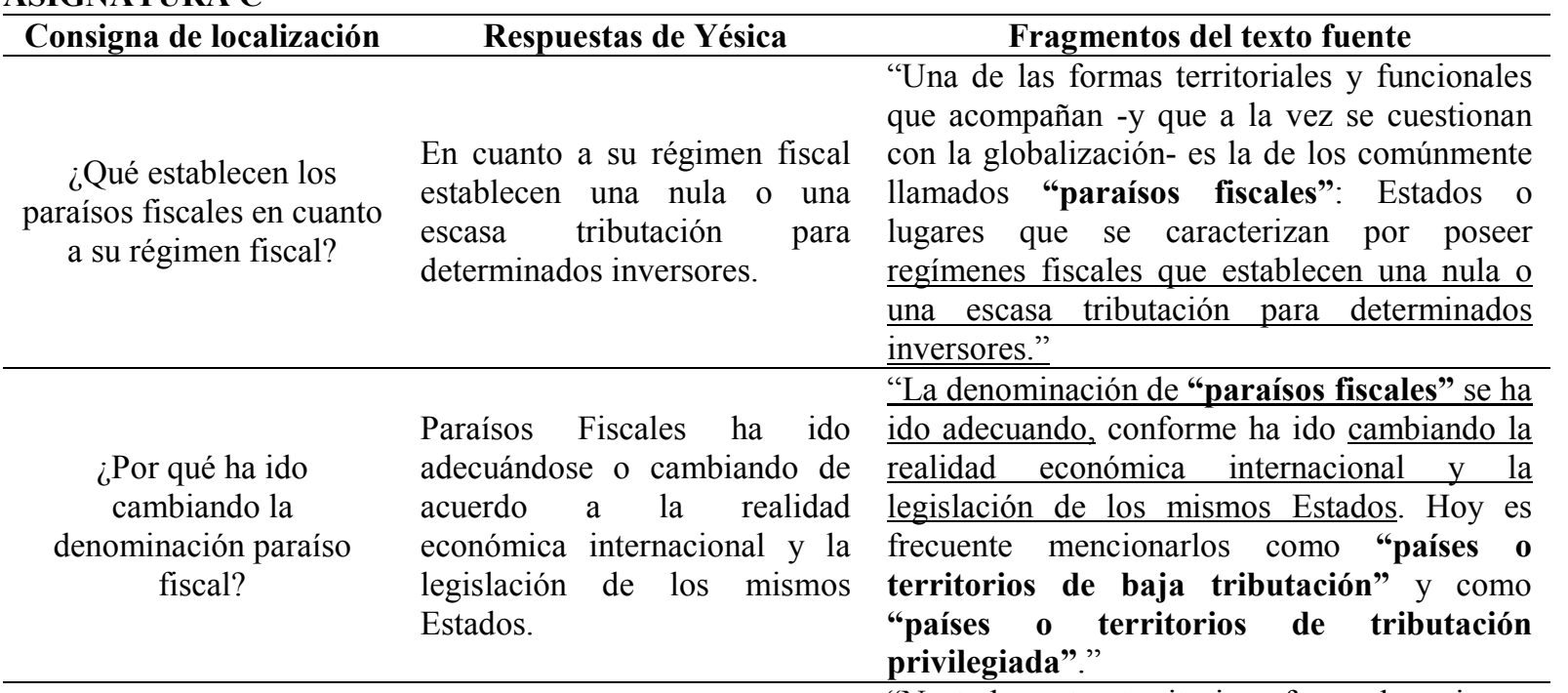

"No todos estos territorios ofrecen las mismas posibilidades, de allí que sus clientes pueden optar según sus necesidades específicas. En

En función de las diferencias centrales, se pueden establecer tres modalidades básicas entre ellos los paraísos fiscales "clásicos". Los territorios de fiscalidad ofrecen ventajas a personas $y$ entidades que ejercen sus actividades en el extranjero y por último que disponen de centros de servicios complejos. función de las diferencias centrales, se pueden establecer tres modalidades básicas entre ellos: Los paraísos fiscales "clásicos"; los territorios de elevada fiscalidad que ofrecen ventajas fiscales a personas y entidades que ejercen sus actividades en el extranjero; finalmente, territorios que disponen de centros de servicios complejos (en cuanto a las telecomunicaciones, los bufetes para asesoramiento a inversores, la disponibilidad de bases de datos, de conocimientos muy especializados necesarios para operar en la economía global y en especial, en las finanzas globales, entre muchos otros)."

Nota: En la última columna se remarca con subrayado la similitud o igualdad de oraciones entre las respuestas escritas de la alumna y los fragmentos del módulo de Cultura Fiscal. Las negritas figuran en el original. 